New techniques and principles in acute aortic pathologies requiring emergency surgical interventions

Dr László Göbölös

PhD Thesis

Institute of Surgical Research and Department of Cardiac Surgery

Faculty of Medicine, University of Szeged, Szeged, Hungary

Szeged

2020 


\section{List of publications related to subject of thesis}

I. Göbölös L, Philipp A, Foltan M, Wiebe K: Surgical management for Stanford type A aortic dissection: direct cannulation of real lumen at the level of the Botallo's ligament by Seldinger technique. Interact Cardiovasc Thorac Surg. 2008;7(6):1107-1109.

II. Göbölös L, Foltan M, Ugocsai M, Thrum A, Philipp A, Livesey SA, Tsang GM, Ohri SK. Recent advances in the management of Acute Aortic Syndrome. In: Nazari S (editor): Front lines of Thoracic Surgery. Milano: 2012; ISBN 978-953-307-915-918.

III. Göbölös L, Miskolczi Sz, Pousios D, Tsang GM, Livesey SA, Barlow CW, Kaarne M, Shambrook J, Lipnevicius A, Ohri SK. Management options for aorto- oesophageal fistula: case histories and review of the literature. Perfusion. 2013;28(4):286-290.

IV. Göbölös L, Philipp A, Ugocsai P, Foltan M, Thrum A, Miskolczi Sz, Pousios D, Khawaja S, Budra M, Ohri SK. Reliability of different body temperature measurement sites during aortic surgery. Perfusion. 2014;29(1):75-81.

V. Göbölös L, Ugocsai P, Foltan M, Philipp A, Thrum A, Miskolczi Sz, Malvindi PG, di Gregorio V, Pousios D, Navaratnarajah M, Ohri SK. Central cannulation by Seldinger technique: A reliable method in Type A aortic dissection repairs. Med Sci Monit. 2014;20:2386-2393.

VI. Göbölös L, Tsang GM, Curzen N, Calver AJ, Ohri SK. Transapical perfusion for periarrest salvage during transcutaneous aortic valve implantation. Perfusion. 2015;30(8):650-652.

VII. Miskolczi S, Sheppard MN, Bogáts G, Göbölös L. Double-locus lymphoplasmacytic aortitis. Asian Cardiovasc Thorac Ann. 2018;26(3):231-233.

VIII. Malvindi PG, Votano D, Ashoub A, Modi A, Miskolczi Sz, Velissaris Th, Barlow CW, Ohri SK, Tsang GM, Livesey SA, Göbölös L. Age-related presentation of acute type A aortic dissection. Asian Cardiovasc Thorac Ann. 2018;26(9):659-666.

IX. Göbölös L, Bajwa G, Ramahi J, Bergonzi PC, Bhatnagar G. An aortic "supravalvular shelf”' is not always innocuous. NEMJ. 2020;2(1):3-5. ISSN: 0250-6882.

X. Göbölös L, Bonatti J, Bogáts G. A comprehensive guide to new directions in thoracic aortic surgery. In: Horizons in World Cardiovascular Research. Nova Science Publishers Inc., Hauppauge, NY: 2020; ISBN 978-1-53617-615-5. (In Press) 


\section{List of presentations related to subject of thesis}

I. Göbölös L, Hejjel L, Philipp A, Foltan M, Imre J, Zelenka M, Birnbaum DE, Wiebe K: Surgical management for Stanford type A aortic dissection: direct cannulation of the real lumen at the level of Botallo's ligament by Seldinger technique. $13^{\text {th }}$ Annual Meeting of the Hungarian Society of Cardiac Surgery (2006)

II. Göbölös L, Philipp A, Thrum A, Foltan M, Lindenmayer-G. R, Wiebe K: Antegrade selective carotid perfusion during surgical repair of the thoracic aorta. Annual Meeting of the Hungarian Society of Cardiology (2008)

III. Göbölös L, Philipp A, Lindenmayer-G. R, Foltan M, Thrum A, Szabados S, Hejjel L, Lénárd L, Wiebe K: Central cannulation by Seldinger technique: a reliable method in ascending aorta and aortic arch replacement. $15^{\text {th }}$ Annual Meeting of the Hungarian Society of Cardiac Surgery (2008)

IV. Göbölös L, Ugocsai P, Foltan M, Lindenmayer-G. R, Philipp A, Thrum A, Szabados S, Hejjel L, Lénárd L, Wiebe K: Reliability of different body temperature measurement methods during aortic surgery. $16^{\text {th }}$ Annual Meeting of the Hungarian Society of Cardiac Surgery (2009)

V. Göbölös L, Miskolczi Sz, Pousios D, Tsang GM, Livesey SA, Kaarne M, Barlow CW, Shambrook J, Ohri SK: Management options for aortooesophageal fistula. Aortic Symposium of the AATS, New York (2012)

VI. Invited lecture: Göbölös L, Ugocsai P, Miskolczi Sz, Foltan M, Philipp A, Ther G, Ohri SK: Management options for Acute Aortic Syndrome. Yangtze River International Congress of Cardiology, Daping Hospital, Third Military Medical University, Chongqing, China (2013)

VII. Invited presentation: Göbölös L, Votano D, Ashoub A, Modi A, Miskolczi Sz, Malvindi PG. Age-related presentation of acute type A aortic dissection. $23^{\text {rd }}$ Annual Meeting of the Hungarian Society of Cardiac Surgery (2016)

VIII. Invited presentation: Göbölös L: Acute Aortic Syndrome - The Southampton Experience. Emergency Medicine Forum, Debrecen, Hungary (2016)

IX. Invited presentation: Göbölös L. Cornerstones in cardiosurgical stroke risk reduction: the CCAD opinion. International Conference on Neurology and Cardiology, Dubai (2018) 


\section{Content}

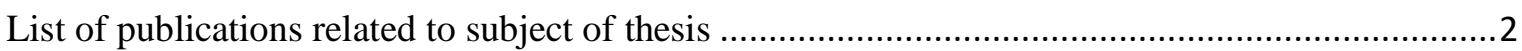

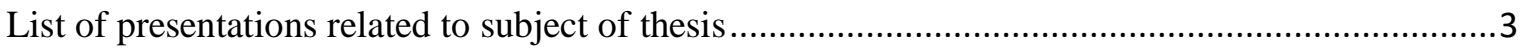

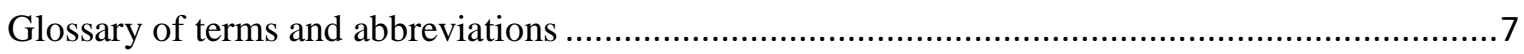

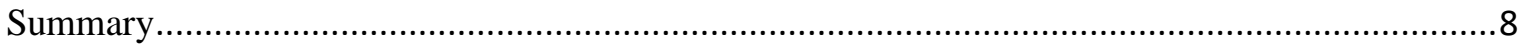

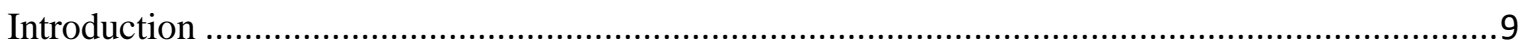

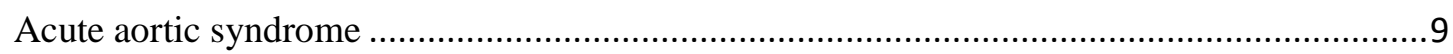

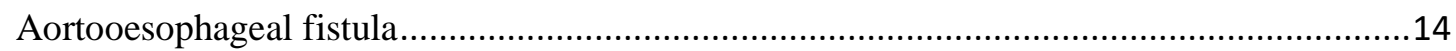

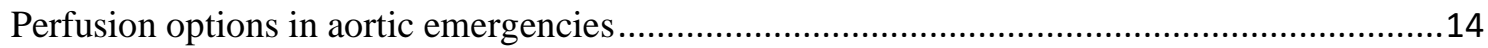

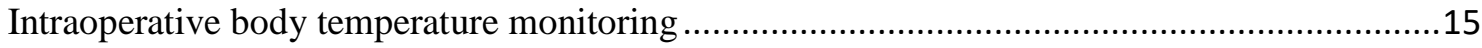

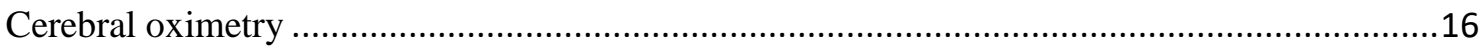

Cerebral blood supply challenges in major aortic surgery .................................................... 18

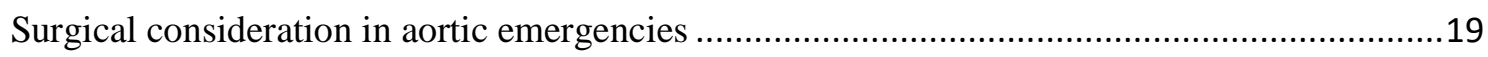

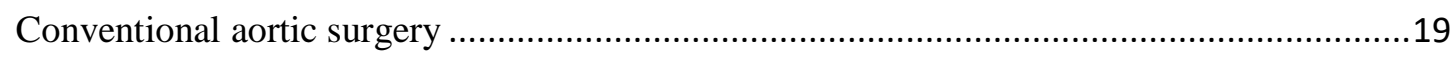

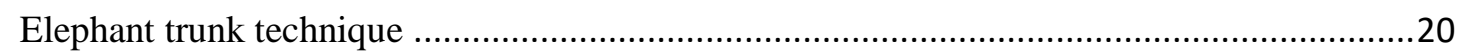

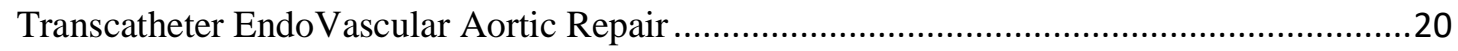

Hybrid approach - 'Frozen elephant trunk' technique …………........................................21

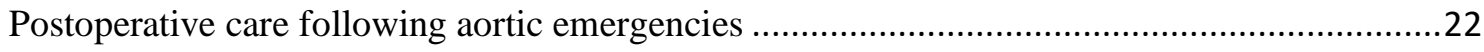

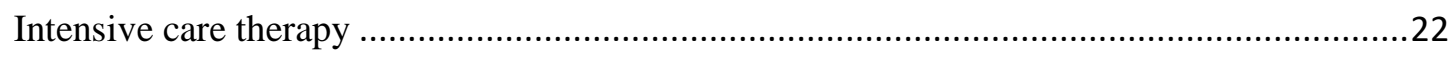

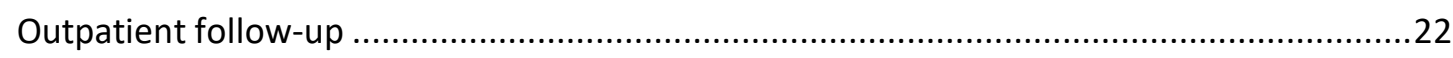


Background.

Patients and methods.

Results

Conclusion

Study II - Body temperature measurement sites in aortic surgery .....

Background.

Patients and methods.

Results

Perioperative data

Core temperature evaluation

Conclusion .35

Study III - Management options for aortooesophageal fistula 36

Background 36

Patients and methods. 36

Management by EVAR and subtotal oesophageal resection followed by gastrooesophageal reconstruction

Management by open thoracic surgery. 38

Conservative management of postoperative graft infection 39

Results 40

Conclusion 40

Study IV - Age-related considerations in acute type A aortic dissection. 


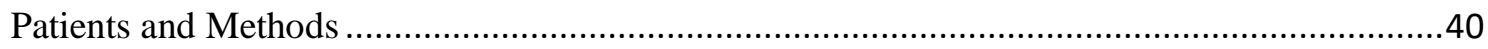

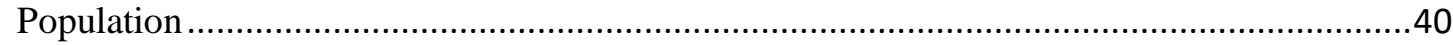

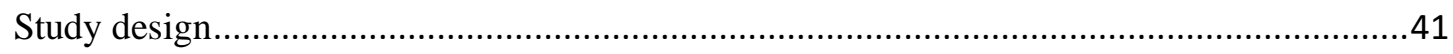

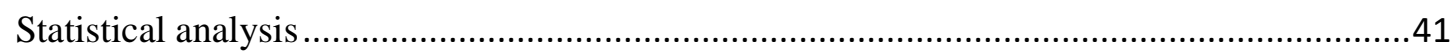

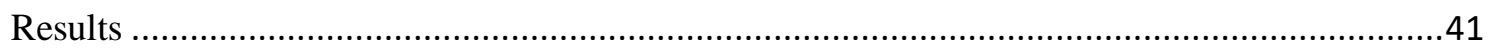

Demographic and preoperative clinical presentation......................................................... 41

Extension of dissection flap and sites of intimal tear ........................................................43

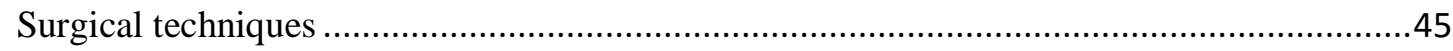

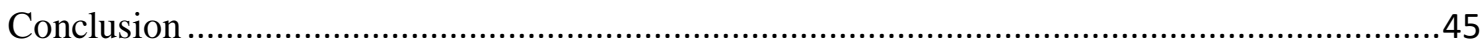

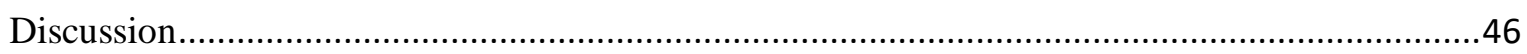

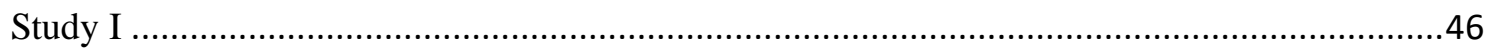

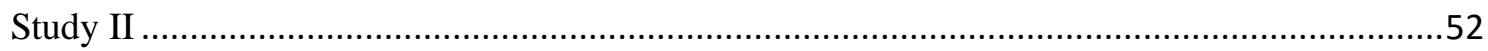

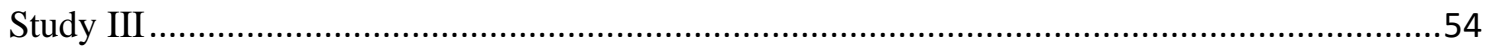

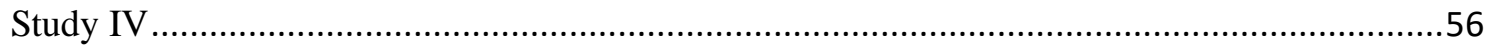

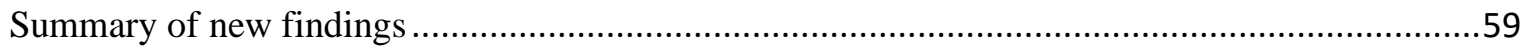

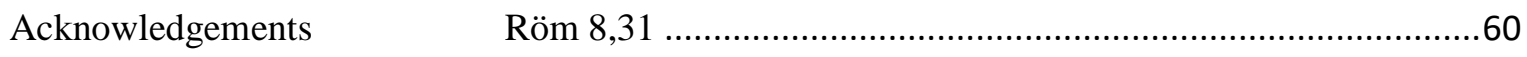

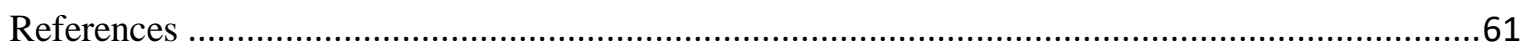

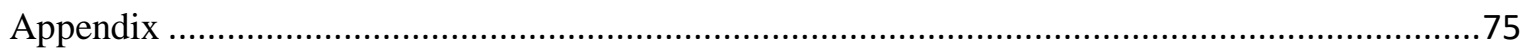




\section{Glossary of terms and abbreviations}

\begin{tabular}{|c|c|}
\hline AAS & Acute Aortic Syndrome \\
\hline $\mathrm{ACP}$ & Antegrade Cerebral Perfusion \\
\hline AHA & American Heart Associantion \\
\hline $\mathrm{AOF}$ & Aortooesophageal Fistula \\
\hline AxS & Axillary/Subclavian Artery \\
\hline BSA & Body Surface Area \\
\hline CAD & Coronary Artery Disease \\
\hline COPD & Chronic Obstructive Pulmonary Disease \\
\hline $\mathrm{CPB}$ & Cardiopulmonary Bypass \\
\hline $\mathrm{CT}$ & Computed Tomography \\
\hline $\mathrm{ECC}$ & Extracorporeal Circulation \\
\hline ECG & Electrocardiogram \\
\hline FTAA & Familial Thoracic Aortic Aneurysms \\
\hline GERAADA & German Registry for Acute Aortic Dissection Type A \\
\hline $\mathrm{HCA}$ & Hypothermic Circulatory Arrest \\
\hline $\mathrm{ICU}$ & Intensive Care Unit \\
\hline $\mathrm{IMH}$ & Intramural Haematoma \\
\hline IRAD & International Registry of Aortic Dissection \\
\hline MMP & Matrix Metalloproteinase \\
\hline MRI & Magnetic Resonance Imaging \\
\hline NIRS & Near Infrared Spectroscopy \\
\hline PAU & Penetrating Atherosclerotic Ulcer \\
\hline SACP & Selective Antegrade Cerebral Perfusion \\
\hline STJ & Sinotubular Junction \\
\hline TAA & Thoracic Aortic Aneurysm \\
\hline TAAD & Type A Aortic Dissection \\
\hline TBAD & Type B Aortic Dissection \\
\hline TEVAR & Transcatheter Endovascular Aortic Repair \\
\hline TOE & Transoesophageal Echocardiogram \\
\hline TTE & Transthoracic Echocardiogram \\
\hline $\mathrm{UACP}$ & Unilateral Antegrade Cerebral Perfusion \\
\hline
\end{tabular}




\section{Summary}

Aortic surgery, especially for pathologies requiring urgent surgical intervention has undergone significant changes in the past twenty years, leading to major improvement in short- and long-term outcomes. This thesis aims to provide a comprehensive, up-to-date overview on clinical characteristics of acute aortic syndrome, with special emphasis on current operative treatment possibilities, including well-established and novel, innovative surgical approaches. Within this scheme, further specific goals are to analyse different cannulation and perfusion options, the role of core temperature management during hypothermic circulatory arrest and impact of age-related differences in surgical approach of AAS.

Ultrasound-guided direct cannulation on the concavity of aortic arch applying Seldinger technique is a reliable method in dissection repairs. Prompt antegrade perfusion provides not only cerebral, but also peripheral organ and tissue protection, which is an advantage in this high-risk group of patients. This alternative arterial inflow technique can be applied for prompt establishment of cardiopulmonary bypass in type A dissections or other aortic emergencies, especially during haemodynamic instability.

We have proven that tympanic temperature measurements correlate with arterial blood temperature monitoring during aortic surgery applying hypothermic circulatory arrest, therefore, should replace bladder and rectal measurements.

Early diagnosis and aggressive surgical approach without delay is a key factor in effective treatment for aortooesophageal fitulas. Endovascular treatment is essential to save the patient, but as a standalone procedure often ends-up with life threatening mid-term graft infection. Eliminating the source of bleeding as an emergency, resecting the oesophagus urgently to prevent sepsis and reconstructing the gastrointestinal continuity as an elective case after having the inflammatory processes settled seems to justify the sequence of endovascular aortic repair and subtotal oesophageal resection, followed by a gastro-oesophageal reconstruction, as an effective surgical approach.

More frequent proximal and distal progression of the dissection flap occurs in younger patients with acute type A aortic dissection. Older age is associated with a lower probability of an intimal tear at the level of sinus of Valsalva. These findings, associated with prognostic implications, account for the choice of more radical proximal procedures for repair of aortic dissection in younger patients. 


\section{Introduction}

Aortic surgery, especially for pathologies requiring urgent surgical intervention has undergone significant changes in the past two decades leading to major improvement in short- and long-term outcomes. Better understanding of underlying diseases, improved guidelines and classifications have also contributed to more effective, prompt diagnosis and treatment of this high-risk segment of patient population. New imaging modalities, evolvement of perfusion methods, intra- and postoperative monitoring, improved intensive care are also of importance for achieving favourable outcomes. Nevertheless, continuous development of cardiac surgery itself is perhaps the most important component of this evolutionary process. As an example, the entry of catheter-based techniques including thoracic endovascular aortic repair and a combination of this method with conventional operative procedures resulted in novel devices, such as the "frozen elephant trunk", which led to reduced operative burden, lower mortality/morbidity and favourable long-term results.

The aim of this thesis is to provide a comprehensive, up-to-date overview on clinical characteristics of acute aortic syndrome, with special emphasis on current operative treatment possibilities, including well-established and novel, innovative surgical approaches. Within this scheme further specific goals were to analyze different cannulation and perfusion options, the role of core temperature management during hypothermic circulatory arrest and impact of age-related differences in surgical approach of AAS.

\section{Acute aortic syndrome}

AAS became a widely accepted term in the last decade, first mentioned by Vilacosta et al (1). By definition, AAS is an acute pathophysiological process involving the tunica media of the aortic wall, which results in rupture or any further life-threatening complications, and consists of aortic dissection, intramural haematoma and penetrating atherosclerotic ulcer. The incidence of AAS is approximately 30 patients/million/year; of which $80 \%$ is TAAD, $15 \%$ IMH, 5\% PAU. $65.3 \%$ of patients suffering from AAS are men, mean age cumulates at 63 years (2). Peak frequency of AAS occurs between 8:00 am and 9:00 am, with increased likelihood during winter period (3). This severe disease leads to $20 \%$ prehospital mortality, $30 \%$ perioperative death and $20 \%$ loss within the following 10 years (4). 


\section{Acute aortic dissection}

First historic record of the disease was registered by Galenus in 2nd century AC, the initial scientific description given by Nicholls in 1760 at autopsy of King George II. The definition of "aneurysma dissecans" originates from Laënnec (1819).

\section{Classification}

Classifications of thoracic aortic dissections aim to aid more accurate radiological diagnosis and also provide guidance on surgical versus medical management of patients. DeBakey divides dissections into 3 groups based on location of the entry and extension of aortic lesion:

- Type I - Entry on the ascending aorta, with concomitant involvement of aortic arch, and descending aorta (60\%)

- Type II - Confined to ascending aorta (10-15\%)

- Type III - Confined to descending aorta (25-30\%) (5).

More convenient is the Stanford classification for everyday patient management based on involvement of the ascending aorta (6):

- Type A (TAAD) - involves the ascending aorta (featuring DeBakey types I and II)

- Type B (TBAD) - does not involve the ascendens (equivalent to DeBakey type III)

Usually, type A dissections require surgery, while type B dissections might be managed medically under most conditions.

\section{Diagnostic modalities in AAS}

Definitive diagnosis of thoracic aortic disease or one of its anatomic variants requires dedicated aortic imaging. Selection of the most appropriate imaging study may depend on patient related factors (i.e. haemodynamic status, kidney function, contrast allergy, etc.) and/or institutional capabilities (i.e. availability of imaging modalities, imaging specialist expertise, etc.) (7). Chest X-ray may reveal mediastinal widening or haemothorax, but does not provide exclusive diagnosis. ECG could show ischaemic signs, if the coronary ostia are involved in the pathological process, albeit not specific for TAAD. TTE might demonstrate a dissection flap in the ascending aorta and reveal acute aortic valve regurgitation. TOE could further investigate larger segments of the aorta; for initial preoperative assessment is not the 
first choice as time consuming and not as sensitive as CT, but provides good real-time imaging intraoperatively. MRI scan represents the backbone of long-term postoperative follow-up as imposes no radiological burden on patients, but in the acute phase is not ideal as requires significantly more time at a critically ill patient than $\mathrm{CT}$ and not available in most of moderate size district general hospitals. These diagnostic modalities are analysed in Tables 1 . and 2. (8).

$\begin{array}{cccc}\text { Transthoracic } & \text { Transoesophageal } & \begin{array}{c}\text { Computed } \\ \text { echocardiography }\end{array} & \begin{array}{c}\text { Magnetic resonance } \\ \text { echocardiography }\end{array}\end{array}$

\begin{tabular}{l|cccc}
\hline Availability & +++ & ++ & +++ & + \\
Portability & +++ & +++ & +- & + \\
Investigation tolerance & +++ & + & ++ & - \\
Real-time follow-up & ++ & +++ & + & + \\
Imaging speed & +++ & ++ & ++ &
\end{tabular}

Table 1. Diagnostic features of imaging modalities in AAS

Transthoracic Transoesophageal Computed Magnetic resonance echocardiography echocardiography tomography imaging

\begin{tabular}{l|cccc}
\hline Aortic dissection & + & ++ & +++ & +++ \\
Intramural haematoma & +- & ++ & +++ & +++ \\
Penetrating ulcer & - & + & +++ & +++ \\
Dissection entry & + & +++ & ++ & +++ \\
Periaortic haematoma & +- & +++ & ++ \\
Pericardial effusion & +++ & +++ & - & ++ \\
Aortic regurgitation & +++ & & +++
\end{tabular}

Table 2. Efficacy of different imaging modalities in AAS

\section{Initial management of AAS}

Initial management of thoracic aortic dissections should be targeted to decrease aortic wall stress by controlling heart rate and blood pressure. In absence of contraindications, intravenous $\beta$-blockade (e.g. labetalol) should be administered and titrated to a target heart rate of 60/min or less. Beta-blockers should be administered cautiously in the setting of acute aortic regurgitation as they can block the compensatory tachycardia. In patients with clear 
contraindications to $\beta$-blockade, non-dihydropyridine calcium channel-blocking agents (e.g. diltiazem, verapamil) should be utilized as an alternative for rate control. If systolic blood pressure remains $\geq 120 \mathrm{mmHg}$ after adequate heart rate control has been obtained, then angiotensin-converting enzyme inhibitors and/or other vasodilators should be administered intravenously to further reduce blood pressure that maintains adequate end-organ perfusion. Sufficient pain control is usually achievable with the aid of morphine analogues (7).

\section{Surgical considerations for AAS}

In case of thoracic aortic dissection urgent surgical consultation should be undertaken regardless of the anatomic location (ascending versus descending) as soon as the diagnosis is established or highly suspected. TAAD should be urgently evaluated for emergent surgical repair due to the high risk of associated life-threatening complications, i.e. rupture. The mortality of TAAD is $>40 \%$ in the first week (2). TBAD should be managed rather medically (10\% mortality) unless life-threatening complications develop (i.e. malperfusion syndrome, progression of dissection, enlarging aneurysm, inability to control blood pressure or symptoms, progressive left haemothorax). Surgical approach of TBAD carries a risk of life approximately $30 \%$ (7) (2). In patients with TAAD, all aneurysmal aorta and proximal extent of the dissection should be resected. A partially dissected aortic root may be repaired with aortic valve resuspension. Extensive dissection of the aortic root should be treated with aortic root replacement with a composite graft or with a valve sparing root replacement. If a DeBakey Type II dissection is present, the entire dissected aorta should be replaced (7). Furthermore, the "frozen elephant trunk" technique could be considered in younger patients to avoid secondary operations (9). For TBAD, if surgical intervention is required, TEVAR would be the first treatment of choice as providing similar anatomical results as conventional surgery, but at a lower perioperative risk rate (2).

\section{Intramural hematoma}

IMH results from a haemorrhage into the aortic wall (tunica media) originating from the vasa vasorum without an intimal tear. Typical in elderly, mainly hypertensive patients, albeit can result sometimes from blunt chest trauma. IMH weakens the aortic wall and can penetrate to the outer aortic surface leading to rupture or propagate to the intimal surface creating an entry and progressing to a dissection. Therapeutic approach of IMH is similar to aortic dissection in the corresponding segment of the great vessel (7). Cases with TAAD analogue localisation 
without progression and periaortic bleeding can be operated at a low risk. Elderly patients with significant comorbidities can be managed medically, but require intensive monitorisation for 2 weeks and repeat imaging to exclude IMH progression. Only a few limited papers examined this patient segment; Kaji et al observed complete haematoma involution in $40 \%$, and in this group, there was no mortality in a period of 4 years (10). Evangelista-Masip found $34 \%$ spontaneous regression of IMH, 36\% progression to dissection (12\% to acute aortic dissection, $24 \%$ to localised dissection), $30 \%$ late aneurysm formation. It was also described that rupture or dissection is very rare $<60 \mathrm{~mm}^{2}$ extension of IMH (8).

\section{Penetrating atherosclerotic ulcer}

PAU is typical in elderly male patients with a history of hypertension (92\%), smoking (77\%), CAD (46\%) and also associated with COPD (24-68\%). PAU accounts for 5\% of all AAS. In half of the cases there are concurrent aortic aneurysms, mainly abdominal (11). Patients usually present with symptoms of AAS, but sometimes PAU is asymptomatic and emerges as an incidental finding.

The term of PAU describes an ulcerating atherosclerotic lesion that penetrates the aortic intima and progresses into the media. In the early stages the lesion just ulcerates the intima and often asymptomatic. With further progression it may ulcerate the media and result in a medial hematoma of variable size (12).

PAU can resolve completely or stay stable, although can also lead to aortic dissection, saccular aortic saccular aneurysms or even spontaneous aortic rupture. There is a higher predilection to involve the mid to distal thoracic aorta (13). 


\section{Aortooesophageal fistula}

Aortooesophageal fistula is a rare cause of gastrointestinal bleeding, albeit is a highly lethal condition, even when promptly diagnosed and treated. The exsanguination is imminent in most of the cases, many patients do not have the chance to reach a sufficient therapeutic facility as the aorta has a direct communication with the inner body surface. Main causes of $\mathrm{AOF}$ are lesions of the oesophageal wall resulting from a thoracic aortic aneurysm (in up to $54 \%$ of cases), ingestion of foreign bodies (in up to $19 \%$ of cases), trauma (usually iatrogenic), carcinoma, or seldom aortitis tuberculotica (14). Conservative treatment of AOF results in a high in-hospital mortality rate, and conventional surgical procedure has also a reported inhospital mortality rate of nearly $40 \%$ (15). Transcatheter endovascular aortic repair as a standalone procedure has recently gained recognition as a possible technique for the emergent treatment of AOF, despite a considerable risk of infection (16), in contrast to the conventional solution of open thoracic surgery with higher mortality and morbidity. However, relatively little is known about long-term results of TEVAR for AOF due to its rarity and the lack of large clinical experience.

\section{Perfusion options in aortic emergencies}

TAAD, with or without involvement of the aortic arch, is a clinical emergency that requires immediate surgical intervention. Mortality rates of these operations have dramatically improved as the result of recent advances in preoperative preparation, intraoperative techniques, and postoperative care. Nevertheless, operations for aortic emergencies are still associated with a relatively high rate of mortality and postoperative morbidity compared to routine heart surgery, especially when the presentation is complicated by haemodynamic instability.

Establishing perfusion might be challenging as we aim to access the targeted diseased organ, the aorta. Classical femoral approach results in higher incidence of malperfusion, neurological complications and mortality (17). Cardiopulmonary bypass via axillary/subclavian artery has become popular as an alternative perfusion site in recent years predominantly for acute aortic dissections and patients with severe aortic atherosclerosis (18) (19) (20). AxS inflow may not be suitable for rapid establishment of antegrade perfusion in cases with hemodynamic instability, since the preparation is more time consuming. Obese patients might also represent a technical challenge; on the other side of the spectrum, in patients with small body surface 
area, limitation of pump flow due to a narrow axillary artery could be a concern. In numerous studies failure rate and requirement for an alternative cannulation site of $\mathrm{AxS}$ measures $4.2 \%$ $11 \%$; albeit this is the most widely applied arterial access (21) (22) (23).

Anatomical variations, such as lusorian artery might also jeopardize the safe applicability of AxS and also unilateral antegrade cerebral perfusion. Furthermore, cannulation for extensive aortic lesion can be challenging either through AxS or lower limb arteries, if these vessels are involved in the pathological process (24). Therefore, other alternative approaches, especially central cannulations should be kept in evidence. In the light of the problems associated with peripheral cannulation techniques, we started to apply an innovative ultrasound-guided entry method on the usually uninvolved aortic wall segment on the concavity of aortic arch via Seldinger technique. As a further alternative or a bail-out for other unsuccessful arterial cannulation attempts, transapical approach of the heart-ascending aortic complex is also a feasible (25) (26)

\section{Intraoperative body temperature monitoring}

Accurate monitoring of core temperature during aortic surgery, especially with application of deep hypothermic circulatory arrest is an important component of routine perioperative care. Preservation of neurological function is one of the main goals in such patients. Increasing the tolerance of brain to ischaemia by application of systemic hypothermia allows for a safe period of circulatory arrest and has remained the mainstay of neuroprotection since decades (27) (28). The safety of this procedure relies on adequate systemic cooling under strict control. If this control is incomplete or fails, neurological injury may occur during HCA. Whereas hypothermia is neuroprotective, even mild hyperthermia is hazardous during cerebral ischaemia since it accelerates neuronal death (29). This results from oxygen free radical production (30), destabilization of cytoskeleton (31), intracellular acidosis (32) and increased blood-brain barrier permeability (33). Thus, to estimate actual brain temperature, different sites are used for perioperative temperature assessment, for example; urinary bladder, oesophagus, rectum and tympanic membrane. Body temperatures measured on these alternative sites may, however, substantially deviate from the actual cerebral temperature. Adequate neuroprotection requires meticulous temperature management to avoid too low or high temperatures leading to overcooling or overheating the patient due to inappropriate "slow responding" temperature monitoring. 
Although application of hypothermia has been an important contribution to patient management as a neuroprotective method from the dawn of cardiac surgery (34), proper body temperature management relies on the accurate measurement of temperature, to enable adequate monitoring of changes during $\mathrm{CPB}$ and HCA. Oxygen consumption drops with lower body temperature, so that ischaemic tolerance is increased by cooling. Cerebral oxygen requirement decreases to approximately one-fifth of normothermic needs at $20^{\circ} \mathrm{C}$ (35) allowing a safe period of 45-50 minutes for HCA (Figure 1) (36). In addition, hypothermia may contribute to neuroprotection by a variety of complex mechanisms including decreased vascular permeability, reduced ion influx and decreased excitatory transmitter release (37). Albeit hypothermia is neuroprotective, it leads to platelet dysfunction, coagulation cascade blockade, vasoconstriction resulting in localized areas of hypoperfusion. During the rewarming phase of $\mathrm{CPB}$, conventional temperature monitoring sites may not reflect true brain temperature so that cerebral hyperthermia may not be detected, if conventional temperature monitoring underestimates brain temperature or there is a delay with arterial heat exchange (38).

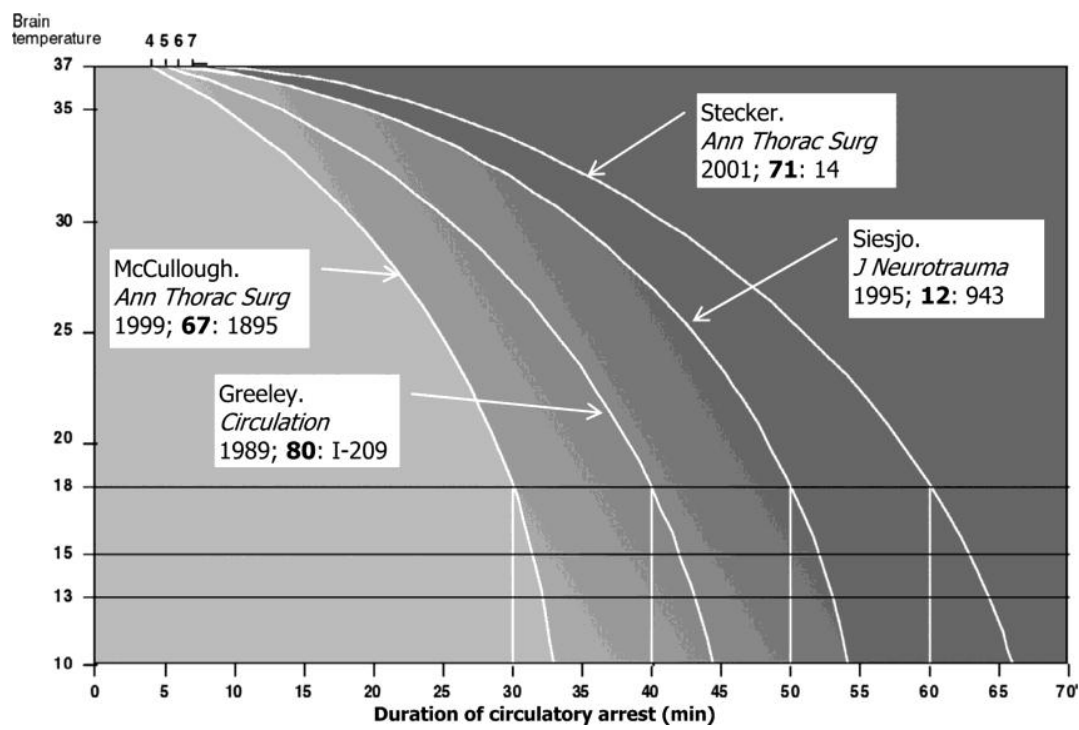

Figure 1. Relation of brain temperature and safe duration of HCA in the literature (36)

\section{Cerebral oximetry}

Classical complex aortic surgery, especially in combination with HCA represented high patient risk with significant postoperative morbidity - commonly associated with stroke - and mortality. One milestone in reduction of hazard in complex aortic procedures is tissue oximetry performed on the forehead, constantly monitoring brain tissue saturation on bases of 
near infrared spectroscopy. Near infrared spectroscopy was initially published nearly four decades ago, utilizing the Lambert-Beer law as a measurement principle, where transmittance of material sample is related to its optical depth and to its absorbance. The radiation is emitted by a photodiode or laser undergoes reflection, absorption and deflection in the brain tissue, mainly on haemoglobin enabling concentration assessment of the substance. Standard wavelength of light applied in NIRS system measures 730-910 $\mathrm{nm}$. The measurement is undertaken on mixed blood, although not able to differentiate between the arterial and venous phase, as pulsoximetry can. As $70 \%$ of absorption is resulting from venous blood, $25 \%$ from arterial phase, $5 \%$ from the capillary bed; NIRS dominantly detects increased local O2 extraction, when the cerebral saturation value drops (39).The sensor measures oxygenation of the anterior and medial cerebral artery territories. As there is some individual variability in oxygenation parameters, the baseline value has to be established right before starting the surgical procedure, then intraoperative values can be interpreted in reference to the baseline (Figure 2). Intraoperative drop of $20 \%$ in comparison to baseline or saturations below $50 \%$ are strongly associated with postoperative stroke, cognitive dysfunction or coma. NIRS is a valuable tool in prevention of severe postoperative neurological dysfunction in aortic surgery (40).

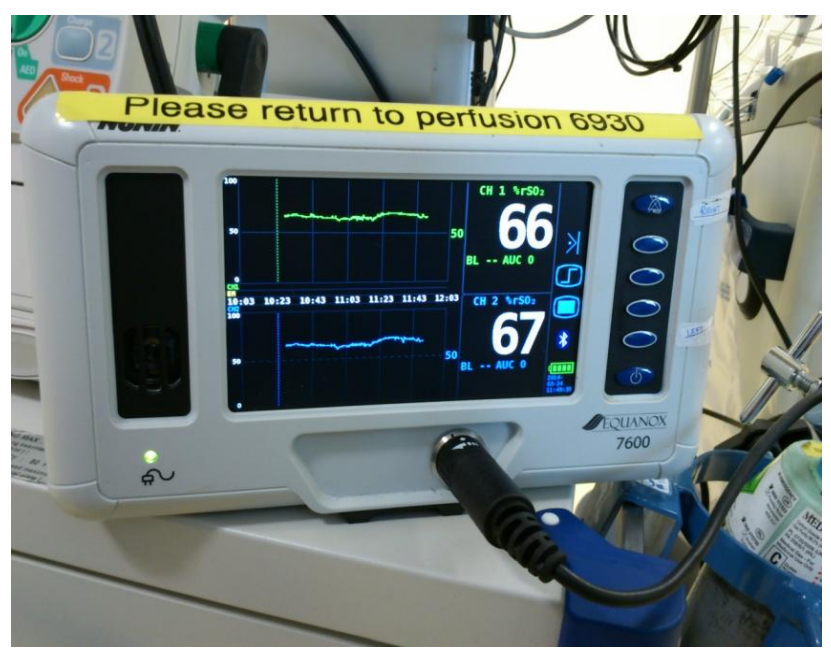

Figure 2. NIRS demonstrates a well conducted perfusion management in HCA 


\section{Cerebral blood supply challenges in major aortic surgery}

In aortic emergencies patients have a good chance to end up in haemodynamical instability, therefore; well planned perfusion strategies are required to obtain optimal outcome. As we are working on a diseased aorta, this aim in not always easy to be achieved. To avoid malperfusion and protect organs, especially the cerebrum, prompt perfusion of the true lumen without any bias is mandatory. The classical femoral perfusion does not entirely fulfil all these requirements, alternative approaches were developed in the last two decades. As visible in the paragraph on HCA, safe duration of circulatory arrest measures $45-50$ minutes at $20^{\circ} \mathrm{C}$, which time span would not entirely satisfy requirements for some complex arch reconstruction. To avoid further neurological damage, cerebral perfusion has been implied in several institutions. Cerebral perfusion can be performed in an antegrade fashion either directly on both carotid arteries or non-selectively, through a branch of the aortic tree, i.e. AxS. Retrograde cerebral perfusion is usually performed through the superior vena cava, rarely via right internal jugular vein. Following initial enthusiasm, mid- and long-term results of loan retrograde cerebral perfusion were rather modest in comparison to the antegrade. Japan Cardiovascular Surgery Database Organization concluded from an analysis of 16,218 that although antegrade and retrograde cerebral perfusion demonstrate comparable clinical outcomes regarding mortality and stroke rates, but retrograde perfusion results in higher incidence of prolonged intensive care unit stay. Antegrade cerebral perfusion might be preferred as brain protection method for complex aortic arch procedures (41).

Antergrade cerebral perfusion can be subdivided into selective antegrade cerebral perfusion providing direct bilateral brain supply and unilateral antegrade cerebral perfusion. At SACP both common carotid arteries are cannulated and direct perfusion is provided on the normal anatomical pathway at a total rate of $10 \mathrm{ml} / \mathrm{kg} / \mathrm{min}$ constantly monitored by NIRS (Figure 3). To administer UACP, AxS represents the most convenient way, as the right axillary artery fills the right common carotid artery via innominate artery. Other alternative access for UACP is a direct cannulation of the internal carotid artery proposed by Urbanski et al. (42). Applying the standard technique, however, only the right hemisphere is continuously perfused, which can result in malperfusion of the contralateral hemisphere; as Merkkola et al. demonstrated, up to $17 \%$ of the patients have incomplete circle of Willis (43). Even with a complete circle of Willis, concern has been raised, if this type of perfusion alone can sufficiently supply the left hemisphere. Although UACP is simple, widely used method, but not the most physiological way of brain perfusion. A recent meta-analysis has concluded, albeit UACP and SACP did 
not result in different mortality and neurologic morbidity rates, among prolonged HCA times UACP resulted in poorer outcomes with respect to SACP (44).

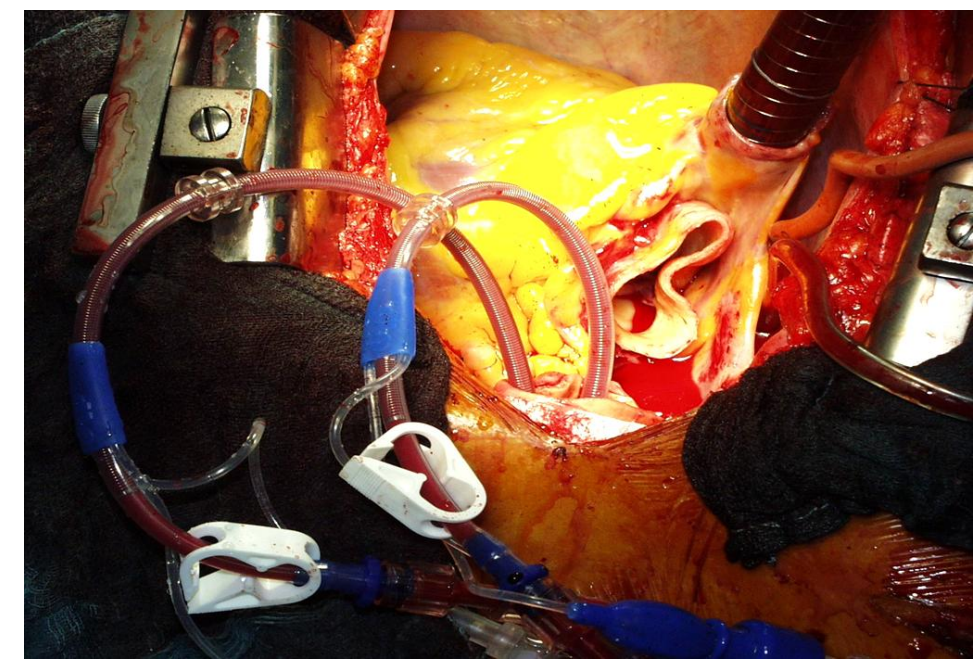

Figure 3. Selective antegrade carotid perfusion in situ

\section{Surgical consideration in aortic emergencies}

\section{Conventional aortic surgery}

Albeit aortic dissection, the most common aortic emergency is well known since centuries, Dubost utilized a homograft for abdominal aneurysm replacement in 1951 at first, and Gibbon created in 1953 the first relatively safe extarcorporeal system. In 1956 De Bakey replaced the ascending aorta, then the aortic arch (1967); one year later Bentall and De Bono implanted the first composite graft at an aortic root-ascending aorta replacement.

The most simple solution for surgical management of TAAD is an interposition graft replacement of the ascending aorta or also including in the replacement a large section of the lesser curvature of the arch; the so called "hemiarch" technique. In case of a simple ascending replacement no HCA is required, so long a "closed distal" anastomosis is with aortic cross clamp on performed. Current medical literature has the consensus, that in younger patients a "hemiarch technique" is desired, but in septua- and octogenarians, especially with significant comorbidities onboard, a "closed distal" technique is acceptable. Furthermore, this latter technique puts less operative burden on elderly; therefore, better recovery and survival can be achieved with a limited surgical procedure (45) (46). Surgical reconstruction of aortic root involvement has developed step-by-step from a simple valve resuspension, then valve 
replacement to a mechanical composite root replacement. Later on, biological "full root" (e.g. Medtronic Freestyle ${ }^{\mathrm{TM}}$ ) substitutes came on the market, followed by root remodelling technique by Yacoub (47) and root reconstruction by David (48). Recently De Paulis (49) has published haemodynamic advantages of a Valsalva graft, which allows a better anatomical replacement of the aortic root. Combination of this graft with a biological valve prosthesis as "custom made" biological root proposed by Urbanski, enables easy redo valve surgery in the future (50).

\section{Elephant trunk technique}

In case of aortic arch involvement, next surgical step was an interposition graft replacement with island transposition of supraaortic vessels in HCA. As in younger patients the descending aorta has to be replaced often as a second stage procedure, Borst (51) introduced the"elephant trunk technique" to facilitate the second stage operation's proximal anastomosis with a hovering distal end of arch graft situated in the proximal descending aorta, such as the trunk of an elephant (Figure 4).
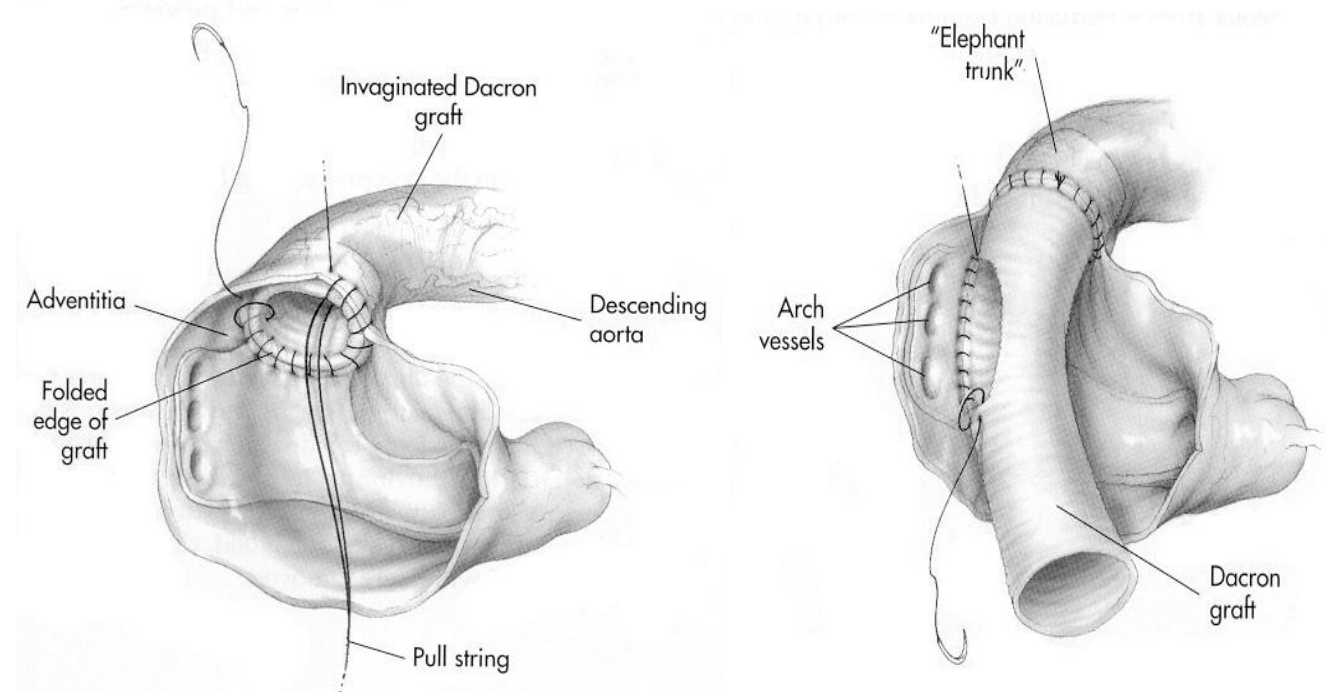

Figure 4. Elephant trunk technique by Hans Borst (52)

\section{Transcatheter EndoVascular Aortic Repair}

TEVAR has revolutionised noninvasive treatment of descending aortic aneursysms and TBADs. The initial idea came from Volodos, who developed Z-stents and fabric coated stents in 1980s (53). TEVAR grafts are intravascular expandable devices coated by fabric to 
remodel the normal aortic lumen and to cover transvascular communication. In combination with debranching of the aortic arch, TEVAR can substitute even some complex arch operations. Requirements for sufficient stenting are a generous landing zone to well anchor the device, optimal radial pressure of stent frame to provide a good apposition of aortic wall with minimal trauma. Radial pressure is determined by stent frame geometry, length, spacing, wire material and correct oversizing. Following meticulous planning, TEVAR procedure is a relatively quick and low risk procedure in comparison to a surgical intervention in certain aortic pathologies (54).

\section{Hybrid approach - 'Frozen elephant trunk' technique}

Although "elephant trunk technique" has revolutionarized complex arch surgery with aim of facilitating a secondary descending aortic procedure, a significant proportion of patients was not suitable at all after 3-6 months following initial arch surgery to undergo a secondary procedure. Combination of the original "elephant trunk technique" with a TEVAR stent graft resulted in a hybrid device that allowed one stage completion of the previous double procedure. During HCA the aortic arch and some portion of proximal descending aorta is resected, then CT angiography guidance sized TEVAR portion of the Thoraflex Hybrid TM (Vascutek Ltd, Inchinnan, Glasgow, UK) graft is inserted and expanded (Figure 5) distally. The device cuff is sutured to seal the descending aorta, after this the aortic arch plexus is anastomosed step-by-step to all supraaortic vessels, and at last the ascending anastomosis is completed. This unique device reduces operative burden in fragile patients (55).

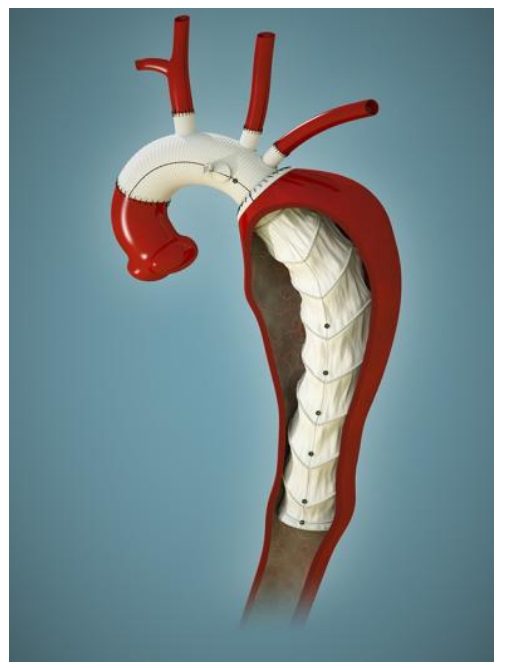

Figure 5. Thoraflex Hybrid TM device in situ (Vascutek Ltd, Inchinnan, Glasgow, UK) - image is courtesy of Vascutek Ltd, UK (Mr T. Pacuka) 


\section{Postoperative care following aortic emergencies}

\section{Intensive care therapy}

Constant improvement in anaesthetic and intensive care therapy has significantly reduced postoperative mortality and morbidity following major aortic surgery in the last two decades. These advances enabled us to extend the operative indications for elderly patients with multiple co-morbidities, and improvement in surgical techniques have also contributed to reduction of previous patient selection limitations. Certain evolvement in respiratory therapy has reduced the incidence of lung related severe postoperative complications; continuous- and bilevel positive airway pressure (CPAP, BIPAP) have facilitated recruitment of the atelectatic lung fields following HCA and longer ECC times. Even tracheostomy has a smaller impact on recovery with availability of Seldinger type mini-tracheostomy. Kidney failure and major electrolyte/fluid imbalance is more effectively managed via continuous veno-venous filtration, and long-term dialysis also offers a better quality of life, then before. Improved understanding of the coagulation system led to development of prothrombin complex concentrate, recombinant fibrin, recombinant factor VIIa and several different surgical sealants as well, thus reducing intra- and postoperative blood loss. All the above factors have led to significant shortening of operative times and frequency of rethoracotomies, the major contributors in postoperative morbidity and mortality. German Registry for Acute Aortic Dissection Type A (GERAADA) has concluded after analysis of 1558 patients, that emergency aortic procedures for septuagenarians can be performed with acceptable mortality. Octogenarians showed up significantly higher 30-day mortality, although this was also lower, then the mortality without any surgical intervention (56).

\section{Outpatient follow-up}

As AAS mainly develops on a background of preexisting aortic aneurysms, this fact mandates regular follow-up in aortic patients to facilitate an elective intervention, if required. These elective procedures carry less risks, as the patient can be thoroughly prepared utilizing ideal imaging modalities, and pre-existing medical condition can be timely optimized for a major surgery. Regular postoperative outpatient follow-ups are essential in provision of excellent long-term outcomes by the opportunity of early endo-leak detection, monitoring aortopathy progression, managing hypertension, etc. The usual AAS population is relatively young, average age of affected individuals measures about sixty years, regular follow-ups 
additionally contribute to restoration of health in this still relatively active age group. Patients with AAS possess a less favorable long-term outcome with a past medical history of previous cardiac surgery or generalized atherosclerosis (57). Blood pressure control is essential for these patients, aiming to maintain a pressure no more than $130 / 80 \mathrm{mmHg}(58)$. If there is a well-known hereditary burden present, the patient's complete family should be offered the opportunity to be genetically tested and counselled.

Some recent publications have highlighted the role of angiotensin II in progression of aortic aneurysms, although the relative contribution of its type 1 (AT1) and type 2 (AT2) receptors remain unknown. Habashi et al. demonstrated, that loss of AT2 expression accelerates aberrant growth and rupture of aorta in a mouse model of Marfan`s syndrome. Losartan, a selective AT1 blocker reduces aneurysm progression in mice; a full protection requires intact AT2 signaling. The angiotensin-converting enzyme inhibitor enalapril, which limits signaling through both receptors, is less effective. Both drugs attenuate transforming growth factor- $\beta$ (TGF ß) signaling in the aorta, but losartan uniquely inhibits TGF $\beta$-mediated activation of extracellular signal-regulated kinase, by allowing continued signaling through AT2, which demonstrates a protective nature of AT2 signaling and a possible choice of therapy in aortic aneurysms (59). International multicentric studies are currently evaluating possible pharmacological prevention and postoperative medical supportive therapy options in Marfan's syndrome provided by AT1 blockers, especially losartan in a combination with a ß-blocker, such as nebivolol. The key molecule in aortic aneurysms, TGF $\beta$, normally attached to extracellular matrix, is free and activated. Under experimental circumstances, TGF $\beta$ blockade prevents aortic wall damage and dilation. AT1 blockers exert an anti-TGF $\beta$ effect; trials are now ongoing for evaluating the above effect of losartan compared with atenolol or nebivolol. The third generation $\beta$-blocker nebivolol retains a $\beta$-adrenergic blocker effect on heart rate, and further exerts an anti-stiffness effect, that is typically increased in aortic aneurysms (60). After thorough evaluation of ongoing human studies we are going to gain more insight into optimal pharmacological support of AAS and aortic aneurysms, which completes the therapeutic circle of this severe disease group. 


\section{Aims}

Based on this background, we designed four clinical studies (Study I - IV) in the last decade aiming to improve diagnostics and treatment of aortic emergencies. The final goal of these protocols was to improve safety of this major surgical procedure.

The aim of Study I. was to develop a reliable central cannulation method in type A aortic dissection repairs. In Study II., the reliability of different body temperature measurement sites was investigated during aortic surgery; in Study III., management options for aortooesophageal fistulas; while in Study IV., age-related considerations of acute type A aortic dissection were analyzed. 


\section{Study I - Central cannulation by Seldinger technique in type A aortic dissection repairs}

\section{Background}

Extensive aortic disease, such as giant aneurysms combined with atherosclerosis or dissections that involve the ascending aorta, can complicate the choice of cannulation site for cardiopulmonary bypass. Ideal perfusion during ascending aorta/arch surgery should allow easy implementation of antegrade cerebral perfusion while avoiding atheroembolization or false lumen perfusion in dissections. Alternative cannulation sites such as $\mathrm{AxS}$ or innominate artery have been recently preferred to femoral artery to improve postoperative outcomes in patients undergoing surgery of the thoracic aorta. Prompt establishment of antegrade perfusion may lead to favourable outcomes in type A dissections, especially in case of hemodynamic instability. We started to employ direct cannulation of the true lumen targeting the concavity of aortic arch by Seldinger technique in aortic dissections, later this method was applied in ascending/arch aneurysm resections too. We have evaluated the efficacy of this access technique as an alternative arterial inflow pathway in aortic surgery.

\section{Patients and methods}

Within a period of 2.5 years, 24 consecutive patients (mean age: $59 \pm 14$ years, CI: 53.0 - 64.8; 17 men and 7 women) underwent procedures of the thoracic aorta. In all patients a standard operative technique for acute aortic dissection was applied and the only difference in surgical strategy was the choice of arterial cannulation site. Direct cannulation by Seldinger technique was utilized in 14 cases (58\%), subclavian access in 6 patients (25\%), and femoral entry on 4 occasions (17\%). Further preoperative data is provided in Table 3.

\begin{tabular}{lccc}
\hline Characteristics & Direct & Subclavian & Femoral \\
\hline $\mathrm{N}^{\mathrm{o}}$ of patients & 14 & 6 & 4 \\
Male & 8 & 6 & 3 \\
Female & 6 & 0 & 1 \\
& $65 \pm 10(66)$ & $51 \pm 17(49)$ & $51 \pm 13(46)$ \\
Age (years (median)) & & [N.S. $=0.11]$ & [N.S. p=0.13] \\
Hypertension & 13 & 5 & 3 \\
Preoperative ventilated & 4 & 4 & 3 \\
Preoperative renal insufficiency & 2 & 2 & 0
\end{tabular}

Table 3. Demographic and preoperative data. Statistical analyses are provided as comparisons to the group with direct cannulation 
The preoperative diagnosis was established on basis of emergency computed tomography with additional intraoperative transoesophageal echocardiography support in all patients. Aortography or coronary angiography was not performed for preoperative evaluation. The standard operative technique for aortic dissection repair at our institution has been graft replacement of the ascending aorta and proximal aortic arch ("hemiarch technique"). Inspection of the supraaortic vessels was always carried out to decide whether to perform a concomitant island transposition depending on the supraaortic status. The patient was placed in standard supine position. The arms were horizontal beside the body as for a usual cardiac procedure. Monitoring of arterial pressure was performed by placing three lines routinely in both radials and the right femoral artery. The ascending aorta and aortic arch were exposed through a median sternotomy, then the concavity of aortic arch at level of Botallo`s ligament (ligamentum arteriosum) was cannulated applying a minimal invasive technique with dilation steps, as described by Seldinger (Fem-Flex Femoral Arterial Cannula ${ }^{\circledR}, 24$ Fr TFA 02425H Edwards Lifesciences LLC, Irvine, USA; Joline Special Dilatatorset ${ }^{\circledR}$, Hechingen, Germany) (Fig. 6). No purse-string sutures are required in this area; the arterial line is fixed with a stitch to the cranial sternotomy skin incision corner to avoid accidental dislocation. Correct position of the guide wire and cannula in the aorta during the cannulation procedure was routinely confirmed by TOE, or epiaortic ultrasound in a rare case of technical difficulty with echocardiography. The same type of cannula was inserted in both peripheral access sites. CPB was instituted between the arterial cannulation site and right atrium. The patient was cooled to a tympanic temperature of $19-20^{\circ} \mathrm{C}$ (Mon-a-therm ${ }^{\circledR}$ Thermistor YSI 400 Series tympanic temperature probe, Mallinckrodt Inc, St Louis, USA), rectal (Thermocouple probe, Mallinckrodt Medical, USA) and bladder (Curity ${ }^{\circledR}$, Degania, Israel) temperatures were also followed-up simultaneously throughout the procedures as well. After cross-clamping an ascending aortic incision was performed, antegrade crystalloid cardioplegic solution $(2000 \mathrm{ml}$ Custodiol $^{\circledR}$ HTK-Solution by Brettschneider, Dr. F. Köhler Chemie, Hähnlein, Germany) was administered proportionally through both coronary orifices. During HCA, selective antegrade cerebral perfusion was applied via both carotid arteries (DLP Retrograde Coronary Sinus Perfusion Cannula with manual Inflating Cuff ${ }^{\circledR}$, Medtronic Inc, Minneapolis, USA) at a flow rate adapted to maintain a constant cerebral $\mathrm{O}_{2}$ saturation on each side, providing a perfusion pressure of 35-40 mmHg. Cerebral monitoring was performed with NIRS (INVOS ${ }^{\circledR}$ cerebral oxymeter, Somanetics Inc, Troy, USA), brain tissue oxygen saturation measured 60-70\% continuously during perfusion, which corresponded to the induction values. 


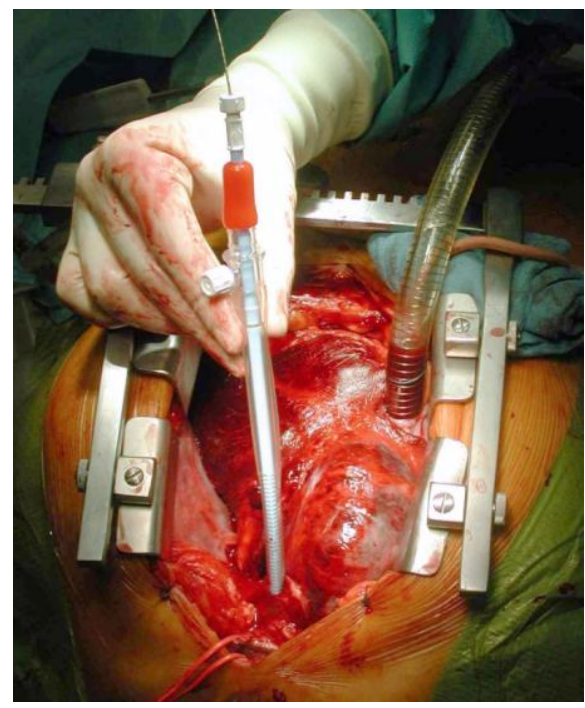

Figure 6. Direct aortic cannulation via Seldinger technique

Reconstruction of the aorta was undertaken with a woven Dacron side-branched vascular prosthesis (Hemashield Platinum Woven Double Velour Vascular Graft ${ }^{\circledR}$, Boston Scientific Inc, Wayne, USA) including the island type reinsertion of all supraaortic vessels, if applicable. The false lumen was eradicated with $45 \%$ bovine serum albumin-10\% glutaraldehyde glue (BioGlue $^{\circledR}$, CryoLife International Inc, Kennesaw, USA); aortic valve commissures were refixed applying the resuspension suture technique. The valve was replaced, if appeared diseased. Composite valve graft replacement was performed in patients with Marfan's syndrome, or if intraoperatively severe local involvement of the aortic wall could be observed. The decision, whether to implant a composite graft did not depend on a maximal diameter of the aortic root but was based on presence of Marfan's syndrome or severity of wall destruction. Systemic reperfusion with concomitant rewarming was started through the graft side-branch. Summary of performed surgical procedures is presented in Table 4.

\begin{tabular}{|c|c|c|c|c|}
\hline \multicolumn{2}{|l|}{ Surgical procedure } & Direct & Subclavian & Femoral \\
\hline \multicolumn{2}{|l|}{ Ascending aorta + hemiarch } & 13 & 6 & 4 \\
\hline \multicolumn{2}{|l|}{ Ascending aorta + total arch } & 1 & $*$ & $*$ \\
\hline & ${ }^{\circ}$ David reconstruction & 1 & $*$ & * \\
\hline & ${ }^{\circ}$ Yacoub reconstruction & 2 & 1 & 1 \\
\hline & ${ }^{\circ}$ Bentall procedure & 3 & 1 & $*$ \\
\hline & ${ }^{\circ}$ Coronary bypass grafting & & 1 & $*$ \\
\hline
\end{tabular}

${ }^{o}$ marks an additional procedure of aortic graft implantation 
Statistical analysis was undertaken using SPSS v15.0 software (IBM Corporation, Armonk, New York, USA). For statistical comparison of the groups Mann-Whitney's U test and Chisquare test were applied. Although the number of cases in two groups; femoral cannulation and subclavian approach was relatively low (4 and 6 cases, respectively), we considered a pvalue $<0.05$ to be significant to enhance the statistical power of comparisons. Where appropriate, confidence interval (CI) was calculated with a confidence level of $95 \%$. Data are presented as mean values $\pm \mathrm{SD}$ and, where applicable, corresponding CI are shown in parentheses.

\section{Results}

There were no intraoperative deaths; cumulative 30-day mortality rate measured 25\% (6) for the entire patient population; 3 of $14(21 \%)$ in the direct group, 2 of $6(33 \%)$ subclavian, 1 of $4(25 \%)$ femoral cannulated patients ( $\mathrm{p}=0.24$ and $\mathrm{p}=0.46$, respectively), all due to multiorgan failure. Direct aortic cannulation was safely performed in all cases; there was no need to switch to an alternative cannulation site. The adventitia of the dissected aorta was firm enough to support a cannula being inserted with Seldinger technique utilizing staged dilatators, and there was no case of complicated local massive haemorrhage on the cannulation site. No malperfusion or apparent thromboembolism due to cannulation procedure was observed. Malperfusion would have been anticipated, if a cerebral saturation difference of $10 \%$ occurred compared to preoperative values, and/or a pressure difference between the peripheral arteries greater than $20 \mathrm{mmHg}$ found. Permanent neurological deficits were not present, in one patient transient changes occurred (4\%) in the direct group. Since the Seldinger technique was easier and quicker to apply, than the peripheral approaches (Table 5) and showed certain advantages in the preliminary results, we have permanently changed our cannulation method to direct aortic entry in all patients. Transoesophageal echo guidance along with colour Doppler imaging was helpful for following-up the aortic cannulation procedure; the imaging provided additional real-time information about true lumen antegrade perfusion.

Mean extracorporeal perfusion duration measured 183 \pm 63 minutes (156.4 - 209.6), mean time demand to reach circulatory arrest was $28 \pm 14$ minutes $(23.1$ - 34.9) in the entire cohort, with no significant differences between the groups (Table 5). Initial SACP flow was comparable in all three groups, however, we observed a significant difference in SACP flow requirements to maintain the initial cerebral saturation at constant blood pressure by the end of cerebral perfusion period between direct cannulation group (right: 196 $\pm 37 \mathrm{ml} / \mathrm{min}$ [177.3 - 227.4]; left: 
$227 \pm 68 \mathrm{ml} / \mathrm{min}$ [184.8 - 247.2]), and both femoral (right: $350 \pm 54 \mathrm{ml} / \mathrm{min}$ [264.1 - 435.9] [p=0.006]; left: $275 \pm 64 \mathrm{ml} / \mathrm{min}[173.2-376.8]$ [p=0.24]) and subclavian access groups (right: $282 \pm 56 \mathrm{ml} / \mathrm{min}$ [223.2 - 340.8] [p=0.02]; left: $283 \pm 49 \mathrm{ml} / \mathrm{min}[231.6-334.4]$ [p=0.05]), in favour of direct cannulation. Further intraoperative data were evaluated to identify reliability and benefits of direct cannulation method and are presented in Table 5.

Time requirement to reach circulatory arrest was the shortest in the direct access group with a mean value of $27 \pm 11$ (20.6 - 33-3) minutes; at femoral cannulation it measured $43 \pm 22$ (28.0 78.0) minutes $(\mathrm{p}=0.058)$; at subclavian entry $32 \pm 8(23.6-40.4)$ minutes $(\mathrm{p}=0.34)$, respectively.

\begin{tabular}{lccc}
\hline Intraoperative data & Direct & Subclavian & Femoral \\
\hline & & Mean \pm SD (Median) \\
Time to HCA (min) & $27 \pm 11(26)$ & $32 \pm 8(31)$ & $43 \pm 22(48)$ \\
CPB time (min) & $181 \pm 77(149)$ & $188 \pm 32(193)$ & $180 \pm 52(200)$ \\
HCA time (min) & $51 \pm 20(52)$ & $51 \pm 22(50)$ & $53 \pm 31(48)$ \\
SACP time (min) & $39 \pm 18(39)$ & $36 \pm 24(25)$ & $41 \pm 29(31)$ \\
SACP flow right start (ml/min) & $201 \pm 41(200)$ & $218 \pm 52(200)$ & $258 \pm 59(250)$ \\
SACP flow right end (ml/min) & $196 \pm 37(185)$ & $282 \pm 56(300)$ & $350 \pm 54(330)$ \\
SACP flow left start (ml/min) & $216 \pm 54(205)$ & $243 \pm 99(275)$ & $240 \pm 37(240)$ \\
SACP flow left end (ml/min) & $227 \pm 68(220)$ & $283 \pm 49(300)$ & $275 \pm 64(275)$ \\
Tympanic temperature minimum & $20.8 \pm 0.9(20.8)$ & $19.5 \pm 1.0(19.7)$ & $20.8 \pm 0.3(20.9)$ \\
Rectal temperature minimum & $26.9 \pm 3.3(27.3)$ & $26.8 \pm 4.3(27.6)$ & $26.0 \pm 2.3(26.0)$ \\
Urinary bladder temperature minimum & $26.0 \pm 4.8(25.6)$ & $24.8 \pm 3.4(24.8)$ & $23.8 \pm 2.3(23.7)$ \\
\hline
\end{tabular}

HCA: Hypothermic circulatory arrest, CBP: Cardiopulmonary bypass

SACP: Selective antegrade cerebral perfusion

Table 5. Intraoperative data. Statistical analyses are given as comparisons to the group with direct cannulation.

Direct arch cannulation resulted in the best renal function on the first postoperative day with a creatinine level of mean $140 \pm 48 \mathrm{mmol} / \mathrm{L}$ (112.3 - 167.7); femoral entry showed 179 \pm 79 $\mathrm{mmol} / \mathrm{L}(53.4-304.6 ; \mathrm{p}=0.08)$; at subclavian access we found 199 $\pm 69 \mathrm{mmol} / \mathrm{L}(89.3-308.7$; 
$\mathrm{p}=0.25$ ). Although a clear tendency between creatinine levels in direct cannulation group and the other two approaches can be observed in favour of the direct cannulation technique, these differences did not reach the level of significance due to a relatively low number of patients in the subclavian and femoral access groups. Figure 7 demonstrates plasma creatinine levels during the first 72 postoperative hours. 2 of direct and 2 of subclavian cannulated patients were excluded from the statistical analysis due to preoperative renal impairment. Similar characteristics could be observed in lactic acid levels, as a marker of perioperative global ischemia on intensive care unit following up our patients; results are depicted in Figure 8. Four of direct, one of femoral and two of subclavian artery perfused patients were not considered for statistical analysis with an initial lactic acid level over $2 \mathrm{mmol} / \mathrm{l}$.

Lenght of intensive care unit stay over 5 days could be observed at 5 of 14 (36\%) patients in the direct group, 4 of $6(66 \% ; p=0.21)$ in subclavian, 2 of $4(50 \% ; p=0.51)$ at femoral cannulated patients.

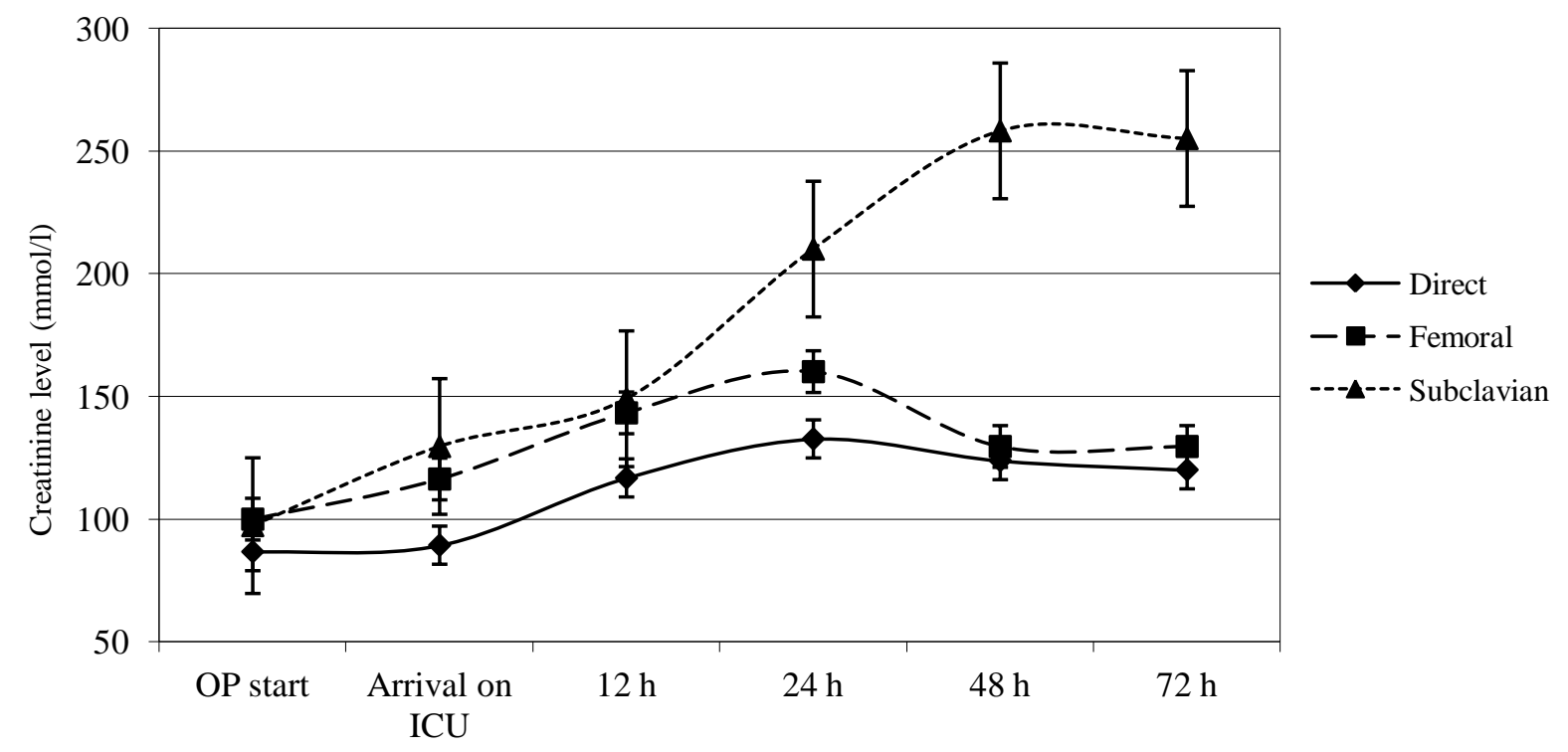

Figure 7. Changes in creatinine levels at different cannulation methods 


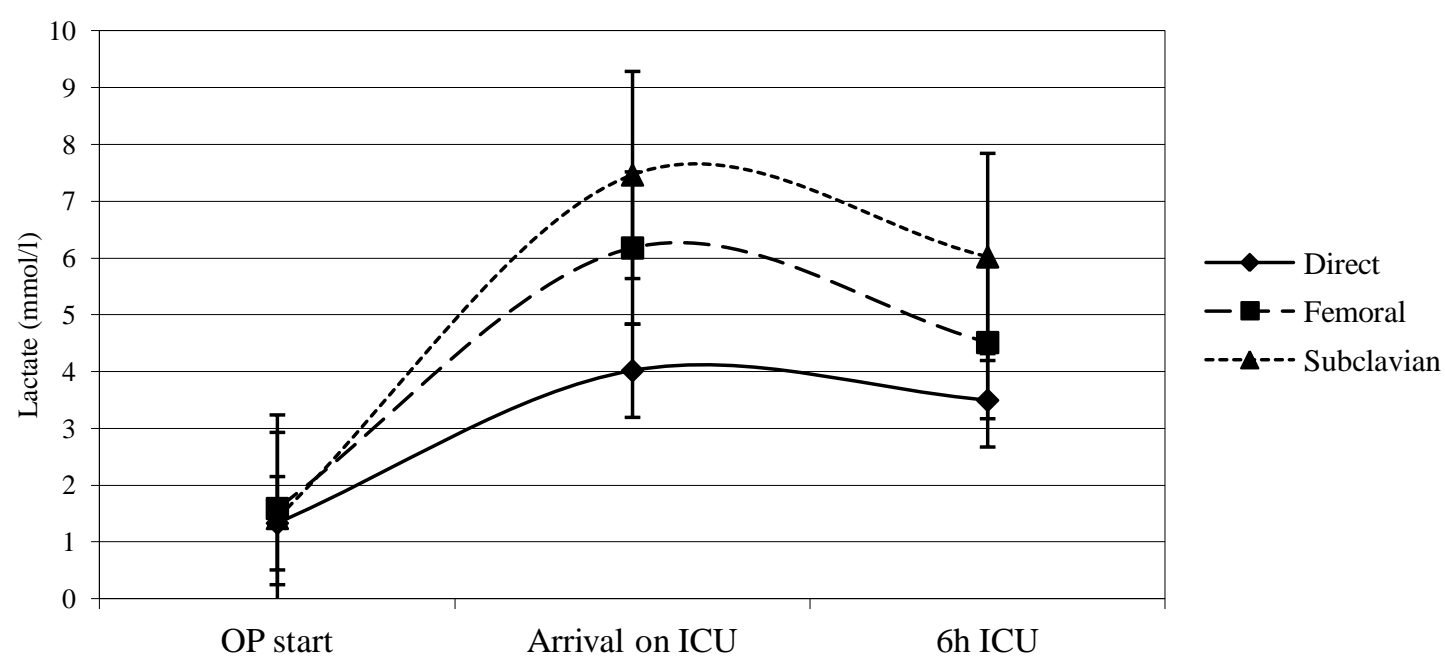

Figure 8. Lactate screen of the three perfusion groups

\section{Conclusion}

Arterial access for establishing CPB, especially in patients requiring repair of acute type A aortic dissection, is a controversial subject in the current literature (61). Minimal invasive central cannulation by Seldinger on the concavity of aortic arch is technically feasible and safe. It may avoid cerebral embolization and organ malperfusion; therefore, may reduce the rate of neurological and malperfusion complications. This alternative arterial inflow technique can be applied for prompt establishment of CPB in type A dissections, especially during hemodynamic instability.

\section{Study II - Body temperature measurement sites in aortic surgery}

\section{Background}

We performed a retrospective, comparative analysis of different, but widely used temperature measurement sites during surgical repair of thoracic aorta in HCA to determine reliability of methods for intraoperative core temperature monitoring. Preservation of neurological function is one of the main goals in such patients. Safety of this type of procedure relies on adequate systemic cooling under strict control. If this control is incomplete or fails neurological injury may occur during HCA. 


\section{Patients and methods}

22 patients (mean age: $63 \pm 12$ years, 12 men and 10 women) underwent operations on the thoracic aorta. In all patients a standard operative technique for acute aortic dissection or aneurysm resection was used at our institution. CBP was established via arterial cannulation performed on the concavity of aortic arch applying the Seldinger technique, and during HCA selective bilateral antegrade carotid perfusion was used. Indications for surgery included: acute type A dissection $(n=14,64 \%)$, degenerative aneurysm $(n=6,27 \%)$, aortic infiltration of thymic carcinoma $(n=1,4.5 \%)$ and intraaortic stent refixation $(n=1,4.5 \%)$. Fifteen patients $(68 \%)$ underwent emergency operations. Preoperative patient characteristics are provided in Table 6.

Diagnosis was confirmed by contrast-enhanced computed tomography and intraoperative TOE in all patients. Aortography or coronary angiography was not performed in emergency cases.

\begin{tabular}{lc}
\hline Characteristics & \\
\hline $\mathrm{N}^{\mathrm{o}}$ of patients & 22 \\
Male & 12 \\
Female & 10 \\
Mean age in years \pm standard deviation & $63 \pm 12$ \\
Emergency operations & 15 \\
Indications & \\
$\quad$ Type A dissection & 14 \\
$\quad$ Degenerative aneurysm & 6 \\
$\quad$ Aortic infiltration of thymic & 1 \\
$\quad$ carcinoma & 1 \\
$\quad$ Intra-aortic stent refixation & 16 \\
Hypertension & 4 \\
Preoperative ventilation & 3 \\
Preoperative renal insufficiency &
\end{tabular}

Table 6. Preoperative patient characteristics

The standard institutional operative technique for aortic dissection or aortic aneurysm at our institution was applied, as described in Study I; exactly same intra- and perioperative management and decision making algorythm was undertaken in all patients. Summary of performed surgical procedures is presented in Table 7. 


\begin{tabular}{lc}
\hline Surgical procedure & $n$ \\
\hline Ascending aorta + hemiarch & 20 \\
Ascending aorta + total arch & 2 \\
${ }^{\circ}$ David reconstruction & 3 \\
${ }^{\circ}$ Yacoub reconstruction & 4 \\
o Bentall procedure & 4 \\
${ }^{\circ}$ Coronary bypass grafting & 4 \\
\hline${ }^{\circ}$ marks an additional procedure of aortic graft implantation
\end{tabular}

Table 7. Surgical procedures performed

Statistical analysis for body temperature measurement sites was undertaken by univariate analyses (Pearson's correlation and Student's t-test) with SPSS v17.0 (SPSS Inc. Chicago, Illinois, USA) to identify the best reference point for arterial blood temperature assessment during HCA and SACP. A p value $<0.05$ was considered as significant.

\section{Results}

\section{Perioperative data}

There were no operative deaths; cumulative 30-day mortality rated $13 \%(n=3)$. The cause of death was multiorgan failure in all 3. Eight patients (36\%) stayed in the intensive care unit $>5$ days. Direct aortic cannulation was safely performed in all cases; there was no need to switch to an alternative cannulation site, and there was no case of complicated local massive haemorrhage on the cannulation site. TOE guidance was useful for aortic cannulation along with colour Doppler imaging, which provided information about the true lumen antegrade perfusion. No malperfusion or apparent thrombo-embolism due to cannulation was observed. Malperfusion was defined by a cerebral saturation difference of $10 \%$ compared to preoperative values and/or pressure difference between the peripheral arteries $>20 \mathrm{mmHg}$. There were no permanent neurological deficits, but two patients (9\%) suffered from transient neurological dysfunction. Mean CPB time measured 176 \pm 63 minutes (median: 158), mean duration to reach HCA was $25 \pm 12$ minutes (median: 21), mean HCA time was $46 \pm 21$ minutes (median: 45) and mean selective antegrade carotid perfusion time was $36 \pm 18$ minutes (median: 34). Intraoperative patient data is shown in Table 8. 


\begin{tabular}{lc}
\hline Intraoperative data & Mean \pm SD (Median) \\
\hline Time to HCA (min) & $25 \pm 12(21)$ \\
CPB time (min) & $176 \pm 63(158)$ \\
HCA time (min) & $46 \pm 21(45)$ \\
SACP time (min) & $36 \pm 18(34)$ \\
SACP flow right start $(\mathrm{ml} / \mathrm{min})$ & $216 \pm 55(200)$ \\
SACP flow right end $(\mathrm{ml} / \mathrm{min})$ & $199 \pm 40(190)$ \\
SACP flow left start $(\mathrm{ml} / \mathrm{min})$ & $224 \pm 55(210)$ \\
SACP flow left end $(\mathrm{ml} / \mathrm{min})$ & $230 \pm 61(220)$
\end{tabular}

Table 8. Intraoperative data

\section{Core temperature evaluation}

Statistical analysis revealed strong association between tympanic temperature and arterial blood temperature during HCA, while rectal and bladder values did not represent the core temperature adequately. The difference between rectal and arterial blood temperatures was significantly greater than the difference between tympanic and arterial blood temperatures [average temperature difference (rectal minus arterial): 7.9 (pre $\mathrm{HCA}$ ), 8.3 (pre SACP), $5.6^{\circ} \mathrm{C}$ (end SACP); average temperature difference (tympanic minus arterial): $1.9,1.7,0.3^{\circ} \mathrm{C}$, respectively; $(\mathrm{p}<0.001)]$. There was a similar relationship between the bladder and tympanic temperatures (average temperature difference (bladder minus arterial): $7.3,6.7,4.8^{\circ} \mathrm{C}$, respectively; average temperature difference (tympanic minus arterial): $1.9,1.7,0.3^{\circ} \mathrm{C}$, respectively; $(p<0.001)]$. Figure 9 shows the temperature detected at different sites during the course of the operation.

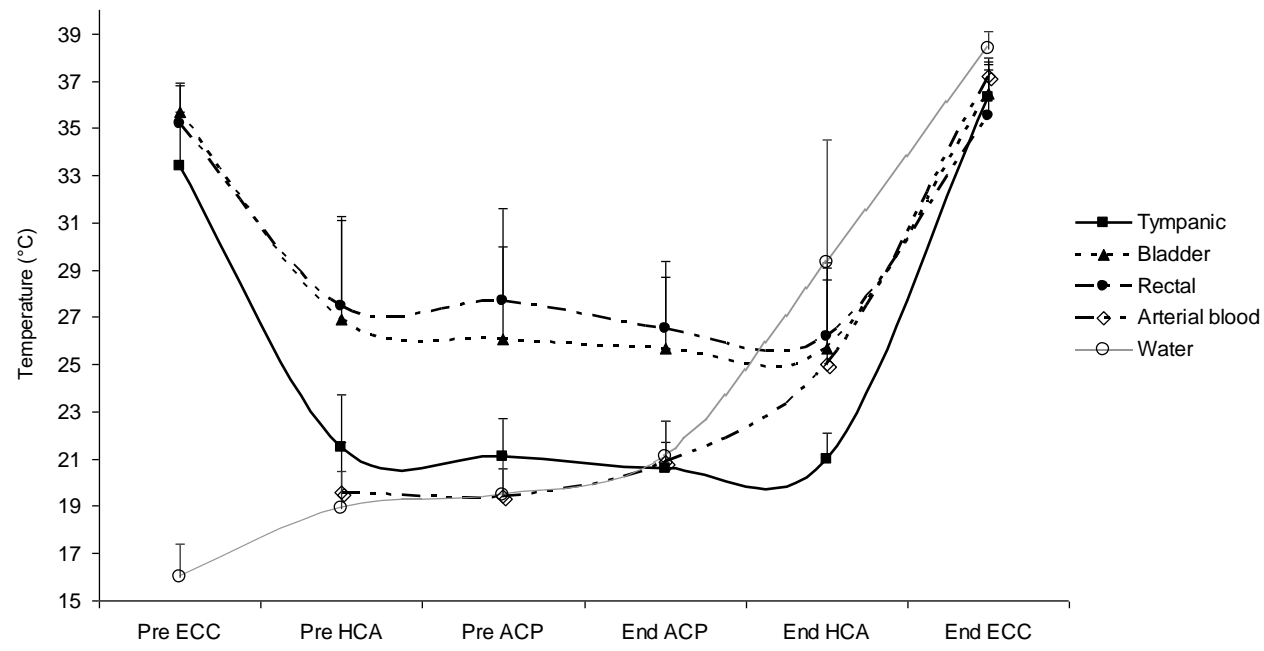

Figure 9. Temperature changes at different measurement sites during ECC, HCA and SACP 
Analysis of rewarming phase revealed strong correlation between tympanic and arterial blood temperature $(\mathrm{r}=0.9541 ; \mathrm{p}<0.001)$ as well as between the arterial blood and heat exchanger water temperature $(\mathrm{r}=0.9879 ; \mathrm{p}<0.001)$. Urinary bladder and rectal values showed less correlation with the arterial blood $(r=0.7939, p=n . s . ; r=0.7654, p=n . s$. , respectively). Figure 10 shows core temperature detected at different sites during the rewarming phase.

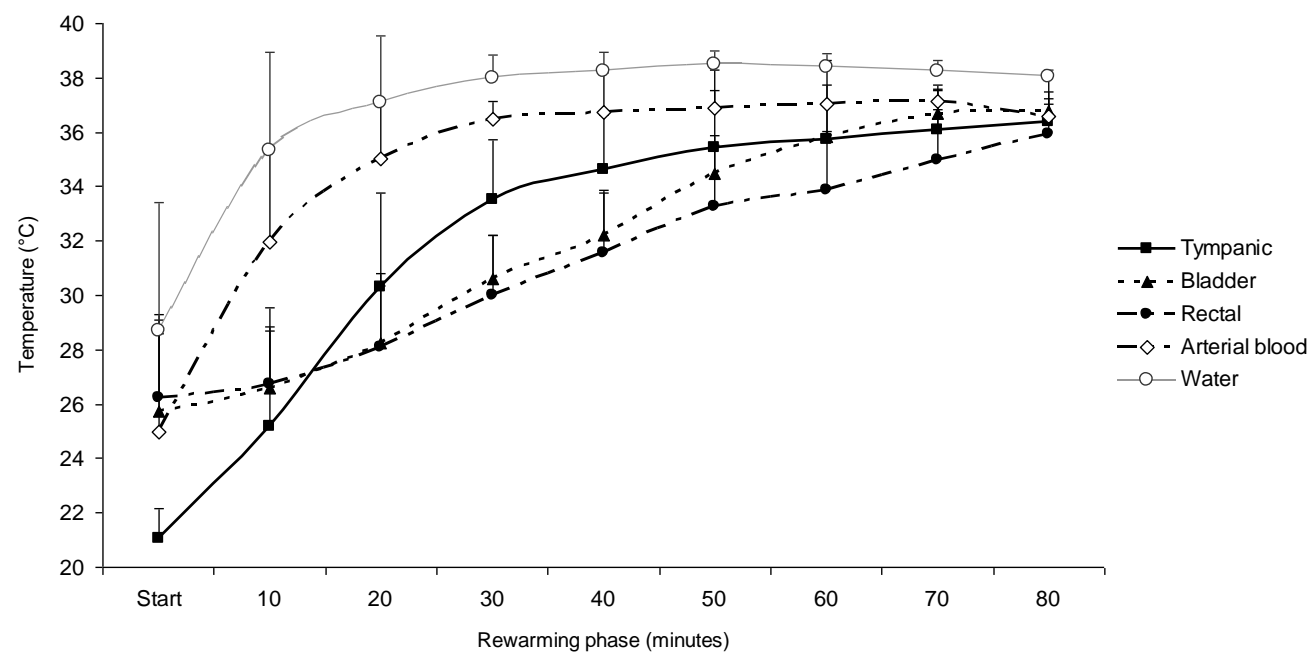

Figure 10. Core temperature at various intervals during rewarming from HCA

\section{Conclusion}

We recommend multiple temperature measurement sites during aortic surgery applying HCA and SACP to be able to assess homogenous cooling and rewarming of the patient. To achieve good postoperative neurological outcome, we believe that tympanic values are highly reliable as a guide to temperature changes of the brain during HCA and rewarming. 


\section{Study III - Management options for aortooesophageal fistula}

\section{Background}

Aortooesophageal fistula is a very rare clinical entity often leading to a life-threatening gastrointestinal bleeding. Thoracic aortic aneurysms are the most common cause of aortooesophageal fistula, further causes involve foreign body ingestion, trauma, which is in most of the cases iatrogenic, carcinoma, or very rarely aortitis tuberculotica. Conservative treatment of AOF results in a high in-hospital mortality rate, and conventional surgical procedure has a reported in-hospital mortality rate of nearly $40 \%$ (62). TEVAR as a standalone procedure has recently gained recognition as a possible technique for emergent treatment of $\mathrm{AOF}$, despite a considerable risk of infection (16); in contrast to conventional solution of open thoracic surgery with higher mortality and morbidity. However, relatively little is known about long-term results of TEVAR for AOF due to its rarity and lack of large clinical experience.

\section{Patients and methods}

We retrospectively analysed all our patients with AOF in a period of two consecutive years undergoing different management approaches by separate surgeons. There were all together 5 patients treated by TEVAR and oesophagectomy, due to the low number and also lack of homogenous matching size control group, no statistical analysis could have been performed. We have demonstrated pros and cons of different therapeutic strategies, since each of them represent a possible management pathway in this group of patients with different advantages and disadvantages through one characteristic case each. The current literature has been also reviewed for treatment options, low number of isolated case reports are present, even much limited number of larger scale single centre analyses show up usually less than ten patients.

\section{Management by EVAR and subtotal oesophageal resection followed by gastrooesophageal reconstruction}

Our most challenging, but educational TEVAR case, a 69-year-old man presented with 3 days of central chest pain, coughing and haematemesis. Past medical history included hypertension, hyperlipidemia and gastrooesophageal reflux disease. Laboratory findings showed increased inflammatory markers. Computed tomography revealed a saccular mycotic aneurysm of the 
mid-descending thoracic aorta in a close relation to the thickened wall oesophagus anteriorly. Air inclusions were visible within the aneurysm thrombus. No pathological lymph nodes were present. A communication between the descending aorta and oesophagus was demonstrated on computed tomography (Figure 11). The patient underwent massive blood- and blood product transfusions to maintain haemodynamic stability. Urgent TEVAR was performed as a life saving procedure, which successfully isolated the aneurysm (Figure 12).

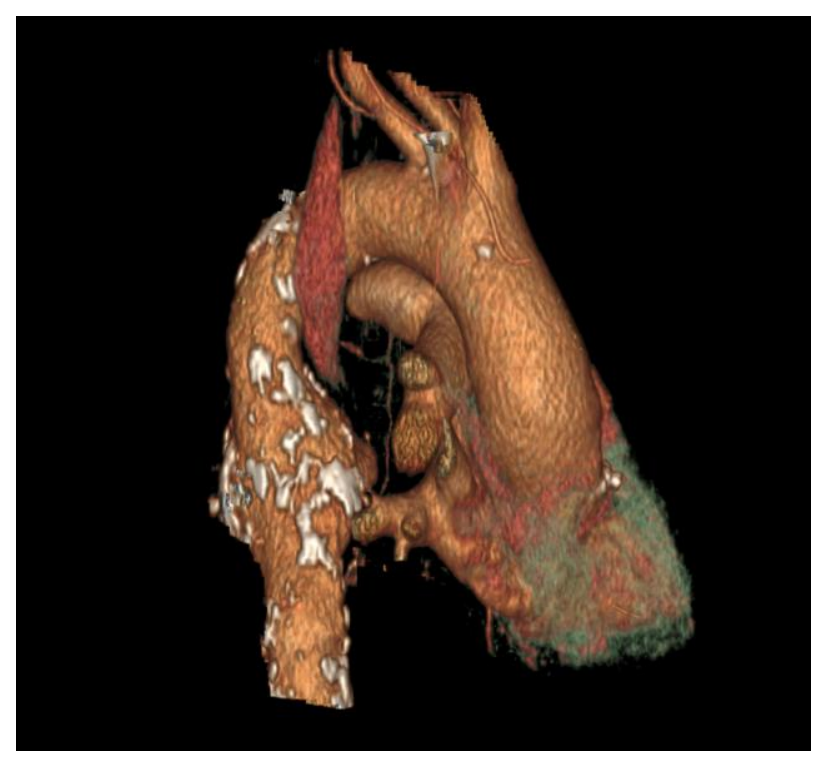

Figure 11. 3D reconstruction of the aortooesophageal relation at AOF, contrast enhancement outlines the oesophageal silhouette

Total oesophageal resection, evacuation of infected thrombus and a tunnelled feeding jejunostomy was undertaken thereafter to prevent sepsis on the next day. Surprisingly, histology of the resected specimen showed a clearly defined fistula tract on basis of a moderately differentiated squamous cell carcinoma colonised by E. coli, suggesting that this rather than pressure was the aetiology of the AOF. 


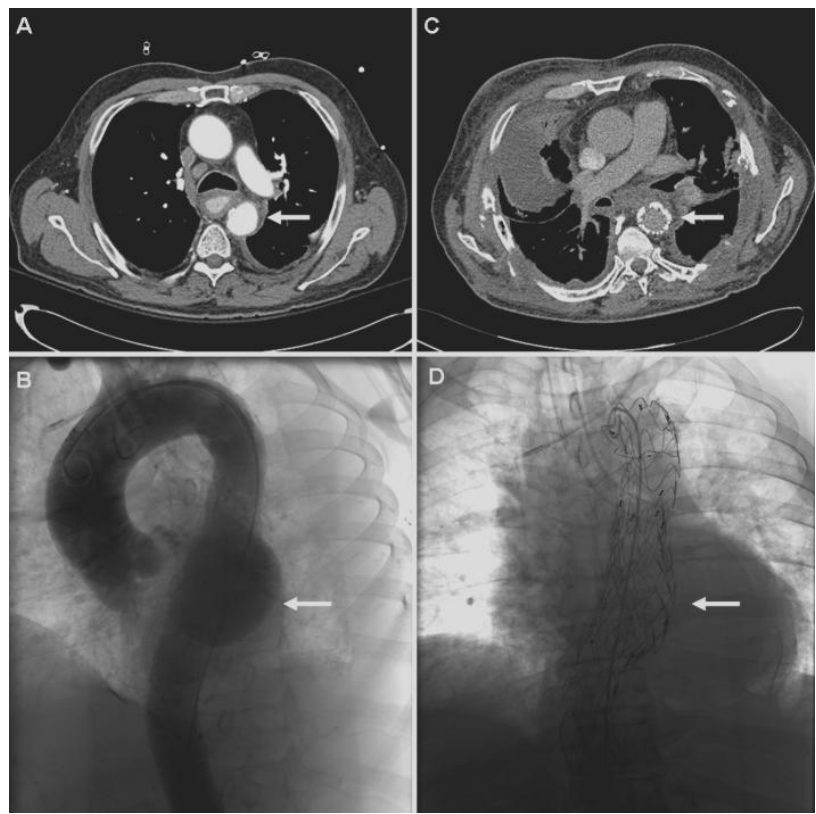

Figure 12. Pre- and postoperative diagnostic images of TEVAR treatment in AOF

Panel A - Arrow marks the level of AOF, note the contrast enhancement inside the oesophagus

Panel B - Saccular aneurysm of the mid-descending thoracic aorta on fluoroscopic image

Panel C - Arrow shows TEVAR in position, note the absence of oesophagus

Panel D - Fluoroscopic image of endovascular stent graft in situ

Patient's prolonged postoperative course was complicated by respiratory distress syndrome and acute renal failure, which were both successfully managed. The patient was discharged well recovered after 71 days postoperatively with normal inflammatory markers. Outpatient rehabilitation was undertaken prior to gastrooesophageal reconstruction which was scheduled six months following TEVAR.

\section{Management by open thoracic surgery}

A 30-year-old patient was admitted as emergency after having an electromechanical dissociation arrest during oesophago-gastroscopy for gastrointestinal bleeding. OGD showed an oesophageal ulcer. Computed tomography demonstrated a communication with the descending aorta, where an aneurysm was situated.

An aortic repair was performed with a 30-mm-diameter gelatin-coated woven polyester interposition tube graft (Gelwave; Vascutek, Inchinnan, UK) followed by a McKeown 
oesophagectomy and a gastrooesophageal reconstruction with orthotopic gastric interposition at the same operation. For this approach the surgical decision was based on the patient's young age, good general condition and a limited oesophageal laesion. Postoperatively he became septic with Pseudomonas in the blood cultures and developed a left upper lobe lung infarct. A redo thoracotomy was undertaken, the necrotic left upper lobe was removed followed by a pleurectomy.

During the patient's regular outpatient follow-up repeat CT scan after six months showed a fluid collection around the graft anastomosis with some inflammatory signs. The graft was replaced by a homograft as an urgent procedure. After this surgical intervention the patient was discharged after 15 days in a good general condition.

\section{Conservative management of postoperative graft infection}

A 62-year-old male patient presented with back pain and severe shortness of breath. He had no significant past medical history. A computed tomography angiogram showed a Crawford type I descending aortic aneurysm extending from the left subclavian artery and ending at the renal arteries. Diameter of descending aorta was 6-7 $\mathrm{cm}$ at the beginning, the maximum diameter reached $10 \mathrm{~cm}$ at the level of tracheal bifurcation with an obvious rupture and a large haematoma compressing both trachea and oesophagus; there was an oesophageal communication also demonstrated. The aneurysm was replaced by an interpositional Dacron tube graft, the oesophageal rupture orifice was closed with a bovine pericardial patch so that Dacron graft could have been separated from trachea and oesophagus.

After a couple of days, a recurrent oesophageal leakage was demonstrated on per oral feeding. The patient refused a radical oesophageal surgery, so he was further treated conservatively with the aid of antibiotics. In the following weeks his general condition was stabilized and he was discharged on a six months course of antibiotics. The patient was reluctant to carry on with the prescribed treatment after one month; later on he was readmitted with recurrent graft infection. This time he also refused further surgical intervention, under a long-term (one year) antibiotic therapy he could be discharged following a prolonged inpatient care. Once more he had a relapse as not taking the prescribed medication meticulously, refused again invasive therapy, therefore, after longish recovery his was discharged on life-long antibiotic coverage. 


\section{Results}

No statistical outcome could have been achieved from this limited number of treatments, which still represents a higher range of single centre AOF experience in the current medical literature.

\section{Conclusion}

Our empirical conclusion is, that early diagnosis and aggressive surgical approach without delay is the key for effective treatment for AOF. TEVAR treatment is essential to save the patient, but as the process is usually situated in an infected environment due to communication with the inner body surface; TEVAR as a stand-alone procedure would often end-up with life threatening mid-term graft infection. Therefore, following short-term vital stabilization, the oesophagus should be removed and the infected posterior mediastinal area cleared. After sufficient recovery, a second stage interval gastrooesophageal reconstruction may lead to the most optimal long-term results.

\section{Study IV - Age-related considerations in acute type A aortic dissection}

\section{Background}

Our aim was to investigate on clinical and anatomic presentation of TAAD according to patients' age. Only a limited number of reports in literature are focused on preoperative features and their correlation with age of patients presenting with TAAD. On this basis, we have studied clinical and anatomic presentation of TAAD, characterized their relationship with patients' age and evaluated possible implications in terms of pathologic background and surgical management.

\section{Patients and Methods}

\section{Population}

Internal database of Wessex Cardiothoracic Centre at University Hospital of Southampton, United Kingdom was interrogated and 235 patients were identified, who had undergone repair of spontaneous TAAD between January 2000 and December 2014. 


\section{Study design}

Retrospective cohort study. We investigated on clinical presentation, anatomic features of TAAD and operative techniques for aortic repair. Distribution of intimal tear was coded according to involvement of the aortic root, isolated to ascending aorta or affecting the aortic arch. Extension of dissection was reported based on presence of a dissecting flap in the aortic root, aortic arch, descending thoracic aorta and the abdominal aorta.

\section{Statistical analysis}

Continuous data are presented as mean $\pm \mathrm{SD}$, categorical variables are represented as counts and percentages. Student t-test was utilized to compare age between groups defined by clinical presentation, anatomical presentation and surgical procedures. Influence of age on probability of anatomical presentation was assessed with logistic regression.

Statistical analyses were performed with Stat-View Statistical Software Package 5.0 (SAS Institute, Inc. Cary, NC) and NCSS 2001 (Number Chruncher Statistical System, Kaysville, Utah).

\section{Results}

\section{Demographic and preoperative clinical presentation}

Figure 13 provides details on age distribution in our population; patients younger than 40 years represent $6 \%$ of total number of patients, who underwent surgical repair of TAAD, $18 \%$ were younger than 50 years and $32 \%$ older than 70 years. Male patients experienced acute dissection earlier in their life. Age of patients with a known connective tissue disorder or bicuspid aortic valve was significantly lower than those without any syndromic features and presenting with a tricuspid aortic valve. No significant differences in preoperative clinical presentation were found, but predominant signs of myocardial ischaemia, which were more common in younger patients $(\leq 50$ years). Table 9 provides further details on preoperative clinical characteristics. 


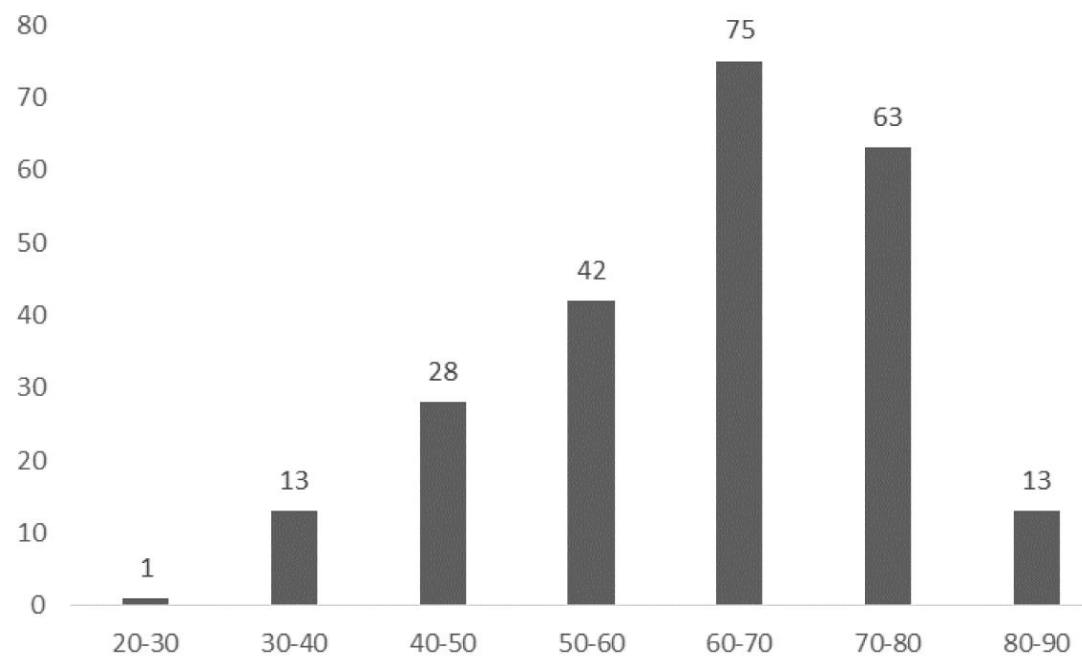

Figure 13. Age distribution of patients who underwent TAAD repair

\begin{tabular}{|l|c|c|c|c|}
\hline Variables & \multirow{2}{*}{ No (\%) } & \multicolumn{2}{|c|}{ Age (mean \pm SD) years } & \multirow{2}{*}{ p value } \\
\cline { 3 - 4 } & & Variable & Variable & \\
& & YES & NO & \\
\hline Gender (male) & $154(66 \%)$ & $61.4 \pm 12.6$ & $68.0 \pm 12.1$ & $<0.0001$ \\
\hline Presentation & & & & \\
\hline Myocardial ischaemia & $36(15 \%)$ & $60.0 \pm 14.8$ & $64.9 \pm 13.5$ & 0.04 \\
\hline Tamponade & $39(17 \%)$ & $66.2 \pm 18.3$ & $63.6 \pm 13.5$ & 0.24 \\
\hline New onset of cerebral stroke & $18(8 \%)$ & $65.6 \pm 22.9$ & $63.9 \pm 13.4$ & 0.59 \\
\hline Mechanical ventilation & $16(7 \%)$ & $61.6 \pm 22.1$ & $64.2 \pm 13.4$ & 0.41 \\
\hline Acute Renal Failure & $12(5 \%)$ & $64.9 \pm 25.2$ & $64.1 \pm 13.4$ & 0.82 \\
\hline Limb ischaemia & $12(5 \%)$ & $62.7 \pm 25.2$ & $64.0 \pm 14.0$ & 0.72 \\
\hline Abdominal ischaemia & $2(1 \%)$ & & & \\
\hline Cardiopulmonary resuscitation & $10(4 \%)$ & $67.3 \pm 27.5$ & $63.9 \pm 13.4$ & 0.41 \\
\hline Connective tissue disorders/BAV & $22(9 \%)$ & $50.1 \pm 17.2$ & $64.5 \pm 12.6$ & 0.004 \\
\hline Marfan syndrome & $6(3 \%)$ & $45.5 \pm 22.4$ & $64.3 \pm 13.3$ & $<0.0001$ \\
\hline Previous cardiac surgery & $14(6 \%)$ & $62.6 \pm 25.4$ & $64.2 \pm 13.1$ & 0.65 \\
\hline
\end{tabular}

Table 9. Preoperative clinical characteristics 


\section{Extension of dissection flap and sites of intimal tear}

The more extensive dissecting process is associated with more frequent involvement of the coronary sinus(es), additional descending thoracic and abdominal aorta progression. The above features characterize the anatomic presentation in younger patients. Investigations of distribution of primary tear sites showed that significantly lower age was associated with presence of intimal tear at level of the aortic root. We found similar results regarding proximal aorta involvement, even when analysed the population excluding patients with syndromic disorders and bicuspid aortic valve. Table 10 summarizes all these findings. Probability of aortic dissection extension into the coronary sinus(es), descending thoracic aorta and abdominal aorta involvement decreases with patients' age; OR 0.96, 95\% CI: 0.933 0.980; OR 0.97, 95\% CI: 0.95-0.99; OR 0.97, 95\% CI: 0.95-0.99, respectively. A higher age was associated with lower probability of intimal tear in the aortic root, OR $0.95,95 \%$ CI: 0.93-0.98 (Figure 14).

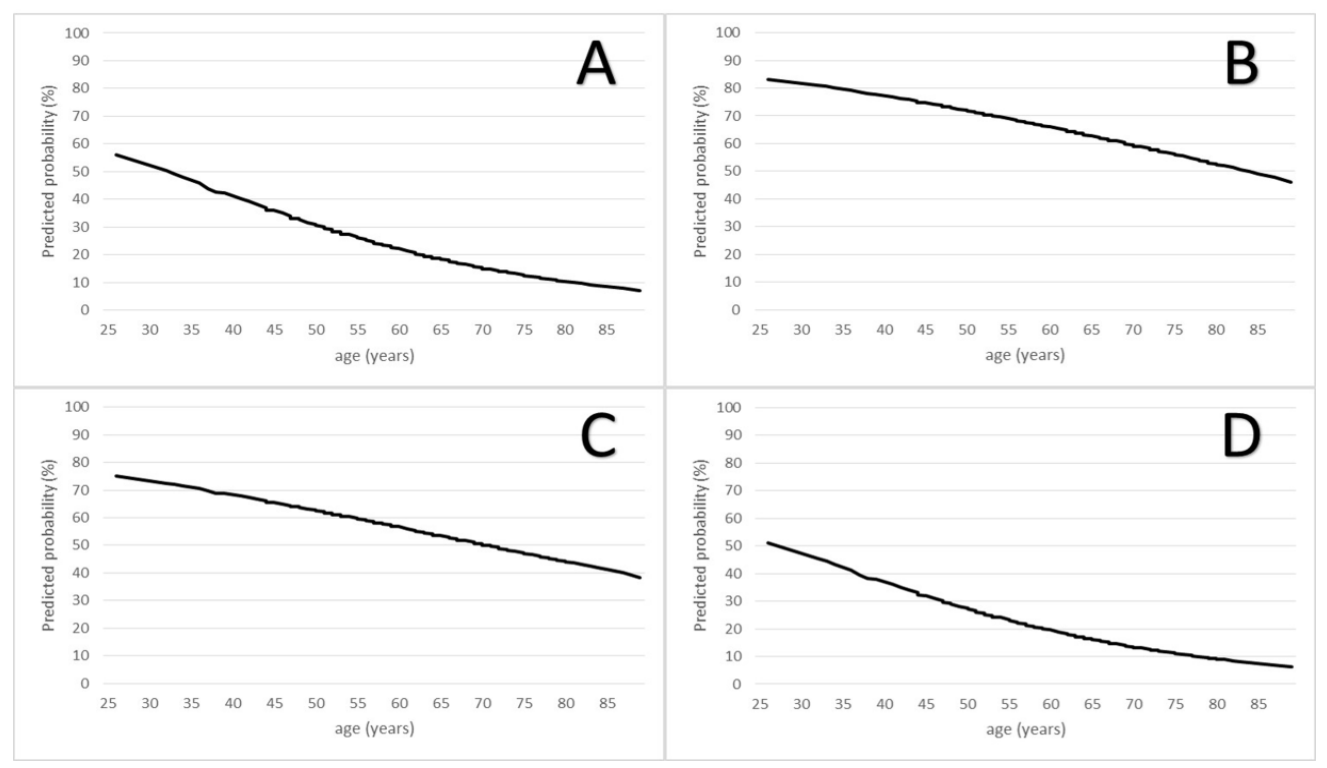

Figure 14. Relation of age and probability of dissection in different aortic regions

Panel A -Coronary sinus(es) dissection $(\mathrm{p}=0.0003)$

Panel B - Descending thoracic aorta dissection $(\mathrm{p}=0.016)$

Panel C - Abdominal aorta dissection $(\mathrm{p}=0.029)$

Panel D - Intimal tear affecting the aortic root $(\mathrm{p}=0.0017)$ 


\begin{tabular}{|c|c|c|c|c|}
\hline \multirow[t]{2}{*}{ Variables } & \multirow[t]{2}{*}{ No $(\%)$} & \multicolumn{2}{|c|}{ Age $($ mean \pm SD) years } & \multirow[t]{2}{*}{ p value } \\
\hline & & $\begin{array}{c}\text { Variable } \\
\text { YES }\end{array}$ & $\begin{array}{c}\text { Variable } \\
\text { NO }\end{array}$ & \\
\hline \multicolumn{5}{|l|}{ Overall population $(\mathbf{n}=\mathbf{2 3 5})$} \\
\hline \multicolumn{5}{|l|}{ Extension } \\
\hline Coronary sinus(es) & $50 / 235(21 \%)$ & $57.8 \pm 13.2$ & $65.4 \pm 13.1$ & 0.0002 \\
\hline Aortic Arch & $205 / 235(87 \%)$ & $63.6 \pm 12.4$ & $65.5 \pm 18.7$ & 0.44 \\
\hline Descending thoracic Aorta & $129 / 175(74 \%)$ & $62.0 \pm 12.9$ & $66.6 \pm 14.8$ & 0.014 \\
\hline Abdominal Aorta & $109 / 171(64 \%)$ & $61.9 \pm 12.8$ & $66.0 \pm 14.5$ & 0.03 \\
\hline \multicolumn{5}{|l|}{ Intimal tear } \\
\hline Tear identified & $196 / 221(89 \%)$ & & & \\
\hline Tear root & $36(19 \%)$ & $57.3 \pm 13.0$ & $65.2 \pm 13.1$ & 0.0007 \\
\hline Tear ascending aorta & $103(53 \%)$ & $64.7 \pm 13.6$ & $63.1 \pm 13.3$ & 0.34 \\
\hline Tear arch & $57(28 \%)$ & $66.1 \pm 11.0$ & $63.1 \pm 14.0$ & 0.13 \\
\hline \multicolumn{5}{|c|}{ Excluding connective tissue disorders and bicuspid aortic valve $(n=213)$} \\
\hline \multicolumn{5}{|l|}{ Extension } \\
\hline Coronary sinus(es) & $45 / 213(21 \%)$ & $58.4 \pm 13.4$ & $65.9 \pm 13.1$ & 0.0004 \\
\hline Aortic Arch & $184 / 213(86 \%)$ & $64.4 \pm 12.1$ & $64.5 \pm 19.7$ & 0.96 \\
\hline Descending thoracic Aorta & $118 / 161(73 \%)$ & $62.8 \pm 13.5$ & $66.3 \pm 16.8$ & 0.13 \\
\hline Abdominal Aorta & $100 / 155(64 \%)$ & $62.9 \pm 12.7$ & $66.8 \pm 14.3$ & 0.06 \\
\hline \multicolumn{5}{|l|}{ Intimal tear } \\
\hline Tear identified & $175 / 200(88 \%)$ & & & \\
\hline Tear root & $32(18 \%)$ & $57.8 \pm 12.4$ & $66.0 \pm 13.6$ & 0.0009 \\
\hline Tear ascending aorta & $91(52 \%)$ & $65.6 \pm 13.4$ & $63.3 \pm 12.1$ & 0.24 \\
\hline Tear arch & $52(30 \%)$ & $66.6 \pm 10.7$ & $63.5 \pm 13.6$ & 0.14 \\
\hline
\end{tabular}




\section{Surgical techniques}

No difference in patients' age was found regarding distal repair strategy. A higher mean age characterized patients, who underwent associated isolated aortic valve replacement; in contrast to significantly younger age of patients, who had a full root replacement (Table 11).

\begin{tabular}{|l|c|c|c|c|}
\hline Variables & No (\%) & \multicolumn{2}{|c|}{ Age (mean \pm SD) years } & p value \\
\hline & & $\begin{array}{c}\text { Variable } \\
\text { YES }\end{array}$ & Variable & \\
& & NO & \\
\hline Aortic valve replacement & $13(6 \%)$ & $71.1 \pm 10.7$ & $63.7 \pm 13.3$ & 0.04 \\
\hline Aortic root replacement & $61(26 \%)$ & $57.2 \pm 12.1$ & $66.5 \pm 12.9$ & $<0.0001$ \\
\hline Aortic valve sparing & $2(1 \%)$ & & & \\
\hline Hemiarch replacement & $65(28 \%)$ & $64.2 \pm 11.7$ & $64.1 \pm 13.8$ & 0.93 \\
\hline Total arch replacement & $13(6 \%)$ & $58.4 \pm 12.0$ & $64.4 \pm 13.3$ & 0.09 \\
\hline & & & & \\
\hline 30-day mortality & $26(11 \%)$ & $67.0 \pm 11.2$ & $63.7 \pm 12.7$ & 0.19 \\
\hline
\end{tabular}

Table 11. Operative procedures for dissection repair

\section{Conclusion}

Clinical presentation and occurrence of dissection related malperfusion syndrome were not associated - apart from presence of signs of myocardial ischaemia and syndromic connective disorders - with the age of patients presenting with TAAD. More extensive involvement of proximal and distal aorta characterized younger patients. Different pathologic background promoting onset of TAAD in young and elderly patients could explain this finding. Higher rate of connective tissue disorders and a wide prevalence of undiagnosed intrinsic underlying disease of proximal aortic wall may account for this peculiar presentation in the young. An intimal tear localization in the aortic root is more common at lower age of presentation. This finding associated with prognostic reasons supports the higher requirement for a full root replacement in younger patients. 


\section{Discussion}

\section{Study I}

This study demonstrates that direct cannulation on concavity of the aortic arch instead of femoral or right subclavian artery may improve outcomes of ascending aorta and aortic arch replacement, especially in case of haemodynamic instability, although it is an observational study because the three groups are not balanced.

Albeit the idea of cannulating ascending aorta in type A aortic dissection was described decades ago (63), direct cannulation of ascending aorta has only been performed occasionally as an emergency technique to avoid retrograde malperfusion (64). Recently, successful attempts have been made to establish antegrade perfusion via ascending aorta primarily for type A dissections (65) (66) (67). Ascending aorta or arch cannulation may have the great advantage of technical simplicity, especially when there is haemodynamic instability or at dissected limb arteries (68) (69) (70) (71). According to these reports this technique can be performed safely under ultrasound-guidance. An access point at level of Botallo`s ligament utilizing the Seldinger technique could provide a useful alternative to establish rapid arterial entry. At this section of aorta the pulmonary bifurcation is firmly connected by a massive connective tissue, which usually prevents a complete dissection in this area. With the aid of this rapid and atraumatic cannulation method CPB can be established, thereby reducing likelihood of perioperative shock, which would lead to an increased mortality (72). Although time demand to reach circulatory arrest was remarkably lower applying the direct cannulation technique compared to the other two accession methods, level of significance was not reached because of a relatively low number of patients in the other two groups, and greater standard deviation values.

Rapid establishment of arterial access facilitates quicker initiation of antegrade systemic perfusion and core cooling, which also contributes to effective reduction of surgical procedural duration. This may result in lower morbidity through enhanced organ perfusion and reduction of coagulation disorder probability. Our method of aortic cannulation has additional advantages. One additional benefit of this type of arch cannulation is having the tip of the cannula located in the proximal descending aorta. Consequently, turbulence at the tip of cannula occurs in the proximal descending aorta, thereby reducing the risk of embolization of debris into the carotid arteries. Further advantage of proximal descending aortic perfusion is a 
reduction of fluid jet stream - Coanda`s - effect that can be associated with relative carotid hypoperfusion in patients undergoing perfusion with a short cannula from the ascending aorta (73). Most patients suffering from TAAD undergo at least a "hemiarch replacement" in our practice, so the cannulations site is removed with the affected aortic wall segment and the repositioned cannula fits perfectly into the side-branched prosthesis.

In addition, transoesophageal or epiaortic ultrasonographic guidance may also be indispensable for reliable real lumen cannulation, which examinations are simple methods to obtain imaging information of ascending aorta and proximal arch. Although preoperative computed tomographic scan is mandatory to obtain correct operative planning, the ultrasonographic control provides real-time information on location of intimal tear, intimal flap, true and false lumen; as this intraluminal situation can change progressively following the tomographic scan. Moreover, the guide wire and correct position of the cannula can be checked continuously, so false lumen perfusion is surely avoided, which is not always the case at peripheral approaches. Simultaneous application of ultrasonographic control and cerebral monitoring by NIRS reduces the likelihood of malperfusion, thromboembolism and subsequent extension of false lumen. We have observed no local complications with Seldinger technique, but were always prepared to perform an apical cannulation described by Wada et al $(25 ; 20)$ as a bail-out procedure.

The challenge of neurological injury resulting from embolic events and cerebral malperfusion in aortic dissections should be discussed with having a regard to that there are a number of different cannulation approaches. Femoral cannulation is well known associated with a higher risk of retrograde embolization and potential perfusion of false lumen via a distal re-entry point, although in our cohort there were no perfusion complications in this group. In this view, techniques providing antegrade flow may offer a better option, especially in patients with Stanford A dissections (74).

In our practice, Seldinger cannulation on concavity of aortic arch became the standard approach for arterial access in both elective and emergency cases as by the Hannover group (66) (75). This cannulation technique is fast and simple, which can be an important issue, especially in haemodynamically unstable patients. It avoids additional time-consuming incisions, thereby avoiding additional surgical trauma and possible local complications at peripheral cannulation sites. In combination with cold SACP and deep/moderate HCA, this technique allows adequate protection for the body and is not associated with higher risk of 
cerebral microemboli (76) (77). Efficacy of SACP as an adjunctive to hypothermic arrest has been proven in numerous publications (78) (79).

As with other surgical approaches, there are some disadvantages, which need to be recognised. This includes cannulation of the false lumen with potential malperfusion or even complete rupture of the cannulated aorta. For those emergency situations, alternative strategies have to be available. In the above mentioned cases there are basically three major goals to be achieved; cerebral protection, myocardium conservation and finally a proper perfusion of the lower body. This stepwise approach necessitates an efficient cooperation of anaesthesiologist, perfusionist and surgeon to obtain optimal results.

Reece et al applied the Seldinger technique for cannulation in 24 patients, resulting in no misplacement (80). However, their study was not randomized, and various aortic pathologies were excluded, leading to a potential selection bias. Furthermore, the cannula is held in position manually during the cooling phase, not allowing further surgical activity during this period; the authors are not convinced that sutures in the dissected aorta remain stable. With our technique there is no need for sutures in the aorta; the cannula is fixed to the cranial skin incision corner by a suture and sits also deep enough in the proximal descending aorta not requiring any further support. Inoue et al report an experience in 32 cases, also using the Seldinger technique, controlled by epiaortic ultrasound. Prior to ascending aortic cannulation, they cannulated the femoral artery to be able to regulate the aortic pressure (70). Although no malperfusion occurred in their series, a double arterial approach is questionable in context of avoiding time-consuming preparations and potential retrograde embolism or further dissection $(81)$.

Kitamura et al have presented recently the "Samurai cannulation" in AAS; 61 patients were cannulated within a period of six years, and have reported favourable postoperative stroke and in-hospital mortality rates in comparison to other cannulation methods of their patient population. Their central access is not novel, Kitamura applies a long-ago published bail-out method of Hannover group, where the patient is exsanguinated via venous drainage, the aorta is transsected, and the aortic cannula is placed into the exposed true lumen under direct visual control. Their potential hazard relies on normothermic circulatory arrest for minimum one minute leaving not much leverage to react on emerging complications, and air embolization is also more likely in case of an open aorta, where a short period of de-airing is available only under normothermic conditions (82). 
Transapical cannulation is another elegant method for achieving reliable antegrade access, as described by Wada et al (25). In large cohort of 138 patients, the cannula was inserted through a $1 \mathrm{~cm}$ apical incision direct into the true lumen via the aortic valve under TOE guidance. The impact of causing an acute aortic insufficiency in this context is not discussed in detail. Both Wada's technique and Reece's method have disadvantages of resulting in prolonged cardiopulmonary bypass times, since no additional procedures can be performed during cooling, such as inspection and preparation of the aortic root.

$\mathrm{AxS}$ is also an elegant, widely applied method for arterial access during aortic arch surgery (83). However, it is presumably more time consuming, and carries the possibility of failure rates up to $4.2 \%-11 \%$ (21). Nevertheless, it provides an opportunity of continuous unilateral cerebral blood flow without interruption (23). Applying the standard technique, however, only the right hemisphere is continuously perfused, which can result in malperfusion of contralateral hemisphere, as Merkkola et al demonstrated that up to $17 \%$ of patients have an incomplete circle of Willis (43). Even in presence of a complete circle of Willis, it is still an open question, if the exclusively right sided perfusion can sufficiently supply the left hemisphere. Our results with SACP demonstrate too, that the lowest perfusion volume is necessary to maintain a proper bilateral cerebral oxygenation in the direct cannulated group. Since the brachiocephalic trunk divides anatomically into two nearly equivalent branches, namely the right carotid and subclavian artery, the provided flow through the latter vessel on CPB can lead to a relative hyperperfusion of the right carotid parallel to a relative hypoperfusion of the aorta. This could explain our findings regarding SACP flow values and peripheral organic perfusion monitored by renal function and lactate level. The Seldinger technique delivers rapid arterial access, which results in a shorter ischemic period both cerebral and peripheral. AxS perfusion provides sufficient oxygenation for the right hemisphere but may not for the contralateral side, so the required initial right SACP flow is similar to the direct group, but the left shows such values as in the femoral group. Additionally, a constant relative hyperperfusion of right hemisphere most probably leads to an intracerebral oedema, which elevates SACP flow requirements to maintain a proper cerebral saturation at the end of HCA. Relative hypoperfusion of the body is characterized by diminished renal function at subclavian cannulation. It has to be considered as well, that at AxS approach usually smaller size cannulas can be applied due to the anatomical situation. Femoral access is more time consuming to be established resulting in relative cerebral hypoperfusion/longer ischemic period demonstrated by higher initial SACP flow requirements 
in this group. Femoral perfusion, in case of no malperfusion, provides a proper renal blood supply, thus the renal function is better preserved than at subclavian access, but the initial hypoxia due to delayed establishment of perfusion is visible comparing the creatinine levels in this group to the direct cohort. Peripheral arterial access is not only challenging in dissected vessel, but also at high body mass index, or on the other side of the spectrum, in patients with a delicate stature, e.g. in East-Asia.

Cakir et al have demonstrated beneficial perfusion effects of a bidirectional novel innominate cannula in an experimental model, achieving higher perfusion readings than with AxS approach. This experimental model well supports our outcomes that perfusion in close vicinity of both carotid origins leads to most favourable cerebral supply in aortic surgery (84).

Moizumi et al could not use $\mathrm{AxS}$ access in 5.5\% of their aortic dissection cohort, as pathological changes extended into the axillary artery (85). Our first experience with the Seldinger technique was also a patient having dissection in all limb arteries (69). Carotid artery cannulation, performed by Urbanski over 100 patients so far, including some with Stanford A dissections, seems to be another alternative method, but also carries a risk of brain malperfusion and later complications in the vessel (42). The experience with innominate artery cannulation by Di Eusanio et al includes 55 patients with only two in acute aortic dissections (86). In the past couple of years the latter two authors have shared their increasing number of patient experience regarding the own cannulation method, although the above techniques are still applied rather in elective aneurysm surgery, than in AAS.

The Kiel group has published Ramihi's 5-year experience regarding transatrial cannulation in TAAD, where 46 patients were cannulated through right upper pulmonary vein and the cannula tip was progressed into the left ventricle. They also report shorter procedural times, lower stroke and renal failure rate, and in-hospital morality. Despite the excellent outcomes strongly supporting our findings with direct aortic cannulation in AAS, some potential drawbacks have to be recognised regarding Ramihi's method; no manipulations are possible on the aorta until reaching $\mathrm{HCA}$, mitral regurgitation may lead to pulmonary flooding endangering early postoperative ventilation. Another potential complication may emerge from the most common location of the aortic tear itself, as situated often on greater aortic curvature right above the STJ. Retraction for right upper pulmonary vein access may result in AAS progression, even in acute aortic rupture (87). 
Fusco et al presented their results in femoral artery cannulation (88), with a conversion rate of $2.5 \%$ to ascending aortic cannulation, they conclude that femoral cannulation is appropriate and yields excellent clinical results. They have, however, not considered the problem of retrograde embolism from the downstream aorta, probably since atherosclerosis is less common in dissection patients in their experience.

Recent meta-analyses have also revealed advantages of central cannulation methods in complex aortic aneurysms and AAS surgery; proximal arterial cannulation adds-on a useful armamentarium for management of complex aortic disease in various aortic pathologies (89) (90) (91). Both Ma et al (2018) and Shimura et al (2019) have emphasized safety and advantages of ultrasound guided central aortic cannulation in TAAD regarding 33 and 208 patients in their series, respectively (92) (93).

Seldinger technique delivers rapid arterial access, which results in shorter ischemic periods both cerebral and peripheral (94). Potential drawbacks of the technique are requirement for a smoothly operating team, which emphasises the importance of specialised aortic teams; technical ability to perform transapical cannulation as a bail-out; local dissection in cannulation area is extremely rare.

As eventual drawbacks do not impose significant challenges in moderate size cardiac centres and real-time ultrasonographic monitoring provides a safe procedure; the Seldinger cannulation on the lesser curvature is a good-to-know central arterial access in case of failing peripheral methods. 


\section{Study II}

Our other study on intraoperative core temperature monitoring demonstrates that tympanic measurements provide reliable temperature estimation during aortic surgery performed under HCA. This may aid in improved postoperative outcomes due to a reduced cooling phase and adequate rewarming. Although application of hypothermia has been an important contribution to patient management as a neuroprotective method from the dawn of cardiac surgery (34) (95), proper body temperature management relies on accurate measurement of temperature, to enable adequate monitoring of changes during CPB and HCA. Oxygen consumption drops with lower body temperature so that ischaemic tolerance is increased by cooling. Cerebral oxygen requirement decreases to approximately one-fifth of normothermic needs at $20^{\circ} \mathrm{C} \mathrm{(35)}$ allowing a safe period of 45-50 minutes for HCA. In addition, hypothermia may contribute to neuroprotection by a variety of complex mechanisms including decreased vascular permeability, reduced ion influx and decreased excitatory transmitter release (37). During the rewarming phase of $\mathrm{CPB}$, conventional temperature monitoring sites may not reflect true brain temperature so that cerebral hyperthermia may not be detected, if conventional temperature monitoring underestimates brain temperature or there is a delay with arterial heat exchange (96) (38). Monitoring rectal or urinary bladder temperature to control intraoperative core temperature is standard in many institutions all over the world. Rewarming, which aims to normalise temperature after HCA, relies on measured data from the above sites. We have shown that temperature measurement at these sites could be misleading, possibly due to latency in the heat exchange process at these points. Clinicians are often concerned about risks of postoperative hypothermia, such as shivering leading to increased myocardial oxygen consumption, arrhythmias, coagulopathy, greater risk of wound infections and extended hospital stay (97) (98) (99) (100), but possible side effects of cerebral hyperthermia are rarely taken into account. Thus, the rewarming phase must be carefully monitored and managed to avoid cerebral hyperthermia, since it elevates the risk of post-ischaemic tissue injury (101) (102), and intraoperative hyperthermia is well known to be associated with post-operative neurological impairment (103) (104).

Arterial blood temperature is considered to be the most accurate indicator of cerebral temperature (105) (106). It is not surprising as this is the medium for heat exchange for the brain during HCA and SACP. According to our results, tympanic temperatures correlate well with arterial blood temperatures and hence with cerebral temperatures, not only during HCA but also during the rewarming phase of the surgical procedure. Urinary bladder and rectal 
temperatures lag behind arterial blood temperatures, therefore, these measurement sites cannot be relied upon to provide accurate estimation of temperature change. This affects management of these patients at various phases of cooling and re-warming. The tympanic membrane is situated in the immediate vicinity of internal carotid artery and is supplied by its branches. Thus, the tympanic temperature is well-placed to closely represent cerebral thermal state. Although some authors consider tympanic temperature as a good standard for cerebral temperature monitoring reflecting the hypothalamic status (107) (108), others have suggested that tympanic temperature can be influenced by changes in ambient temperature (109) (110). If prior to insertion of a tympanic probe, a debris-free status of the auditory channel is confirmed via otoscopic examination along with careful insulation by cotton swabs and the probe is securely fixed by tape and gauze bandage over the external ear, so the ambient temperature influence on tympanic measurement can be effectively diminished. Variations in urinary flow, which is a usual phenomenon during CPB and especially with HCA may affect the bladder temperature sensors (111). On the other hand, rectal probes can become lodged in faecal matter, which insulates them from the surrounding tissues (112). The above factors contribute to a weak correlation of these temperature measurements with those of arterial blood.

In our institute we do not use nasopharyngeal/oesophageal temperature monitoring in HCA as standard measurement site, as it has been shown in several studies to modestly, but significantly over- and underestimating brain temperatures during the cooling and rewarming phase, respectively (113) (114) (115). Probably this is a result of the suboptimal heat exchange environment as these probes are situated in larger air containing cavities. Although oesophageal probes are placed relatively close to the descending aorta, the open chest or eventually applied topical cooling in the pericardium could also influence measurement accuracy. Akata et al. have furthermore demonstrated, that pulmonary artery temperatures closely reflect changes in brain temperatures, but nasopharyngeal/oesophageal measurements could not be considered as a reliable index of brain temperature at all during rapid induction of moderate/deep hypothermia (116).

We can conclude that tympanic temperature measurements correlate with arterial blood temperature monitoring during aortic surgery with HCA and SACP, and therefore should replace bladder and rectal measurements. 


\section{Study III}

Aortooesophageal fistula is a rare cause of gastrointestinal bleeding, characterized by significant morbidity and mortality, even with early diagnosis and intervention. Several therapeutical management options have been reported in literature, although all rely on the same principle; urgent management of the aortic tear with immediate or delayed repair of the oesophageal lesion. There are many approaches to treat AOF, but the treatment has to be adapted to the patient's wishes in some cases. In our experience the most straight-forward therapeutic option is emergency TEVAR followed by an urgent subtotal oesophageal resection, the therapeutic circle is completed by a second stage gastrooesophageal reconstruction. Securing the bleeding source as emergency, removing the oesophagus urgently to prevent sepsis, and subsequent elective reconstruction of gastrointestinal continuity appears to be a justified surgical approach, as in the current available literature also states, although there are no large studies available. TEVAR is a new, lower risk emergency alternative, although stand-alone TEVAR leaves the oesophageal defect untreated, contributing to a higher risk of mediastinitis and increased mortality and morbidity (16). A similar conclusion resulted from the Regensburg experience; TEVAR is an effective emergency alternative to prevent early fatal exsanguinations, however, can rarely be utilized as a stand-alone procedure (117). A nationwide, multicentric Italian study provided information on 25 aortooesophageal and aortobronchial fistulas that were treated with TEVAR. The results demonstrated that patients, who underwent combined TEVAR and tracheobronchial/oesophageal intervention, had lower graft infection rates and better survival than patients receiving TEVAR treatment exclusively (118). Most probably, the long-term prognosis is affected by a concomitant mediastinal infection and graft contamination.

Surgical approach of the oesophageal lesion is controversial in the literature. Snyder et al reported a primary suture of the oesophageal defect with minimal mediastinal contamination, although it was associated with a higher risk of dehiscence and fistula recurrence, probably due to local ischaemia (119). Instant oesophago-gastric anastomosis after subtotal oesophagectomy may be another alternative (120), although associated with increased risk of perioperative death, but this risk could be reduced by omentopexy around the tube graft. Subtotal oesophageal resection followed by gastric or jejuneal interposition as a second stage surgical intervention could minimize the hazard of graft infection (121) (122). For feeding, transdiaphragmatic or transthoracic gastrostomy are reliable solutions that both avoid further opening of the abdomen for a separate gastrostomy or jejunostomy and minimizes damage to 
the stomach, but maintains patency of the upper gastrointestinal tract. Another interesting complex solution to prevent late thoracic interposition graft infections has been described by Aleksic et al and Aizawa et al Although with different etiology, they both demonstrated reasonable long-term results after implantation of an extraanatomic ascending-descending aortic interposition tube graft bypass with stump closure of the affected descending aorta, with or without omentopexy around the descending stump (123) (124). Our personal experience with extraanatomical bypasses is limited to extensive chronic TBADs, in which cases the distal abdominal and lower limb perfusion was severely compromised. The operative solution of bilateral subclaviofemoral bypasses provided acceptable perfusion results, although the long-term patency was significantly influenced by the efficacy of anticoagulation. Müller et al have investigated 33 patients with anatomic and extraanatomic repair following mycotic aneurysms of the thoracic and abdominal aorta, their conclusion shows that in situ reconstructions did not carry a higher risk of morbidity and mortality than extraanatomic counterparts (125).

Similar conclusions to our therapeutic considerations were drawn by the so far largest multicentric database analysed by Japanese Association for Thoracic Surgery in 2014. 47 AOF cases were reported from whole Japan, their conclusion was that TEVAR alone for AOF management is associated with high mid-term mortality and does not improve mid-term outcome; therefore, not be considered as a definitive stand-alone therapeutic option. In addition, oesophageal reconstruction might be acceptable for single stage operations in patients in a stable condition, as no significant differences were observed between patients treated with oesophageal reconstruction at the same or a different occasion (126).

In conclusion, early diagnosis and aggressive surgical approach without delay is the only option for effective treatment for AOF. Second stage interval gastrooesophageal reconstruction may lead to most optimal long-term results as majority of patients are in a poor condition at the initial life-saving TEVAR and oesophagectomy. Imaging examination is essential in the primary diagnosis; computerized tomography is a safe, reliable, non-invasive method in early recognition of this highly lethal entity. We have to emphasise the importance of multidisciplinary character of the treatment involving radiologists, gastroenterologists, upper-gastrointestinal- and cardiothoracic surgeons to obtain the most favourable results in management of AOF. 


\section{Study IV}

TAAD is more common from seventh decade of life, albeit it is an unexpected pathology in healthy subjects; it represents one of well recognized causes of sudden death in young people (127) (128). Our data entirely supports previous findings reporting that among patients undergoing TAAD repair $6 \%$ is younger than 40 years, and $20 \%$ is aged less than 50 years (129) (130). Several triggers including hypertension, smoking habit, cocaine abuse and amphetamine have been associated with occurrence of this catastrophic event in the young (131) (132), but the presence of underlying connective tissue disorder has been extensively recognized as a fundamental predisposing factor strongly bound to this population (130) (133). It is not surprising that patients with known connective tissue disorders came to our attention at a significantly lower age than those without any syndromic disease and presenting with a tricuspid aortic valve. An inherited pathology of the aortic wall leads to a faster development of aortic aneurysms and to a higher risk of aortic complications. This early pathologic evolution does not characterize only syndromic patients, who represent only a small subgroup in surgical series, and a minority among young patients. IRAD investigators reported that people under 40 years with positive family history showed a significantly increased size of aortic root and ascending aorta when compared with older patients (133). This finding was common both in Marfan and non-Marfan patients. Several non-syndromic genetic conditions can lead to early development of thoracic aortic aneurysms, which are further characterized by rapid dilation, and high risk of dissection. These non-syndromic Familial Thoracic Aortic Aneurysms are related to genetically heterogeneous disorders, and are estimated to represent $20 \%$ of cases in diagnosed thoracic aneurysms (134). Mutations in five genes (MYH11, TGF3R1, TGF3R2, MYLK, and ACTA2) have been identified so far with all autosomal dominant inheritance (135). From molecular point of view, consequences of genetic alterations translate into a degenerative remodelling of the aortic medial extracellular matrix resulting in progressive loss of elastic properties (136) (137). Clinical, anatomical, genetic and molecular evidences suggest that prevalence of inherited aortic wall disorders in young people presenting with aortic complications is probably higher than expected and diagnosed.

This pathologic background can have an important role in extension of dissection. In our series, a significantly lower mean age characterized the presentation with a more prominent involvement of the aortic root and distal aorta. Within the characteristics of our population, we have confirmed the findings coming from the experience of Nishida et al (138), describing a strategy for aortic root repair, and from the analysis of the large GERAADA database, 
which reported that probability of TAAD extension into the supraaortic vessels and abdominal aorta decreases with patients' increasing age (130). Even after excluding patients from the analysis having syndromic disorders or bicuspid aortic valve, we found that more severe involvement of the aortic root and coronary sinus(es) were present in younger than in patients having a proximal flap of dissection involving just the ascending aorta and limited to the non-coronary sinus. Association of lower age and dissection of coronary sinus(es) may further account for the preoperative presenting sign of myocardial ischaemia. This event has been associated with aortic root complication after dissection repair and can be seen as a marker of severe proximal aortic tissue disruption (139).

Intimal tear at the level of the aortic root is a feature of the younger subgroup and this result was additionally confirmed via analysis following exclusion of patients with known connective tissue disorders or bicuspid aortic valve. In a different population, Ma et al. (140) described a similar distribution of intimal tear site and reported age and hypertension as risk factors for an arch entry tear. Alongside genetic and metabolic alterations, the aortic flow properties play a key role in progression of the wall disease (141) (142), and maybe an active variable in promoting the onset of dissection. Recent studies investigated on aortic flow patterns and wall stress with the aid computational fluid dynamics. Wall shear stress seems to have a significant impact in triggering and progression of medial degeneration, and represents a mechanical force able to separate aortic layers once imbalance between the tissue strength and flow-induced wall stress occurs (143) (144). Numata et al investigated on six different anatomical models of aortic disease. In all patients the oscillatory shear index (a parameter describing the deviation on wall shear stress from its mean direction) was higher close to the sinotubular junction (STJ), near the origin of innominate artery, and on the lesser curvature of proximal descending aorta. All these areas are predilection points for intimal tears (143). Clinical evidences are limited, but suggest that different patterns of aortic segment dilatation and blood flow properties across the aortic valve can promote development of intimal tear in different areas of proximal aorta; with major involvement of the lesser curvature of ascending aorta in patients with preserved or not extremely dilated STJ; the right lateral side of the aorta in case of diffusely dilated proximal aorta; and the sinus(es) of Valsalva/STJ in presence of a dilated aortic root (143) (144).

Different pathologic and pathogenetic substrates between young and elderly patients - the latter are affected by long-standing hypertension and a progressive atherosclerotic process require a significantly different approach in proximal repair of aortic dissection. We found 
that full root replacement was regularly performed in younger patients, while elderly patients underwent a more conservative proximal repair. The literature reports an average rate of $23 \%$ $25 \%$ full root replacement in the overall population of patients undergoing TAAD repair, around $40 \%-60 \%$ in people under the age of 50 (130) (145) (133), 10\%-20\% in septua- and $5 \%-10 \%$ in octogenarians. Isolated aortic valve associated with interposition graft replacement of the ascending aorta is nowadays reserved in case of valve leaflets degeneration or calcification, and reported in about $5 \%$ of cases; mostly in people aged over 70 years. There is no doubt that younger people deserve more radical aortic resection, but besides clinical and prognostic reasons we should recognize the importance of pathologic background and anatomic features in determining the surgical strategy for proximal repair. Nevertheless, recommendation for a full root replacement in case of connective tissue disorders, dilated or severely dissected aortic root, and in presence of an intimal tear in the aortic root, is nowadays widely accepted aiming a safe procedure in an acute setting and reduction of risk of reoperation in mid- and long-term. Evaluation of anatomical characteristics can also explain similar prevalence of arch procedures in young and elderly patients in the literature (130); more extensive distal repair is usually reserved in case of an intimal tear situated in the aortic arch or in presence of an aortic arch aneurysm. We were not able to report aortic dimensions, but we found no difference in patients' age regarding presence of an intimal tear involving the aortic arch.

Clinical presentation and occurrence of dissection related malperfusion syndrome were not associated, apart from presence of signs of myocardial ischaemia and syndromic connective disorders, with the age of patients presenting with TAAD. More extensive involvement of the proximal and distal aorta characterized the younger patients. Different pathologic background triggering the onset of TAAD in young and elderly could explain this finding. Higher rate of connective tissue disorders and wide prevalence of undiagnosed intrinsic underlying disease of the proximal aortic wall might be accountable for this peculiar presentation in the young. Intimal tear in the aortic root is also more common at lower age of presentation. This finding associated with prognostic reasons is strongly supports a higher prevalence of full root replacement in younger patients. 


\section{Summary of new findings}

1. Minimal invasive central cannulation by Seldinger method on concavity of the aortic arch is technically feasible and safe. It may avoid cerebral embolization and organ malperfusion; therefore, may reduce the rate of neurological and malperfusion complications. This alternative arterial inflow technique can be applied for prompt establishment of $\mathrm{CPB}$ in type A dissections or other aortic emergencies, especially during haemodynamic instability. SACP provides more homogenous perfusion to both haemispheres than UACP, reducing the risk of overperfusion of the right, and relative hypoperfusion on the contralateral side.

2. We have proven that tympanic temperature monitoring is highly reliable as a guide to temperature changes of the brain during HCA and rewarming, as best correlating with arterial and brain temperatures. We recommend multiple temperature measurement sites additional bladder or rectal - during aortic surgery applying HCA and SACP to be able to assess homogenous cooling and rewarming of the patient.

3. Early diagnosis and aggressive surgical approach without delay is a key factor in effective treatment for AOF. TEVAR treatment is essential to save the patient, but as the process is usually situated in an infected environment due to communication with the inner body surface; TEVAR as a stand-alone procedure would often end-up with life threatening midterm graft infection. Therefore, following short-term vital stabilization, the oesophagus should be removed, and the infected posterior mediastinal area cleared. After sufficient recovery period, a second stage interval gastrooesophageal reconstruction may lead to the most optimal long-term results.

4. We have demonstrated that more extensive involvement of proximal and distal aorta, myocardial ischaemia and syndromic connective disorders characterize younger patients. Different pathologic background promoting onset of TAAD in young and elderly patients could explain this finding. Intimal tear localized in the aortic root is also more common at lower age of presentation. These findings associated with prognostic reasons support the necessity for radical surgical approach in younger patients. 
Hereby I express my highest appreciation to Associate Professor Gábor Bogáts, Lead Cardiac Surgeon and Professor Mihály Boros for their thorough support and guidance in undertaking this work at the Department of Cardiac Surgery and Institute of Surgical Research (University of Szeged, Hungary). I am indebted to Professor Karsten Wiebe (University of Regensburg/Münster, Germany), who enabled me to gain the necessary surgical and experimental skills. I wish to express my gratitude to my friend, Dr Péter Ugocsai (University of Regensburg, Germany) for taking me through the world of numbers. Special thanks are due to $\mathrm{Mr}$ Alois Philipp and Mr Maik Foltan (University of Regensburg, Germany) for their skilful technical activities and enthusiastic contribution facilitating to overcome several hurdles and greatly promoting these experiments.

I am also grateful to Dr Pietro Giorgio Malvindi (Southampton University Hospital Trust, United Kingdom) for the fresh ideas and all my colleagues in Germany, Hungary and the United Kingdom for their valuable contributions to this project.

Special acknowledgments owing to my wife, my parents and the complete family for providing a firm, but caring background to fulfil the task. 


\section{References}

1. Vilacosta I, Román JA. Acute Aortic Syndrome. Heart. 2001, Vol. 85(4), 365-368.

2. Hagan PG, Nienaber CA, Isselbacher EM, Bruckman D, Karavite DJ, Russman PL, Evangelista A, Fattori R, Suzuki T, Oh JK, Moore AG, Malouf JF, Pape LA, Gaca C, Sechtem U, Lenferink S, Deutsch HJ, Diedrichs H, Marcos y Robles J, Llovet A, Gilon D, Das SK et al. The International Registry of Acute Aortic Dissection (IRAD): new insights into an old disease. JAMA. 2000, Vol. 16;283(7), 897-903.

3. Mehta RH, Manfredini R, Hassan F, Sechtem U, Bossone E, Oh JK, Cooper JV, Smith DE, Portaluppi F, Penn M, Hutchison S, Nienaber CA, Isselbacher EM, Eagle KA. Chronobiological patterns of acute aortic dissection. Circulation. 2002, Vol. 106(9), 1110-1115.

4. Olsson C, Thelin S, Ståhle E, Ekbom A, Granath F. Thoracic aortic aneurysm and dissection: increasing prevalence and improved outcomes reported in a nationwide population-based study of more than 14,000 cases from 1987 to 2002. Circulation. 2006, Vol. 114(24), 2611-2618.

5. DeBakey ME, Henly WS, Cooley DA, Morris GC, Crawford ES, Beall AC. Surgical management of dissecting aneurysms of the aorta. J Thorac Cardiovasc Surg. 1965, Vol. 49, 130-149.

6. Daily PO, Trueblood HW, Stinson EB, Wuerflein RD, Shumway NE. Management of acute aortic dissections. Ann Thorac Surg. 1970, Vol. 10(3), 237-247.

7. Hiratzka LF, Bakris GL, Beckman JA, Bersin RM, Carr VF, Casey DE Jr, Eagle KA, Hermann LK, Isselbacher EM, Kazerooni EA, Kouchoukos NT, Lytle BW, Milewicz DM, Reich $\begin{array}{llllllll}\text { DL, Sen } & \text { S, Shinn } & \text { JA, Svensson } & \text { LG, } & \text { Williams } & \text { DM. } & 2010\end{array}$ ACCF/AHA/AATS/ACR/ASA/SCA/SCAI/SIR/STS/SVM guidelines for the diagnosis and management of patients with Thoracic Aortic Disease: a report of the American College of Cardiology Foundation/American Heart Association Task Force on Practice Guidelines, A. Circulation. 2010, Vol. 121(13), 266-369.

8. A, Evangelista Masip. Progress in the acute aortic syndrome. Rev Esp Cardiol. 2007, Vol. 60(4), 428-439.

9. Shrestha M, Kaufeld T, Beckmann E, Fleissner F, Umminger J, Abd Alhadi F, Boethig D, Krueger H, Haverich A, Martens A. Total aortic arch replacement with a novel 4-branched frozen elephant trunk prosthesis: Single-center results of the first 100 patients. J Thorac Cardiovasc Surg. 2016, Vols. pii: S0022-5223(16), 30036-30038. 
10. Kaji S, Akasaka T, Horibata Y, Nishigami K, Shono H, Katayama M, Yamamuro A, Morioka S, Morita I, Tanemoto K, Honda T, Yoshida K. Long-term prognosis of patients with type a aortic intramural hematoma. Circulation. 2002, Vol. 106(12 Suppl 1), 248-252.

11. Lansman SL, Saunders PC, Malekan R, Spielvogel D. Acute Aortic Syndrome. J Thorac Cardiovasc Surg. 2010, Vol. 140, 92-97.

12. Hayashi H, Matsuoka Y, Sakamoto I, Sueyoshi E, Okimoto T, Hayashi K, Matsunaga N. Penetrating atherosclerotic ulcer of the aorta: imaging features and disease concept. Radiographics. 2000, Vol. 20(4), 995-1005.

13. AC, Braverman. Penetrating atherosclerotic ulcers of the aorta. Curr Opin Cardiol. 1994, Vol. 9(5), 591-597.

14. Hollander JE, Quick G. Aortoesophageal fistula: a comprehensive review of the literature. Am J Med. 1991, Vol. 91 (3), 279-287.

15. Kieffer E, Chiche L, Gomes D. Aortoesophageal fistula: value of in situ aortic allograft replacement. Ann Surg. 2003, Vol. 238 (2), 283-290.

16. Prokakis C, Koletsis E, Apostolakis E, Dedeilias P, Dougenis D. Aortroesophageal fistulas due to thoracic aorta aneurysm: surgical versus endovascular repair. Is there a role for combined aortic management? Med Sci Monit. 2008, Vol. 14 (4), 48-54.

17. Patris V, Toufektzian L, Field M, Argiriou M. Is axillary superior to femoral artery cannulation for acute type A aortic dissection surgery? Interact Cardiovasc Thorac Surg. 2015, Vol. 21 (4), 515520.

18. Schachner T, Vertacnik K, Laufer G, Bonatti J. Axillary artery cannulation in surgery of the ascending aorta and the aortic arch. Eur J Cardiothorac Surg. 2002, Vol. 22 (3), 445-447.

19. Schachner T, Laufer G, Vertacnik K, Bonaros N, Nagiller J, Bonatti J. Is the axillary artery a suitable cannulation site in aortic surgery? J Cardiovasc Surg. 2004, Vol. 45 (1), 15-19.

20. Watanabe K, Fukuda I, Osaka M, Imazuru T. Axillary artery and transapical aortic cannulation as an alternative to femoral artery cannulation. Eur J Cardiothorac Surg. 2003, Vol. 23 (5), 842-843.

21. Schachner T, Nagiller J, Zimmer A, Laufer G, Bonatti J. Technical problems and complications of axillary artery cannulation. Eur J Cardiothorac Surg. 2005, Vol. 27 (4), 634-637. 
22. Imanaka K, Kyo S, Tanabe H, Ohuchi H, Asano H, Yokote Y. Fatal intraoperative dissection of the innominate artery due to perfusion through the right axillary artery. J Thorac Cardiovasc Surg. 2000, Vol. 120 (2), 405-406.

23. Panos A, Murith N, Bednarkiewicz M, Khatchatourov G. Axillary cerebral perfusion for arch surgery in acute type A dissection under moderate hypothermia. Eur J Cardiothorac Surg. 2006, Vol. 29 (6), 1036-1039.

24. Reuthebuch O, Schurr U, Hellermann J, Pretre R, Künzli A, Lachat M, Turina MI. Advantages of subclavian artery perfusion for repair of acute type A dissection. Eur J Cardiothorac Surg. 2004, Vol. 26 (3), 592-598.

25. Wada S, Yamamoto S, Honda J, Hiramoto A, Wada H, Hosoda Y. Transapical aortic cannulation for cardiopulmonary bypass in type A aortic dissection operations. $J$ Thorac Cardiovasc Surg. 2006, Vol. 132 (2), 369-372.

26. Göbölös L, Tsang GM, Curzen N, Calver AJ, Ohri SK. Transapical perfusion for peri-arrest salvage during transcutaneous aortic valve implantation. Perfusion. 2015, Vol. 30 (8), 650-652.

27. Borst HG, Schaudig A, Rudolph W. Arteriovenous fistula of the aortic arch: repair during deep hypothermia and circulatory arrest. J Thorac Cardiovasc Surg. 1964, Vol. 48, 443-447.

28. Hogue CW, Palin CA Jr, Arrowsmith JE. Cardiopulmonary bypass management and neurologic outcomes: an evidence-based appraisal of current practices. Anesth Analg. 2006, Vol. 103 (1), 21-37.

29. Reith J, Jørgensen HS, Pedersen PM, Nakayama H, Raaschou HO, Jeppesen LL. Body temperature in acute stroke: relation to stroke severity, infarct size, mortality, and outcome. Lancet. 1996, Vol. 347 (8999), 422-425.

30. Globus MY, Busto R, Lin B, Schnippering H, Ginsberg MD. Detection of free radical activity during transient global ischemia and recirculation: effects of intraischemic brain temperature modulation. J Neurochem. 1995, Vol. 65 (3), 1250-1256.

31. Morimoto T, Ginsberg MD, Dietrich WD, Zhao W. Hyperthermia enhances spectrin breakdown in transient focal cerebral ischemia. Brain Res. 1997, Vol. 746, 43-51.

32. Chopp M, Welch KM, Tidwell CD, Knight R, Helpern JA. Effect of mild hyperthermia on recovery of metabolic function after global cerebral ischemia in cats. Stoke. 1988, Vol. 19 (12), 1521 1525. 
33. Dietrich WD, Busto R, Halley M, Valdes I. The importance of brain temperature in alterations of the blood-brain barrier following cerebral ischemia. J Neuropathol Exp Neurol. 1990, Vol. 49(5), 486497.

34. Bigelow WG, Callaghan JC, Hopps JA. General hypothermia for experimental intracardiac surgery; the use of electrophrenic respirations, an artificial pacemaker for cardiac standstill and radiofrequency rewarming in general hypothermia. Ann Surg. 1950, Vol. 132 (3), 531-539.

35. Tanaka J, Shiki K, Asou T, Yasui H, Tokunaga K. Cerebral autoregulation during deep hypothermic nonpulsatile cardiopulmonary bypass with selective cerebral perfusion in dogs. $J$ Thorac Cardiovasc Surg. 1988, Vol. 95 (1), 124-132.

36. Conolly S, Arrosmith JE, Klein AA. Deep hypothermic circulatory arrest. Contin Educ Anaesth Crit Care Pain. 2010, Vol. 10 (5), 138-142.

37. Barone FC, Feuerstein GZ, White RF. Brain cooling during transient focal ischemia provides complete neuroprotection. Neurosci Biobehav Rev. 1997, Vol. 21 (1), 31-44.

38. Kern FH, Jonas RA, Mayer JE Jr, Hanley FL, Castaneda AR, Hickey PR. Temperature monitoring during CPB in infants: does it predict efficient brain cooling? Ann Thorac Surg. 1992, Vol. 54 (4), $749-754$.

39. Biedrzycka A, Lango R. Tissue oximetry in anaesthesia and intensive care. Anaesthesiol Intensive Ther. 2016, Vol. 48 (1), 41-48.

40. ST, Tan. Cerebral oximetry in cardiac surgery. Hong Kong Med J. 2008, Vol. 14 (3), 220-225.

41. Okita Y, Miyata H, Motomura N, Takamoto S and Organization, Japan Cardiovascular Surgery Database. A study of brain protection during total arch replacement comparing antegrade cerebral perfusion versus hypothermic circulatory arrest, with or without retrograde cerebral perfusion: analysis based on the Japan Adult Cardiovascular Surgery Database. J Thorac Cardiovasc Surg. 149 (2), 2015, 65-73.

42. Urbanski PP, Lenos A, Lindemann Y, Weigang E, Zacher M, Diegeler A. Carotid artery cannulation in aortic surgery. J Thorac Cardiovasc Surg. 2006, Vol. 132 (6), 1398-1403.

43. Merkkola P1, Tulla H, Ronkainen A, Soppi V, Oksala A, Koivisto T, Hippeläinen M. Incomplete circle of Willis and right axillary artery perfusion. Ann Thorac Surg. 2006, Vol. 82 (1), 74 79. 
44. Angeloni E, Melina G, Refice SK, Roscitano A, Capuano F, Comito C, Sinatra R. Unilateral versus bilateral antegrade cerebral protection during aortic surgery: an updated meta-analysis. Ann Thorac Surg. 2015, Vol. 99 (6), 2024-2031.

45. Malvindi PG, Modi A, Miskolczi S, Kaarne M, Barlow C, Ohri SK, Livesey S, Tsang G, Velissaris T. Acute type A aortic dissection repair in elderly patients. Eur J Cardiothorac Surg. 2015, Vol. 48 (5), 664-670.

46. Malvindi PG, Modi A, Miskolczi S, Kaarne M, Velissaris T, Barlow C, Ohri SK, Tsang G, Livesey S. Open and closed distal anastomosis for acute type A aortic dissection repair. Interact Cardiovasc Thorac Surg. 2016, Vol. 22 (6), 776-783.

47. Yacoub MH, Gehle P, Chandrasekaran V, Birks EJ, Child A, Radley-Smith R. Late results of a valve-preserving operation in patients with aneurysms of the ascending aorta and root. $J$ Thorac Cardiovasc Surg. 1999, Vol. 115 (5), 1080-1090.

48. David TE, Feindel CM, Webb GD, Colman JM, Armstrong S, Maganti M. Long-term results of aortic valve-sparing operations for aortic root aneurysm. J Thorac Cardiovasc Surg. 2006, Vol. 132 (2), 347-354.

49. De Paulis R, Scaffa R, Nardella S, Maselli D, Weltert L, Bertoldo F, Pacini D, Settepani F, Tarelli G, Gallotti R, Di Bartolomeo R, Chiariello L. Use of the Valsalva graft and long-term follow-up. J Thorac Cardiovasc Surg. 2010, Vol. 140 (6), 23-27.

50. PP, Urbanski. Bio-Bentall: Do Not Sew the Valve Prosthesis Suture Ring to the Annulus. Ann Thorac Surg. 2016, Vol. 102 (1), 347-348.

51. Borst HG, Walterbusch G, Schaps D. Extensive aortic replacement using "elephant trunk" prosthesis. Thorac Cardiovasc Surg. 1983, Vol. 31 (1), 37-40.

52. Borst HG, Heinemann MK, Stone CD. Surgical treatment of aortic dissection. s.1. : Churchill Livingstone, 1996. ISBN-10: 044307531X.

53. Volodos NL, Karpovich IP, Troyan VI, Kalashnikova YuV, Shekhanin VE, Ternyuk NE, Neoneta AS, Ustinov NI, Yakovenko LF. Clinical experience of the use of self-fixing synthetic prostheses for remote endoprosthetics of the thoracic and the abdominal aorta and iliac arteries through the femoral artery and as intraoperative endoprosthesis for aorta reconstruction. Vasa Suppl. 1991, Vol. 33, 93-95.

54. Grabenwöger M, Alfonso F, Bachet J, Bonser R, Czerny M, Eggebrecht H, Evangelista A, Fattori R, Jakob H, Lönn L, Nienaber CA, Rocchi G, Rousseau H, Thompson M, Weigang E, 
Erbel R. Thoracic Endovascular Aortic Repair (TEVAR) for the treatment of aortic diseases: a position statement from the European Association for Cardio-Thoracic Surgery (EACTS) and the European Society of Cardiology (ESC), in collaboration with the European Assoc. Eur Heart J. 2012, Vol. 33 (13), 1558-1563.

55. Karck M, Chavan A, Hagl C, Friedrich H, Galanski M, Haverich A. The frozen elephant trunk technique: a new treatment for thoracic aortic aneurysms. J Thorac Cardiovasc Surg. 2003, Vol. 125 (6), 1550-1553.

56. Rylski B, Suedkamp M, Beyersdorf F, Nitsch B, Hoffmann I, Blettner M, Weigang E. Outcome after surgery for acute aortic dissection type A in patients over 70 years: data analysis from the German Registry for Acute Aortic Dissection Type A (GERAADA). Eur J Cardiothorac Surg. 2011, Vol. 40 (2), 435-440.

57. Tsai TT, Evangelista A, Nienaber CA, Trimarchi S, Sechtem U, Fattori R, Myrmel T, Pape L, Cooper JV, Smith DE, Fang J, Isselbacher E, Eagle KA and (IRAD), International Registry of Acute Aortic Dissection. Long-term survival in patients presenting with type A acute aortic dissection: insights from the International Registry of Acute Aortic Dissection (IRAD). Circulation. 2006, Vol. 114 (1), 350-356.

58. Shores J, Berger KR, Murphy EA, Pyeritz RE. Progression of aortic dilatation and the benefit of long-term beta-adrenergic blockade in Marfan's syndrome. N Engl J Med. 1994, Vol. 330 (19), $1335-1341$.

59. Habashi JP, Doyle JJ, Holm TM, Aziz H, Schoenhoff F, Bedja D, Chen Y, Modiri AN, Judge DP, Dietz HC. Angiotensin II type 2 receptor signaling attenuates aortic aneurysm in mice through ERK antagonism. Science. 2011, Vol. 332 (6027), 361-365.

60. Gambarin FI1, Favalli V, Serio A, Regazzi M, Pasotti M, Klersy C, Dore R, Mannarino S, Viganò M, Odero A, Amato S, Tavazzi L, Arbustini E. Rationale and design of a trial evaluating the effects of losartan vs. nebivolol vs. the association of both on the progression of aortic root dilation in Marfan syndrome with FBN1 gene mutations. J Cardiovasc Med. 2009, Vol. 10 (4), 354-362.

61. De Paulis R, Czerny M, Weltert L, Bavaria J, Borger MA, Carrel TP, Etz CD, Grimm M, Loubani M, Pacini D, Resch T, Urbanski PP, Weigang E and Group, EACTS Vascular Domain. Current trends in cannulation and neuroprotection during surgery of the aortic arch in Europe. Eur $J$ Cardiothorac Surg. 2015, Vol. 47 (5), 917-923.

62. Kieffer E, Chiche L, Gomes D. Aortoesophageal fistula: value of in situ aortic allograft replacement. Ann Surg. 2003, Vol. 238 (2), 283-290. 
63. Robicsek F, Zimmern SH, Howe HR. Subintimal retrograde perfusion during repair of aortic dissection: a potential cause of disaster. Ann Vasc Surg. 1988, Vol. 2 (3), 298-302.

64. Borst HG, Laas J, Heinemann M. Type A aortic dissection: diagnosis and management of malperfusion phenomena. Semin Thorac Cardiovasc Surg. 1991, Vol. 3 (3), 238-241.

65. Lijoi A, Scarano F, Dottori V, Parodi E, Casali G, Bartolozzi F. Stanford type A aortic dissection. A new surgical approach. Tex Heart Inst J. 1998, Vol. 25 (1), 65-67.

66. Minatoya K, Karck M, Szpakowski E, Harringer W, Havernich A. Ascending aortic cannulation for Stanford type A acute aortic dissection: another option. J Thorac Cardiovasc Surg. 2003, Vol. 125 (4), 952-953.

67. Khaladj N, Shrestha M, Peterss S, Strueber M, Karck M, Pichlmaier M, Havernich A, Hagl C. Khaladj N, Shrestha M, Peterss S, Strueber M, Karck M, PichlAscending aortic cannulation in acute aortic dissection type A: the Hannover experience. Eur J Cardiothorac Surg. 2008, Vol. 34 (4), 792-796.

68. Khoynezhad A, Plestis KA. Cannulation in the diseased aorta: a safe approach using the Seldinger technique. Tex Heart Inst J. 2006, Vol. 33 (3), 353-355.

69. Göbölös L, Philipp A, Foltan M, Wiebe K. Surgical management for Stanford type A aortic dissection: direct cannulation of real lumen at the level of the Botallo's ligament by Seldinger technique. Interact Cardiovasc Thorac Surg. 2008, Vol. 7 (6), 1107-1109.

70. Inoue Y, Ueda T, Taguchi S, Kashima I, Koizumi K, Takahashi R, Kiso I. Ascending aorta cannulation in acute type A aortic dissection. Eur J Cardiothorac Surg. 2007, Vol. 31 (6), 979-981.

71. Inoue Y, Takahashi R, Ueda T, Yozu R. Inoue Y, TakSynchronized epiaortic two-dimensional and color Doppler echocardiographic guidance enables routine ascending aortic cannulation in type A acute aortic dissection. J Thorac Cardiovasc Surg. 2011, Vol. 141 (2), 354-360.

72. Girardi LN, Krieger KH, Lee LY, Mack CA, Tortolani AJ, Isom OW. Girardi LN, Krieger KH, Lee Management strategies for type A dissection complicated by peripheral vascular malperfusion. Ann Thorac Surg. 2004, Vol. 74 (4), 1309-1314.

73. Salerno TA, Lince DP, White DN, Lynn RB, Charrette EJ. Arch versus femoral artery perfusion during cardiopulmonary bypass. J Thorac Cardiovasc Surg. 1978, Vol. 76 (5), 681-684.

74. Svensson LG, Blackstone EH, Rajeswaran J, Sabik JF 3rd, Lytle BW, Gonzalez-Stawinski G, Varvitsiotis P, Banbury MK, McCarthy PM, Pettersson GB, Cosgrove DM. Does the arterial 
cannulation site for circulatory arrest influence stroke risk? Ann Thorac Surg. 2004, Vol. 78 (4), 12741284.

75. Hagl C, Khaladj N, Karck M, Kallenbach K, Leyh R, Winterhalter M, Haverich A. Hagl C, Khaladj N, Karck M, Kallenbach K,Hypothermic circulatory arrest during ascending and aortic arch surgery: the theoretical impact of different cerebral perfusion techniques and other methods of cerebral protecti. Eur J Cardiothorac Surg. 2003, Vol. 24 (3), 371-378.

76. Kamiya H, Hagl C, Kropivnitskaya I, Bothig D, Kallenbach K, Khaladj N, Martens A, Haverich A, Karck M. Kamiya H, Hagl C, Kropivnitskaya I, Bothig D, Kallenbach K, Khaladj N, MartThe safety of moderate hypothermic lower body circulatory arrest with selective cerebral perfusion: a propensity score analysis. J Thorac Cardiovasc Surg. 2007, Vol. 133 (2), 501-509.

77. Kamiya H, Klima U, Hagl C, Logemann F, Winterhalter M, Shrestha ML, Kallenbach K, Khaladj N, Haverich A, Karck M. Kamiya H, Klima U, Hagl C, Logemann F, Winterhalter M, Shrestha ML, KalCerebral microembolization during antegrade selective cerebral perfusion. Ann Thorac Surg. 2006, Vol. 81 (2), 519-521.

78. Hagl C, Khaladj N, Peterss S, Hoeffler K, Winterhalter M, Karck M, Haverich A. Hypothermic circulatory arrest with and without cold selective antegrade cerebral perfusion: impact on neurological recovery and tissue metabolism in an acute porcine model. Eur J Cardiothorac Surg. 2004, Vol. 26 (1), 73-80.

79. Khaladj N, Peterss S, Oetjen P, von Wasielewski R, Hauschild G, Karck M, Haverich A, Hagl C. Hypothermic circulatory arrest with moderate, deep or profound hypothermic selective antegrade cerebral perfusion: which temperature provides best brain protection? Eur J Cardiothorac Surg. 2006, Vol. 30 (3), 492-498.

80. Reece TB, Tribble CG, Smith RL, Singh RR, Stiles BM, Peeler BB, Kern JA. entral cannulation is safe in acute aortic dissection repair. J Thorac Cardiovasc Surg. 2007, Vol. 133 (2), 428-434.

81. J, Bachet. Editorial comment: ascending aorta cannulation in acute type A aortic dissection. Eur J Cardiothorac Surg. 2007, Vol. 31 (6), 979-981.

82. Kitamura T, Torii S, Kobayashi K, Tanaka Y, Sasahara A, Ohtomo Y, Horikoshi R, Miyaji K. Samurai cannulation (direct true-lumen cannulation) for acute Stanford Type A aortic dissection. Eur J Cardiothorac Surg. 2018, Vol. 54(3), 498-503. 
83. Strauch JT, Spielvogel D, Lauten A, Lansman SL, McMurtry K, Bodian CA, Griepp RB. Strauch JT, Spielvogel D, Lauten A, Lansman SL, McMurAxillary artery cannulation: routine use in ascending aorta and aortic arch replacement. Ann Thorac Surg. 2004, Vol. 78 (1), 103-108.

84. Cakir H, Kestelli M, Yurekli I, Eygi B, Iscan S, Isık Y, Aşar K, Ogut H. Should we change the cannulation site for right subclavian artery cannulation? An experimental study with a newly designed cannula. Perfusion. 2016, Vol. 31(8), 668-675.

85. Moizumi Y, Motoyoshi N, Sakuma K, Yoshida S. Axillary artery cannulation improves operative results for acute type a aortic dissection. Ann Thorac Surg. 2005, Vol. 80 (1), 77-83.

86. Di Eusanio M, Ciano M, Labriola G, Lionetti G, Di Eusanio G. Di Eusanio M, Ciano M, Labriola G, Lionetti G, Di Eusanio G. Cannulation of the innominate artery during surgery of the thoracic aorta: our experience in 55 patients. Eur J Cardiothorac Surg. 2007, Vol. 32 (2), 270-273.

\section{Rahimi-Barfeh A, Grothusen C, Haneya A, Schöttler J, Eide AM, Erdmann M, Friedrich C,}

Hoffmann G, Cremer J, Schoeneich F. Transatrial cannulation of the left ventricle for acute Type A aortic dissection: a 5-year experience. Ann Thorac Surg. 2016, Vol. 101 (5), 1753-1758.

88. Fusco DS, Shaw RK, Tranquilli M, Kopf GS, Elefteriades JA. Femoral cannulation is safe for type A dissection repair. Ann Thorac Surg. 2004, Vol. 78 (4), 1285-1289.

89. Harky A, Bashir H, Shaw M, Howard C, Sharif M, Oo A. Aortic cannulation in complex aortic disease: playing or planning on fear. J Vis Surg. 2019, Vol. 5, 18 doi: 10.21037/jovs.2019.01.13.

90. S, Yavuz. Alternative cannulation techniques in surgical repair for acute type A aortic dissection. Eur Res J. 2016, Vol. 2(1), 1-6 doi: 10.18621/eurj.2016.2.1.1.

91. Pinnelas R, Vaishnava P, Eagle KA. Ascending aortic dissection, penetrating aortic ulcer, and intramural hematoma. [book auth.] Dieter Jr R, Dieter III R (eds) Dieter R. Diseases of the aorta. pp 127-147 doi: 10.1007/978-3-030-11322-3_9 : Springer, Cham, 2019.

92. Ma H, Xiao Z, Shi J, Liu L, Qin C, Guo Y. Aortic arch cannulation with the guidance of transesophageal echocardiography for Stanford type A aortic dissection. J Cardiothorac Surg. 2018, Vol. 13(1), 106. doi: 10.1186/s13019-018-0779-5.

93. Shimura S, Odagiri S, Furuya H, Okada K, Ozawa K, Nagase H, Yamaguchi M, Cho Y. Echocardiography-guided aortic cannulation by the Seldinger technique for type A dissection with cerebral malperfusion. J Thorac Cardiovasc Surg. 2019, Vols. pii: S0022-5223(19)30565-3. doi: 10.1016/j.jtcvs.2019.02.097. [Epub ahead of print]. 
94. Göbölös L, Ugocsai P, Foltan M, Philipp A, Thrum A, Miskolczi Sz, Malvindi PG, di Gregorio V, Pousios D, Navaratnarajah M, Ohri SK. Central cannulation by Seldinger technique: a reliable method in ascending aorta and aortic arch replacement. Med Sci Monit. 2014, Vol. 20, 23862393.

95. WC, Sealy. Hypothermia: its possible role in cardiac surgery. Ann Thorac Surg. 1989, Vol. 47 (5), 788-791.

96. J, Van der Linden. Cerebral hemodynamics after low-flow versus no-flow procedures. Ann Thorac Surg. 1995, Vol. 59 (5), 1321-1325.

97. DI, Sessler. Complications and treatment of mild hypothermia. Anesthesiology. 2001, Vol. 95 (2), 531-543.

98. Kurz A, Sessler DI, Lenhardt R. Perioperative normothermia to reduce the incidence of surgicalwound infection and shorten hospitalization. N Engl J Med. 1996, Vol. 334 (19), 1209-1215.

99. Frank SM, Fleisher LA, Breslow MJ, Higgins MS, Olson KF, Kelly S, Beattie C. Frank SM, Fleisher LA, Breslow MJ, Higgins MSPerioperative maintenance of normothermia reduces the incidence of morbid cardiac events. JAMA. 1997, Vol. 277 (14), 1127-1134.

100. Insler SR, O'Connor MS, Leventhal MJ, Nelson DR, Starr NJ. Insler SR, O'Connor MS, LeAssociation between postoperative hypothermia and adverse outcome after coronary artery bypass surgery. Ann Thorac Surg. 2000, Vol. 70 (1), 175-181.

101. DJ, Cook. Cerebral hyperthermia and cardiac surgery: consequences and prevention. Semin Thorac Cardiovasc Surg. 2001, Vol. 13 (2), 176-183.

102. Ginsberg MD, Busto R. Combating hyperthermia in acute stroke: a significant clinical concern. Stroke. 1998, Vol. 29 (2), 529-534.

103. Mora CT, Henson MB, Weintraub WS, Murkin JM, Martin TD, Craver JM, Gott JP, Guyton RA. Mora CT, Henson MB, Weintraub WS, Murkin JM, Martin TD, CravThe effect of temperature management during cardiopulmonary bypass on neurologic and neuropsychologic outcomes in patients undergoing coronary revascularization. J Thorac Cardiovasc Surg. 1996, Vol. $112(2), 514-522$.

104. Buss MI, McLean RF, Wong BI, Fremes SE, Naylor CD, Harrington EM, Snow WG, Gawel M. Cardiopulmonary bypass, rewarming, and central nervous system dysfunction. Ann Thorac Surg. 1996, Vol. 61 (5), 1423-1437. 
105. NA, Nussmeier. Management of temperature during and after cardiac surgery. Tex Heart Inst J. 2005, Vol. 32 (4), 472-476.

106. Camboni D, Philipp A, Schebesch KM, Schmid C. Accuracy of core temperature measurement in deep hypothermic circulatory arrest. Interact Cardiovasc Thorac Surg. 2008, Vol. 7 (5), 922-924.

107. Baker MA, Stocking RA, Meehan JP. Thermal relationship between tympanic membrane and hypothalamus in conscious cat and monkey. J Appl Physiol. 1972, Vol. 32 (6), 739-742.

108. M, Benzinger. Tympanic thermometry in surgery and anesthesia. JAMA. 1969, Vol. 209 (8), 1207-1211.

109. McCaffrey TV, McCook RD, Wurster RD. Effect of head skin temperature on tympanic and oral temperature in man. J Appl Physiol. 1975, Vol. 39 (1), 114-118.

110. Shiraki K, Sagawa S, Tajima F, Yokota A, Hashimoto M, Brengelmann GL. Independence of brain and tympanic temperatures in an unanesthetized human. J Appl Physiol. 1988, Vol. 65 (1), $482-486$.

111. Horrow JC, Rosenberg H. Does urinary catheter temperature reflect core temperature during cardiac surgery. Anesthesiology. 1988, Vol. 69 (6), 986-989.

112. JW, Severinghaus. Temperature gradients during hypothermia. Ann N Y Acad Sci. 1959, Vol. $80,515-521$.

113. Stone JG, Young WL, Smith CR, Solomon RA, Wald A, Ostapkovich N, Shrebnick DB. Stone JG, Young WL, Smith CR, Solomon RA, Wald A, ODo standard monitoring sites reflect true brain temperature when profound hypothermia is rapidly induced and reversed? Anesthesiology. 1995, Vol. 82 (2), 344-351.

114. Hercus V, Cohen D, Bowring AC. Temperature gradients during hypothermia. Br Med J. 1959, Vol. 1 (5135), 1439-1441.

115. Stefaniszyn HJ, Novick RJ, Keith FM, Salerno TA. Is the brain adequately cooled during deep hypothermic cardiopulmonary bypass? Curr Surg. 1983, Vol. 40 (4), 294-297.

116. Akata T, Yamaura K, Kandabashi T, Sadamatsu S, Takahashi S. Akata T, Yamaura K, Kandabashi T,Changes in body temperature during profound hypothermic cardiopulmonary bypass in adult patients undergoing aortic arch reconstruction. J Anesth. 2004, Vol. 18 (2), 73-81. 
117. Topel I, Stehr A, Steinbauer MG, Piso P, Schlitt HJ, Kasprzak PM. Topel I, Stehr A, Steinbauer MG, Piso P, Surgical strategy in aortoesophageal fistulae: endovascular stentgrafts and in situ repair of the aorta with cryopreserved homografts. Ann Surg. 2007, Vol. 246 (5), 853-859.

118. Chiesa R, Melissano G, Marone EM, Kahlberg A, Marrocco-Trischitta MM, Tshomba Y. Endovascular treatment of aortoesophageal and aortobronchial fistulae. J Vasc Surg. 2010, Vol. 51 (5), 1195-202.

119. Snyder DM, Crawford ES. Successful treatment of primary aorto-esophageal fistula resulting from aortic aneurysm. J Thorac Cardiovasc Surg. 1983, Vol. 85 (3), 457-463.

120. Oppell UO, Groot MA, Thierfelder C, Zilla P, Odell JA. Successful management of aortoesophageal fistula due to thoracic aortic aneurysm. Ann Thorac Surg. 1991, Vol. 52 (5), 11681170.

121. Flores J, Shiiya N, Kunihara T, Yoshimoto K, Yasuda K. Flores J, Shiiya N,Aortoesophageal fistula: alternatives of treatment case report and literature review. Ann Thorac Cardiovasc Surg. 2004, Vol. 10 (4), 241-246.

122. Pirard L, Creemers F, Van Damme H, Laurent S, Honoré P, Limet R. Pirard L, Creemers In situ aortic allograft insertion to repair a primary aortooesophageal fistula due to thoracic aortic aneurysm. J Vasc Surg. 2005, Vol. 42 (6), 1213-1217.

123. Aleksic I, Leyh R, Schorn B. Extra-anatomic management of homograft reinfection after thoracic aortic rupture. Thorac Cardiovasc Surg. 2006, Vol. 54 (6), 428-430.

124. Aizawa K, Ohki S, Konishi H, Misawa Y. Extraanatomical ascending-abdominal aorta bypass with stump closure for aortic graft infection. Interact Cardiovasc Thorac Surg. 2008, Vol. 7 (4), 646647.

125. Müller BT, Wegener OR, Grabitz K, Pillny M, Thomas L, Sandmann W. Müller BT, Wegener OR, GrMycotic aneurysms of the thoracic and abdominal aorta and iliac arteries: experience with anatomic and extra-anatomic repair in 33 cases. J Vasc Surg. 2001, Vol. 33 (1), 106-113.

126. Akashi H, Kawamoto S, Saiki Y, Sakamoto T, Sawa Y, Tsukube T, Kubota S, Matsui Y, Karube N, Imoto K, Yamanaka K, Kondo S, Tobinaga S, Tanaka H, Okita Y, Fujita H. Therapeutic strategy for treating aortoesophageal fistulas. Gen Thorac Cardiovasc Surg. 2014, Vol. 62 (10), 573-580.

127. Puranik R, Chow CK, Duflou JA, Kilborn MJ, McGuire MA. Sudden death in the young. Heart Rhythm. 2005, Vol. 2 (12), 1277-1282. 
128. Li Y, Li L, Mu HS, Fan SL, He FG, Wang ZY. Aortic dissection and sudden unexpected deaths: A retrospective study of 31 forensic autopsy cases. J Forensic Sci. 2015, Vol. 60 (5), 12061211.

129. Trimarchi S, Eagle KA, Nienaber CA, Rampoldi V, Jonker FH, De Vincentiis C, Frigiola A, Menicanti L, Tsai T, Froehlich J, Evangelista A, Montgomery D, Bossone E, Cooper JV, Li J, Deeb MG, Meinhardt G, Sundt TM, Isselbacher EM and investigators, IRAD. Role of age in acute type A aortic dissection outcome: report from the International Registry of Acute Aortic Dissection (IRAD). J Thorac Cardiovasc Surg. 2010, Vol. 140 (4), 784-789.

130. Rylski B, Hoffmann I, Beyersdorf F, Suedkamp M, Siepe M, Nitsch B, Blettner M, Borger MA, Weigang E and Study, Multicenter Prospective Observational. Acute aortic dissection type A: age-related management and outcomes reported in the German Registry for Acute Aortic Dissection Type A (GERAADA) of over 2000 patients. Ann Surg. 2014, Vol. 259 (3), 598-604.

131. Dean JH, Woznicki EM, O'Gara P, Montgomery DG, Trimarchi S, Myrmel T, Pyeritz RE, Harris KM, Suzuki T, Braverman AC, Hughes GC, Kline-Rogers E, Nienaber CA, Isselbacher EM, Eagle KA, Bossone E. Cocaine-related aortic dissection: lessons from the International Registry of Acute Aortic Dissection. Am J Med. 2014, Vol. 127 (9), 878-885.

132. Westover AN1, Nakonezny PA. Aortic dissection in young adults who abuse amphetamines. Am Heart J. 2010, Vol. 160 (2), 315-321.

133. Januzzi JL, Isselbacher EM, Fattori R, Cooper JV, Smith DE, Fang J, Eagle KA, Mehta RH, Nienaber CA, Pape LA and (IRAD), International Registry of Aortic Dissection. Characterizing the young patient with aortic dissection: results from the International Registry of Aortic Dissection (IRAD). J Am Coll Cardiol. 2004, Vol. 43 (4), 665-669.

134. Elefteriades JA, Pomianowski P. Practical genetics of thoracic aortic aneurysm. Prog Cardiovasc Dis. 2013, Vol. 56 (1), 57-67.

135. Pomianowski P, Elefteriades JA. The genetics and genomics of thoracic aortic disease. Ann Cardiothorac Surg. 2013, Vol. 2 (3), 271-279.

136. Ruddy JM, Jones JA, Ikonomidis JS. Pathophysiology of Thoracic Aortic Aneurysm (TAA): Is It Not One Uniform Aorta? Role of embryologic origin. Prog Cardiovasc Dis. 2013, Vol. 56 (1), 6873. 
137. Bee KJ, Wilkes DC, Devereux RB, Basson CT, Hatcher CJ. TGF $\beta$ RIIb mutations trigger aortic aneurysm pathogenesis by altering transforming growth factor $\beta 2$ signal transduction. Circ Cardiovasc Genet. 2012, Vol. 5 (6), 621-629.

138. Nishida H, Tabata M, Fukui T, Takanashi S. Surgical strategy and outcome for aortic root in patients undergoing repair of acute type A aortic dissection. Ann Thorac Surg. 2016, Vol. 101 (4), 1464-1469.

139. Geirsson A, Bavaria JE, Swarr D, Keane MG, Woo YJ, Szeto WY, Pochettino A. Fate of the residual distal and proximal aorta after acute type a dissection repair using a contemporary surgical reconstruction algorithm. Ann Thorac Surg. 2007, Vol. 84 (6), 1955-1964.

140. Ma WG, Zhang W, Wang LF, Zheng J, Ziganshin BA, Charilaou P, Pan XD, Liu YM, Zhu JM, Chang Q, Rizzo JA, Elefteriades JA, Sun LZ. Type A aortic dissection with arch entry tear: Surgical experience in 104 patients over a 12-year period. J Thorac Cardiovasc Surg. 2016, Vol. 151 (6), 1581-1592.

141. Girdauskas E, Rouman M, Disha K, Scholle T, Fey B, Theis B, Petersen I, Borger MA, Kuntze T. Correlation between systolic transvalvular flow and proximal aortic wall changes in bicuspid aortic valve stenosis. Eur J Cardiothorac Surg. 2014, Vol. 46 (2), 234-239.

142. Mahadevia R, Barker AJ, Schnell S, Entezari P, Kansal P, Fedak PW, Malaisrie SC, McCarthy P, Collins J, Carr J, Markl M. Bicuspid aortic cusp fusion morphology alters aortic three-dimensional outflow patterns, wall shear stress, and expression of aortopathy. Circulation. 2014, Vol. 129 (6), 673-682.

143. Numata S, Itatani K, Kanda K, Doi K, Yamazaki S, Morimoto K, Manabe K, Ikemoto K, Yaku H. Blood flow analysis of the aortic arch using computational fluid dynamics. Eur $J$ Cardiothorac Surg. 2016, Vol. 49 (6), 1578-1585.

144. Torii R, Kalantzi M, Theodoropoulos S, Sarathchandra P, Xu XY, Yacoub MH. Predicting impending rupture of the ascending aorta with bicuspid aortic valve: spatiotemporal flow and wall shear stress. JACC Cardiovasc Imaging. 2013, Vol. 6 (9), 1017-1019.

145. Niclauss L, Delay D, von Segesser LK. Type A dissection in young patients. Interact Cardiovasc Thorac Surg. 2011, Vol. 12 (2), 194-198. 
Appendix 
I 


\title{
Proposal for bail-out procedures - Vascular thoracic Surgical management for Stanford type A aortic dissection: direct cannulation of real lumen at the level of the Botallo's ligament by Seldinger technique
}

\author{
Laszlo Göbölös*, Alois Philipp, Maik Foltan, Karsten Wiebe \\ Department of Cardiothoracic Surgery, University Hospital of Regensburg, Germany
}

Received 11 August 2008; received in revised form 26 August 2008; accepted 27 August 2008

\begin{abstract}
A 50-year-old man was diagnosed with Stanford type A acute aortic dissection with cerebral malperfusion and unconsciousness. This clinical presentation was investigated by computed tomography which revealed a severe type A dissection involving all limb arteries. Successful operative treatment based on the direct arterial cannulation of the real lumen of dissected aorta at the level of Botallo's ligament by Seldinger technique achieves an appropriate perfusion and rapid cooling of the instable patient. To our knowledge this is the first reported case in the literature.

(c) 2008 Published by European Association for Cardio-Thoracic Surgery. All rights reserved.
\end{abstract}

Keywords: Aortic dissection; Type A; Direct cannulation; Seldinger; Botallo's ligament

\section{Introduction}

Acute Stanford type A dissection, with or without involvement of the aortic arch, represents an emergency situation that requires immediate surgical intervention. Surgical therapy consists mainly in replacing the ascending aorta, and as extended procedure also removing the arch up to the proximal descending region as well, regardless of the extent of the pathological process. Acute aortic insufficiency, when present, is generally treated by valve resuspension or replacement. Mortality rates from these operations have dramatically improved as the result of recent advances in preoperative recognition, intraoperative techniques, and postoperative care [1]. Nevertheless, operations for acute type A dissections is still associated with high mortality rates [2]. Cannulation of an extended lesion presents often an enormous challenge either through subclavian or lower limb arteries [3-5]. We prefer an innovative cannulation method through the dissection membrane at the level of Botallo's ligament by Seldinger manner.

\section{Case}

A 50-year-old man complained of sudden chest pain, was admitted unconscious with anisochoria to our hospital. A computed tomography scan showed a Stanford type A aortic dissection. The dissection began directly over the aortic valve; the maximal aortic diameter of $6.0 \times 5.5 \mathrm{~cm}$ was detected on the ascending part. A connection of real lumen

\footnotetext{
*Corresponding author. Heart Institute, University of Pecs, Ifjusag u. 13 7624 Pecs, Hungary. Tel.: + 36-20-9889-949; fax: + 36-72-536-001/5658.

E-mail address: isartor@hotmail.com (L. Göbölös).

(C) 2008 Published by European Association for Cardio-Thoracic Surgery
}

with the adjacent wall elements could be observed at the level of the Botallo's ligament (Fig. 1). The dissection involved both brachiocephalic trunk, left carotid and subclavian artery. The visceral arteries originated from the real lumen except the left renal artery. Wall destruction showed in the iliac arteries too.

Because of rapid worsening of general status and cardiovascular instability, the ascending aorta and aortic arch were exposed through a median sternotomy. The punction of the aorta adjacent to the pulmonary trunk at the level of Botallo's ligament was followed by a minimal invasive cannulation with dilation steps by Seldinger technique (Fem-Flex Femoral Arterial Cannula ${ }^{\circledR}$, 24 Fr TFA 02425H Edwards Lifesciences LLC, Irvine, USA; Joline Special Dilatatorset $^{\circledR}$, Hechingen, Germany) (Fig. 2). Correct position of the guidewire and cannula was confirmed by TEE in the descending aorta. Cardiopulmonary bypass was instituted between the arterial cannulation site and right atrium. The patient was cooled down to a tympanic temperature of $23.5{ }^{\circ} \mathrm{C}$ (Mon-a-therm ${ }^{\circledR}$ Thermistor YSI 400 Series tympanic temperature probe, Mallinckrodt Inc, St Louis, USA), rectal temperature measured $25.3^{\circ} \mathrm{C}$, bladder temperature reached $20.7{ }^{\circ} \mathrm{C}$. After cross-clamping an ascending aortic incision was made, antegrade crystalloid cardioplegic solution (2000 ml Custodiol ${ }^{\circledR}$ HTK-Solution by Brettschneider, Dr F. Köhler Chemie, Hähnlein, Germany) was administered through both coronary orifices. Hypothermic cerebral perfusion was maintained through selective cannulation of both carotids (DLP Retrograde Coronary Sinus Perfusion Cannula with manual Inflating Cuff ${ }^{\circledR}$, Medtronic Inc, Minneapolis, USA) at a flow rate of $190-200 \mathrm{ml} / \mathrm{min}$ each side 


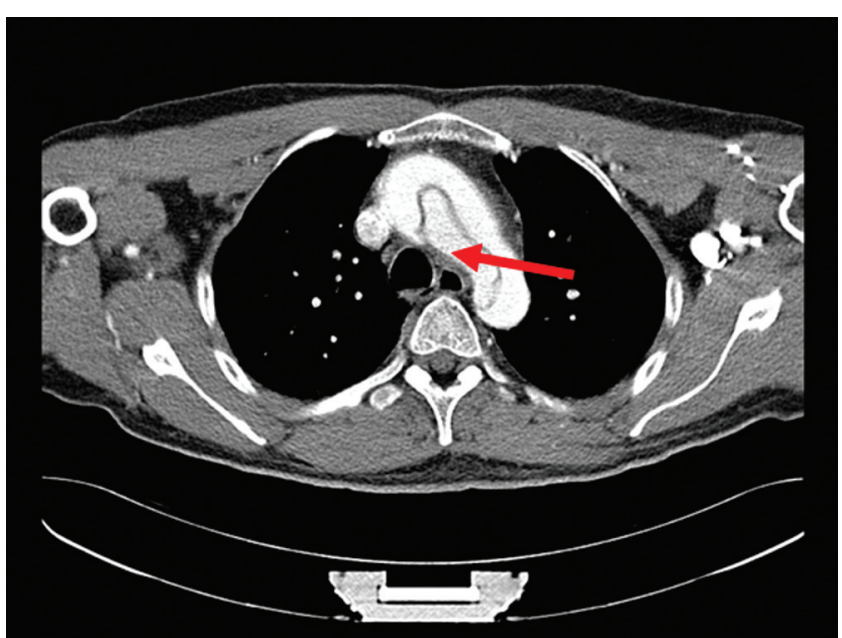

Fig. 1. Real lumen attachment to further aortic wall elements at Botallo's ligament.

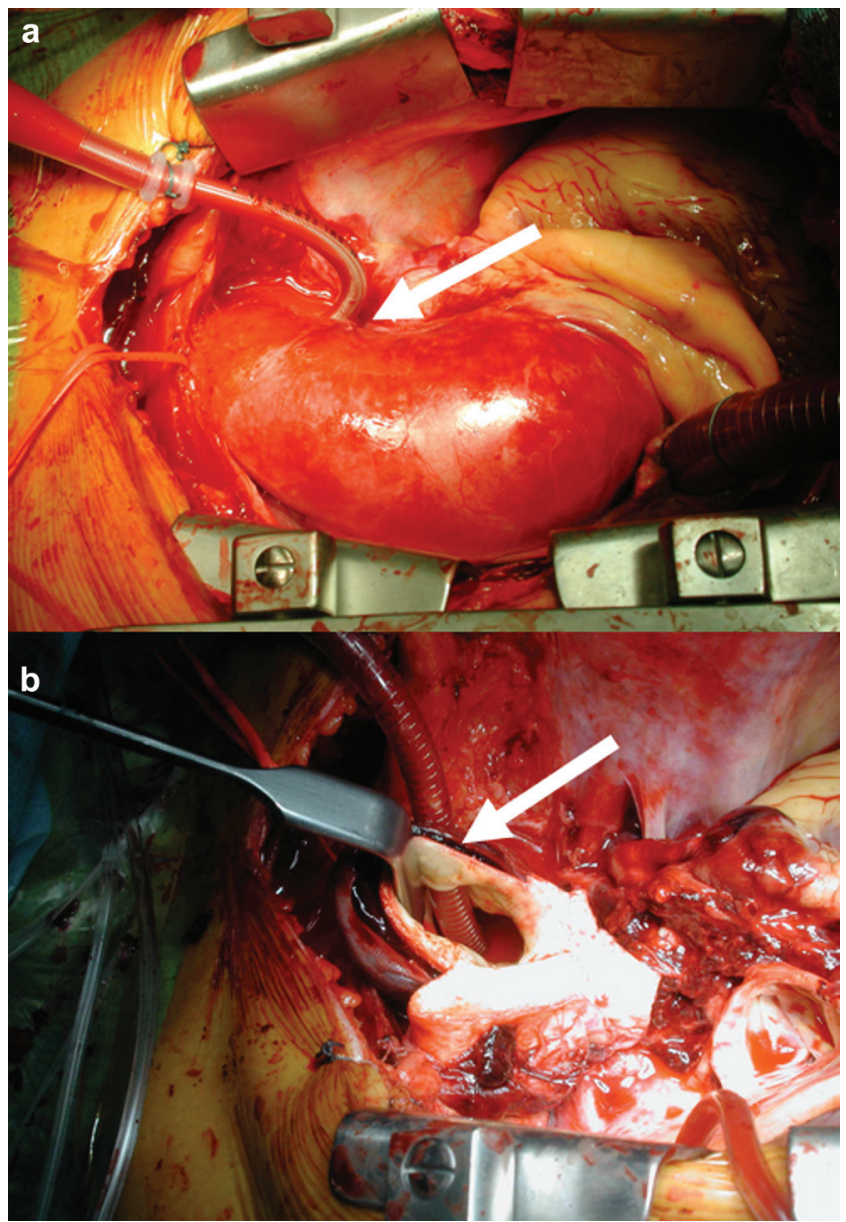

Fig. 2. Direct cannulation by Seldinger technique (a - mediastinal situs; b - intraluminal position).

and a perfusion pressure of $25-30 \mathrm{mmHg}$. Cerebral monitoring was performed with near infrared spectroscopy (INVOS ${ }^{\circledR}$ cerebral oxymeter, Somanetics Inc, Troy, USA), brain tissue oxygen saturation measured $60-65 \%$ continuously during perfusion.
Under systemic circulatory arrest, a complete reconstruction of the aorta up to proximal descending section was performed by a $30-\mathrm{mm}$ vascular prosthesis (Hemashield Platinum Woven Double Velour Vascular Graft ${ }^{\circledR}$, Boston Scientific Inc, Wayne, USA) including the island type reinsertion of all supraaortic vessels. The false lumen was eradicated with $45 \%$ bovine serum albumin-10\% glutaraldehyde glue (BioGlue ${ }^{\circledR}$, CryoLife International Inc, Kennesaw, USA); aortic valve commissures were refixed with the resuspension suture technique. Systemic reperfusion and rewarming were started through a graft side-branch. ECC time measured $156 \mathrm{~min}$, circulatory arrest $63 \mathrm{~min}$, antegrade selective cerebral perfusion time $50 \mathrm{~min}$.

Pathological study of the aortic wall showed a degenerative atherosclerosis in combination with adventitial hemorrhage. A computed tomographic scan undertaken 12 days after the operation showed consolidation of the complete vascular situation and proper perfusion of both supraaortic and visceral branches. The postoperative course was uneventful except for a reversible left upper limb palsy. The patient was discharged after 22 days, and event free at six-month outpatient visit with consolidated vascular status.

\section{Discussion}

A Stanford type A dissection should always be treated surgically consisting of at least an ascending aortic grafting, although ascending aorta and total aortic arch grafting is appropriate for some of the complicated cases. The cannulation is a crucial point in dissection patients, if medial tear involves all great limb arteries. Establishing an access point at the level of the Botallo's ligament by Seldinger technique could provide a useful alternative to achieve a quick arterial entry. At this portion of aorta the pulmonary trunk is firmly bound by a massive connective tissue, which usually prevents complete dissection in this area. Through the rapid and atraumatic cannulation method ECC is introduced, thereby reducing the likelihood of peroperative shock leading to an increased mortality [6]. With increasing experience in arch reconstructions and improvement in outcome, the indications of minimal invasive direct cannulation could be expanded to include all type A aortic dissections with or without limb artery involvement. Concomitant replacement of aortic arch in ascending aorta surgery recently has been recommended for event-free long-term survival $[7,8]$. It is mandatory to protect the central nervous system; a successful cerebral protection contributes to lower hospital mortality rate to $28 \%$ [9]. Reversible unilateral limb palsy is a rare complication of the procedure, in $3.8 \%$ observed according to some studies [10]. To our knowledge this is the first reported case of direct Seldinger cannulation of a Stanford A aortic dissection in the literature.

\section{References}

[1] Svensson LG, Blackstone EH, Rajeswaran J, Sabik JF 3rd, Lytle BW, Gonzalez-Stawinski G, Varvitsiotis P, Banbury MK, McCarthy PM, Pettersson GB, Cosgrove DM. Does the arterial cannulation site for circulatory arrest influence stroke risk? Ann Thor Surg 2004;78:1274-1284. 
[2] Ehrlich MP, Ergin MA, McCullough JN, Lansman SL, Galla JD, Bodian CA Apaydin A, Griepp RB. Results of immediate surgical treatment of all acute type A dissections. Circulation 2000;102:248-252.

[3] Strauch JT, Spielvogel D, Lauten A, Lansman SL, McMurtry K, Bodian CA, Griepp RB. Axillary artery cannulation: routine use in ascending aorta and aortic arch replacement. Ann Thor Surg 2004;78:103-108.

[4] Reuthebuch O, Schurr U, Hellermann J, Pretre R, Künzli A, Lachat M, Turina MI. Advantages of subclavian artery perfusion for repair of acute type A dissection. Eur J Cardiothorac Surg 2004;26:592-598.

[5] Pasic M, Schubel J, Bauer M, Yankah C, Kuppe H, Weng YG, Hetzer R. Cannulation of the right axillary artery for surgery of acute type $A$ aortic dissection. Eur J Cardiothorac Surg 2003;24:231-236.

[6] Girardi LN, Krieger KH, Lee LY, Mack CA, Tortolani AJ, Isom OW. Management strategies for type A dissection complicated by peripheral vascular malperfusion. Ann Thorac Surg 2004;77:1309-1314.

[7] Kazui T, Tamiya Y, Tanaka T, Komatsu S. Extended aortic replacement for acute type A dissection with the tear in the descending aorta. J Thorac Cardiovasc Surg 1996;112:973-978.

[8] Mori Y, Hirose H, Takagi H, Umeda Y, Fukumoto Y, Shimabukuro K, Matsuno Y. Aortic arch repair for Stanford type A aortic dissection with distal anastomosis to the proximal level of the distal aortic arch. J Thorac Cardiovasc Surg 2003;126:415-419.

[9] Guilmet D, Bachet J, Goudot B, Dreyfus G, Martinelli GL. Aortic dissection: anatomic types and surgical approaches. J Cardiovasc Surg 1993;34:23-32.

[10] Bergeron P, Coulon P, De Chaumaray T, Ruiz M, Mariotti F, Gay J, Mangialardi N, Costa P, Serreo E, Cavazzini C, Tuccimei I. Great vessel transposition and aortic arch exclusion. J Cardiovasc Surg 2005;46:141147.

eComment: Perfusion of the true lumen during surgery for aortic dissection

Authors: Salvatore Lentini, Cardiac Surgery Unit, University of Messina, Messina, Italy; Marcello Savasta, Francesco Monaco, Roberto Gaeta doi:10.1510/icvts.2008.189878A

We read with interest the paper of Gobolos and co-workers [1], and we congratulate the authors for this precise technique.

Retrograde perfusion via the femoral artery has been the perfusion mode of choice in aortic dissection surgery. However, many groups have moved to routine axillary artery cannulation to avoid potential malperfusion and atheroembolic complications associated with retrograde perfusion. However, in cases of hemodynamic instability, the axillary approach is time-consuming. We also have to consider that sometimes the dissection may extend to the innominate artery, with difficulties in the cannulation. Furthermore, even with axillary cannulation and antegrade perfusion, due to the presence of internal flap, there may be a malperfusion syndrome during cardiopulmonary bypass (CPB). This is usually due to the presence of multiple flaps inside the dissected aorta. Alternately, Wada and colleagues [2] reported good results with transapical left ventricular cannulation across the aortic valve into the true lumen guided by transesophageal echocardiography. Jakob and coworkers [3] reported the use of an open direct cannulation of the ascending aorta after exanguination of the patient through the venous line.

All those techniques share together an important point: the importance of true lumen perfusion. We should consider that aortic dissection is an acute disease with often rapid progression. Areas of intact aorta during the diagnosis by CT scan may result dissected at the time of surgery. The dissection may progress, and new intimal tears with new flaps may be present. Cannulation sites thought to be appropriate at the moment of diagnosis may later result insufficient to give an appropriate perfusion for the presence of new flaps. Malperfusion with low flow during CPB will prolong the time to reach the temperature chosen for the circulatory arrest and will predispose to malperfusion of vital organs and incidence of acidosis. The cannulation and perfusion of the true lumen appear then of vital importance.

We had a case where we used a technique similar to the one used by Gobolo. We would add that really, in our case, there was no need to cannulate near the Botallos ligament, and that the ascending aorta or the arch, even if dissected, may be cannulated using the Seldinger technique and ultrasound control.

In conclusion, we congratulate again the authors and we look forward to using this technique in particular clinical settings to further improve it.

\section{References}

[1] Gobolos L, Philipp A, Foltan M, Wiebe K. Surgical management for Stanford type A aortic dissection: direct cannulation of real lumen at the level of the Botallo's ligament by Seldinger technique. Interact CardioVasc Thorac Surg 2008;7:1107-1109.

[2] Wada S, Yamamoto S, Honda J, Hiramoto A, Wada $H$, Hosoda $Y$ Transapical aortic cannulation for cardiopulmonary bypass in type A aortic dissection operations. J Thorac Cardiovasc Surg 2006;132:369372.

[3] Jakob H, Tsagakis K, Szabo A, Wiese I, Thielmann M, Herold U. Rapid and safe direct cannulation of the true lumen of the ascending aorta in acute type A aortic dissection. J Thorac Cardiovasc Surg 2007;134: 244-245. 
1[ 
Received: 2014.04.05

Accepted: 2014.08.10

Published: 2014.11.22

\section{Central Cannulation by Seldinger Technique: A Reliable Method in Type A Aortic Dissection Repairs}

Authors' Contribution: Study Design A Data Collection B Statistical Analysis C Data Interpretation D Manuscript Preparation E Literature Search F Funds Collection $G$
ABCDEF 1,2 Laszlo Göbölös

CE 3 Peter Ugocsai

BDE 1 Maik Foltan

ABD 1 Alois Philipp

B 1 Andrea Thrum

EF 2 Szabolcs Miskolczi

EF 2 Pietro G. Malvindi

E 2 Vincenzo di Gregorio

E 2 Dimitrios Pousios

EF 2 Manoraj Navaratnarajah

ADEF 2 SUnil K. Ohri
Corresponding Author: Source of support:
1 Department of Cardiothoracic Surgery, University Hospital Regensburg, Regensburg, Germany

2 Department of Cardiothoracic Surgery, University Hospital Southampton NHS Trust, Southampton, United Kingdom

3 Institute for Clinical Chemistry and Laboratory Medicine, University Hospital Regensburg, Regensburg, Germany

Background: Extensive type A aortic dissections that involve peripheral great vessels can complicate the choice of a cannulation site for cardiopulmonary bypass. We started to employ direct cannulation of the true lumen on the concavity of the aortic arch by Seldinger technique and evaluated the efficacy of this access technique as an alternative arterial inflow target in aortic surgery.

Material/Methods: Twenty-four consecutive patients (mean age: 59 \pm 14 years) underwent type A aortic dissection repair using selective antegrade cerebral perfusion. Direct aortic cannulation was used in 14 cases, subclavian access in 6 patients, and femoral entry in 4 patients. Perioperative factors were evaluated to identify the reliability and eventual benefits of direct cannulation method at the aortic arch.

Results: There were no operative deaths and cumulative 30 -day mortality rate was $25 \%$ (6). Permanent neurological deficits were not observed; in 1 patient transient changes occurred (4\%). Time to reach circulatory arrest was the shortest in the direct access group, with mean $27 \pm 11$ (Cl: 20.6-33.3) min vs. $43 \pm 22(28.0-78.0) \min (p=0.058)$ and $32 \pm 8(23.6-40.4) \min (p=0.34)$ by femoral cannulation and subclavian entry, respectively. Direct arch cannulation resulted in the best renal function in the first $72 \mathrm{~h}$ after surgery and similar characteristics were observed in lactic acid levels.

Conclusions: Ultrasound-guided direct cannulation on the concavity of the aortic arch using a Seldinger technique is a reliable method in dissection repairs. Prompt antegrade perfusion provides not only cerebral but also peripheral organ and tissue protection, which is an advantage in this high-risk group of patients.

MeSH Keywords: Aortic Aneurysm • Aortic Diseases • Hemodynamics • Tissue Preservation

Full-text PDF: http://www.medscimonit.com/abstract/index/idArt/890813

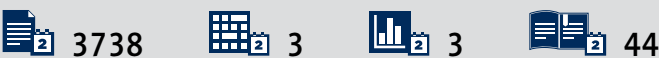




\section{Background}

Acute Stanford type A dissection, with or without involvement of the aortic arch, is a clinical emergency that requires immediate surgical intervention. Despite remarkable achievements by Cooley [1], DeBakey [2], Alley [3], and Bahnson [4], surgery of the aortic arch remains a high-risk intervention. Surgical therapy today consists mainly of an interposition graft replacement of the ascending aorta. When indicated, this may be extended to include aortic arch replacement; usually as a hemiarch replacement or, when required, total arch replacement. Acute aortic valve insufficiency, when present, is generally treated by valve resuspension or replacement. Mortality rates of these operations have dramatically improved as the result of recent advances in preoperative preparation, intraoperative techniques, and postoperative care [5]. Nevertheless, operations for acute type $A$ dissections are still associated with a relatively high rate of mortality and postoperative morbidity compared to routine heart surgery [6].

In patients undergoing aortic surgery, especially with involvement of the aortic arch, perioperative stroke and death can be precipitated by either dislodgement of atherosclerotic debris from the aortic wall or organic malperfusion. Cardiopulmonary bypass (CPB) via axillary/subclavian artery has become popular as an alternative perfusion site in recent years, predominantly for acute aortic dissections and patients with severe aortic atherosclerosis [7-13]. Despite several advantages of axillary/subclavian artery cannulation (e.g., antegrade perfusion of the aorta), problems and complications of this technique are becoming increasingly recognized with more frequent use of this approach. Axillary/subclavian artery inflow may not be suitable for rapid establishment of antegrade perfusion in cases with hemodynamic instability, because it requires more time for preparation prior to cardiopulmonary bypass. In patients with a small body surface area, limitation of pump flow due to a narrow axillary artery may be a concern $[14,15]$.

However, cannulation for extensive aortic lesion in type A aortic dissection can present an enormous challenge, either through axillary/subclavian or lower limb arteries, if they are involved in the pathological process $[12,16,17]$. In light of problems associated with the above cannulation techniques, we started to use an innovative ultrasound-guided entry method on the usually uninvolved aortic wall segment on the concavity of the aortic arch via Seldinger technique. This aortic wall segment at the ligamentum arteriosum is not completely identical to the vast majority of the aorta, because it contains more connective tissue as a remnant of the ductus arteriosus; also, coarctations are located here due to this exclusive histological background. This relative rigidity can play a role in preventing dissections in the area and therefore providing an ideal point for arterial cannulation without purse-string stitches. As this aortic area allows easy landing into the true lumen at cannulation, the rest of the configuration of the aortic dissection is not important for perfusion. With the aid of preoperative CT scan for planning the cannulation spot and continuous intraoperative transesophageal ultrasound (TEE) guidance throughout the direct cannulation procedure of the diseased aorta, we achieved prompt antegrade perfusion to repair the involved ascending aorta and aortic arch, and subsequently evaluated its safety and efficacy.

\section{Material and Methods}

Within a period of 2.5 years, 24 consecutive patients (mean age: 59 \pm 14 years, $\mathrm{Cl}$ : 53.0-64.8, 17 men and 7 women) underwent operations on the thoracic aorta. In all patients, a standard operative technique for acute aortic dissection was used and the only difference in surgical strategy was the choice of site for arterial cannulation. Direct cannulation by Seldinger technique was used in 14 patients (57\%), subclavian access in 6 patients (25\%), and femoral entry in 4 patients $(17 \%)$. Further preoperative data is provided in Table 1.

The preoperative diagnosis was established on the basis of emergency computed tomography with additional intraoperative transesophageal echocardiography in all patients. Aortography or coronary angiography was not performed for preoperative evaluation.

Table 1. Demographic and preoperative data. Significance calculations are given as comparisons to the group with direct cannulation.

\begin{tabular}{|c|c|c|c|}
\hline Characteristics & Direct & Subclavian & Femoral \\
\hline No. of patients & 14 & 6 & 4 \\
\hline Male & 8 & 6 & 3 \\
\hline Female & 6 & 0 & 1 \\
\hline Age (years (median)) & $65 \pm 10(66)$ & $51 \pm 17$ (49) $[$ N.S. $p=0.11]$ & $51 \pm 13(46)[$ N.S. $p=0.13]$ \\
\hline Hypertension & 13 & 5 & 3 \\
\hline Preoperative ventilated & 4 & 4 & 3 \\
\hline Preoperative renal insufficiency & 2 & 2 & 0 \\
\hline
\end{tabular}




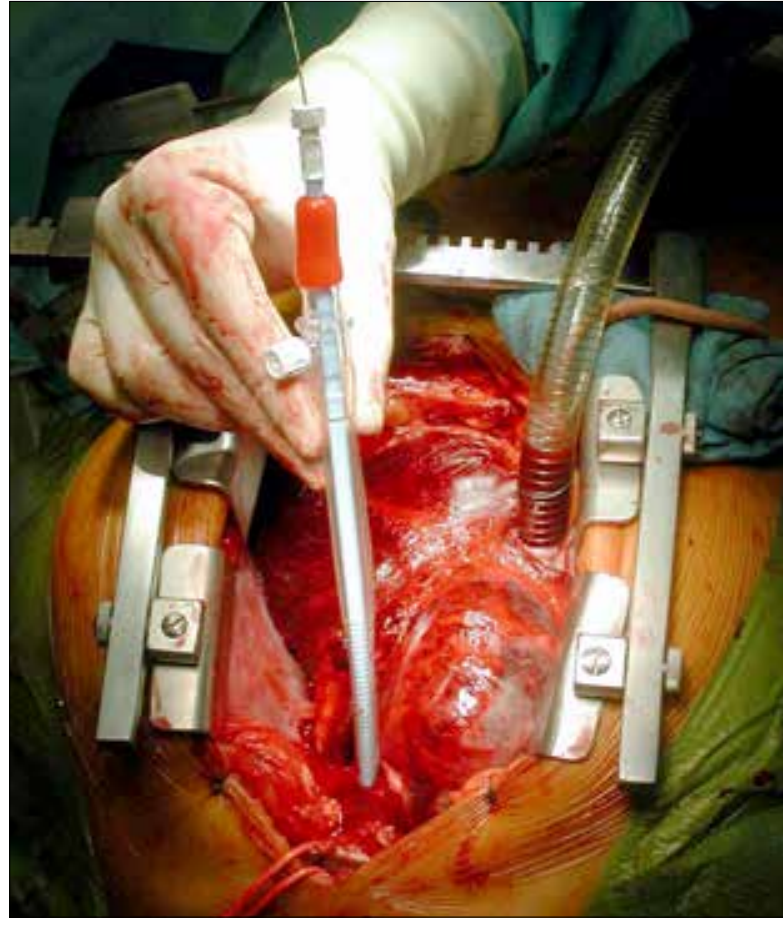

Figure 1. Direct aortic cannulation via Seldinger technique.

The standard operative technique for aortic dissection repair at our institution has been graft replacement of the ascending aorta and proximal aortic arch. Inspection of the supraaortic vessels was always carried out to decide whether to perform a concomitant island transposition, depending on the supraaortic status. The patient was placed in the standard supine position. The arms were horizontal beside the body as for the usual cardiac procedure. Monitoring of arterial pressure was performed by placing 3 lines routinely in both radials and the right femoral artery.

The ascending aorta and aortic arch were exposed through a median sternotomy. The approach of concavity of the aortic arch at level of Botallo's ligament (ligamentum arteriosum) was followed by a minimally invasive cannulation with dilation steps by Seldinger technique (Fem-Flex Femoral Arterial Cannula ${ }^{\circledR}$, 24 Fr TFA 02425H Edwards Lifesciences LLC, Irvine, USA; Joline Special Dilatatorset ${ }^{\circledR}$, Hechingen, Germany) (Figure 1). As previously described, no purse-string sutures are required in this area; the arterial line is fixed with a stitch to the cranial sternotomy skin incision corner to avoid accidental dislocation. Correct position of the guide wire and cannula in the aorta was routinely confirmed by TEE, or by epiaortic ultrasound in rare cases of technical difficulty with TEE. The same type of cannula was inserted in both peripheral access sites. CPB was instituted between the arterial cannulation site and right atrium. The patient was cooled to a tympanic temperature of $19-20^{\circ} \mathrm{C}$ (Mon-a-therm ${ }^{\circledR}$ Thermistor YSI 400 Series tympanic temperature probe, Mallinckrodt Inc., St. Louis, USA). Rectal (Thermocouple probe, Mallinckrodt Medical, USA) and bladder
(Curity ${ }^{\circledR}$, Degania, Israel) temperatures were also followed-up simultaneously throughout the procedures. After cross-clamping, an ascending aortic incision was made and antegrade crystalloid cardioplegic solution (2000 ml Custodiol ${ }^{\circledR}$ HTK-Solution by Brettschneider, Dr. F. Köhler Chemie, Hähnlein, Germany) was administered proportionally through both coronary orifices. During deep hypothermic circulatory arrest (HCA), selective antegrade cerebral perfusion (SACP) was applied via the carotid arteries (DLP Retrograde Coronary Sinus Perfusion Cannula with manual Inflating Cuff ${ }^{\circledR}$, Medtronic Inc., Minneapolis, USA) at a flow rate adapted to keep a constant cerebral $\mathrm{O}_{2}$ saturation on each side, providing a perfusion pressure of 35-40 $\mathrm{mmHg}$. Cerebral monitoring was performed with near infrared spectroscopy $\left(\right.$ INVOS $^{\circledR}$ cerebral oximeter, Somanetics Inc., Troy, USA), and brain tissue oxygen saturation measured 65$70 \%$ continuously during perfusion, which corresponded to the induction values.

Reconstruction of the aorta was done with a woven Dacron side-branched vascular prosthesis (Hemashield Platinum Woven Double Velour Vascular Graft ${ }^{\circledR}$, Boston Scientific Inc., Wayne, USA) including the island-type reinsertion of all supraaortic vessels, if applicable. The false lumen was eradicated with $45 \%$ bovine serum albumin-10\% glutaraldehyde glue (BioGlue ${ }^{\circledR}$, Cryolife International Inc., Kennesaw, USA); aortic valve commissures were refixed with the resuspension suture technique. The valve was replaced if it appeared diseased. Composite valve graft replacement was applied in patients with Marfan syndrome or if intraoperatively severe local involvement of the aortic wall could be observed. The decision whether to implant a composite graft did not depend on the maximal diameter of the aortic root, but rather was based on the presence of Marfan syndrome or the severity of wall destruction. Systemic reperfusion and rewarming was started through the graft side-branch. The summary of performed surgical procedures is presented in Table 2.

\section{Statistical analysis}

Statistical analysis was performed using SPSS v15.0 software (IBM Corporation, Armonk, New York, USA). For graphic demonstration, Microsoft Excel $2007^{\circledR}$ (Microsoft Corporation, Redmond, Washington, USA) was used.

For statistical comparisons of the groups, the Mann-Whitney $U$ test and chi-square test. Although the number of cases in 2 groups (femoral cannulation and subclavian approach) was relatively low ( 4 and 6 cases, respectively), we considered a p-value $<0.05$ to be significant to enhance the statistical power of the comparisons. Where appropriate, confidence interval $(\mathrm{Cl})$ was calculated with a confidence level of $95 \%$. Data are presented as mean values $\pm \mathrm{SD}$ and, where applicable, the corresponding $\mathrm{Cl}$ is in parentheses. 
Table 2. Surgical procedures.

\begin{tabular}{|cccc|}
\hline Surgical procedure & Direct & Subclavian & Femoral \\
\hline Ascending aorta + hemi arch & 13 & 6 & 4 \\
\hline Ascending aorta + total arch & 1 & $*$ & $*$ \\
\hline${ }^{\circ}$ David reconstruction & 1 & 1 & 1 \\
\hline${ }^{\circ}$ Yacoub reconstruction & 2 & 3 & 1 \\
\hline${ }^{\circ}$ Bentall procedure & 2 & 1 & $*$ \\
\hline${ }^{\circ}$ Coronary bypass grafting & 2 & $*$ \\
\hline
\end{tabular}

- Marks an additional procedure of aortic graft implantation.

Table 3. Intraoperative data. Significance calculations are given as comparisons to the group with direct cannulation.

\begin{tabular}{|c|c|c|c|c|c|c|}
\hline \multirow{2}{*}{ Intraoperative data } & \multicolumn{2}{|c|}{ Direct } & \multicolumn{2}{|c|}{ Subclavian } & \multicolumn{2}{|c|}{ Femoral } \\
\hline & \multicolumn{6}{|c|}{ Mean \pm SD (median) } \\
\hline Time to HCA (min) & $27 \pm 11$ & $(26)$ & $32 \pm 8$ & $(31)$ & $43 \pm 22$ & (48) \\
\hline CPB time (min) & $181 \pm 77$ & $(149)$ & $188 \pm 32$ & $(193)$ & $180 \pm 52$ & (200) \\
\hline HCA time (min) & $51 \pm 20$ & $(52)$ & $51 \pm 22$ & $(50)$ & $53 \pm 31$ & (48) \\
\hline SACP time (min) & $39 \pm 18$ & (39) & $36 \pm 24$ & $(25)$ & $41 \pm 29$ & (31) \\
\hline SACP flow right start $(\mathrm{ml} / \mathrm{min})$ & $201 \pm 41$ & $(200)$ & $218 \pm 52$ & $(200)$ & $258 \pm 59$ & $(250)$ \\
\hline SACP flow right end $(\mathrm{ml} / \mathrm{min})$ & $196 \pm 37$ & $(185)$ & $282 \pm 56$ & $(300)$ & $350 \pm 54$ & (330) \\
\hline SACP flow left start $(\mathrm{ml} / \mathrm{min})$ & $216 \pm 54$ & $(205)$ & $243 \pm 99$ & $(275)$ & $240 \pm 37$ & $(240)$ \\
\hline SACP flow left end (ml/min) & $227 \pm 68$ & $(220)$ & $283 \pm 49$ & $(300)$ & $275 \pm 64$ & (275) \\
\hline Tympanic temperature minimum & $20.8 \pm 0.9$ & $(20.8)$ & $19.5 \pm 1.0$ & $(19.7)$ & $20.8 \pm 0.3$ & $(20.9)$ \\
\hline Rectal temperature minimum & $26.9 \pm 3.3$ & $(27.3)$ & $26.8 \pm 4.3$ & $(27.6)$ & $26.0 \pm 2.3$ & $(26.0)$ \\
\hline Urinary bladder temperature minimum & $26.0 \pm 4.8$ & $(25.6)$ & $24.8 \pm 3.4$ & $(24.8)$ & $23.8 \pm 2.3$ & $(23.7)$ \\
\hline
\end{tabular}

HCA - hypothermic circulatory arrest; CBP - cardiopulmonary bypass; SACP - selective antegrade cerebral perfusion.

\section{Results}

There were no intraoperative deaths; cumulative 30-day mortality rate was $25 \%$ (6) for the entire patient population; 3 of $14(21 \%)$ in the direct group, 2 of $6(33 \%)$ in the subclavian group, and 1 of $4(25 \%)$ in the femoral cannulated group $(p=0.24$ and $p=0.46$, respectively), all due to multiorgan failure. Direct aortic cannulation was safely performed in all cases and there was no need to switch to an alternative cannulation site. The adventitia of the dissected aorta was firm enough to support the cannula inserted by Seldinger technique with staged dilatators, and there was no case of complicated local massive hemorrhage at the cannulation site. No malperfusion or apparent thromboembolism due to cannulation was observed. Malperfusion would have been anticipated if a cerebral saturation difference of $10 \%$ occurred compared to preoperative values and/or if there was a pressure difference between the peripheral arteries greater than $20 \mathrm{mmHg}$. Permanent neurological deficits were not present. Transient changes occurred in 1 patient (4\%) in the direct group. Because the Seldinger technique was easier and quicker to apply than the peripheral approaches (Table 3) and it showed certain advantages in the preliminary results, we permanently changed our cannulation method to the direct aortic entry in all patients. The transesophageal echo guidance was useful for aortic cannulation along with color Doppler imaging, which provided realtime information about the true lumen antegrade perfusion.

Mean extracorporeal perfusion duration was $183 \pm 63$ min (156.4-209.6) and mean time to reach circulatory arrest was $28 \pm 14$ (23.1-34.9) $\mathrm{min}$ in the entire cohort, with no significant differences between groups (Table 3 ). Initial SACP flow was comparable in all 3 groups, but we observed a significant difference between the SACP flow required to maintain 


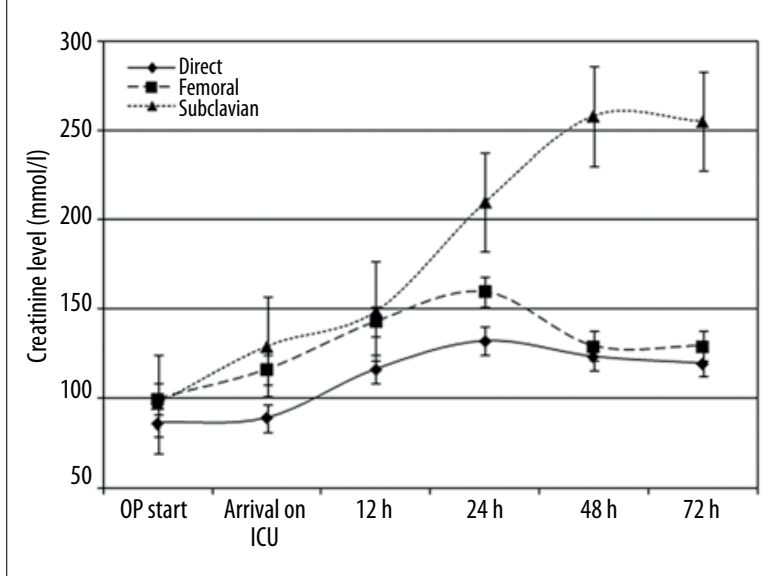

Figure 2. Changes in creatinine levels with different cannulation methods.

the initial cerebral saturation at constant blood pressure at the end of the perfusion period between the direct cannulation group (right: $196 \pm 37 \mathrm{ml} / \mathrm{min}$ [177.3-227.4]; left: $227 \pm 68$ $\mathrm{ml} / \mathrm{min}$ [184.8-247.2]) and both the femoral entry group (right: $350 \pm 54 \mathrm{ml} / \mathrm{min}$ [264.1-435.9] [ $\mathrm{p}=0.006$ ]; left: $275 \pm 64 \mathrm{ml} / \mathrm{min}$ [173.2-376.8] [p=0.24]) and the subclavian access group (right: $282 \pm 56 \mathrm{ml} / \mathrm{min}$ [223.2-340.8] [p=0.02]; left: $283 \pm 49 \mathrm{ml} / \mathrm{min}$ [231.6-334.4] [p=0.05]) in favor of the direct cannulation. Further intraoperative data were evaluated to identify the reliability and benefits of direct cannulation method (Table 3).

Time required to reach circulatory arrest was the shortest in the direct access group, with mean $27 \pm 11(20.6-33.3) \mathrm{min}$; in the femoral cannulation group it was $43 \pm 22(28.0-78.0)$ $\min (p=0.058)$; and in the subclavian entry group it was $32 \pm 8$ (23.6-40.4) $\min (p=0.34)$.

Direct arch cannulation resulted in the best renal function on the first postoperative day, with a creatinine level of mean $140 \pm 48 \mathrm{mmol} / \mathrm{L}$ (112.3-167.7); the femoral entry showed $179 \pm 79 \mathrm{mmol} / \mathrm{L}(53.4-304.6 ; p=0.08)$; at subclavian access $199 \pm 69 \mathrm{mmol} / \mathrm{L}(89.3-308.7 ; p=0.25)$. Although comparison of creatinine levels in the direct cannulation group and the other 2 approaches shows the clear superiority of the direct cannulation technique, the differences did not reach the level of significance due to a relatively low number of patients in the subclavian access and femoral entry groups. Figure 2 demonstrates the plasma creatinine levels during the first postoperative 72 hours. Two of the direct and 2 of the subclavian cannulated patients were excluded from the statistical analysis due to preoperative renal impairment. Similar characteristics could be observed in lactic acid levels in the intensive care unit as a marker of preoperative global ischemia (Figure 3). Four of the direct, 1 of the femoral, and 2 of the subclavian perfused patients were not considered for statistical analysis due to an initial lactic acid level over $2 \mathrm{mmol} / \mathrm{l}$.

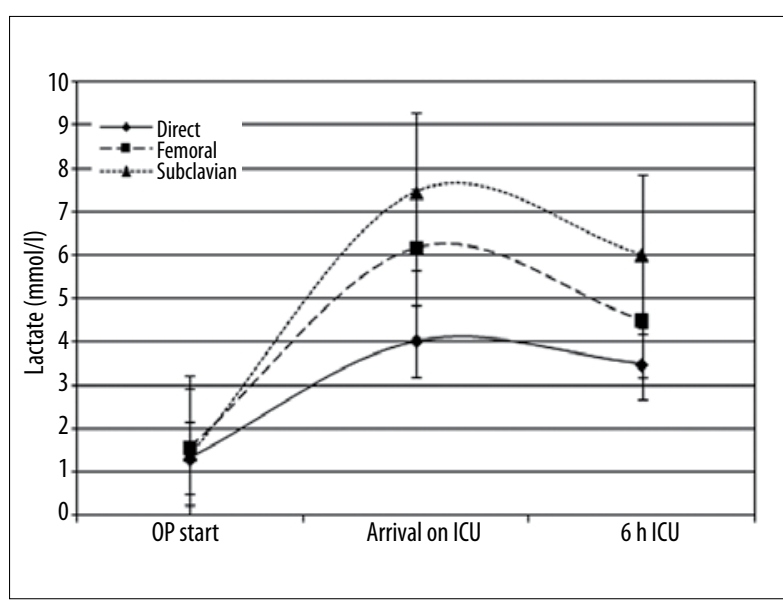

Figure 3. Lactate mirror of the 3 perfusion groups.

Treatment duration in the intensive care unit (ICU) of over 5 days occurred in 5 of 14 (36\%) patients in the direct group, 4 of $6(66 \% ; p=0.21)$ in the subclavian group, and 2 of $4(50 \%$; $\mathrm{p}=0.51$ ) in the femoral cannulated patients.

\section{Discussion}

Our study demonstrates that direct cannulation on the concavity of the aortic arch instead of the femoral or right subclavian artery may improve the results of ascending aorta and aortic arch replacement. However, this was an observational study because the 3 groups were not balanced.

Although the idea of cannulating ascending aorta in type A aortic dissection was described decades ago [18,19], direct cannulation to the ascending aorta has only been performed occasionally as an emergency technique to avoid retrograde malperfusion [20]. Recently, successful attempts have been made to establish antegrade perfusion via the ascending aorta primarily for type A dissections [21-23]. Ascending aorta or arch cannulation may have the great advantage of technical simplicity, especially when there is hemodynamic instability or at dissected limb arteries [24-27]. According to these reports, this technique can be performed safely under ultrasound guidance. Establishing an access point at the level of Botallo's ligament by Seldinger technique could provide a useful alternative to establish rapid arterial entry. At this section of the aorta the pulmonary bifurcation is firmly connected by massive connective tissue, which usually prevents complete dissection in this area. With the aid of this rapid and atraumatic cannulation method, CPB can be established, thereby reducing the likelihood of perioperative shock, which would lead to an increased mortality [28]. Although the time to reach circulatory arrest was remarkably lower using the direct cannulation technique compared to the other 2 accession methods, the level of significance was not reached because of the 
relatively low number of patients in the other 2 groups and greater standard deviation values.

Rapid establishment of arterial access facilitates quicker initiation of antegrade systemic perfusion and core cooling, which also reduces the duration of the surgical procedure. This may also contribute to lower morbidity through enhanced organ perfusion and reducing the probability of coagulation disorders. Our method of aortic cannulation has additional advantages. The benefit of this type of arch cannulation is combined with having the tip of the cannula located in the proximal descending aorta. Consequently, the turbulence at the tip of the cannula occurs in the descending aorta, thereby reducing the risk of embolization of debris into the carotid arteries. A further advantage of proximal descending aortic perfusion is the reduction of the fluid jet stream - Coanda's effect - which can be associated with relative carotid hypoperfusion in patients undergoing perfusion with a short cannula from the ascending aorta [29]. Most patients who have a type A aortic dissection undergo at least a hemiarch replacement in our practice, so the cannulations site is removed with the affected aortic wall segment, and the repositioned cannula fits perfectly into the side-branched prosthesis.

In addition, transesophageal or epiaortic ultrasonographic guidance may also be indispensable for reliable real lumen cannulation, examinations of which are simple methods to obtain imaging information of the ascending aorta and proximal arch. Although preoperative CT scan is mandatory to obtain correct operative planning, the ultrasonographic control provides real-time information on the location of intimal tear, intimal flap, true and false lumen, because this intraluminal situation can change progressively following the CT scan. Moreover, the guide wire and the correct position of the cannula can be checked continuously, avoiding false lumen perfusion, which is not the case with the peripheral approaches. The simultaneous application of ultrasonographic control and cerebral monitoring by near infrared spectroscopy reduces the likelihood of malperfusion, thromboembolism, and subsequent extension of the false lumen. We have observed no local complications with the Seldinger technique, but were always prepared to perform an apical cannulation described by Wada et al. [30] as a bail-out procedure.

The problem of neurological injury resulting from embolic events and cerebral malperfusion in aortic dissections should be discussed because there are a number of different cannulation approaches. Femoral cannulation is associated with a higher risk of retrograde embolization and potential perfusion of the false lumen via the distal re-entry point; although in our cohort there were no perfusion complications in this group. In this respect, techniques providing antegrade flow may offer a better option, especially in patients with Stanford A dissections [5].
In our practice, Seldinger cannulation on the concavity of the aortic arch has become the standard approach for arterial access in both elective and emergency cases as by the Hannover group [22,31]. This cannulation technique is fast and simple, which can be important, especially in hemodynamically unstable patients. It avoids additional time-consuming incisions, thereby avoiding additional surgical trauma and possible local complications at peripheral cannulation sites. In combination with cold selective antegrade cerebral perfusion and deep/moderate hypothermic circulatory arrest, this technique allows adequate protection for the body and is not associated with higher risk of cerebral microemboli [32,33]. The effectiveness of selective antegrade cerebral perfusion as an adjunct to hypothermic arrest has been proven in numerous studies [34,35].

As with other surgical approaches, there are some disadvantages that need to be recognized. This includes cannulation of the false lumen with potential malperfusion or even complete rupture of the cannulated aorta. For those emergency situations, alternative strategies have to be available. In the above-mentioned cases there are basically 3 major goals to be achieved: cerebral protection, myocardium conservation, and proper perfusion of the lower body. This stepwise approach necessitates the cooperation of the anesthesiologist, perfusionist, and surgeon to obtain optimal results.

Reece et al. applied the Seldinger technique for cannulation in 24 patients, resulting in no misplacement [36], but the study was not randomized and various aortic pathologies were excluded, leading to potential selection bias. Furthermore, the cannula is held in position manually during the cooling phase, preventing further surgical activity during this period; the authors are not convinced that sutures in the dissected aorta remain stable. With our technique there is no need for sutures in the aorta; the cannula is fixed to the cranial skin incision corner by a suture and situated deep enough in the proximal descending aorta to not require any further support. Inoue et al. report on 32 cases using the Seldinger technique, controlled by epiaortic ultrasound. Prior to ascending aortic cannulation, they cannulated the femoral artery to be able to regulate the aortic pressure [26]. Although no malperfusion occurred in their series, the double arterial approach is questionable in the context of avoiding time-consuming preparations and potential retrograde embolism or further dissection [37].

Transapical cannulation is another elegant method for achieving reliable antegrade access, as described by Wada et al. [30]. In a large cohort of 138 patients, the cannula was inserted through a $1-\mathrm{cm}$ apical incision directly into the true lumen via the aortic valve under TEE guidance. The impact of causing an acute aortic insufficiency in this context has not been discussed in detail. Both Wada's technique and Reece's method have the disadvantages of resulting in prolonged cardiopulmonary 
bypass times because no additional procedures can be performed during cooling, such as inspection and preparation of the aortic root.

Axillary/subclavian cannulation is also an elegant, widely used method for arterial access during aortic arch surgery [16]. However, it is presumably more time consuming, and carries the possibility of failure rates up to $4.2 \%$. Nevertheless, it provides the possibility of continuous unilateral blood flow without interruption [38]. Applying the standard technique, however, only the right hemisphere is continuously perfused, which can result in malperfusion of the contralateral hemisphere; Merkkola et al. demonstrated that up to $17 \%$ of the patients have an incomplete circle of Willis [39]. Even in the presence of a complete circle of Willis, it is still unclear if the exclusively right-sided perfusion can sufficiently supply the left hemisphere. Our results with SACP also demonstrate that the lowest perfusion volume is necessary to maintain the proper bilateral cerebral oxygenation in the direct cannulated group. Since the brachiocephalic trunk divides anatomically into 2 nearly equivalent branches - the right carotid and subclavian artery - the provided flow through the latter vessel on CPB can lead to a relative hyperperfusion of the right carotid parallel to a relative hypoperfusion of the aorta. This could explain our findings regarding SACP flow values and peripheral organic perfusion monitored by the renal function and lactate level. The Seldinger technique delivers rapid arterial access, which results in a shorter cerebral and peripheral ischemic periods. Subclavian perfusion provides sufficient oxygenation for the right hemisphere but may not for the contralateral side, so the required initial right SACP flow is similar to the direct group, but the left shows values similar to the femoral group. Additionally, the constant relative hyperperfusion of the right hemisphere most probably leads to an intracerebral edema, which elevates the SACP flow requirements to maintain a proper cerebral saturation at the end of HCA. The relative hypoperfusion of the body is characterized by diminished renal function at subclavian cannulation. In the subclavian approach, smaller cannulas can usually be applied due to the anatomical situation. The femoral access takes more time to establish, resulting in relative cerebral hypoperfusion/longer ischemic period shown by the higher initial SACP flow requirements in this group. The femoral perfusion, in case of no malperfusion, provides a good

\section{References:}

1. Cooley DA, DeBakey ME: Surgical resection of intrathoracic aneurysms of the aorta and great vessels. Ann Surg, 1952; 135: 660-80

2. DeBakey ME, Cooley DA, Creech O Jr: Surgical considerations of dissecting aneurysm of the aorta. Ann Surg, 1955; 142: 586-612

3. Alley RD, Stranahan A, O'Hern J et al: Use of heterologous vascular shunts in excisional therapy of aneurysms of the thoracic aorta: Report of a case. Trans Am Coll Cardiol, 1955; 5: 158-75

4. Bahnson HT: Considerations in the excision of aortic aneurysms. Ann Surg, 1953; 138: 377-86 renal blood supply, thus the renal function is better preserved than with subclavian access, but the initial hypoxia due to delayed establishment of perfusion is clear when comparing the creatinine levels in this group to the direct cohort.

Moizumi et al. could not use axillary artery access in $5.5 \%$ of their aortic dissection cohort, because the pathological changes extended into the axillary artery [40]. Our first experience with Seldinger technique was in a patient with dissection in all limb arteries [25]. Carotid artery cannulation, performed by Urbanski in 100 patients, including 27 with Stanford A dissections, seems to be another alternative method, but also carries the risk of brain malperfusion and later complications in the vessel [41]. The report on innominate artery cannulation by Di Eusanio et al. included 55 patients, with only 2 in acute aortic dissections [42]. Fusco at al presented their results in femoral artery cannulation in 2004 [43]. With a conversion rate of $2.5 \%$ to ascending aortic cannulation, they conclude that femoral cannulation is appropriate and yields excellent clinical results, but they did not consider the problem of retrograde embolism from the downstream aorta, probably because in their experience arteriosclerosis is less common in dissection patients.

\section{Conclusions}

Our study has some important limitations. It was an observational study without randomization and presents preliminary experience with a small number of patients. These good preliminary results have to be confirmed by further studies in a larger group of patients.

In conclusion, arterial access for establishing CPB, especially in patients requiring repair of acute type $A$ aortic dissection, is a controversial subject in the current literature [44]. Minimal invasive central cannulation by Seldinger on the concavity of the aortic arch is technically feasible and safe. It may avoid cerebral embolization and organ malperfusion, and thus may reduce the rate of neurological and malperfusion complications. This alternative arterial inflow technique can be applied for prompt establishment of CPB in type A dissections, especially during hemodynamic instability.

5. Svensson LG, Blackstone EH, Rajeswaran J et al: Does the arterial cannulation site for circulatory arrest influence stroke risk? Ann Thor Surg, 2004; 78: 1274-84

6. Ehrlich MP, Ergin MA, McCullough JN et al: Results of immediate surgical treatment of all acute type A dissections. Circulation, 2000; 102: 248-52

7. Schachner T, Vertacnik K, Laufer G, Bonatti J: Axillary artery cannulation in surgery of the ascending aorta and the aortic arch. Eur J Cardiothorac Surg, 2002; 22: 445-47 
8. Yavuz S, Gönzü MT, Türk T: Axillary artery cannulation for arterial inflow in patients with acute dissection of the ascending aorta. Eur J Cardiothorac Surg, 2002; 22: 313-15

9. Whitlark JD, Goldman SM, Sutter FP: Axillary artery cannulation in acute ascending aortic dissections. Ann Thorac Surg, 2000; 69: 1127-29

10. Neri E, Massetti M, Capannini G et al: Axillary artery cannulation in type $A$ aortic dissection operations. J Thorac Cardiovasc Surg, 1999; 118: 324-29

11. Schachner T, Laufer $G$, Vertacnik $K$ et al: Is the axillary artery a suitable cannulation site in aortic surgery? J Cardiovasc Surg, 2004; 45: 15-19

12. Pasic $M$, Schubel J, Bauer $M$ et al: Cannulation of the right axillary artery for surgery of acute type A aortic dissection. Eur J Cardiothorac Surg, 2003; 24: 231-36

13. Watanabe K, Fukuda I, Osaka M, Imazuru T: Axillary artery and transapical aortic cannulation as an alternative to femoral artery cannulation. Eur J Cardiothorac Surg, 2003; 23: 842-43

14. Schachner T, Nagiller J, Zimmer A et al: Technical problems and complications of axillary artery cannulation. Eur J Cardiothorac Surg, 2005; 27: 634-37

15. Sinclair MC, Singer RL, Manley NJ, Montesano RM: Cannulation of axillary artery for cardiopulmonary bypass: safeguards and pitfalls. Ann Thorac Surg, 2003; 75: 931-34

16. Strauch JT, Spielvogel D, Lauten A et al: Axillary artery cannulation: routine use in ascending aorta and aortic arch replacement. Ann Thor Surg, 2004; 78: 103-8

17. Reuthebuch 0 , Schurr U, Hellermann J et al: Advantages of subclavian artery perfusion for repair of acute type A dissection. Eur J Cardiothorac Surg, 2004; 26: 592-98

18. Robicsek F, Zimmern SH, Howe HR: Subintimal retrograde perfusion during repair of aortic dissection: potential cause of disaster. Ann Vasc Surg, 1988; 2: 298-302

19. Carey JS, Skow JR, Scott C: Retrograde aortic dissection during cardiopulmonary bypass: "nonoperative"management. Ann Thorac Surg, 1977; 24: 45-48

20. Borst HG, Laas J, Heinemann M: Type A aortic dissection: diagnosis and management of malperfusion phenomena. Semin Thorac Cardiovasc Surg, 1991; 3: 238-41

21. Lijoi A, Scarano F, Dottori V et al: Stanford type A aortic dissection. A new surgical approach. Tex Heart Inst J, 1998; 25: 68-77

22. Minatoya K, Karck M, Szpakowski E et al: Ascending aortic cannulation for Stanford type A acute aortic dissection: another option. J Thorac Cardiovasc Surg, 2003; 125: 952-53

23. Khaladj N, Shrestha M, Peterss S et al: Ascending aortic cannulation in acute aortic dissection type A: the Hannover experience. Eur J Cardiothorac Surg, 2008; 34: 792-97

24. Khoynezhad A, Plestis KA: Cannulation in the diseased aorta. Tex Heart Inst J, 2006; 33: 353-55

25. Göbölös L, Philipp A, Foltan M, Wiebe K: Surgical management for Stanford type A aortic dissection: direct cannulation of real lumen at the level of the Botallo's ligament by Seldinger technique. Interact Cardiovasc Thorac Surg, 2008; 6: 1107-9

26. Inoue $Y$, Ueda T, Taguchi S et al: Ascending aorta cannulation in acute type A aortic dissection. Eur J Cardiothor Surg, 2007; 31: 976-79
27. Inoue Y, Takahashi R, Ueda T, Yozu R: Synchronized epiaortic two-dimensional and color Doppler echocardiographic guidance enables routine ascending aortic cannulation in type $A$ acute aortic dissection. J Thorac Cardiovasc Surg, 2011; 141(2): 354-60

28. Girardi LN, Krieger KH, Lee LY et al: Management strategies for type A dissection complicated by peripheral vascular malperfusion. Ann Thorac Surg, 2004; 77: 1309-14

29. Salerno TA, Lince DP, White DN et al: Arch versus femoral artery perfusion during cardiopulmonary bypass. J Thorac Cardiovasc Surg, 1978; 76: 681-84

30. Wada S, Yamamoto S, Honda J et al: Transapical aortic cannulation for cardiopulmonary bypass in type A aortic dissection operations. J Thorac Cardiovasc Surg, 2006; 2: 369-72

31. Hagl C, Khaladj N, Karck M et al: Hypothermic circulatory arrest during ascending and aortic arch surgery: the theoretical impact of different cerebral perfusion techniques and other methods of cerebral protection. Eur J Cardiothorac Surg, 2003; 24: 371-78

32. Kamiya H, Hagl C, Kropivnitskaya I et al: The safety of moderate hypothermic lower body circulatory arrest with selective cerebral perfusion: a propensity score analysis. J Thorac Cardiovasc Surg, 2007; 133: 501-9

33. Kamiya H, Klima U, Hagl C et al: Cerebral microembolization during antegrade selective cerebral perfusion. Ann Thorac Surg, 2006; 81: 519-21

34. Hagl C, Khaladj N, Peterss S et al: Hypothermic circulatory arrest with and without cold selective antegrade cerebral perfusion: impact on neurological recovery and tissue metabolism in an acute porcine model. Eur J Cardiothorac Surg, 2004; 26: 73-80

35. Khaladj N, Peterss S, Oetjen P et al: Hypothermic circulatory arrest with moderate, deep or profound hypothermic selective antegrade cerebral perfusion: which temperature provides best brain protection? Eur J Cardiothorac Surg, 2006; 30: 492-98

36. Reece TB, Tribble CG, Smith RL et al: Central cannulation is safe in acute aortic dissection repair. J Thorac Cardiovasc Surg, 2007; 133: 428-34

37. Bachet J: Editorial comment: ascending aorta cannulation in acute type $A$ aortic dissection. Eur J Cardiothorac Surg, 2007; 31: 979-81

38. Panos A, Murith N, Bednarkiewicz M, Khatchatourov G: Axillary cerebral perfusion for arch surgery in acute type $A$ dissection under moderate hypothermia. Eur J Cardiothorac Surg, 2006; 29: 1036-39

39. Merkkola P, Tulla H, Ronkainen A et al: Incomplete circle of Willis and right axillary artery perfusion. Ann Thorac Surg, 2006; 82: 74-79

40. Moizumi Y, Motoyoshi N, Sakuma K, Yoshida S: Axillary artery cannulation improves operative results for acute type a aortic dissection. Ann Thorac Surg, 2005; 80: 77-83

41. Urbanski PP, Lenos A, Lindemann $Y$ et al: Carotid artery cannulation in aortic surgery. J Thorac Cardiovasc Surg, 2006; 132: 1398-403

42. Di Eusanio M, Ciano M, Labriola G et al: Cannulation of the innominate artery during surgery of the thoracic aorta: our experience in 55 patients. Eur J Cardiothorac Surg, 2007; 32: 270-73

43. Fusco DS, Shaw RK, Tranquilli $M$ et al: Femoral cannulation is safe for type A dissection repair. Ann Thorac Surg, 2004; 78: 1285-89

44. Gulbins $H$, Pritisanac A, Ennker J: Axillary versus femoral cannulation for aortic surgery: enough evidence for a general recommendation? Ann Thorac Surg, 2007; 83: 1219-24 
III 


\section{Reliability of different body temperature measurement sites during aortic surgery}

\author{
Perfusion \\ 2014, Vol 29(I) 75-8। \\ (c) The Author(s) 2013 \\ Reprints and permissions: \\ sagepub.co.uk/journalsPermissions.nav \\ DOI: $10.1177 / 02676591 \mid 3497228$ \\ prf.sagepub.com
}

(SSAGE

\title{
L Göbölös, ',3 A Philipp,' P Ugocsai, ${ }^{2}$ M Foltan,' A Thrum,' S Miskolczi, ${ }^{3}$ D Pousios, ${ }^{3}$ S Khawaja, ${ }^{3}$ M Budra ${ }^{3}$ and SK Ohri ${ }^{3}$
}

\begin{abstract}
Objective: We retrospectively performed a comparative analysis of temperature measurement sites during surgical repair of the thoracic aorta.

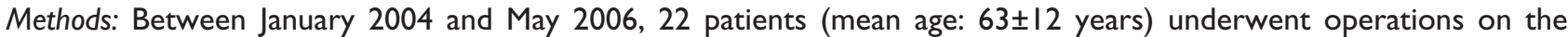
thoracic aorta with arterial cannulation of the aortic arch concavity and selective antegrade cerebral perfusion (ACP) during deep hypothermic circulatory arrest (HCA). Indications for surgical intervention were acute type A dissection in I 4 (64\%) patients, degenerative aneurysm in 6 (27\%), aortic infiltration of thymic carcinoma in I (4.5\%) and intra-aortic stent refixation in I (4.5\%). Rectal, tympanic and bladder temperatures were evaluated to identify the best reference to arterial blood temperature during HCA and ACP.

Results: There were no operative deaths and the 30-day mortality rate was I 3\% (three patients). Permanent neurological deficits were not observed and transient changes occurred in two patients (9\%). During re-warming, there was strong correlation between tympanic and arterial blood temperatures $(r=0.954 \mathrm{I}, \mathrm{p}<0.00 \mathrm{I})$, in contrast to the rectal and bladder temperature $(r=0.7654, p=n . s ; r=0.7939, p=$ n.s., respectively).

Conclusion: We conclude that tympanic temperature measurements correlate with arterial blood temperature monitoring during aortic surgery with HCA and ACP and, therefore, should replace bladder and rectal measurements.
\end{abstract}

\section{Keywords}

aortic surgery; temperature monitoring; antegrade cerebral perfusion; hypothermia; circulatory arrest; tympanic; rectal; bladder

\section{Introduction}

Accurate monitoring of the core temperature during aortic surgery, especially with the application of deep hypothermic circulatory arrest (HCA), is an important component of routine perioperative care. Preservation of neurological function is one of the main goals in such patients. Increasing the tolerance of the brain to ischaemia by the application of systemic hypothermia allows for a safe period of circulatory arrest and has remained the mainstay of neuroprotection for decades ${ }^{1,2}$ The safety of this procedure relies on adequate systemic cooling under strict control. If this control is incomplete or fails, neurological injury may occur during HCA.

Whereas hypothermia is neuroprotective, even mild hyperthermia is hazardous during cerebral ischaemia since it accelerates neuronal death. ${ }^{3-7}$ This results from oxygen free radical production, ${ }^{8}$ destabilization of the cytoskeleton, ${ }^{9}$ intracellular acidosis ${ }^{10}$ and increased blood-brain barrier permeability. ${ }^{11}$ Thus, to estimate the actual brain temperature, different sites are used for perioperative temperature measurements, e.g., urinary bladder, oesophagus, rectum and tympanic membrane. Body temperatures measured on these alternative sites may, however, substantially deviate from the actual cer-

\footnotetext{
'Department of Cardiothoracic Surgery, University Hospital Regensburg, Germany

${ }^{2}$ Institute for Clinical Chemistry and Laboratory Medicine, University Hospital Regensburg, Germany

${ }^{3}$ Department of Cardiothoracic Surgery, Southampton General Hospital, Southampton University Hospital Trust, UK
}

\section{Corresponding author:}

Laszlo Göbölös

Department of Cardiothoracic Surgery

Southampton General Hospital

Southampton University Hospital Trust

Southampton

Hants, UK.

Email: isartor@hotmail.com 
Table I. Preoperative patient characteristics.

\begin{tabular}{lc}
\hline Characteristics & \\
\hline No. of patients & 22 \\
Male & 12 \\
Female & 10 \\
Mean age in years \pm standard & $63 \pm 12$ \\
deviation & \\
Emergency operations & 15 \\
Indications & \\
Type A dissection & 14 \\
$\quad$ Degenerative aneurysm & 6 \\
Aortic infiltration of thymic & 1 \\
carcinoma & \\
Intra-aortic stent refixation & 1 \\
Hypertension & 16 \\
Preoperative ventilation & 4 \\
Preoperative renal insufficiency & 3 \\
\hline
\end{tabular}

ebral temperature. Adequate neuroprotection requires meticulous temperature management to avoid too low or too high temperatures leading to overcooling or overheating the patient due to inappropriate "slow responding" temperature monitoring. The aim of our study was to evaluate the reliability of the commonly used core body temperature measurement sites in contemporary aortic surgery performed with the aid of HCA and selective antegrade cerebral perfusion.

\section{Patients and methods}

Between January 2004 and May 2006, 22 patients (mean age: $63 \pm 12$ years, 12 men and 10 women) underwent operations on the thoracic aorta. In all patients, a standard operative technique for acute aortic dissection or aneurysm resection was used at our institution. Cardiopulmonary bypass (CPB) was established via arterial cannulation performed on the concavity of the aortic arch and, during HCA, selective bilateral antegrade carotid perfusion was used. Indications for surgery included: acute type A dissection ( $\mathrm{n}=14,64 \%)$, degenerative aneurysm $(n=6,27 \%)$, aortic infiltration of thymic carcinoma $(n=1,4.5 \%)$ and intra-aortic stent refixation $(n=1,4.5 \%)$. Fifteen patients $(68 \%)$ underwent emergency operations. Preoperative patient characteristics are given in Table 1.

Diagnosis was confirmed by contrast-enhanced computed tomography and intraoperative transoesophageal echocardiography (TOE) in all patients. Aortography or coronary angiography was not performed in emergency cases.

The standard operative technique for aortic dissection or aortic aneurysm at our institution is Dacron graft replacement of the ascending aorta and proximal aortic arch combined with inspection of the supra-aortic

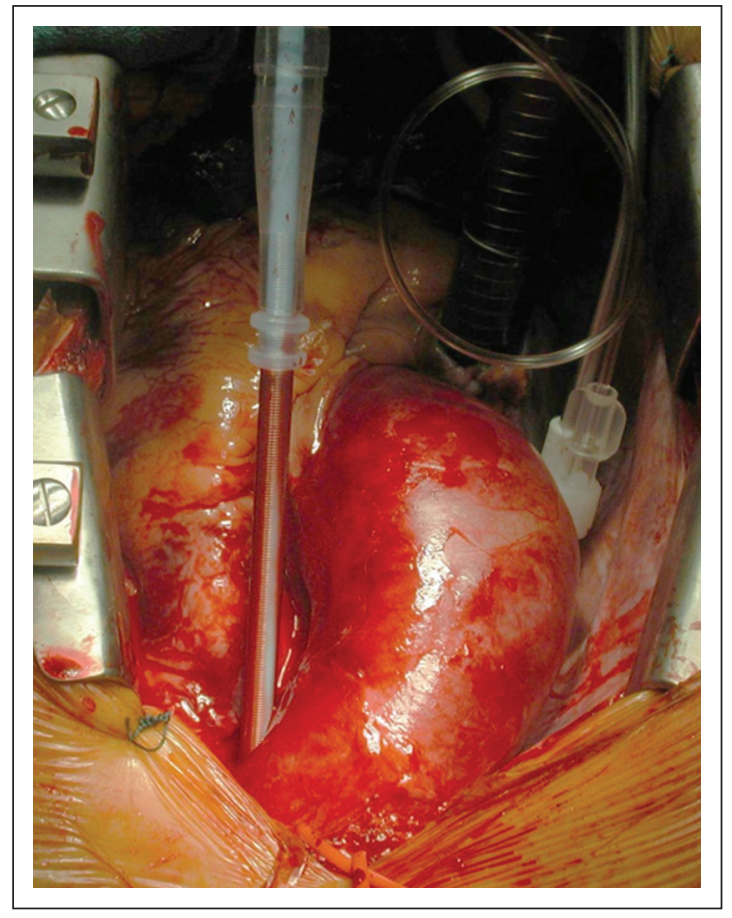

Figure I. Showing direct aortic cannulation over arch concavity with the Seldinger technique.

vessels \pm concomitant island transposition, depending on the supra-aortic status. The patients were placed in the standard supine position. Monitoring of arterial pressure was performed by routinely placing three lines in both radial and right femoral arteries. A median sternotomy was performed in all patients. Puncture of the proximal aortic arch concavity at the level of Botallo's ligament was followed by a minimal invasive cannulation, with dilation steps by the Seldinger technique (Fem-Flex Femoral Arterial Cannula ${ }^{\oplus}$, 24 Fr TFA 02425H Edwards Lifesciences LLC, Irvine, CA, USA; Joline Special Dilatatorset ${ }^{\oplus}$, Hechingen, Germany) (Figure 1). Correct position of the guide wire and cannula was confirmed by TOE of the aorta. CPB was instituted between this and a single, two-stage, right atrial venous cannula.

Patients were cooled down to a tympanic temperature of $19-20^{\circ} \mathrm{C}$ (Mon-a-therm ${ }^{\circ}$ Thermistor YSI 400 Series tympanic temperature probe, Mallinckrodt Inc., St. Louis, MO, USA). Rectal (Thermocouple probe, Mallinckrodt Medical) and urinary bladder (Curity ${ }^{\circledR}$, Degania, Israel) temperatures were simultaneously recorded throughout the procedures. Tympanic, rectal and bladder probes were connected to Mallinckrodt Model 6510 electronic thermometers which require no previous calibration and have an accuracy of around $0.1^{\circ} \mathrm{C}$ with disposable thermocouples, according to the user's manual. Prior to insertion of the tympanic probe, the cerumen-free status of the auditory channel was always controlled by otoscopic examination. The auditory channel was always 
Table 2. Surgical procedures performed.

\begin{tabular}{lr}
\hline Surgical procedure & $n$ \\
\hline Ascending aorta + hemi arch & 20 \\
Ascending aorta + total arch & 2 \\
${ }^{\circ}$ David reconstruction & 3 \\
${ }^{\circ}$ Yacoub reconstruction & 4 \\
${ }^{\circ}$ Bentall procedure & 4 \\
${ }^{\circ}$ Coronary bypass grafting & 4 \\
\hline
\end{tabular}

${ }^{\circ}$ marks an additional procedure of aortic graft implantation.

insulated by a cotton swab, the probe securely fixed by a tape and a gauze bandage was additionally positioned over the external ear. Theatre temperature was continuously kept at $20-22^{\circ} \mathrm{C}$ throughout the operative procedures.

After cross-clamping, an ascending aortic incision was made and antegrade crystalloid cardioplegic solution (2000 ml Custodiol ${ }^{\circ}$ HTK-Solution by Brettschneider, Dr. F. Köhler Chemie, Hähnlein, Germany) was administered through both coronary ostia. During HCA, selective ACP was provided through both carotid arteries (DLP Retrograde Coronary Sinus Perfusion Cannula with manual Inflating Cuff, Medtronic Inc., Minneapolis, $\mathrm{MN}, \mathrm{USA}$ ) at a flow rate adapted to keep a constant cerebral $\mathrm{O}_{2}$ saturation on each side with a perfusion pressure of $35-40 \mathrm{mmHg}$. Cerebral monitoring was performed with near infrared spectroscopy (INVOS cerebral oxymeter, Somanetics Inc., Troy, MI, USA) and brain tissue oxygen saturation measured at $65-70 \%$ continuously during perfusion, which corresponded to the induction values.

Reconstruction of the aorta was performed with a woven Dacron side-branch vascular prosthesis (Hemashield Platinum Woven Double Velour Vascular Graft', Boston Scientific Inc., Wayne, NJ, USA), including the island type reinsertion of all supra-aortic vessels, if applicable. The false lumen was eradicated with $45 \%$ bovine serum albumin-10\% glutaraldehyde glue (BioGlue, CryoLife International Inc., Kennesaw, GA, USA); aortic valve commissures were refixed with the resuspension suture technique. The valve was replaced if it was severely diseased. Composite valve graft replacement was applied in patients with Marfan syndrome or if severe local injury with aortic wall destruction was found intraoperatively. The decision whether or not a composite graft was implanted did not depend on the maximal diameter of the aortic root, but was based on the presence of Marfan syndrome or the severity of the wall destruction. Systemic reperfusion and re-warming were started through the graft side-branch. A summary of performed surgical procedures is presented in Table 2.
Table 3. Intraoperative data.

\begin{tabular}{lc}
\hline Intraoperative data & Mean \pm SD (Median) \\
\hline Time to HCA (min) & $25 \pm 12(2 \mathrm{I})$ \\
CPB time (min) & $176 \pm 63(158)$ \\
HCA time $(\mathrm{min})$ & $46 \pm 21(45)$ \\
ACP time $(\mathrm{min})$ & $36 \pm 18(34)$ \\
ACP flow right start $(\mathrm{ml} / \mathrm{min})$ & $216 \pm 55(200)$ \\
ACP flow right end $(\mathrm{ml} / \mathrm{min})$ & $199 \pm 40(190)$ \\
ACP flow left start $(\mathrm{ml} / \mathrm{min})$ & $224 \pm 55(210)$ \\
ACP flow left end $(\mathrm{ml} / \mathrm{min})$ & $230 \pm 6 I(220)$ \\
\hline
\end{tabular}

CPB: cardiopulmonary bypass; HCA: deep hypothermic circulatory arrest;ACP: selective antegrade cerebral perfusion.

\section{Statistical analysis}

Statistical analysis for body temperature measurement sites was done using univariate analyses (Pearson's correlation and Student's t-test) with SPSS v17.0 (SPSS Inc., Chicago, IL, USA) to identify the best reference to arterial blood temperature during HCA and ACP. A p-value $<0.05$ was considered as significant.

\section{Results}

\section{Perioperative data}

There were no operative deaths; cumulative 30-day mortality rated $13 \%(n=3)$. The cause of death was multiorgan failure in all three patients. Eight patients (36\%) stayed in the intensive care unit $>5$ days.

Direct aortic cannulation was safely performed in all cases; there was no need to switch to an alternative cannulation site. The adventitia of the dissected aorta was firm enough to support the cannula inserted by the Seldinger technique with staged dilatators and there was no case of complicated local massive haemorrhage at the cannulation site. TOE guidance was useful for aortic cannulation along with colour Doppler imaging, which provided information about the true lumen antegrade perfusion. No malperfusion or apparent thrombo-embolism due to the cannulation was observed. Malperfusion was defined by a cerebral saturation difference of $10 \%$ compared to preoperative values and/or pressure difference between the peripheral arteries $>20 \mathrm{mmHg}$. There were no permanent neurological deficits, but two patients (9\%) suffered from transient neurological dysfunction.

Mean CPB time was $176 \pm 63$ minutes (median: 158), mean time to reach HCA was $25 \pm 12$ minutes (median: 21), mean HCA time was $46 \pm 21$ minutes (median: 45 ) and mean selective antegrade carotid perfusion time was $36 \pm 18$ minutes (median: 34 ). Intraoperative patient data is shown in Table 3. 


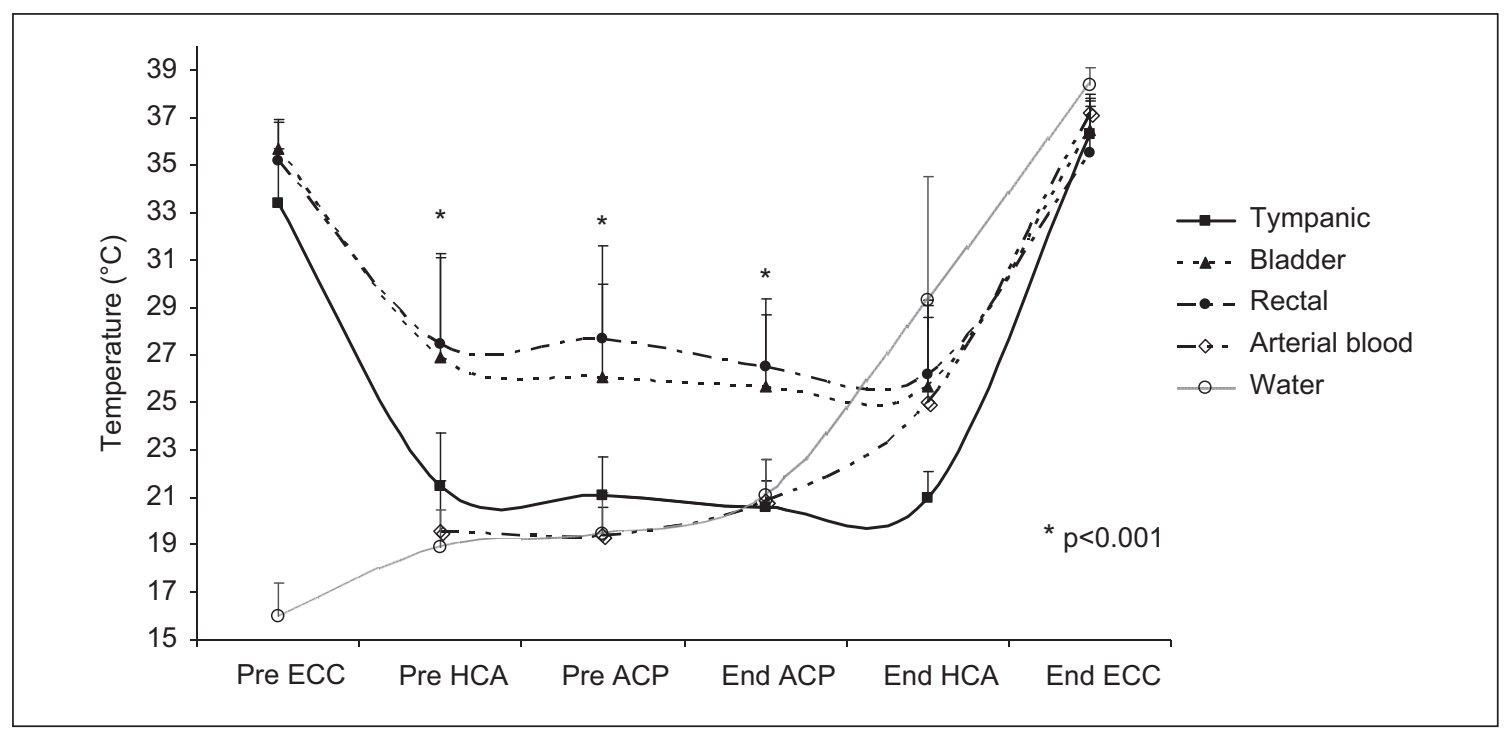

Figure 2. Temperature changes at different measurement sites during extracorporeal circulation (ECC), deep hypothermic circulatory arrest (HCA) and selective antegrade cerebral perfusion (ACP).

\section{Temperature evaluation}

Statistical analysis revealed a strong association between the tympanic temperature and the arterial blood temperature during HCA, while rectal and bladder values did not represent the core temperature adequately. The difference between rectal and arterial blood temperatures was significantly greater than the difference between tympanic and arterial blood temperatures [average temperature difference (rectal minus arterial): 7.9 (pre HCA), 8.3 (pre ACP), $5.6^{\circ} \mathrm{C}$ (end ACP); average temperature difference (tympanic minus arterial): 1.9 , $1.7,0.3^{\circ} \mathrm{C}$, respectively; $\left.(\mathrm{p}<0.001)\right]$. There was a similar relationship between the bladder and tympanic temperatures (average temperature difference (bladder minus arterial): $7.3,6.7,4.8^{\circ} \mathrm{C}$, respectively; average temperature difference (tympanic minus arterial): $1.9,1.7,0.3^{\circ} \mathrm{C}$, respectively; $(p<0.001)]$. Figure 2 shows the temperature detected at the different sites during the course of the operation.

Analysis of the rewarming phase revealed strong correlation between tympanic and arterial blood temperatures $(\mathrm{r}=0.9541 ; \mathrm{p}<0.001)$ as well as between the arterial blood and heat exchanger water temperatures $(r=0.9879$; $\mathrm{p}<0.001)$. The urinary bladder and rectal values showed less correlation with the arterial blood $(\mathrm{r}=0.7939, \mathrm{p}=\mathrm{n}$.s.; $\mathrm{r}=0.7654, \mathrm{p}=$ n.s., respectively). Figure 3 shows the temperature detected at different sites during the re-warming phase.

\section{Discussion}

Our study demonstrates that tympanic measurements are reliable for intraoperative temperature estimation during aortic surgery performed under HCA. This may aid in improved postoperative outcomes due to a reduced cooling phase and adequate rewarming. Although the application of hypothermia has been an important contribution to patient management as a neuroprotective method from the dawn of cardiac surgery, ${ }^{12,13}$ proper body temperature management relies on the accurate measurement of the temperature to enable adequate monitoring of changes during $\mathrm{CPB}$ and HCA. Oxygen consumption drops with lower body temperatures so that ischaemic tolerance is increased by cooling. Cerebral oxygen requirement decreases to approximately one-fifth of normothermic needs at $20^{\circ} \mathrm{C},{ }^{14}$ allowing a safe period of 45-50 minutes for HCA. In addition, hypothermia may contribute to neuroprotection by a variety of complex mechanisms, including decreased vascular permeability, reduced ion influx and decreased excitatory transmitter release. ${ }^{15}$ During the rewarming phase of $\mathrm{CPB}$, conventional temperature monitoring sites may not reflect true brain temperature, so cerebral hyperthermia may not be detected if conventional temperature monitoring underestimates the brain temperature or there is a delay with the arterial heat exchange. ${ }^{16,17}$

Monitoring rectal or urinary bladder temperature to control intraoperative core temperature is standard in many institutions all over the world. Rewarming, which aims to normalise the temperature after HCA, relies on measured data from the above sites. We have shown that temperature measurement at these sites could be misleading, possibly due to latency in the heat exchange process at these points. Clinicians are often concerned about the risks of postoperative hypothermia, such as shivering leading to increased myocardial oxygen 


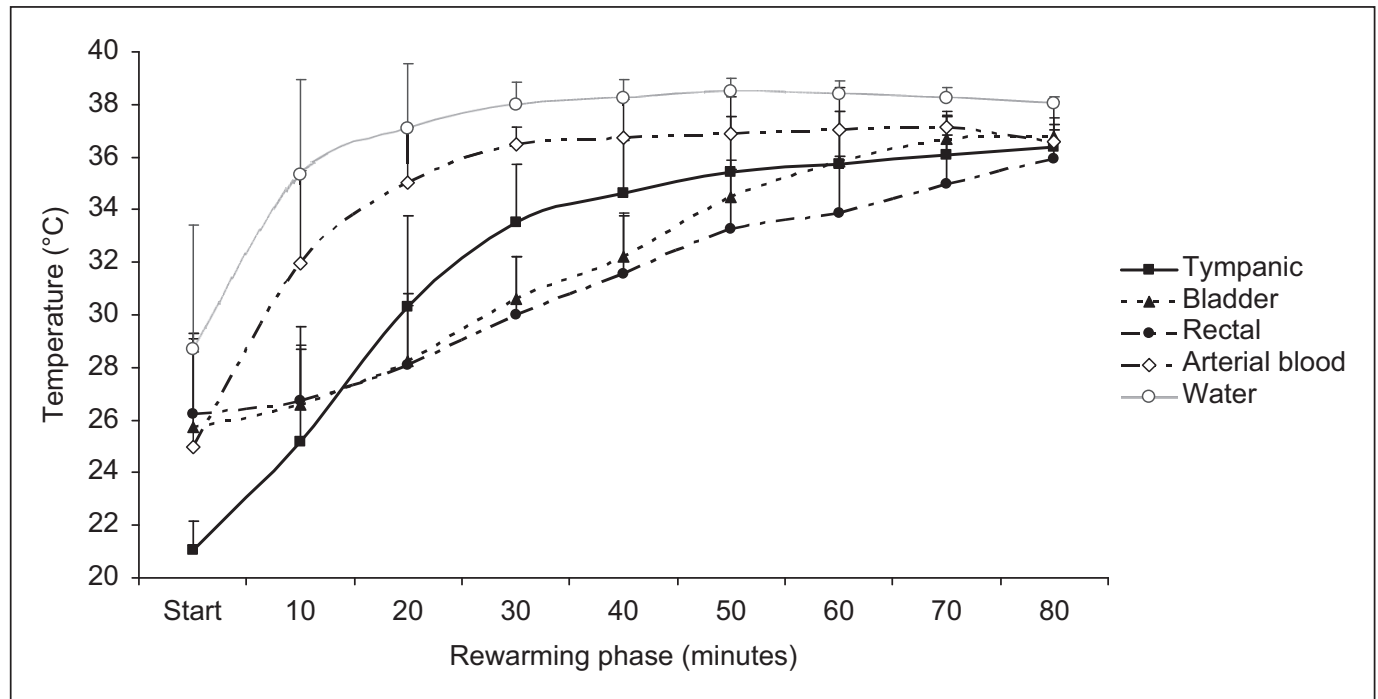

Figure 3. The temperature at various intervals during re-warming, following deep hypothermic circulatory arrest.

consumption, arrhythmias, coagulopathy, greater risk of wound infections and elongated hospital stay, ${ }^{18-21}$ but the possible side effects of cerebral hyperthermia are rarely taken into account. Thus, the rewarming phase must be carefully monitored and managed to avoid cerebral hyperthermia, since it elevates the risk of postischaemic tissue injury ${ }^{22,23}$ and intraoperative hyperthermia is well known to be associated with postoperative neurological impairment. ${ }^{24,25}$

Arterial blood temperature is considered to be the most accurate indicator of cerebral temperature. ${ }^{26}$ This is not surprising as this is the medium for heat exchange for the brain during HCA and ACP. According to our results, tympanic temperatures correlate well with arterial blood temperatures and, hence, with cerebral temperatures, not only during HCA, but also during the rewarming phase of the operation. Urinary bladder and rectal temperatures lag behind arterial blood temperatures, therefore, these measurement sites cannot be relied upon to provide an accurate estimation of temperature change. This affects the management of these patients at various phases of cooling and rewarming.

The tympanic membrane is situated in the immediate vicinity of the internal carotid artery and is supplied by its branches. Thus, the tympanic temperature is wellplaced to closely represent the cerebral thermal state. Although some authors consider tympanic temperature as a good standard for cerebral temperature monitoring by reflecting the hypothalamic status, ${ }^{27,28}$ others have suggested that the tympanic temperature can be influenced by changes in ambient temperature. ${ }^{29,30}$ If, prior to insertion of the tympanic probe, the debris-free status of the auditory channel is confirmed via otoscopic examination along with careful insulation by cotton swab and the probe is securely fixed by tape and a gauze bandage over the external ear, the ambient temperature influence on tympanic measurement can be effectively diminished. Variations in urinary flow, which is a normal phenomenon during $\mathrm{CPB}$ and, especially with $\mathrm{HCA}$, may affect the bladder temperature sensors. ${ }^{31} \mathrm{On}$ the other hand, rectal probes can become lodged in faecal matter, which insulates them from the surrounding tissues. ${ }^{32}$ The above factors contribute to the weak correlation of these temperature measurements with those of the arterial blood.

In our institute, we do not use nasopharyngeal/ oesophageal temperature monitoring in HCA as standard measurement sites, as it has been shown in several studies to modestly, but significantly, over- and underestimating brain temperatures during the cooling and rewarming phases, respectively. ${ }^{33-35}$ It is probable that this is a result of the suboptimal heat exchange environment as these probes are situated in larger, air-containing cavities. Although oesophageal probes are placed relatively close to the descending aorta, the open chest or eventually applied topical cooling in the pericardium could also influence measurement accuracy. Akata, et al. have, furthermore, demonstrated that pulmonary artery temperatures closely reflect changes in brain temperatures, but nasopharyngeal/oesophageal measurements could not be considered as a reliable index of brain temperature, at all, during rapid induction of moderate/deep hypothermia. ${ }^{36}$

Our study has some important limitations. It is an observational, retrospective study without randomisation and presents preliminary experience with a small number of patients. The good preliminary results have to be confirmed by further studies on larger patient groups. 


\section{Conclusion}

We recommend multiple temperature measurement sites during aortic surgery with HCA and ACP to be able to assess homogenous cooling and rewarming of the patient. To achieve good postoperative neurological outcome, we believe that tympanic values are highly reliable as a guide to temperature changes of the brain during HCA and re-warming.

\section{Declaration of conflicting interest}

The authors declare that there is no conflict of interest.

\section{Funding}

This research received no specific grant from any funding agency in the public, commercial or not-for-profit sectors.

\section{References}

1. Borst HG, Schaudig A, Rudolph W. Arteriovenous fistula of the aortic arch: repair during deep hypothermia and circulatory arrest. J Thorac Cardiovasc Surg 1964; 48: 443447.

2. Hogue CW, Palin CA Jr, Arrowsmith JE. Cardiopulmonary bypass management and neurologic outcomes: an evidence based appraisal of current practices. Anesth Analg 2006; 103: 21-37.

3. Dietrich WD, Busto R, Valdes I, Loor Y. Effects of normothermic versus mild hyperthermic forebrain ischemia in rats. Stroke 1990; 21: 1318-1325.

4. Kammersgaard LP, Jorgensen HS, Rungby JA, et al. Admission body temperature predicts long-term mortality after acute stroke: the Copenhagen Stroke Study. Stroke 2002; 33: 1759-1762.

5. Minamisawa H, Smith ML, Siesjö BK. The effect of mild hyperthermia and hypothermia on brain damage following 5, 10, and 15 minutes of forebrain ischemia. Ann Neurol 1990; 28: 26-33.

6. Reith J, Jørgensen HS, Pedersen PM, et al. Body temperature in acute stroke: relation to stroke severity, infarct size, mortality, and outcome. Lancet 1996; 347: 422-425.

7. Azzimondi G, Bassein L, Nonino F, et al. Fever in acute stroke worsens prognosis. A prospective study. Stroke 1995; 26: 2040-2043.

8. Globus MY, Busto R, Lin B, Schnippering H, Ginsberg MD. Detection of free radical activity during transient global ischemia and recirculation: effects of intraischemic brain temperature modulation. J Neurochem 1995; 65: 1250-1256.

9. Morimoto T, Ginsberg MD, Dietrich WD, Zhao W. Hyperthermia enhances spectrin breakdown in transient focal cerebral ischemia. Brain Res 1997; 746: 43-51.

10. Chopp M, Welch KM, Tidwell CD, Knight R, Helpern JA. Effect of mild hyperthermia on recovery of metabolic function after global cerebral ischemia in cats. Stroke 1988; 19: 1521-1525.

11. Dietrich WD, Busto R, Halley M, Valdes I. The importance of brain temperature in alterations of the blood-brain barrier following cerebral ischemia. J Neuropathol Exp Neurol 1990; 49: 486-497.

12. Bigelow WG, Callaghan JC, Hopps JA. General hypothermia for experimental intracardiac surgery; the use of electrophrenic respirations, an artificial pacemaker for cardiac standstill and radio-frequency re-warming in general hypothermia. Ann Surg 1950; 132: 531-539.

13. Sealy WC. Hypothermia: its possible role in cardiac surgery. Ann Thorac Surg 1989; 47: 788-791.

14. Tanaka J, Shiki K, Asou T. Cerebral autoregulation during deep hypothermic nonpulsatile cardiopulmonary bypass with selective cerebral perfusion in dogs. J Thorac Cardiovasc Surg 1988; 95: 124-132.

15. Barone FC, Feuerstein GZ, White RF. Brain cooling during transient focal ischemia provides complete neuroprotection. Neurosci Biobehav Rev 1997; 21: 31-44.

16. Van der Linden J. Cerebral hemodynamics after low-flow versus no-flow procedures. Ann Thorac Surg 1995; 59: 1321-1325.

17. Kern FH, Jonas RA, Mayer JE Jr, Hanley FL, Castaneda $\mathrm{AR}$, Hickey PR. Temperature monitoring during $\mathrm{CPB}$ in infants: does it predict efficient brain cooling? Ann Thorac Surg 1992; 54: 749-754.

18. Sessler DI. Complications and treatment of mild hypothermia. Anesthesiology 2001; 95: 531-543.

19. Kurz A, Sessler DI, Lenhardt R. Perioperative normothermia to reduce the incidence of surgical-wound infection and shorten hospitalization. Study of Wound Infection and Temperature Group. N Engl J Med 1996; 334: 1209-1215.

20. Frank SM, Fleisher LA, Breslow MJ, et al. Perioperative maintenance of normothermia reduces the incidence of morbid cardiac events. A randomized clinical trial. JAMA 1997; 277: 1127-1134.

21. Insler SR, O'Connor MS, Leventhal MJ, Nelson DR, Starr NJ. Association between postoperative hypothermia and adverse outcome after coronary artery bypass surgery. Ann Thorac Surg 2000; 70: 175-181.

22. Cook DJ. Cerebral hyperthermia and cardiac surgery: consequences and prevention. Semin Thorac Cardiovasc Surg 2001; 13: 176-183.

23. Ginsberg MD, Busto R. Combating hyperthermia in acute stroke: a significant clinical concern. Stroke 1998; 29: 529-534.

24. Mora CT, Henson MB, Weintraub WS, et al. The effect of temperature management during cardiopulmonary bypass on neurologic and neuropsychologic outcomes in patients undergoing coronary revascularization. J Thorac Cardiovasc Surg 1996; 112: 514-522.

25. Buss MI, McLean RF, Wong BI, et al. Cardiopulmonary bypass, re-warming, and central nervous system dysfunction. Ann Thorac Surg 1996; 61: 1423-1427.

26. Nussmeier NA. Management of temperature during and after cardiac surgery. Tex Heart Inst $J$ 2005; 32: 472-476.

27. Baker MA, Stocking RA, Meehan JP. Thermal relationship between tympanic membrane and hypothalamus in conscious cat and monkey. J Appl Physiol 1972; 32: 739742. 
28. Benzinger M. Tympanic thermometry in surgery and anesthesia. JAMA 1969; 209: 1207-1211.

29. McCaffrey TV, McCook RD, Wurster RD. Effect of head skin temperature on tympanic and oral temperature in man. J Appl Physiol 1975; 39: 114-118.

30. Shiraki K, Sagawa S, Tajima F, Yokota A, Hashimoto M, Brengelmann GL. Independence of brain and tympanic temperatures in an unanesthetized human. J Appl Physiol 1988; 65: 482-486.

31. Horrow JC, Rosenberg H. Does urinary catheter temperature reflect core temperature during cardiac surgery? Anesthesiology 1988; 69: 986-989.

32. Severinghaus JW. Temperature gradients during hypothermia. Ann N Y Acad Sci 1959; 80: 515-521.
33. Stone JG, Young WL, Smith CR, et al. Do standard monitoring sites reflect true brain temperature when profound hypothermia is rapidly induced and reversed? Anesthesiology 1995; 82: 344-351.

34. Hercus V, Cohen D, Bowring AC. Temperature gradients during hypothermia. BMJ 1959; 1: 1439-1441.

35. Stefaniszyn HJ, Novick RJ, Keith FM, Salerno TA. Is the brain adequately cooled during deep hypothermic cardiopulmonary bypass? Current Surgery 1983; 40: 294-297.

36. Akata T, Yamaura K, Kandabashi T, Sadamatsu S, Takahashi S. Changes in body temperature during profound hypothermic cardiopulmonary bypass in adult patients undergoing aortic arch reconstruction. $J$ Anesth 2004; 18: 73-81. 
Copyright of Perfusion is the property of Sage Publications, Ltd. and its content may not be copied or emailed to multiple sites or posted to a listserv without the copyright holder's express written permission. However, users may print, download, or email articles for individual use. 
IV 
Management options for aortooesophageal fistula: case histories and review of the literature

\author{
L Göbölös,' S Miskolczi,' D Pousios,' GM Tsang,' SA Livesey,' \\ CW Barlow, ' M Kaarne,' J Shambrook, ${ }^{2}$ A Lipnevicius' and \\ SK Ohri'
}

\begin{abstract}
Objective: An aorto-oesophageal fistula is a rare clinical entity, leading to life-threatening gastrointestinal bleeding. Thoracic aortic aneurysms are the most common cause of aorto-oesophageal fistulae; further causes involve foreign body ingestion, trauma (in most cases iatrogenic), carcinoma or, very rarely, aortitis tuberculotica.

Methods: Due to its rarity, there are no large multicentre studies present to evaluate the efficacy of different therapeutic management options. Since it is associated with significant morbidity and mortality, we give a short summary of various treatment approaches performed in our clinical practice in the past three years. The most straightforward therapeutic option may be an endovascular aortic repair and subtotal oesophageal resection followed by gastro-oesophageal reconstruction, but other alternative treatment possibilities are also present, although with probable higher morbidity.

Conclusions: Eliminating the source of bleeding as an emergency, resecting the oesophagus urgently to prevent sepsis and reconstructing the gastrointestinal continuity as an elective case after having the inflammatory processes settled seems to justify the endovascular aortic repair and subtotal oesophageal resection, followed by a gastro-oesophageal reconstruction, as an effective surgical approach.
\end{abstract}

\title{
Keywords
}

aorto-oesophageal fistula; endovascular aortic repair; gastro-oesophageal reconstruction; surgical approach; conservative management

\section{Introduction}

An aorto-oesophageal fistula (AEF) is a rare cause of gastrointestinal bleeding, but is a highly lethal condition, even when promptly diagnosed and treated. The main causes of an AEF are lesions of the oesophageal wall resulting from a thoracic aortic aneurysm (in up to 54\% of cases) and ingestion of foreign bodies (in 19\% of cases). ${ }^{1}$ Conservative treatment of an AEF results in a high in-hospital mortality rate and the conventional surgical procedure has a reported in-hospital mortality rate of nearly $40 \% .^{2}$ Thoracic endovascular aortic repair (EVAR) as a stand-alone procedure has recently gained recognition as a possible technique for the emergency treatment of AEF, despite a considerable risk of infection, ${ }^{3}$ in contrast to the conventional solution of open thoracic surgery with higher mortality and morbidity. However, relatively little is known about long-term results of EVAR for AEF due to its rarity and the lack of large clinical experience.

\section{Methods}

We retrospectively analysed all our patients with an AEF between 2009 and 2010 undergoing different management approaches by separate surgeons. We demonstrate

\footnotetext{
'Department Cardiothoracic Surgery, Southampton General Hospital, Southampton University Hospital Trust, Southampton, UK 2Department Cardiothoracic Radiology, Southampton General Hospital, Southampton University Hospital Trust, Southampton, UK
}

\section{Corresponding author:}

Laszlo Göbölös MD

Department of Cardiothoracic Surgery

Southampton General Hospital

Southampton University Hospital Trust

Southampton

UK.

Email: isartor@hotmail.com

Presented as an electronic poster (Presentation-On-Demand) at the Aortic Symposium 2012 held by the American Association for Thoracic Surgery in New York on $26-27^{\text {th }}$ April, 2012. 
the pros and cons of different strategies since each of them presents a possible management pathway in this group of patients, with different advantages and disadvantages.

\section{Management by EVAR and subtotal oesophageal resection followed by gastro- oesophageal reconstruction}

A 69-year-old man presented with 3 days of central chest pain, coughing and haematemesis. His past medical history included hypertension, hyperlipidaemia and gastro-oesophageal reflux disease. Laboratory findings showed increased inflammatory markers. Computed tomography (CT) revealed a saccular mycotic aneurysm of the mid-descending thoracic aorta in a close relationship to the thickened wall of the oesophagus anteriorly. Air inclusions were visible within the aneurysm thrombus. No pathological lymph nodes were present. A communication between the descending aorta and the oesophagus was demonstrated on the computed tomography (Figure 1). Urgent EVAR was performed, which successfully isolated the aneurysm (Figure 2).

Total oesophageal resection, evacuation of the infected thrombus and a tunnelled feeding jejunostomy was undertaken, thereafter, to prevent sepsis. Surprisingly, histology of the resected specimen showed a clearly defined fistula tract on the basis of moderately differentiated squamous cell carcinoma colonised by E. coli, suggesting that this, rather than pressure, was the aetiology of the AEF.

The patient's prolonged postoperative course was complicated by respiratory distress syndrome and acute renal failure, which were both successfully managed. The patient was discharged well after 71 days, with normal inflammatory markers. Outpatient rehabilitation was undertaken

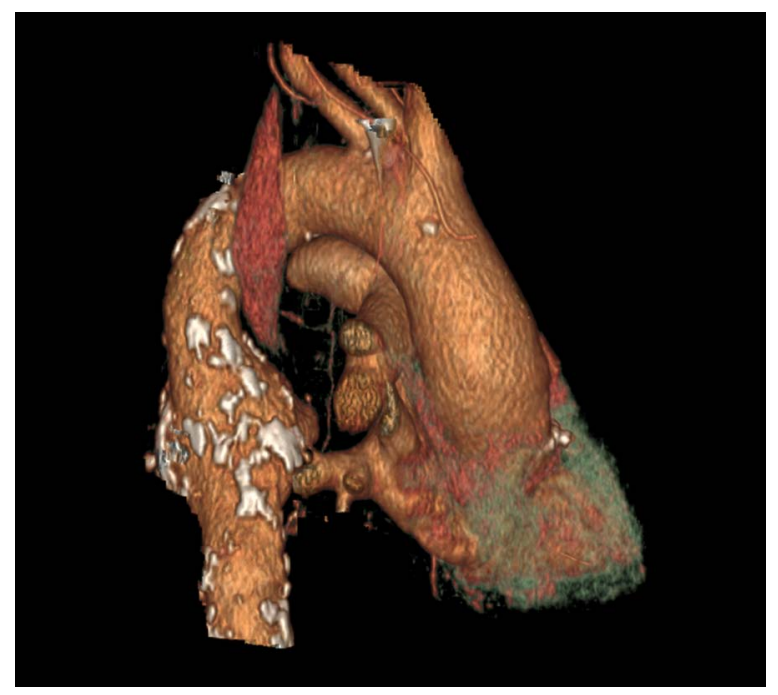

Figure I. 3D reconstruction of the aorto-oesophageal relationship at the AEF: contrast enhancement outlines the oesophageal silhouette. prior to gastro-oesophageal reconstruction which was scheduled six months following EVAR.

\section{Management by open thoracic surgery}

A 30-year-old patient was admitted as an emergency after having an electromechanical dissociation arrest during oesophago-gastroscopy (OGD) for gastrointestinal bleeding. The OGD showed an oesophageal ulcer. Computed tomography demonstrated a communication with the descending aorta where an aneurysm was situated.

An aortic repair was performed with a $30-\mathrm{mm}$ diameter, gelatin-coated, woven polyester, interposition tube graft (Gelwave; Vascutek, Inchinnan, UK) followed by a McKeown oesophagectomy and a gastro-oesophageal reconstruction with orthotopic gastric interposition at the same operation. Postoperatively, he became septic with Pseudomonas in the blood cultures and developed a left upper lobe infarction. A redo-thoracotomy was undertaken; the necrotic left upper lobe was removed followed by a pleurectomy.

During the patient's regular follow-up, a repeat CT scan after six months showed a fluid collection around the graft anastomosis, with some inflammatory signs. The graft was replaced by a homograft as an urgent procedure. After this surgical intervention, the patient was discharged after 15 days in a good general condition.

\section{Conservative management of postoperative graft infection}

A 62-year-old male patient presented with back pain and severe shortness of breath. He had no significant past medical history. A computed tomography angiogram showed a Crawford type I descending aortic aneurysm, extending from the left subclavian artery and ending at the renal arteries. The diameter of the descending aorta was $6-7 \mathrm{~cm}$ at the beginning; the maximum diameter reached $10 \mathrm{~cm}$ at the level of the tracheal bifurcation, with an obvious rupture and a large haematoma compressing both trachea and oesophagus. There was an oesophageal communication also demonstrated.

The aneurysm was replaced by an interpositional Dacron tube graft and the oesophageal rupture orifice was closed with a bovine pericardial patch so that the Dacron graft could be separated from the trachea and the oesophagus.

After a couple of days, a recurrent oesophageal leakage was demonstrated on per oral feeding. The patient refused radical oesophageal surgery, so he was further treated conservatively with the aid of antibiotics. In the following weeks, his general condition was stabilized and he was discharged on a six-months' course of antibiotics. The patient was reluctant to carry on with the prescribed treatment after one month; later on, he was 

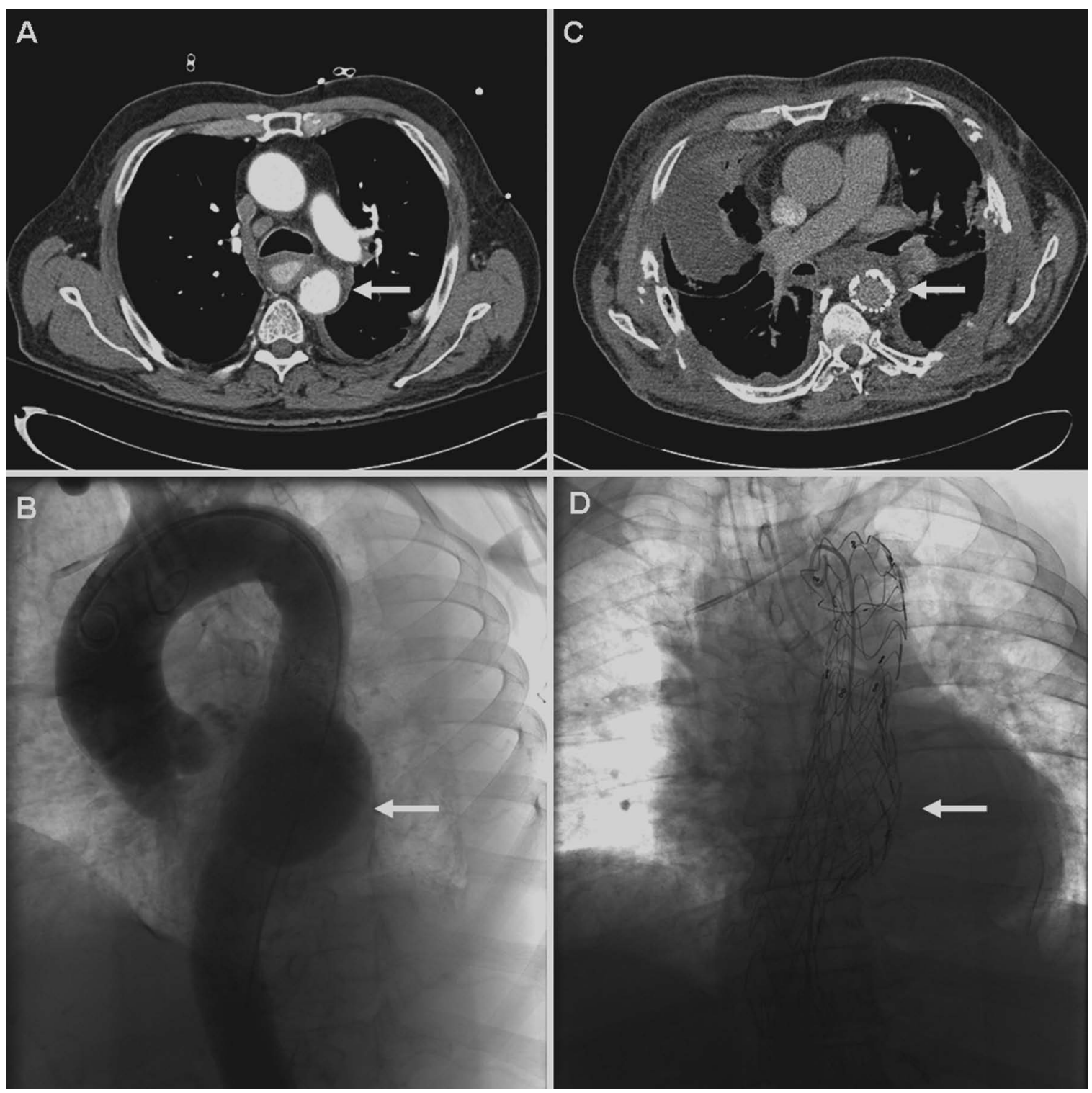

Figure 2. Pre- and postoperative diagnostic images of EVAR treatment in the AEF.

Panel A - Arrow marks the level of the AEF: note the contrast enhancement inside the oesophagus.

Panel B - Saccular aneurysm of the mid-descending thoracic aorta on fluoroscopic image.

Panel C - Arrow shows the EVAR in position: note the absence of the oesophagus.

Panel D - Fluoroscopic image of the endovascular stent graft in situ.

readmitted with recurrent graft infection. This time he also refused further surgical intervention; under longterm (one year) antibiotic therapy, he could be discharged following prolonged in-patient care.

\section{Discussion}

An aorto-oesophageal fistula is a rare cause of gastrointestinal bleeding, characterized by significant morbidity and mortality, even with early diagnosis and intervention. Thoracic aortic aneurysms are the most common cause of an AEF; further causes include foreign body ingestion, trauma (usually iatrogenic), carcinoma or, rarely, aortitis tuberculotica. Several therapeutic management options have been reported in the literature, although all rely on the same principle: urgent management of the aortic tear with immediate or delayed repair of the oesophageal lesion.

Although there are many approaches to treat an AEF, the treatment has to be adapted to the patient's wish in some cases. Our most straightforward therapeutic option was EVAR and subtotal oesophageal resection followed by a gastro-oesophageal reconstruction. Securing the bleeding source as an emergency, removing the oesophagus urgently to prevent sepsis and subsequent elective reconstruction of gastrointestinal continuity appears to 
be a justified surgical approach, as the currently available literature also states, although there are no large studies available.

EVAR is a new, lower-risk, emergency alternative, although EVAR alone leaves the oesophageal defect untreated, contributing to a higher risk of mediastinitis and increased mortality and morbidity. ${ }^{3}$ A similar conclusion resulted from the Regensburg experience; EVAR is an effective emergency alternative to prevent early fatal exsanguinations, however, it can rarely be utilized as a stand-alone procedure. ${ }^{4}$ A nationwide, multicentre, Italian study provided information on 25 aorto-oesophageal and aortobronchial fistulae that were treated with EVAR. The results demonstrated that patients who underwent combined EVAR and tracheobronchial/ oesophageal intervention had lower graft infection rates and better survival than patients receiving EVAR treatment exclusively. ${ }^{5}$ Most probably, the long-term prognosis is affected by a concomitant mediastinal infection and graft contamination.

The surgical approach to the oesophageal lesion is controversial in the literature. Snyder et al. reported a primary suture of the oesophageal defect, with minimal mediastinal contamination, although it was associated with a higher risk of dehiscence and fistula recurrence, probably due to local ischaemia. ${ }^{6}$ Instant oesophago-gastric anastomosis after subtotal oesophagectomy may be another alternative, ${ }^{7}$ although associated with an increased risk of perioperative death, but this risk could be reduced by omentopexy around the tube graft. Subtotal oesophageal resection followed by gastric or jejunal interposition as a second-stage surgical intervention could minimize the hazard of graft infection. ${ }^{8,9}$ For feeding, transdiaphragmatic or transthoracic gastrostomy are reliable solutions that both avoid further opening of the abdomen for a separate gastrostomy or jejunostomy and minimize damage to the stomach, but maintain patency of the upper gastrointestinal tract.

Another interesting complex solution to prevent late thoracic interposition graft infections has been described by Aleksic et al. and Aizawa et al. Although with different aetiologies, they both demonstrated reasonable long-term results after implantation of an extra-anatomic, ascending-descending, aortic, interposition tube-graft bypass with stump closure of the affected descending aorta, with or without omentopexy around the descending stump. ${ }^{10,11}$ Our personal experience with extra-anatomical bypasses is limited to extensive chronic Type B aortic dissections, in which cases the distal abdominal and lower limb perfusion was severely compromised. The operative solution of bilateral subclaviofemoral bypasses provided acceptable perfusion results, although the long-term patency was significantly influenced by the effectiveness of the anticoagulation. Müller et al. have investigated 33 patients with anatomic and extra-anatomic repair following mycotic aneurysms of the thoracic and the abdominal aorta. ${ }^{12}$ Their conclusion shows that the in situ reconstructions did not carry a higher risk of morbidity and mortality than the extra-anatomic reconstructions.

In conclusion, early diagnosis and aggressive surgical approach without delay is the only option for effective treatment for an AEF. Second-stage interval gastrooesophageal reconstruction may lead to the most optimal long-term results. Imaging examination is essential in the primary diagnosis; computerized tomography is a safe, reliable, non-invasive method in the early recognition of this highly lethal entity. We have to emphasise the importance of the multidisciplinary character of the treatment, involving radiologists, gastroenterologists and upper-gastrointestinal and cardiothoracic surgeons to obtain the most favourable results in the management of an AEF.

\section{Conflict of interest statement}

The authors declare that there are no conflicts of interest.

\section{Funding}

This research received no specific grant from any funding agency in the public, commercial or not-for-profit sectors.

\section{References}

1. Hollander JE, Quick G. Aortoesophageal fistula: a comprehensive review of the literature. Am J Med 1991; 91: 279-287.

2. Kieffer E, Chiche L, Gomes D. Aortoesophageal fistula: value of in situ aortic allograft replacement. Ann Surg 2003; 238: 283-290.

3. Prokakis C, Koletsis E, Apostolakis E, Dedeilias P, Dougenis D. Aortoesophageal fistulas due to thoracic aorta aneurysm: surgical versus endovascular repair. Is there a role for combined aortic management? Med Sci Monit 2008; 14: RA48-54.

4. Topel I, Stehr A, Steinbauer MG, Piso P, Schlitt HJ, Kasprzak PM. Surgical strategy in aortoesophageal fistulae: endovascular stentgrafts and in situ repair of the aorta with cryopreserved homografts. Ann Surg 2007; 246: 853-859.

5. Chiesa R, Melissano G, Marone EM, Kahlberg A, Marrocco-Trischitta MM, Tshomba Y. Endovascular treatment of aortoesophageal and aortobronchial fistulae. J Vasc Surg 2010; 51: 1195-1202.

6. Snyder DM, Crawford ES. Successful treatment of primary aorto-esophageal fistula resulting from aortic aneurysm. J Thorac Cardiovasc Surg 1983; 85: 457-463.

7. Oppell UO, Groot MA, Thierfelder C, Zilla P, Odell JA. Successful management of aortoesophageal fistula due to thoracic aortic aneurysm. Ann Thorac Surg 1991; 52: 1168-1170.

8. Flores J, Shiiya N, Kunihara T, Yoshimoto K, Yasuda K. Aortoesophageal fistula: alternatives of treatment case 
report and literature review. Ann Thoracic Cardiovasc Surg 2004; 10: 241-246.

9. Pirard L, Creemers F, Van Damme H, Laurent S, Honoré P, Limet R. In situ aortic allograft insertion to repair a primary aorto-oesophageal fistula due to thoracic aortic aneurysm. J Vasc Surg 2005; 42: 1213-1217.

10. Aleksic I, Leyh R, Schorn B. Extra-anatomic management of homograft reinfection after thoracic aortic rupture. Thorac Cardiovasc Surg 2006 ; 54: 428-430.
11. Aizawa K, Ohki S, Konishi H, Misawa Y. Extraanatomical ascending-abdominal aorta bypass with stump closure for aortic graft infection. Interact Cardiovasc Thorac Surg 2008: 646-647.

12. Müller BT, Wegener OR, Grabitz K, Pillny M, Thomas L, Sandmann W. Mycotic aneurysms of the thoracic and abdominal aorta and iliac arteries: experience with anatomic and extra-anatomic repair in 33 cases. J Vasc Surg 2001; 33: 106-113. 
Copyright of Perfusion is the property of Sage Publications, Ltd. and its content may not be copied or emailed to multiple sites or posted to a listserv without the copyright holder's express written permission. However, users may print, download, or email articles for individual use. 
V 


\section{Age-related presentation of acute type $\mathbf{A}$ aortic dissection}

\author{
Pietro Giorgio Malvindi, Daniela Votano, Ahmed Ashoub, \\ Amit Modi, Szabolcs Miskolczi, Theodore Velissaris, \\ Clifford Barlow, Sunil Ohri, Geoffrey Tsang, Steven Livesey and \\ Laszlo Göbölös
}

Asian Cardiovascular \& Thoracic Annals 2018, Vol. 26(9) 659-666 (C) The Author(s) 2018 Article reuse guidelines: sagepub.com/journals-permissions DOI: $10.1177 / 0218492318810087$ journals.sagepub.com/home/aan (SAGE

\begin{abstract}
Background: We evaluated the clinical and anatomic presentations of acute type A aortic dissection according to patient age.

Methods: We retrospectively reviewed 235 consecutive patients who underwent acute type A dissection repair between January 2000 and December 2014. The influence of age on anatomical and clinical presentation, surgical management in the entire cohort and also after exclusion of patients with known connective tissue disorders was assessed using logistic regression.

Results: Males presented with type $\mathrm{A}$ acute aortic dissection at a younger age than females. Acute onset with signs of myocardial ischemia, connective tissue disorders, or bicuspid aortic valve characterized the younger population. Extension to the coronary sinus(es) $(p=0.0003)$, descending thoracic aorta $(p=0.016)$, and abdominal aorta $(p=0.029)$, and an intimal tear at the level of the aortic root $(p=0.0017)$ correlated inversely with patient age. Similar findings were obtained after exclusion of patients with connective tissue disorders or a bicuspid aortic valve.

Conclusions: More frequent proximal and distal progression of the dissection flap occurs in younger patients with acute type A aortic dissection. Older age is associated with a lower probability of an intimal tear at the level of the sinus of Valsalva. These findings, associated with prognostic implications, account for the choice of more radical proximal procedures for repair of aortic dissection in younger patients.
\end{abstract}

\title{
Keywords
}

Age factors, Aorta, Aneurysm, dissecting, Aortic root, Genetic predisposition to disease, Vascular surgical procedures

\section{Introduction}

The incidence of acute type A aortic dissection (ATAAD) is higher in the seventh and eighth decades of life. ${ }^{1}$ This event is less frequent but not uncommon in younger people, accounting for approximately $7 \%$ of surgical cases involving patients younger than 40 years and $18 \%-22 \%$ of patients younger than 50 years. ${ }^{1,2}$ Surgical mortality in the younger age group is not negligible and not significantly lower than that in advanced age. ${ }^{1-3}$ In younger patients, more frequent involvement of the distal aorta and supraaortic vessels has been described, ${ }^{2,4}$ as well as a higher prevalence of connective tissue disorders. ${ }^{2,4-6}$ These features can also explain the necessity for more radical and extensive surgical procedures in patients with inherited vascular wall disorders. A limited number of reports have focused on the preoperative features and their correlation with age in patients presenting with ATAAD. ${ }^{2,4}$ Therefore, we studied the clinical and anatomic presentations of ATAAD, characterized their relationships with patient age, and considered the implications in terms of pathologic background and surgical management.

\footnotetext{
Wessex Cardiothoracic Centre, Southampton University Hospital NHS Trust, Southampton, UK

\section{Corresponding author:}

Laszlo Göbölös, Wessex Cardiothoracic Centre, Southampton University Hospital NHS Trust, Tremona Road, Southampton SOI6 6YD, United Kingdom.

Email: isartor@hotmail.com
} 


\section{Patients and methods}

The departmental database of Wessex Cardiothoracic Centre at the University Hospital Southampton was interrogated to retrieve data of patients treated for spontaneous ATAAD between January 2000 and December 2014. We identified 235 patients who underwent repair of spontaneous acute type A aortic dissection during the study period. In this retrospective cohort study, we analyzed data on clinical presentation, anatomic features of ATAAD, and operative techniques for aortic repair, according to patient age. Particularly, anatomic details from preoperative imaging and intraoperative findings were available to characterize extension of the dissection flap beyond the ascending aorta, thus involving the aortic arch, descending thoracic aorta, and abdominal aorta. The site of the intimal tear was coded according to its intraoperative description as located at the level of the aortic root (intimal tear at the level of the sinus of Valsalva), ascending aorta, or aortic arch. Because of relevant implications in surgical strategy, an intimal tear extending from the ascending aorta to the aortic root or aortic arch was coded as a tear of the aortic root or aortic arch, respectively. Our institutional surgical protocols in cases of acute aortic dissection repair have been described previously. ${ }^{7,8}$

Patients were consented prior to procedures, according to British legislation: Section $14 \mathrm{U}$ of the National Health Service Act 2006 (as amended by the Health and Social Care Act 2012) with the aid of NHS Standard Consent Forms. Everyone aged 16 or more is presumed to have the capacity to give consent, unless the opposite is demonstrated. The consent form acts as an aide-memoire to patients and health professionals by providing a checklist of information that should be offered, and giving the patient a written record of the main points discussed (NHS Standard Consent Form
Nr 1). The Mental Capacity Act 2005 states that people who lack capacity to make decisions about their care and treatment should be involved in such decisions "so far as practicable" (www.england.nhs.uk/shareddecision-making/why-is-shared-decision-making-impor $\operatorname{tant} /$ shared-decision-making-to-comply-with-nationallegislation-and-policy). If this is not possible, NHS Standard Consent Form Nr 4 is applicable for adults who are unable to consent to investigation or treatment. In this case, two medical professionals act on behalf and in the best interest of the patient if treatment cannot be delayed until the patient recovers capacity. Next-of-kin may receive information either personally or via telephone as part of "good clinical practice", but final responsibility for determining whether a procedure is in an incapacitated patient's best interests lies with the health professionals performing the procedure.

Continuous data are presented as mean \pm standard deviation, categorical variables are provided as counts and percentages. Student's $t$ test was applied to compare age between groups defined by clinical presentation, etiology, anatomical details of aortic involvement, and surgical procedures. The influence of age on the probability of an anatomical presentation was assessed by logistic regression considering the overall population and patients without connective tissue disorders or bicuspid aortic valve (BAV). Statistical analyses were performed by Stat-View Statistical Software Package version 5.0 (SAS Institute, Inc., Cary, NC, USA) and NCSS 2001 (Number Cruncher Statistical System, Kaysville, UT, USA).

\section{Results}

Figure 1 shows the age distribution among the 235 patients who underwent repair of spontaneous acute type A aortic dissection. Patients younger than 40 years represented $6 \%$ of the total, $18 \%$ were younger

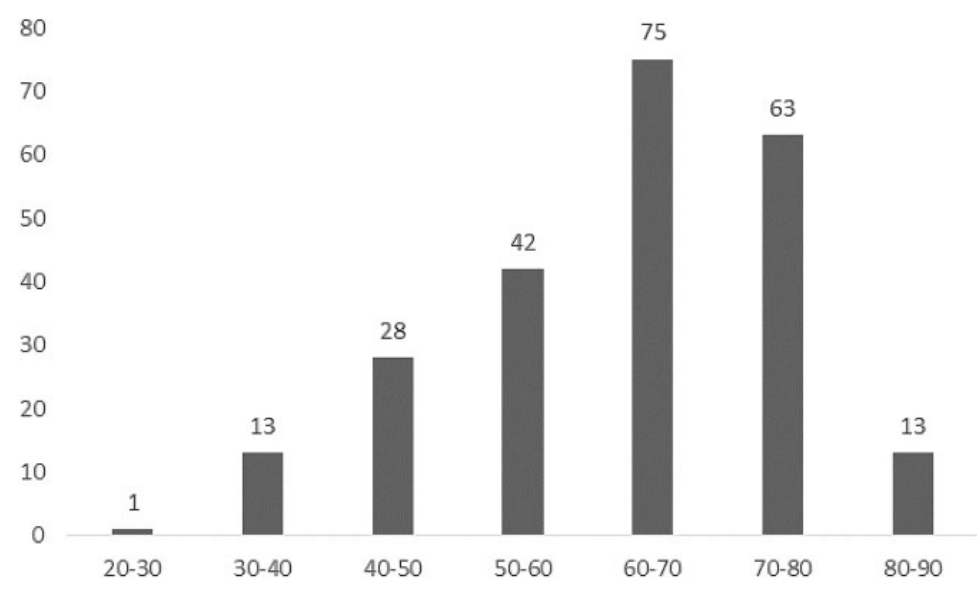

Figure I. Age distribution in patients undergoing acute type A aortic dissection (ATAAD) repair. 
Table I. Patient age in emergency acute type $A$ aortic dissection repair with (variable $=$ yes) or without $($ variable $=$ no) the listed preoperative characteristics according to etiology and clinical presentation.

\begin{tabular}{|c|c|c|c|c|}
\hline \multirow[b]{2}{*}{ Variable } & \multirow[b]{2}{*}{ No. of patients } & \multicolumn{2}{|c|}{ Mean age (years) } & \multirow[b]{2}{*}{$p$ value } \\
\hline & & Variable $=$ yes & Variable $=$ no & \\
\hline Male & $154(66 \%)$ & $61.4 \pm 12.6$ & $68.0 \pm 12.1$ & $<0.0001$ \\
\hline \multicolumn{5}{|l|}{ Presentation } \\
\hline Myocardial ischemia & $36(15 \%)$ & $60.0 \pm 14.8$ & $64.9 \pm 13.5$ & 0.04 \\
\hline Tamponade & $39(17 \%)$ & $66.2 \pm 18.3$ & $63.6 \pm 13.5$ & 0.24 \\
\hline New onset of cerebral stroke & $18(8 \%)$ & $65.6 \pm 22.9$ & $63.9 \pm 13.4$ & 0.59 \\
\hline Mechanical ventilation & $16(7 \%)$ & $61.6 \pm 22.1$ & $64.2 \pm 13.4$ & 0.41 \\
\hline Acute renal failure & $12(5 \%)$ & $64.9 \pm 25.2$ & $64.1 \pm 13.4$ & 0.82 \\
\hline Limb ischemia & $12(5 \%)$ & $62.7 \pm 25.2$ & $64.0 \pm 14.0$ & 0.72 \\
\hline Abdominal ischemia & $2(1 \%)$ & & & \\
\hline Cardiopulmonary resuscitation & $10(4 \%)$ & $67.3 \pm 27.5$ & $63.9 \pm 13.4$ & 0.41 \\
\hline Connective tissue disorders/BAV & $22(9 \%)$ & $50.1 \pm 17.2$ & $64.5 \pm 12.6$ & 0.004 \\
\hline Marfan syndrome & $6(3 \%)$ & $45.5 \pm 22.4$ & $64.3 \pm 13.3$ & $<0.0001$ \\
\hline Previous cardiac surgery & $14(6 \%)$ & $62.6 \pm 25.4$ & $64.2 \pm 13.1$ & 0.65 \\
\hline
\end{tabular}

BAV: bicuspid aortic valve.

than 50 years, and $32 \%$ were older than 70 . Male patients experienced acute dissection earlier in life. Patients with a known connective tissue disorder or BAV $(n=22)$ were significantly younger than patients with no syndromic features and tricuspid aortic valves $(n=213)$. Patient age was not different regarding the featured characteristic of preoperative clinical presentation; however, we found that signs of myocardial ischemia in acute aortic dissection were associated with younger age. Table 1 lists the preoperative clinical characteristics. Aortic dissection involved the ascending aorta in all patients (Stanford type A); according to the DeBakey classification, 205 patients had type I and 30 had type II aortic dissection. Patients presenting with progression of the dissection flap into the coronary sinus(es), descending thoracic aorta, and abdominal aorta were significantly younger than those who had exclusively ascending aorta and/or arch involvement. The distribution of primary tear sites showed that younger age was associated with an intimal tear at the level of the aortic root (Table 2). We found similar results regarding proximal and distal aortic involvement after exclusion of syndromic disorders and BAV. In the entire cohort, the probability of aortic dissection extending into the coronary sinus (es), descending thoracic aorta, and abdominal aorta decreased with patient age: odds ratio $(\mathrm{OR})=0.96$, 95\% confidence interval $(\mathrm{CI}): 0.933-0.980 ; \mathrm{OR}=0.97$, 95\%CI: $0.95-0.99 ; \quad$ OR $=0.97, \quad 95 \% \mathrm{CI}: \quad 0.95-0.99$, respectively. Older age was characterized by a lower probability of an intimal tear in the aortic root $(\mathrm{OR}=0.95,95 \% \mathrm{CI}: 0.93-0.98$; Figure 2$)$. In patients having no known connective tissue disorder, the probability of aortic dissection extending into the coronary sinus(es), descending thoracic aorta, and abdominal aorta decreased with age $(\mathrm{OR}=0.96,95 \% \mathrm{CI}: 0.935$ $0.985 ; \mathrm{OR}=0.98,95 \% \mathrm{CI}: 0.96-1.02 ; \mathrm{OR}=0.98,95 \%$ CI: 0.96-1.003, respectively). Advanced age was characterized by a lower probability of an intimal tear in the aortic root $(\mathrm{OR}=0.95,95 \% \mathrm{CI}: \quad 0.92-0.98$; Figure 3). All patients underwent replacement of the ascending aorta. No difference in patient age was identified regarding the distal repair strategy, considering total arch replacement and proximal arch replacement (including resection limited to two-thirds of the lesser curvature of arch; "hemiarch technique"). Advanced age characterized patients who underwent associated aortic valve replacement due to degenerative changes in the valve; the younger population received full root replacement because the dissection involved the aortic root (Table 3).

\section{Discussion}

ATAAD is more common from the seventh decade of the life. It is an unexpected finding in healthy subjects, and represents one of the well-recognized causes of sudden death in young people. ${ }^{9,10}$ Our data entirely support previous reports that among patients undergoing ATAAD repair, approximately $6 \%$ are younger than 40 years, and nearly $20 \%$ are less than 50 -years old. $^{1,2}$ An underlying connective tissue disorder has been widely recognized as the fundamental predisposing factor strongly characterizing this population., ${ }^{2,4}$ Furthermore, several contributors including hypertension, smoking, cocaine and amphetamine abuse have been associated with the occurrence of this catastrophic disease in patients younger than 50 years. ${ }^{11,12}$ An inherent pathology of the aortic wall leads to faster development of aneurysms and a higher risk of severe 
Table 2. Patient age in emergency acute type $A$ aortic dissection repair with (variable $=$ yes) or without $($ variable $=$ no) the listed characteristics according to anatomical findings.

Mean age (years)

\begin{tabular}{|c|c|c|c|c|}
\hline \multirow{2}{*}{ Variable } & \multirow[b]{2}{*}{ No. of patients } & & \multirow[b]{2}{*}{$P$ value } \\
\hline & & Variable $=$ yes & Variable $=$ no & \\
\hline \multicolumn{5}{|l|}{ Overall population $(n=235)$} \\
\hline \multicolumn{5}{|c|}{ Extension of dissection flap beyond ascending aorta } \\
\hline Coronary sinus(es) & $50 / 235(21 \%)$ & $57.8 \pm 13.2$ & $65.4 \pm 13.1$ & 0.0002 \\
\hline Aortic arch & $205 / 235(87 \%)$ & $63.6 \pm 12.4$ & $65.5 \pm 18.7$ & 0.44 \\
\hline Descending thoracic aorta & $129 / 175(74 \%)$ & $62.0 \pm 12.9$ & $66.6 \pm 14.8$ & 0.014 \\
\hline Abdominal aorta & $109 / 17 \mid(64 \%)$ & $61.9 \pm 12.8$ & $66.0 \pm 14.5$ & 0.03 \\
\hline \multicolumn{5}{|l|}{ Location of primary intimal tear } \\
\hline Tear identified & $196 / 22 \mid(89 \%)$ & & & \\
\hline Aortic root & $36(19 \%)$ & $57.3 \pm 13.0$ & $65.2 \pm 13.1$ & 0.0007 \\
\hline Ascending aorta & $103(53 \%)$ & $64.7 \pm 13.6$ & $63.1 \pm 13.3$ & 0.34 \\
\hline Aortic arch & $57(28 \%)$ & $66.1 \pm 11.0$ & $63.1 \pm 14.0$ & 0.13 \\
\hline \multicolumn{5}{|c|}{ Excluding connective tissue disorders and bicuspid aortic valve $(n=2 \mid 3)$} \\
\hline \multicolumn{5}{|c|}{ Extension of dissection flap beyond ascending aorta } \\
\hline Coronary sinus(es) & $45 / 213(21 \%)$ & $58.4 \pm 13.4$ & $65.9 \pm 13.1$ & 0.0004 \\
\hline Aortic arch & $184 / 2 \mid 3(86 \%)$ & $64.4 \pm 12.1$ & $64.5 \pm 19.7$ & 0.96 \\
\hline Descending thoracic aorta & || $8 / 16 \mid(73 \%)$ & $63.1 \pm 14.0$ & $67.6 \pm 14.9$ & 0.044 \\
\hline Abdominal aorta & $100 / 155(64 \%)$ & $62.9 \pm 12.7$ & $66.8 \pm 14.3$ & 0.06 \\
\hline \multicolumn{5}{|l|}{ Location of primary intimal tear } \\
\hline Tear identified & I75/200 (88\%) & & & \\
\hline Aortic root & $32(18 \%)$ & $57.8 \pm 12.4$ & $66.0 \pm 13.6$ & 0.0009 \\
\hline Ascending aorta & 91 (52\%) & $65.6 \pm 13.4$ & $63.3 \pm 12.1$ & 0.24 \\
\hline Aortic arch & 52 (30\%) & $66.6 \pm 10.7$ & $63.5 \pm 13.6$ & 0.14 \\
\hline
\end{tabular}
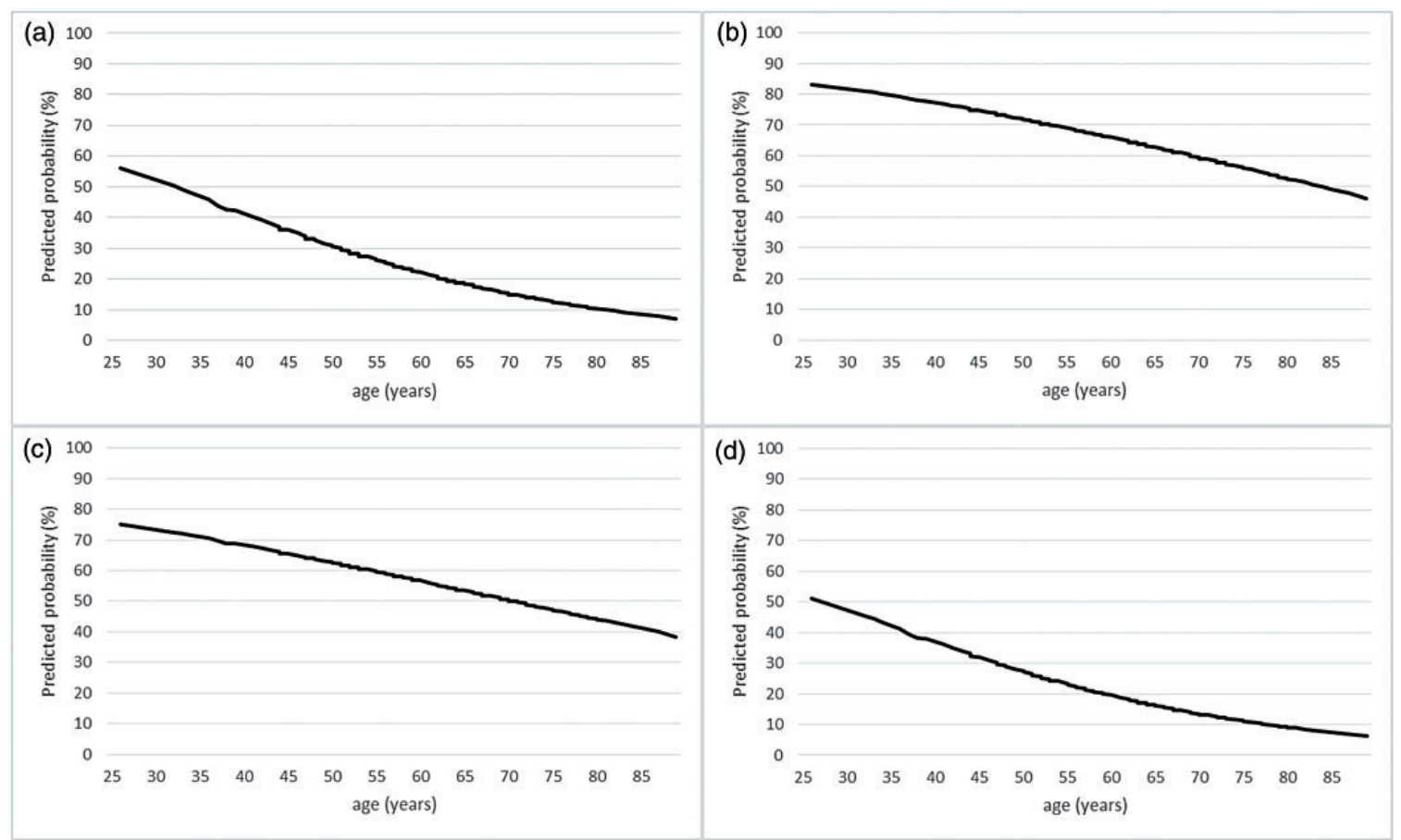

Figure 2. Overall age and probability of (a) coronary sinus dissection $(p=0.0003)$, (b) descending thoracic aortic dissection $(p=0.016)$, (c) abdominal aortic dissection $(p=0.029)$, and $(d)$ an intimal tear in the aortic root $(p=0.0017)$. 

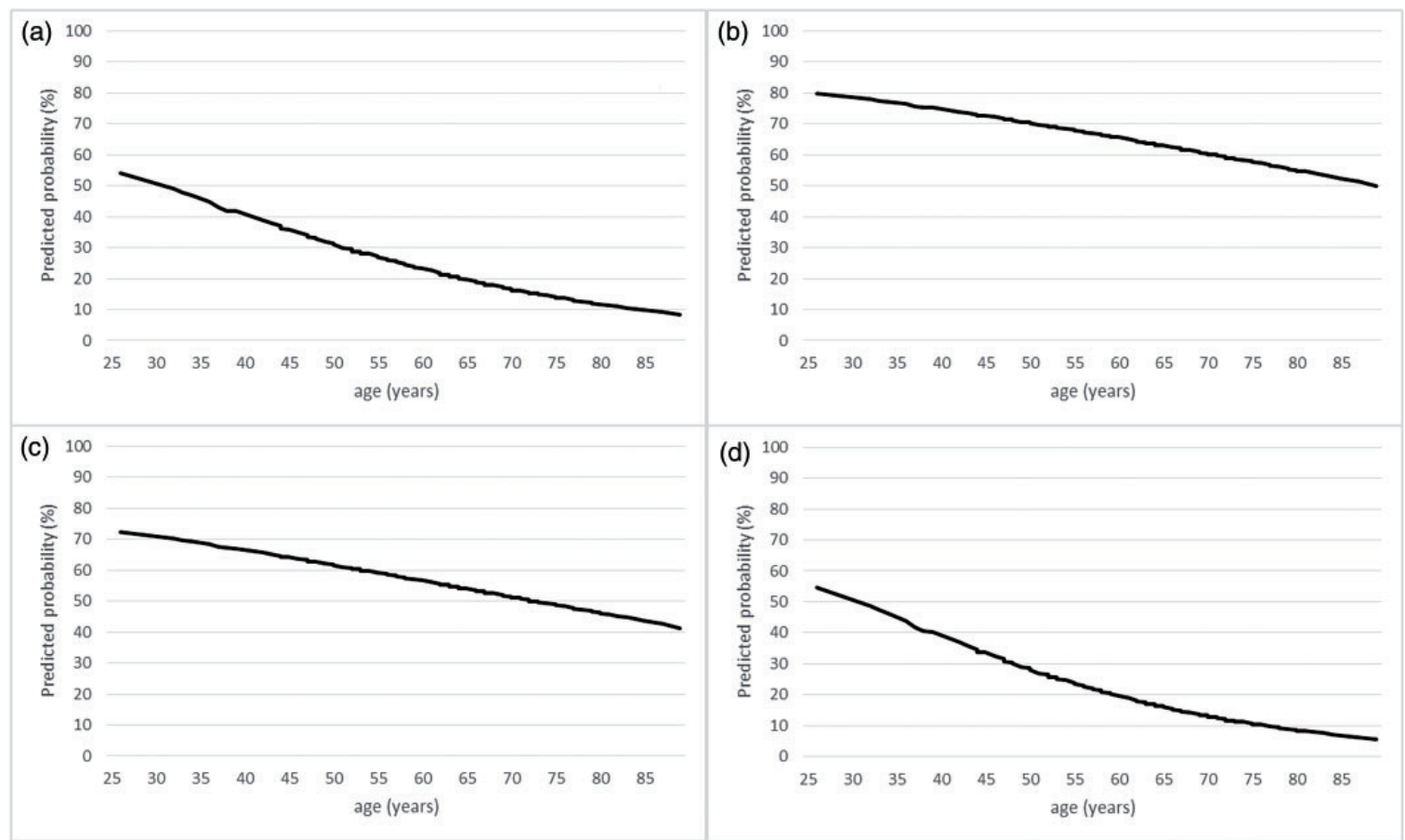

Figure 3. Patients without connective tissue disorders or bicuspid aortic valve. Age and the probability of (a) coronary sinus dissection ( $p=0.0017)$, (b) descending thoracic aortic dissection $(p=0.07)$, (c) abdominal aortic dissection $(p=0.09)$, and (d) an intimal tear in the aortic root $(p=0.0016)$.

Table 3. Patient age in emergency procedures for acute type $A$ aortic dissection repair with (variable $=$ yes) or without ( variable $=$ no) the listed characteristics according to surgical procedure.

\begin{tabular}{|c|c|c|c|c|}
\hline \multirow[b]{2}{*}{ Variable } & \multirow[b]{2}{*}{ No. of patients } & \multicolumn{2}{|c|}{ Mean age (years) } & \multirow[b]{2}{*}{$p$ value } \\
\hline & & Variable $=$ yes & Variable $=$ no & \\
\hline Ascending aorta replacement & 235 & & & \\
\hline + Aortic valve replacement & $13(6 \%)$ & $7 I . I \pm 10.7$ & $63.7 \pm 13.3$ & 0.04 \\
\hline + Aortic root replacement & 61 (26\%) & $57.2 \pm 12.1$ & $66.5 \pm 12.9$ & $<0.0001$ \\
\hline + Valve sparing aortic repair & $2(1 \%)$ & & & \\
\hline + Proximal arch replacement & $65(28 \%)$ & $64.2 \pm 11.7$ & $64.1 \pm 13.8$ & 0.93 \\
\hline+ Total arch replacement & $13(6 \%)$ & $58.4 \pm 12.0$ & $64.4 \pm 13.3$ & 0.09 \\
\hline Concomitant coronary artery bypass & $22(9 \%)$ & $63.5 \pm 11.3$ & $64.2 \pm 12.7$ & 0.79 \\
\hline 30-day mortality & $26(11 \%)$ & $67.0 \pm 11.2$ & $63.7 \pm 12.7$ & 0.19 \\
\hline
\end{tabular}

complications. Surprisingly, early pathologic evolution does not characterize only syndromic patients who represent a small subgroup in surgical series. The investigators of the International Registry of Acute Aortic Dissection reported that patients aged less than 40 years had a significantly larger aortic root and ascending aorta compared to the older population. ${ }^{4}$ This feature was common in both Marfan and non-Marfan patients. Recent evidence has extended our knowledge of the well-known syndromic disorders in understanding the evolution of aortic diseases in the young. Several nonsyndromic genetic conditions can lead to early development of thoracic aortic aneurysms, which are further characterized by rapid dilatation and a high risk of dissection. These nonsyndromic familial thoracic aortic aneurysms are related to genetically heterogeneous disorders and estimated to represent $20 \%$ of diagnosed thoracic aneurysms; ${ }^{5}$ mutations in 5 genes (MYH11, TGFßR1, TGFßR2, MYLK, and $A C T A 2$ ) have been identified so far, and all have autosomal dominant inheritance. ${ }^{13}$ From a molecular point of view, the consequences of these genetic alterations translate into degenerative remodelling of the aortic medial extracellular matrix, leading to progressive 
loss of elastic properties. ${ }^{6,14}$ This clinical, anatomical, genetic, and molecular evidence suggests that the prevalence of inherited aortic wall disorders in young people, resulting in aortic complications, is probably wider than expected or diagnosed.

The above pathologic background may play an important role in extension of the dissection. In our series, a significantly lower mean age characterized this presentation, featuring involvement of the aortic root and/or distal aorta. These characteristics of our cohort reinforce the conclusions of Nishida and colleagues ${ }^{15}$ suggesting a strategy for aortic root repair, and also from the large German Registry for Acute Aortic Dissection Type A analysis that reported decreasing probability of ATAAD extension into the supraaortic vessels and abdominal aorta with increasing patient age. ${ }^{2}$ Even after exclusion of syndromic disorders and BAV, we demonstrated that younger age is frequently associated with severe involvement of the aortic root and coronary sinus(es). The association of younger age and dissection of the coronary sinus(es) may also be responsible for preoperative myocardial ischemia. This has already been associated with aortic root complications after dissection repair, and can be seen as a marker of severe proximal aortic tissue disruption. ${ }^{16}$

In our experience, an intimal tear in the aortic root is a feature of the younger subgroup of patients, and this was confirmed after exclusion of patients with known connective tissue disorders or BAV. In a different population, Ma and colleagues ${ }^{17}$ described a similar distribution of intimal tear sites and reported age and hypertension as risk factors for an arch entry tear; further research on hemodynamic factors might facilitate the understanding of these findings. In addition to genetic and metabolic contributors, aortic flow properties may play a role in the progression of wall disease, ${ }^{18,19}$ and might be an active variable in triggering the onset of dissection. Recent studies have focused on characterization of aortic flow patterns and wall stress, using computational fluid dynamics; wall shear stress seems to have a significant impact on the promotion and progression of medial degeneration, and represents a mechanical force able to separate the aortic layers once the balance between tissue strength and flowinduced wall stress is lost. ${ }^{20,21}$ Numata and colleagues ${ }^{20}$ studied 6 different anatomical models of aortic disease; in all of their patients, the oscillatory shear index (a parameter describing deviation of wall shear stress from its mean direction) was higher close to the sinotubular junction, near the bifurcation of the head and neck vessels and the lesser curvature of the proximal descending aorta. All of these areas are potential sites of an intimal tear. Clinical evidence is limited but suggests that different patterns of aortic segment dilatation and blood flow properties across the aortic valve can promote development of an intimal tear in different areas of the proximal aorta: major involvement of the lesser curvature of ascending aorta in patients with a preserved or not extremely dilated sinotubular junction, or the right lateral side of the aorta in the case of a diffusely dilated proximal aorta and sinus(es) of Valsalva or sinotubular junction in the presence of a dilated aortic root. ${ }^{20,21}$ Undiagnosed inherited disease of the aortic wall and early dilatation of the aortic root possibly associated with aortic valve dysfunction could well explain why ATAAD presents in younger patients with more severe aortic root involvement, more frequent proximal extension of the dissection flap, and a proximal intimal tear.

Different pathologic and pathogenetic substrates exist between younger and older patients; the latter are affected by longstanding hypertension and a progressive atherosclerotic process, leading to a significantly different approach for proximal repair of ATAAD. We found that full root replacement was performed mainly in young patients, whereas older patients underwent a more conservative proximal repair. The literature reports rates of $23 \%-25 \%$ for full root replacement in the overall population of patients undergoing ATAAD repair, with 40\%-60\% in people younger than 50 years, ${ }^{2-4} 10 \%-20 \%$ in septuagenarians, and $5 \%-10 \%$ in octogenarians. Isolated aortic valve and concomitant ascending aorta interposition graft replacement is nowadays reserved for cases of valve leaflet degeneration or calcification, and reported in approximately $5 \%$ of cases, mostly in patients aged over 70 years. There is no doubt that younger people require more radical aortic resection, although besides the clinical and prognostic reasons, we should recognize the importance of pathologic background and anatomic features in determining the surgical strategy for proximal repair. Nevertheless, the recommendation for full root replacement in cases of connective tissue disorders, dilated or severely dissected aortic root, or an intimal tear in the aortic root, is now widely accepted, aiming for a safe procedure in acute settings and reduction of the risk of reoperation in the mid- and long-term. Evaluation of anatomical characteristics can also explain the similar prevalence in the literature of arch procedures in younger and older patients; ${ }^{2}$ a more extensive distal repair is usually reserved for cases of an intimal tear in the aortic arch or an aneurysmal aortic arch. We were not able to report exact aortic dimensions, but found no difference in patient age regarding the presence of an intimal tear involving the aortic arch.

This was a retrospective study from a single institution over a period of 14 years. No information was available regarding patients who declined the surgical 
procedure, were managed conservatively, or died prior to admission. Similarly, we could not include data of patients who were deemed very high-risk or in a terminal clinical condition and were not referred from peripheral hospitals. Availability of preoperative imaging data from district healthcare facilities was limited and, despite a detailed operative description of the aortic valve and root anatomy, we were not able to systematically characterize the size of the different aortic segments. In the absence of pre-dissection studies, interpretation of acute dissection data might be debatable because a significant increase in aortic diameters is expected immediately after the acute dissection event. ${ }^{22}$ However, we concluded that the clinical presentation and occurrence of dissection-related malperfusion syndrome were not associated with the age of a patient presenting with ATAAD, apart from the presence of signs of syndromic connective disorders or myocardial ischemia. More extensive progression of the dissection flap into the aortic root and distally to the descending and abdominal aorta characterized younger patients; different pathologic backgrounds promoting the onset of ATAAD in younger and older patients can explain this finding. The higher rate of connective tissue disorders and prevalence of undiagnosed intrinsic underlying proximal aortic wall disease may account for this particular presentation in the young. An intimal tear in the aortic root is more common at a younger age on presentation; this finding associated with the prognostic reasons supports the higher prevalence of full root replacement in younger patients.

\section{Declaration of conflicting interests}

The author(s) declared no potential conflicts of interest with respect to the research, authorship, and/or publication of this article.

\section{Funding}

The author(s) received no financial support for the research, authorship, and/or publication of this article.

\section{References}

1. Trimarchi S, Eagle KA, Nienaber CA, et al. Role of age in acute type A aortic dissection outcome: report from the International Registry of Acute Aortic Dissection (IRAD). J Thorac Cardiovasc Surg 2010;140:784-9.

2. Rylski B, Hoffmann I, Beyersdorf W, et al. Acute aortic dissection type A. Age-related management and outcomes reported in the German Registry for Acute Aortic Dissection Type A (GERAADA) of over 2000 patients. Ann Surg 2014;259:598-604.
3. Niclauss L, Delay D, von Segesser LK. Type A dissection in young patients. Interact Cardiovasc Thorac Surg 2011;12:194-8.

4. Januzzi JL, Isselbacher EM, Fattori R, et al. Characterizing the young patient with aortic dissection: results from the International Registry of Aortic Dissection (IRAD). J Am Coll Cardiol 2004;43:665-9.

5. Elefteriades JA, Pomianowski P. Practical genetics of thoracic aortic aneurysm. Prog Cardiovasc Dis 2013;56:57-67.

6. Ruddy JM, Jones JA, Ikonomidis JS. Pathophysiology of thoracic aortic aneurysm (TAA): is it not one uniform aorta? Role of embryologic origin. Prog Cardiovasc Dis 2013;56:68-73.

7. Malvindi PG, Modi A, Miskolczi S, et al. Acute type A aortic dissection repair in elderly patients. Eur $J$ Cardiothorac Surg 2015;48:664-70.

8. Malvindi PG, Modi A, Miskolczi S, et al. Open and closed distal anastomosis for acute type A aortic dissection repair. Interact Cardiovasc Thorac Surg 2016;22:776-83.

9. Puranik R, Chow CK, Duflou JA, Kilborn MJ, McGuire MA. Sudden death in the young. Heart Rhythm 2005;2:1277-82.

10. Li Y, Li L, Mu HS, Fan SL, He FG, Wang ZY. Aortic dissection and sudden unexpected deaths: a retrospective study of 31 forensic autopsy cases. J Forensic Sci 2015;60:1206-11.

11. Dean JH, Woznicki EM, O'Gara P, et al. Cocaine-related aortic dissection: lessons from the International Registry of Acute Aortic Dissection. Am J Med 2014;127:878-85.

12. Westover AN, Nakonezny PA. Aortic dissections in young adults who abuse amphetamines. Am Heart $J$ 2010;160:315-21.

13. Pomianowski P, Elefteriades JA. The genetics and genomics of thoracic aortic disease. Ann Cardiothorac Surg 2013;2:271-9.

14. Bee KJ, Wilkes DC, Devereux RB, Basson CT, Hatcher CJ. TGF $\beta$ RIIb mutations trigger aortic aneurysm pathogenesis by altering transforming growth factor $\beta 2$ signal transduction. Circ Cardiovasc Genet 2012;5:621-9.

15. Nishida H, Tabata M, Fukui T, Takanashi S. Surgical strategy and outcome for aortic root in patients undergoing repair of acute type A aortic dissection. Ann Thorac Surg 2016;101:1464-9.

16. Geirsson A, Bavaria JE, Swarr D, et al. Fate of distal and proximal aorta after acute type A dissection repair using a contemporary surgical reconstruction algorithm. Ann Thorac Surg 2007;84:1955-64.

17. Ma W, Zhang W, Wang L, Zheng J, et al. Type A aortic dissection with arch entry tear: surgical experience in 104 patients over a 12-year period. J Thorac Cardiovasc Surg 2015;151:1581-92.

18. Girardauskas E, Rouman M, Disha K, et al. Correlation between systolic transvalvular flow and proximal aortic wall changes in bicuspid aortic valve stenosis. Eur $J$ Cardiothorac Surg 2014;46:234-9.

19. Mahadevia R, Barker AJ, Schnell S, et al. Bicuspid aortic cusp fusion morphology alters aortic three-dimensional 
outflow patterns, wall shear stress, and expression of aortopathy. Circulation 2014;129:673-82.

20. Numata S, Itatani K, Kanda K, et al. Blood flow analysis of the aortic arch using computational fluid dynamics. Eur J Cardiothoracic Surg 2016;46:1578-85.

21. Torii R, Kalantzi M, Theodoropoulos S, Sarathchandra $\mathrm{P}, \mathrm{Xu} \mathrm{XY}$, Yacoub MH. Predicting impending rupture of the ascending aorta with bicuspid aortic valve: spatiotemporal flow and wall shear stress. JACC Cardiovasc Imaging 2013;6:1017-9.

22. Rylski B, Blanke P, Beyersdorf F, et al. How does the ascending aorta geometry change when it dissects? J Am Coll Cardiol 2014;63:1311-9. 
VI 


\title{
Recent Advances in the Management of Acute Aortic Syndrome
}

\author{
Laszlo Göbölös ${ }^{1,3^{*}}$ et al., \\ ${ }^{1}$ Department of Cardiothoracic Surgery, University Hospital Regensburg, \\ 2Institute for Clinical Chemistry and Laboratory Medicine, \\ University Hospital Regensburg, \\ ${ }^{3}$ Department Cardiothoracic Surgery, Southampton General Hospital, \\ Southampton University Hospital Trust, \\ 1,2Germany \\ ${ }^{3}$ United Kingdom
}

\section{Introduction}

Type A acute aortic dissection is one of the most serious cardiovascular conditions and is associated with significant morbidity and mortality. A half century ago, Hirst et al published a milestone article describing the linearized mortality rate of one percent per hour after the onset of an ascending aortic dissection [1]. Hence, the importance of accurate, quick and reliable diagnosis, as the timing of procedure is vital for optimal management of this highly lethal condition. Despite improvements in the diagnostic modalities, surgical techniques and perioperative care, the overall mortality remains high, between $10 \%$ and $30 \%$ [2].

Due to its major role in systemic perfusion, the aorta and its main branches after dissection are often challenging when trying to prevent surgical morbidity and mortality. The complexity of aortic dissection presents not only a pure cardiovascular surgical task, but also consideration must be given to protection of the myocardium, cerebrum, peripheral tissues and organs. An early fatal result of aortic dissection is due to ischaemic injury to the brain or heart, although longer peripheral ischaemia can cause multiorgan failure resulting in extended hospital stay, increased morbidity and mortality. Alexis Carrel highlighted the risks of surgery in 1910 with the following short summary on aortic interventions: "The main danger of the aortic operation does not come from the heart or from the aorta itself, but from the central nervous system." Even a century later, we are still trying to optimize cerebral protection, despite having significantly wider range of diagnostic and therapeutic modalities.

Advances in our understanding of varying pathologies of aortic dissections have improved as have the technological developments in the modes of detection. These advances together with improved therapeutic options have raised expectations for better outcomes.

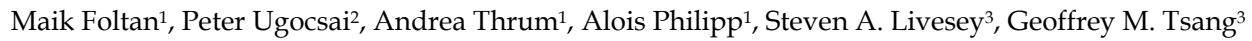
and Sunil K. Ohri ${ }^{3}$ 


\section{Acute aortic syndrome}

The term "acute aortic syndrome" (AAS) became widely accepted in the last decade. It involves not only aortic dissections, but intramural haematomas and penetrating atherosclerotic ulcers in the same anatomical location. This constellation of presentations have similar emergency status, diagnostic and therapeutic requirements. As a definition, AAS is an acute pathophysiological process involving the tunica media of aortic wall, which results in rupture or any further life-threatening complications.

\subsection{Epidemiology}

Population-based epidemiological studies suggest an incidence of AAS of about thirty cases per one million people per year. Eighty percent is represented by acute aortic dissections, $15 \%$ by intramural haematomas and $5 \%$ as penetrating ulcers. Seventy percent of the affected population is male with an average of 60 years [3]. A Swedish epidemiological study found the same incidence in an observational period between 1987 and 2002 among 4425 cases. In this study, the incidence of AAS has increased by $50 \%$ in men and $30 \%$ in women over study period. This may be related to enhanced diagnostics, although a further component could also be the increasing age of the population. Overall, $20 \%$ of affected patients died before reaching a medical facility, 30\% during the hospital stay and further $20 \%$ over the following 10 years [4]. Both circadian and seasonal variations have been observed in the occurrence of AAS, with the peak frequency found between $0800 \mathrm{hr}$ and 0900hr, with an increased likelihood during the winter period. The most likely explanation is a link to the circadian variation in blood pressure $[5,6]$.

\subsection{Pathophysiology}

The mechanisms leading to AAS arise from many sources, although preexisting medial degeneration is proven to be an important risk factor for acute aortic dissection. Cystic medial necrosis is a hallmark of the histology, especially in aortic aneurysm patients. Microscopic features include decreased amount of vascular smooth-muscle cells, mucoid deposits and elastin deficiency [7]. However, over $80 \%$ of acute dissections occur in absence of a pre-existing aneurysm. The International Registry of Acute Aortic Dissection (IRAD) has collected an impressive amount of data for the demography of patients who present with AAS. The most commonly associated factors are:

- Hypertension

- Atherosclerosis

- Elderly

- Previous cardiovascular surgery, especially previous aortic aneurysm or dissection repair

- Connective tissue disorders (Marfan`s syndrome, Ehlers-Danlos`syndrome, ErdheimGsell`s syndrome)

- Infective involvement of the aortic tissue (Lues, Takayashu aortitis)

- Congenital causes (PDA ampulla, Sinus of Valsava aneurysm, bicuspid aortic valve)

- $\quad$ External factors (Trauma, cocaine abuse)

Improvements in the resolution of aortic imaging has led to the identification of pathological submodalities, i.e. intramural haematoma or penetrating atherosclerotic ulcer. Histological 
findings of these lesions generally demonstrate significant intimal atherosclerosis, which is not a constant finding in aortic dissection biopsies. Studies suggest that aortic dissection is an end process with a wide pathological spectrum, many of which facilitate weakening and/or increased stress of the aortic wall. The chain of pathological events might begin with a small superficial intimal rupture; atherosclerotic ulcers may provide a good millieu for development of such a tear. Alternatively, disruption of vasa vasorum might result in an intramural haematoma, which later ruptures into the aortic lumen or leads to dissection. However, it is likely that many aortic dissections develop without having a pre-stage of intramural haematoma or penetrating ulcer [8].

\subsection{Presentation and diagnosis}

Although the typical symptom is described as sharp, tearing, ripping chest pain, the presentation is diverse and about $10 \%$ do not complain of pain; sometimes the aortic pathology is an accidental clinical finding. In some patients shoulder or back pain occurs or just a husky voice, with or without shortness of breath and/or haemophthysis. Hypotension or shock is seen in $25 \%$ of patients, whereas hypertension can also be a presenting symptom, although more often found in type B dissections. Further findings, such as migrating pain, neurological deficits, acute abdomen, cardiac failure, myocardial ischaemia, aortic valve regurgitation are less common. Connective tissue diseases are characterized by additional specific symptoms, i.e. skeletal, pharyngeal or lens abnormalities and extreme laxity [3].

Early acute diagnosis can be vital, as an emergency surgery may be indicated. Blood pressure control is essential, and a goal of systolic $\leq 110 \mathrm{mmHg}$ is recommended. The administration of $\beta$-blockers, sodium-nitroprusside, calcium-channel-blockers with analgesia is helpful, if indicated. In some advanced dissections resustitative measurements such as intubation and pericardiocentesis may be required.

\begin{tabular}{|c|c|c|c|c|}
\hline & $\begin{array}{c}\text { Transthoracic } \\
\text { echocardiography }\end{array}$ & $\begin{array}{l}\text { Transoesophageal } \\
\text { echocardiography }\end{array}$ & $\begin{array}{l}\text { Computed } \\
\text { tomography }\end{array}$ & $\begin{array}{c}\text { Magnetic } \\
\text { resonance } \\
\text { imaging }\end{array}$ \\
\hline Aortic dissection & + & +++ & +++ & +++ \\
\hline $\begin{array}{l}\text { Intramural } \\
\text { haematoma }\end{array}$ & - & ++ & ++ & +++ \\
\hline Penetrating ulcer & - & + & +++ & +++ \\
\hline Dissection entry & + & +++ & ++ & ++ \\
\hline $\begin{array}{l}\text { Aortic } \\
\text { regurgitation }\end{array}$ & +++ & +++ & - & +++ \\
\hline Pericardial effusion & +++ & +++ & ++ & ++ \\
\hline Periaortic bleeding & - & + & +++ & +++ \\
\hline
\end{tabular}

Table 1. Efficacy of different imaging modalities in AAS. 
In patients with suspected acute aortic dissection various investigations are performed on admission including blood tests, electrocardiography, chest radiography, echocardiography, computed tomography and magnetic resonance imaging. Some investigations, such as ECG, chest radiography and routine blood tests do not carry sufficient sensitivity and specificity to exclude or confirm the diagnosis of an acute aortic dissection. Biomarker assays are increasingly utilized in the diagnosis of AAS, i.e. elastin fragments, smooth-muscle myosin heavy-chain protein, D-dimers, but are not widely available and provide only supporting evidence. The definite diagnosis can only be established using an imaging modality [9]. Table 1. summarizes efficacy of different imaging modalities in AAS. Table 2. shows the diagnostic features of the imaging modalities currently available in a hospital setting.

\begin{tabular}{l|cccc}
\multicolumn{1}{|c}{} & $\begin{array}{c}\text { Transthoracic } \\
\text { echocardiography }\end{array}$ & $\begin{array}{c}\text { Transoesophageal } \\
\text { echocardiography }\end{array}$ & $\begin{array}{c}\text { Computed } \\
\text { tomography }\end{array}$ & $\begin{array}{c}\text { Magnetic } \\
\text { resonance } \\
\text { imaging }\end{array}$ \\
\hline \begin{tabular}{l|cccc} 
Availability \\
Speed
\end{tabular} & +++ & ++ & +++ & + \\
Portability & +++ & +++ & ++ & + \\
Tolerance & +++ & +++ & - & - \\
Monitoring & +++ & + & ++ & ++ \\
\hline
\end{tabular}

Table 2. Diagnostic features of imaging modalities in AAS.

\subsection{Management of AAS}

Currently, there are no randomized trials available to guide the management of AAS. The European Society of Cardiology has developed guidelines for diagnosis and management of aortic dissection based on a task force of international societies [10], although in most of decision making clinical pathways are usually based on case series or registries, systematic reviews, local experience, consensus based guidelines. Following initial stabilization of the patient, after diagnostic measurements and imaging, a treatment should be tailored to the pathological entity:

- $\quad$ Type A dissection

Over $50 \%$ mortality in the first 48 hours without surgical intervention, only $1-10 \%$ survives the first 5 weeks on conservative treatment. The perioperative mortality is $10-30 \%$. Contraindications are quite limited as type A dissection is a highly lethal condition without surgical treatment, although age $>80$ years, ongoing coma with definitive extensive cerebral lesions (but not localized ischaemia or paraplegia!) or extensive abdominal necrosis may be contraindications for surgery. A subacute type A dissection, is a rare finding that requires an elective/semi-urgent operation as the patient has already successfully survived the high mortality period may now benefit from a well planned elective procedure [10].

- Intramural haematoma

Classical therapeutic indication as for type A dissection, although in an uncomplicated and non-progressing situation, without ongoing pain and periaortic bleeding, patients can undergo surgery on an urgent basis (within 24 hours) rather than as an emergency. Over the age of 80 years, accompanied by significant comorbidities, conservative therapy in an intensive care 
facility with the support of repeat imaging should be considered. If sudden progression occurs, a surgical intervention may be life saving. In this patient group $40 \%$ of intramural haematomas resolve after 4 years of follow up without mortality according to a small patient cohort study [11]. Another study demonstrated 34\% regression of the disease, while 36\% progressed into a dissection (12\% acute type A dissection, $24 \%$ localized dissection) and 30\% resulted in aneurysm formation over long term. They have also demonstrated, that a rupture or dissection is a very rare phenomenon with an aortic diameter of $<60 \mathrm{~mm}$ at any location with an intramural haematoma [9]. These observations guide the clinical management of intramural haematomas, despite the lack of large multicentric studies, each patient requires a tailored individual management plan. As penetrating atherosclerotic ulcers are usually incidental operative or postmortem findings and are seldom discovered at imaging, there are no widely discussed clinical therapeutic strategies available.

- Typ B dissection

As this diagnosis generally requires conservative medical treatment in an intensive care setting, we only briefly discuss the indications for surgery. Medical treatment is associated with a mortality of $20 \%$, compared to surgery, which has much higher mortality of $30 \%$; medical therapy is therefore considered first. Classical operative indications are progressive organ malperfusion, ongoing pain with uncontrollable hypertension. In the last decade stent grafting of the affected region has become an alternative option as it can treat these problems at a low risk profile in most of the cases and without need for further cardiovascular surgery [12].

\section{Surgical considerations and recent techniques for repair of type $A$ dissections}

\subsection{Perfusion approaches in type A dissections}

Cannulation of an extended type A dissection often represents a challenge for surgeons when either the subclavian or lower limb arteries are involved in the process. There are some alternative cannulation sites published in current literature i.e. brachiocephalic trunk, right common carotid artery, transapical cannulation, although we prefer an innovative method through non dissected aortic wall on lesser curvature at level of Botallo`s ligament using a Seldinger technique.

Our first experience was a 50 year-old man with sudden onset of ripping chest pain, admitted unconscious accompanied by anisochoria. Computed tomography scan revealed an extensive type A aortic dissection. The dissection began exactly over the aortic valve; maximal diameter of ascending aorta measured $60 \times 55 \mathrm{~mm}$. On the lesser curvature of arch, particularly at Botallo`s ligament, preservation of the true lumen with an intact wall was observed, although the dissection involved all supraaortic vessels. Visceral arteries originated from the true lumen except the left renal artery. Dissection in both iliac arteries was also present. Rapid deterioration of the patient with cardiovascular instability led us to cannulate at Botallo`s ligament applying a minimal invasive cannulation method with a Seldinger technique [Figure 1, 2]. At Botallo`s ligament the aorta is firmly bound to pulmonary trunk with a mass of connective tissue, which usually protects it from a complete dissection in this area. Position of cannula has to be guided by either transoesophageal or epiaortic ultrasonography. With this rapid and safe cannulation method extracorporeal circulation can be easily established, thus reducing the risk of perioperative shock and increased mortality [13]. 


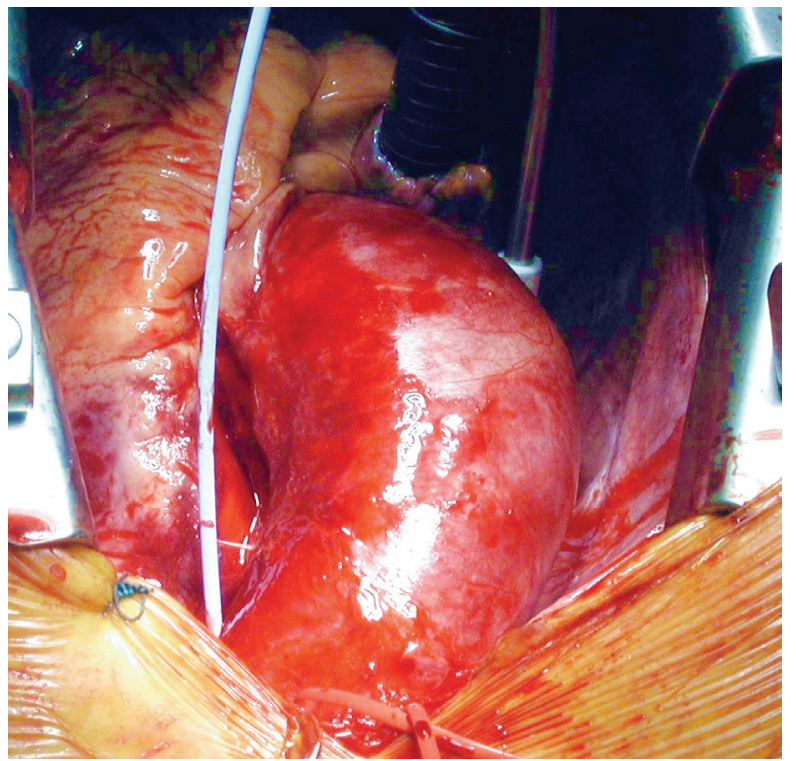

Fig. 1. Seldinger cannulation of a type A aortic dissection (first dialation step)

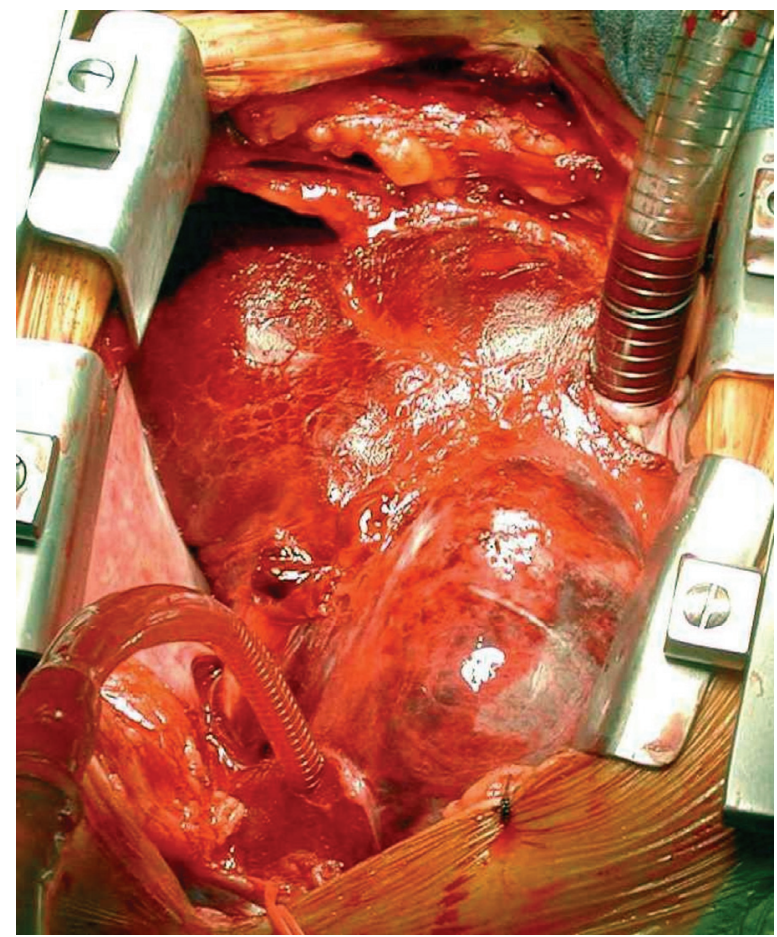

Fig. 2. Arterial cannula in situ at Botallo’s ligament 
Cardiopulmonary bypass via axillary/subclavian artery has become an alternative perfusion site in the past decade, predominantly in acute aortic dissections but also for patients with severe aortic atherosclerosis [14-20]. Despite several advantages of axillary/subclavian artery cannulation such as dominantly antegrade perfusion of the aorta, this technique is not without its complications. Establishment of axillary/subclavian artery inflow may not be ideal for providing rapid antegrade perfusion in cases with hemodynamic instability, as dissection and cannulation can take too long. In small patients, a limitation of CPB pump flow due to a narrow axillary artery may be a concern [21, 22]. Applying the standard technique, however, only the right hemisphere is continuously perfused, which can result in malperfusion of the contralateral hemisphere, as Merkkola et al demonstrated, up to $17 \%$ of the patients having incomplete circle of Willis [23]. Even with a complete circle of Willis, concern has been raised, if this type of perfusion alone can sufficiently supply the left hemisphere.

Transapical cannulation is another technique for establishing reliable antegrade arterial access, as described by Wada et al [24]. In large cohort of 138 patients, cannula was placed through a $1 \mathrm{~cm}$ apical incision into true lumen via aortic valve under transoesophageal echocardiography guidance. Impact of causing an acute aortic insufficiency in this context is not discussed in detail. This technique carries disadvantage of resulting in prolonged cardiopulmonary bypass times, since no additional manipulations can be performed during cooling phase, i.e. inspection and preparation of aortic root.

Right carotid artery cannulation, performed by Urbanski in 100 patients, including 27 with type A dissections, provides another possible alternative, but also carries the risk of left hemisphere malperfusion and potential complications when the vessel is de-cannulated [25]. Experience with innominate artery cannulation by Di Eusanio et al includes 55 patients with only two in acute aortic dissections [26], so it is difficult to evaluate the efficacy of this method due to the small experience.

Fusco at al presented their results in femoral artery cannulation in 2004 [27]. With a conversion rate of $2.5 \%$ to ascending aortic cannulation, they conclude that femoral cannulation is appropriate and yields excellent clinical results. They are not aware of having encountered retrograde embolism from the descending aorta, probably since atherosclerosis is less common in dissection patients.

\subsection{Cerebral protection in dissection surgery}

Avoiding neurological damage is one of the main aims of dissection surgery, as Carrel emphasised a century ago. Deep hypothermia with circulatory arrest (HCA) is the most common technique for cerebral protection in aortic surgery with a well defined safe period for circulatory arrest, of $45-50$ minutes at a core temperature of $20^{\circ} \mathrm{C}$. Systemic hypothermia to extend the period of safe cerebral ischaemia has been the mainstay of neuroprotection for many decades $[28,29]$. Safety of this approach relies on adequate systemic cooling and if this is incomplete, it risks the patient for neurological injury. Introduction of selective antegrade carotid perfusion (ACP) has prolonged this safe period. A combination of cold selective antegrade cerebral perfusion and deep/moderate hypothermic circulatory arrest allows adequate protection for the body and is not associated with higher risk of cerebral microemboli $[30,31]$. The efficacy of selective antegrade cerebral perfusion as an adjunctive to hypothermic arrest has been proven by numerous publications [32, 33]. 
Unilateral brain perfusion, i.e. right subclavian/axillary artery, right carotid artery, brachiocephalic trunk is safe under monitoring with near infrared spectroscopy (NIRS), as nearly $1 / 5$ of the population has an incomplete circle of Willis. Therefore a significant number of patients require bilateral $\mathrm{ACP}$, on the other hand, in the rest population it is still debatable, if in left haemisphere the same temperature can be achieved as the contralateral hemisphere, with unilateral perfusion, after blood has perfused the right side. Further concern is raised with unilateral perfusion, that by aiming for bilateral equal brain saturations, the right haemisphere is may be slightly overperfused, leading to right hemishperal oedema. Near infrared spectroscopy does not provide this type of information, so unilateral perfusion enhances but cannot guarantee cerebral protection. These latter considerations require further research, although applying bilateral ACP may resolve these issues.

In our practice, during HCA, selective antegrade cerebral perfusion is applied through both carotid arteries (DLP Retrograde Coronary Sinus Perfusion Cannula with manual Inflating Cuff ${ }^{\circledR}$, Medtronic Inc., Minneapolis, USA) at a flow rate adapted to keep a constant cerebral $\mathrm{O}_{2}$ saturation each side with a perfusion pressure of $35-40 \mathrm{mmHg}$ [Figure 3]. Cerebral monitoring is performed using NIRS, with the aim of maintaining brain tissue oxygen saturation measures at $65-70 \%$ continuously during perfusion, which should correspond to the induction values.

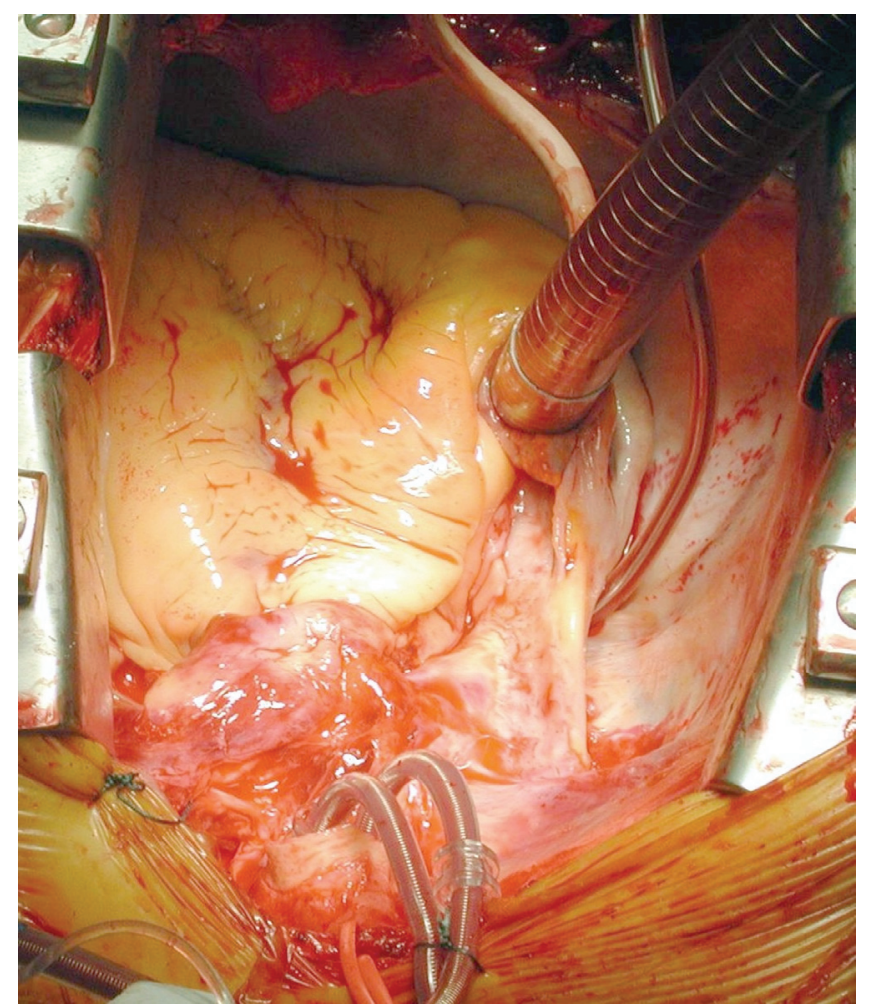

Fig. 3. Selective antegrade carotid perfusion 
Retrograde cerebral perfusion via superior vena cava may also be undertaken, although in arch surgery carotids are available for ACP. If the carotids are severely destroyed by dissection, retrograde cerebral perfusion may be considered as an option, so long carotids are replaced by tube grafts. However, retrograde cerebral perfusion is associated with a significantly higher incidence of temporary neurological complications, later extubation, longer ICU-stay, hospitalization, than ACP [34].

In a study of 4670 patients who underwent extensive aortic surgery between 1985 and 2002 at the Heart Centre Leipzig, Germany, superiority of ACP over retrograde cerebral perfusion or stand-alone deep hypothermia was confirmed. ACP was associated with 5-14\% mortality and $4-10 \%$ permanent neurological deficit, retrograde cerebral perfusion showed $12-22 \% ; 10-20 \%$, stand- alone deep hypothermia $15-30 \% ; 8-24 \%$, respectively.

Rigorous patient temperature monitoring is crucial to a balanced cerebral protection during $\mathrm{CPB}$. As a standard body temperature measurement, rectal monitoring has been widely used for decades in many departments. In the past decade tympanic and urinary bladder temperature monitoring has been studied and suggested as an alternative to gold standard. Tympanic measurements provide a very good estimation of the brain temperature with minimal delay in the changes due to its close proximity to the central nervous system [35, 36]. Tympanic measurements are well established even in everyday body temperature measurement with portable thermometers in general health care. However, to obtain reliable values from the tympanic membrane, debris free status of the ear channel has to be proven by otoscopy prior to placement of probe, followed by a good heat insulation of ears by i.e. using swabs to prevent accidental heat loss due to theatre ventilation system.

Urinary probes are available built into urinary catheters, so their placement is very convenient, although measurement reliability depends slightly on urine flow [37]. Rectal measurements are less reliable, since faecal matter prevents sudden heat exchange [38]. Nasopharyngeal/oesophageal temperature monitoring in HCA as standard measurement site, has limitations as it may significantly over- and underestimate brain temperatures during the cooling and rewarming phases [39-41]. Akata et al have furthermore demonstrated, that pulmonary artery temperatures closely reflect changes in brain temperatures, but nasopharyngeal/oesophageal measurements could not be considered as a reliable index of brain temperature during the rapid induction of moderate/deep hypothermia [42].

\section{Follow-up}

As aortic dissections often develop on a background of preexisting aortic aneurysms, this mandates regular follow-up in these patients to facilitate elective intervention when required. These elective operations carry less risks as the patient can be thoroughly prepared using the ideal imaging modalities and optimizing the patient's medical condition for major surgery. At the Department of Cardiothoracic Surgery, University Hospital Regensburg, Germany there is a regular aortic day-clinic available on weekly basis for preand postoperative follow-ups, that has been running for over a decade, which allows this endangered patient population to be monitored on a 6-monthly basis. Regular postoperative monitoring is essential to provide good long term results with the early discovery of endoleaks, progression of aortopathy, control of hypertension, etc. As the AAS population is 
young, average age of involved is sixty years [3], regular follow up contributes to the restoration of health in this still relatively active age group.

Patients with AAS have a long-term outcome which is less favorable when associated with a past medical history of previous cardiac surgery or generalized atherosclerosis [43]. Surgical repair has been recommended when maximal ascending aortic diameter reaches $50 \mathrm{~mm}$ (45 $\mathrm{mm}$ at Marfan's syndrome) or $60 \mathrm{~mm}$ when involving the descending aorta, although decision making has to be individualized to patient and other comorbidities [10]. Blood pressure control is essential for these patients, with the aim of maintaining the blood pressure no more than $130 / 80 \mathrm{mmHg}$ [44]. If there is a well know hereditary component present, the patient's complete family should be offered the opportunity to be genetically tested and councilled.

Some recent publications have already highlighted the role of angiotensin II in progression of aortic aneurysms, although the relative contribution of its type 1 (AT1) and type 2 (AT2) receptors remain unknown. Habashi et al demonstrated that loss of AT2 expression accelerates the aberrant growth and rupture of aorta in a mouse model of Marfan's syndrome. Losartan, a selective AT1 blocker reduces aneurysm progression in mice; a full protection required intact AT2 signaling. The angiotensin-converting enzyme inhibitor enalapril, which limits signaling through both receptors, is less effective. Both drugs attenuated transforming growth factor- $B$ (TGF $\beta$ ) signaling in the aorta, but losartan uniquely inhibited TGF $\beta$-mediated activation of extracellular signal regulated kinase, by allowing continued signaling through AT2, which shows the protective nature of AT2 signaling and the choice of therapy in aortic aneurysms [45].

International multicentric studies are currently evaluating the possible pharmacological prevention and postoperative medical supportive therapy options in Marfan's syndrome provided by AT1 blockers, especially losartan in a combination with a B-blocker, such as nebivolol. The key molecule in aortic aneurysms, TGF $B$, normally attached to extracellular matrix, is free and activated. Under experimental circumstances, TGF $B$ blockade prevents aortic wall damage and dilatation. AT1 blockers exert an anti-TGF $§$ effect; trials are now ongoing for evaluating the effect of losartan compared with atenolol or nebivolol. The third generation $B$-blocker nebivolol retains the $B$-adrenergic blocker effects on heart rate and further exerts antistiffness effects, typically increased in aortic aneurysms [46, 47].

After evaluation these ongoing human studies we have more insight to the pharmacological support of AAS and aortic aneurysms, which completes the surgical management possibilities of this severe disease group.

\section{References}

[1] Hirst AE, Johns Vr, Kime SW. Dissecting aneurysm of the aorta: a review of 505 cases. Medicine (Baltimore) 1958;37:217-279.

[2] Ehrlich MP, Ergin MA, McCullough JN, Lansman SL, Galla JD, Bodian CA, Apaydin A, Griepp RB. Results of immediate surgical treatment of all acute type A dissections. Circulation 2000;102: 248-252.

[3] Hagan PG, Nienaber CA, Isselbacher EM, Bruckman D, Karavite DJ, Russman PL; International Registry of Acute Aortic Dissection (IRAD). New insights into an old disease. JAMA 2000;283:897-903. 
[4] Olsson C, Thelin S, Stahle E, Ekbom A, Granath F. Thoracic aortic aneurysm and dissection: increasing prevalence and improved outcomes reported in a nationwide population-based study of more than 14000 cases from 1987 to 2002. Circulation 2006;114:2611-2618.

[5] Mehta RH, Manfredini R, Hassan F, Sechtem U, Bossone E, Oh JK, Cooper JV, Smith DE, Portaluppi F, Penn M, Hutchison S, Nienaber CA, Isselbacher EM, Eagle KA; International Registry of Acute Aortic Dissection (IRAD) Investigators. Chronobiological patterns of acute aortic dissection. Circulation 2002;106:11101115.

[6] Millar-Craig MW, Bishop CN, Raftery EB. Circadian variation of blood pressure. Lancet 1978;311:795-797.

[7] Boutouyrie P, Germain DP, Fiessinger JN, Laloux B, Perdu J, Laurent S. Increased carotid wall stress in vascular Ehlers-Danlos syndrome. Circulation 2004;109:1530-1535.

[8] Golledge J, Eagle KA. Acute aortic dissection. Lancet 2008;372:55-66.

[9] Evangelista Masip A. Progress in the acute aortic syndrome. Rev Esp Cardiol 2007;60:428-439.

[10] Erbel R, Alfonso F, Boileau C, Dirsch O, Eber B, Haverich A, Rakowski H, Struyven J, Radegran K, Sechtem U, Taylor J, Zollikofer C, Klein WW, Mulder B, Providencia LA; Task Force on Aortic Dissection, European Society of Cardiology. Diagnosis and management of aortic dissection. Eur Heart J 2001;22:1642-1681.

[11] Kaji S, Akasaka T, Horibata Y, Nishigami K, Shono H, Katayama M, Yamamuro A, Morioka S, Morita I, Tanemoto K, Honda T, Yoshida K. Long-term prognosis of patients with type a aortic intramural hematoma. Circulation 2002;106: 248-252.

[12] Arts CHP, Muhs BE, Moll FL, Verhagen HJM. Endovascular management of type B aortic dissection. In: Davies AH, Mitchell AWM, eds. Vascular and endovascular surgery highlights 2006-2007. Abingdon: Health Press, 2007.

[13] Göbölös L, Philipp A, Foltan M, Wiebe K. Surgical management for Stanford type A aortic dissection: direct cannulation of real lumen at the level of the Botallo's ligament by Seldinger technique. Interact Cardiovasc Thorac Surg. 2008; 6:11071109.

[14] Schachner T, Vertacnik K, Laufer G, Bonatti J. Axillary artery cannulation in surgery of the ascending aorta and the aortic arch. Eur J Cardiothorac Surg 2002; 22: 445-447.

[15] Yavuz S, Gönzü MT, Türk T. Axillary artery cannulation for arterial inflow in patients with acute dissection of the ascending aorta. Eur J Cardiothorac Surg 2002; 22: 313315.

[16] Whitlark JD, Goldman SM, Sutter FP. Axillary artery cannulation in acute ascending aortic dissections. Ann Thorac Surg 2000; 69: 1127-1129.

[17] Neri E, Massetti M, Capannini G, Carone E, Tucci E, Diciolla F. Axillary artery cannulation in type A aortic dissection operations. J Thorac Cardiovasc Surg 1999; 118: 324-329.

[18] Schachner T, Laufer G, Vertacnik K, Bonaros N, Nagiller J, Bonatti J. Is the axillary artery a suitable cannulation site in aortic surgery? J Cardiovasc Surg 2004; 45: 1519. 
[19] Pasic M, Schubel J, Bauer M, Yankah C, Kuppe H, Weng YG, Hetzer R. Cannulation of the right axillary artery for surgery of acute type A aortic dissection. Eur J Cardiothorac Surg 2003; 24: 231-236.

[20] Watanabe K, Fukuda I, Osaka M, Imazuru T. Axillary artery and transapical aortic cannulation as an alternative to femoral artery cannulation. Eur J Cardiothorac Surg 2003; 23: 842-843.

[21] Schachner T, Nagiller J, Zimmer A, Laufer G, Bonatti J. Technical problems and complications of axillary artery cannulation. Eur J Cardiothorac Surg 2005; 27: $634-637$.

[22] Sinclair MC, Singer RL, Manley NJ, Montesano RM. Cannulation of axillary artery for cardiopulmonary bypass: safeguards and pitfalls. Ann Thorac Surg 2003; 75: $931-$ 934.

[23] Merkkola P, Tulla H, Ronkainen A, Soppi V, Oksala A, Koivisto T, Hippelainen M. Incomplete circle of Willis and right axillary artery perfusion. Ann Thorac Surg 2006; 82: 74-79.

[24] Wada S, Yamamoto S, Honda J, Hiramoto A, Wada H, Hosoda Y. Transapical aortic cannulation for cardiopulmonary bypass in type A aortic dissection operations. J Thorac Cardiovasc Surg. 2006; 2: 369-372.

[25] Urbanski PP, Lenos A, Lindemann Y, Weigang E, Zacher M, Diegeler A. Carotid artery cannulation in aortic surgery. J Thorac Cardiovasc Surg 2006; 132: 1398-1403.

[26] Di Eusanio M, Ciano M, Labriola G, Lionetti G, Di Eusanio G. Cannulation of the innominate artery during surgery of the thoracic aorta: our experience in 55 patients. Eur J Cardiothorac Surg 2007; 32: 270-273.

[27] Fusco DS, Shaw RK, Tranquilli M, Kopf GS, Elefteriades JA. Femoral cannulation is safe for type A dissection repair. Ann Thorac Surg 2004; 78: 1285-1289.

[28] Borst HG, Schaudig A, Rudolph W. Arteriovenous fistula of the aortic arch: repair during deep hypothermia and circulatory arrest. J Thorac Cardiovasc Surg 1964;48:443-447.

[29] Hogue CW, Palin CA Jr, Arrowsmith JE. Cardiopulmonary bypass management and neurologic outcomes: an evidence based appraisal of current practices. Anesth Analg 2006;103:1-37.

[30] Kamiya H, Hagl C, Kropivnitskaya I, Bothig D, Kallenbach K, Khaladj N, Martens A, Haverich A, Karck M. The safety of moderate hypothermic lower body circulatory arrest with selective cerebral perfusion: a propensity score analysis. J Thorac Cardiovasc Surg 2007; 133: 501-509.

[31] Kamiya H, Klima U, Hagl C, Logemann F, Winterhalter M, Shrestha ML, Kallenbach K, Khaladj N, Haverich A, Karck M. Cerebral microembolization during antegrade selective cerebral perfusion. Ann Thorac Surg 2006; 81: 519-521.

[32] Hagl C, Khaladj N, Peterss S, Hoeffler K, Winterhalter M, Karck M, Haverich A. Hypothermic circulatory arrest with and without cold selective antegrade cerebral perfusion: impact on neurological recovery and tissue metabolism in an acute porcine model. Eur J Cardiothorac Surg 2004; 26: 73-80.

[33] Khaladj N, Peterss S, Oetjen P, von Wasielewski R, Hauschild G, Karck M, Haverich A, Hagl C. Hypothermic circulatory arrest with moderate, deep or profound 
hypothermic selective antegrade cerebral perfusion: which temperature provides best brain protection? Eur J Cardiothorac Surg 2006; 30: 492-498.

[34] Apostolakis E, Koletsis EN, Dedeilias P, Kokotsakis JN, Sakellaropoulos G, Psevdi A, Bolos K, Dougenis D. Antegrade versus retrograde cerebral perfusion in relation to postoperative complications following aortic arch surgery for acute aortic dissection type A. J Card Surg. 2008;23:480-487.

[35] Baker MA, Stocking RA, Meehan JP. Thermal relationship between tympanic membrane and hypothalamus in conscious cat and monkey. J Appl Physiol 1972;32:739742 .

[36] Benzinger M. Tympanic thermometry in surgery and anesthesia. JAMA 1969;209:12071211.

[37] Horrow JC, Rosenberg H. Does urinary catheter temperature reflect core temperature during cardiac surgery? Anesthesiology 1988;69:986-989.

[38] Severinghaus JW. Temperature gradients during hypothermia. Ann N Y Acad Sci 1959;80:515-521.

[39] Stone JG, Young WL, Smith CR, Solomon RA, Wald A, Ostapkovich N, Shrebnick DB. Do standard monitoring sites reflect true brain temperature when profound hypothermia is rapidly induced and reversed? Anesthesiology 1995;82:344-351.

[40] Hercus V, Cohen D, Bowring AC. Temperature gradients during hypothermia. BMJ 1959;1:1439-1441.

[41] Stefaniszyn HJ, Novick RJ, Keith FM, Salerno TA. Is the brain adequately cooled during deep hypothermic cardiopulmonary bypass? Current Surgery 1983;40:294-297.

[42] Akata T, Yamaura K, Kandabashi T, Sadamatsu S, Takahashi S. Changes in body temperature during profound hypothermic cardiopulmonary bypass in adult patients undergoing aortic arch reconstruction. J Anesth 2004;18:73-81

[43] Tsai TT, Evangelista A, Nienaber CA, Trimarchi S, Sechtem U, Fattori R, Myrmel T, Pape L, Cooper JV, Smith DE, Fang J, Isselbacher E, Eagle KA; International Registry of Acute Aortic Dissection (IRAD). Long-term survival in patients presenting with type A acute aortic dissection: insights from the International Registry of Acute Aortic Dissection (IRAD). Circulation 2006;114:350-356.

[44] Shores J, Berger KR, Murphy EA, Pyeritz RE. Progression of aortic dilatation and the benefit of long-term beta-adrenergic blockade in Marfan's syndrome. N Engl J Med 1994;330:1335-1341.

[45] Habashi JP, Doyle JJ, Holm TM, Aziz H, Schoenhoff F, Bedja D, Modiri AN, Judge DP, Dietz HC. Angiotensin II type 2 receptor signaling attenuates aortic aneurysm in mice through ERK antagonism. Science 2011;332:361-365.

[46] Gambarin FI, Favalli V, Serio A, Regazzi M, Pasotti M, Klersy C, Dore R, Mannarino S, Vigano M, Odero A, Amato S, Tavazzi L, Arbustini E. Rationale and design of a trial evaluating the effects of losartan vs. nebivolol vs. the association of both on the progression of aortic root dilation in Marfan syndrome with FBN1 gene mutations. J Cardiovasc Med 2009;10:354-362. 
[47] Radonic T, de Witte P, Baars MJ, Zwinderman AH, Mulder BJ, Groenink M; COMPARE study group. Losartan therapy in adults with Marfan syndrome: study protocol of the multi-center randomized controlled COMPARE trial. Trials. 2010;12:11:3. 
VII 


\title{
Double-locus lymphoplasmacytic aortitis
}

\author{
Szabolcs Miskolczi', Mary N Sheppard ${ }^{2}$, Gábor Bogáts ${ }^{3}$ and \\ Laszlo Göbölös'
} DOI: $10.1177 / 0218492317732250$ journals.sagepub.com/home/aan

\begin{abstract}
Thoracic aortic aneurysm is an indication for major cardiovascular operative procedures. The etiology is usually hypertension and/or atherosclerotic disease; reaching a certain diameter often results in acute aortic syndrome. Immunoglobulin G4-related aortitis, characterized by lymphoplasmacytic vascular tunica media induration without well-defined underlying infectious or autoimmune systemic causes, is uncommon. Histological similarity to immunoglobulin G4 disease in other organs suggests that this aortitis might be a manifestation of systemic pathology. We describe a case of double-locus lymphoplasmacytic aortitis in a 72-year-old man who had the incidental finding of intramural hematoma on elective thoracic computed tomography as part of a respiratory work-up.
\end{abstract}

\section{Keywords}

Aortic aneurysm, Thoracic, Aortitis, Intramural hematoma, Immunoglobulin G4, Plasma cells

\section{Introduction}

Immunoglobulin $\mathrm{G}$ subclass 4 (IgG4)-related aortitis is part of a systemic disease with high variability in diverse organ manifestations, including autoimmune pancreatitis, retroperitoneal fibrosis, IgG nephropathy, sclerosing cholangitis, mediastinal pseudotumors, and inflammatory pericarditis. It is commonly observed in elderly men with abdominal aortic aneurysm (AAA) and concomitant retroperitoneal fibrosis; $3 / 4$ have increased serum IgG4 levels. ${ }^{1}$ Studies have identified significant differences between the abdominal and thoracic presentations; the latter appears more frequently in females and correlates less with serum $\operatorname{IgG} 4$, although the histopathological picture is similar in both. ${ }^{2}$ Inflammatory aortic aneurysms represent $4 \%$ of all thoracic aneurysms according to Kasashima and colleagues, ${ }^{3,4}$ but IgG4 aortitis accounts for $57 \%$ of all inflammatory aortic diseases. Although the pathological process is mainly localized in the adventitia, some observers have described variable extensions of intramural lymphoplasmacytic infiltrations, suggesting an autoimmune response directed against the different aortic wall layers. ${ }^{2}$

\section{Case report}

A 72-year-old man attended Respiratory Outpatient Care with coughing over 5 years and recent shortness of breath; he denied any form of angina. Past medical history consisted of hypertension, previous smoking, and inflammatory infrarenal abdominal aortic aneurysm (AAA) repair with an interposition tube graft 4 years earlier. Previous abdominal computed tomography (CT) findings were not available at this admission. Histology had confirmed lymphoplasmacytic changes in the intraoperative abdominal specimens. Vascular surgical follow-up did not discover any further progression of aortic disease. Recent spirometry suggested mild chronic obstructive pulmonary disease, but the transfer factors were not reduced. Elective chest $\mathrm{CT}$ was initiated by the respiratory team. As an incidental finding, CT demonstrated an intramural hematoma (Figure 1a) throughout the ascending aorta, appearing to terminate in the transverse arch, but no evidence of morphological pulmonary disease.

\footnotetext{
'Department Cardiothoracic Surgery, Southampton General Hospital, Southampton, UK

${ }^{2}$ Department of Cardiovascular Pathology, Cardiovascular Sciences Division, St George's Hospital, London, UK

${ }^{3}$ Department of Cardiac Surgery, University of Szeged, Szeged, Hungary
}

\section{Corresponding author:}

Laszlo Göbölös, Department of Cardiothoracic Surgery, Southampton General Hospital, Tremona Rd, Southampton SOI6 6YD,

United Kingdom.

Email: isartor@hotmail.com 

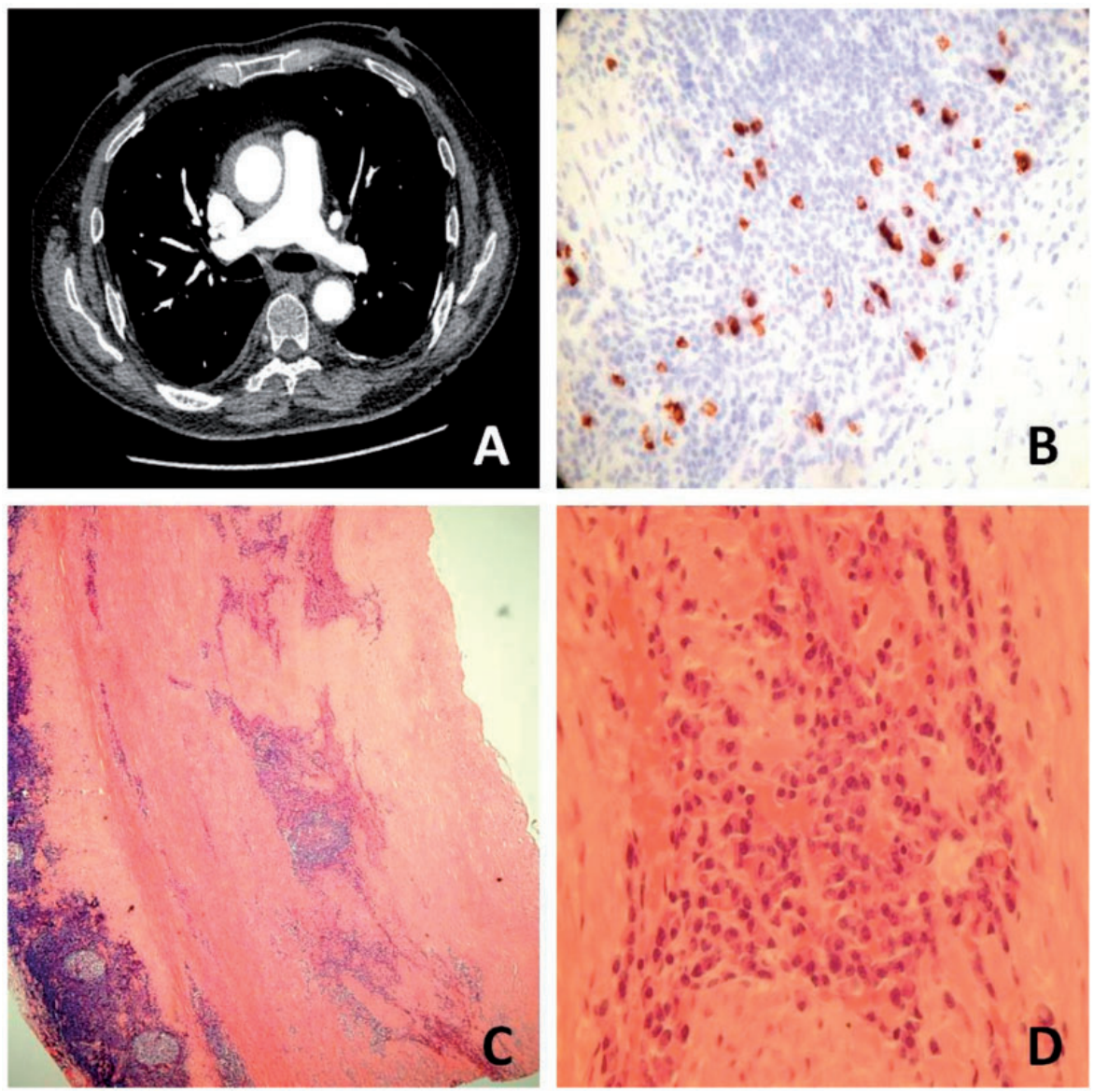

Figure I. (a) Computed tomography showing the unfolded ascending aorta with a rim of intramural hematoma to a depth of up to $14 \mathrm{~mm}$ at the level of the pulmonary artery bifurcation. (b) Immunostaining of plasma cells with IG4 antibody. Immunoperoxidase staining, original magnification $\times 600$. (c) Low-powered view of the aorta with lymphoplasmacytic inflammation in the media. Hematoxylin and eosin stain, original magnification $\times 200$. (d) High-powered view of the aortic media, showing plasma cells and lymphocytes. Hematoxylin and eosin stain, original magnification $\times 700$.

The maximal aortic diameter was $5 \mathrm{~cm}$, and the coronary calcium score was positive at 2769 (equal to the 96 percentile matched for ethnicity, sex, and age). CT-angiography revealed extensive coronary artery calcification in the proximal left anterior descending, proximal and mid right coronary arteries. Echocardiography showed left ventricular pump function in the lower normal range, without regional wall motion abnormalities or valvular pathologies. The patient underwent supracoronary interposition graft replacement of the ascending aorta (28-mm Vascutek Gelweave; Vascutek Ltd., Inchinnan, Scotland, UK), as per our institutional protocol for intramural hematoma, within one week of admission, using the "closed distal" technique, and additional doublecoronary artery bypass with saphenous venous grafts to the left anterior descending and right coronary artery. The aortic crossclamp time was $76 \mathrm{~min}$, cardiopulmonary bypass time was $104 \mathrm{~min}$. Histopathology demonstrated lymphoplasmacytic aortitis (Figure 1c, 1d) associated with the intramural hematoma; a similar microscopic picture to the previous AAA repair. The ascending aortic specimen stained for IgG4 within the plasma cells (Figure 1b). Serum investigations revealed normal IgG4 levels $\left(<1.3 \mathrm{~g} \cdot \mathrm{L}^{-1}\right)$, autoimmune and inflammatory markers were within the normal ranges, and the eosinophil count was twice the upper limit of normal $\left(<0.5 \times 10^{9} / \mathrm{L}\right)$. After an uneventful postoperative course, the patient was discharged home on steroids on postoperative day 10. Follow-up CT after six months confirmed a settled intrathoracic status and excluded any further abdominal organic manifestations and retroperitoneal fibrosis. Therefore, an interdisciplinary decision by us and the hematology-immunology team recommended no long-term steroid treatment.

\section{Discussion}

IgG4-related disease, first defined as an independent disease less than 15 years ago, has been reported in several organs. Inflammatory aortic aneurysms are uncommon and differ in etiology, but the 
lymphoplasmacytic subtype is probably associated with IgG4-related systemic disease. IgG4-related disease is usually characterized by fibrous tissue proliferation with numerous infiltrations of IgG4-positive plasma cells, raised IgG4 plasma levels, and steroid sensitivity. The efficacy of long-term steroid therapy is still debated because it might reduce adventitial thickening and periorgan fibrosis, although it could also increase the risk of aortic rupture by thinning the aortic wall. ${ }^{4}$ There are several triggers anticipated in the background of IgG4related aortitis, leading to aneurysmal dilatation or acute aortic syndrome, including autoimmune reactions against aortic wall elements, ${ }^{5}$ and chronic aortic wall infections caused by Cytomegalovirus or Chlamydia. ${ }^{6,7}$ Some studies have found that ${ }^{18}$ fluorordeoxyglucose positron-emission tomography might be helpful for initial diagnosis and follow-up of IgG4-related disease if this pathology is suspected from the initial presentation. ${ }^{8}$ These aspects require further investigation, although the relatively low patient numbers do not facilitate large-scale multicenter studies. Our report highlights a fairly unusual double-locus thoracic and abdominal lymphoplasmacytic aortitis, which initially presented as AAA and later as thoracic intramural hematoma as an incidental outpatient finding. However, this patient did not have raised serum $\mathrm{IgG} 4$ levels, which feature in $25 \%$ of lymphoplasmacytic aortitis cases.

\section{Declaration of conflicting interests}

The author(s) declared no potential conflicts of interest with respect to the research, authorship, and/or publication of this article.

\section{Funding}

The author(s) received no financial support for the research, authorship, and/or publication of this article.

\section{References}

1. Ishizaka N, Sakamoto A, Imai Y, Terasaki F and Nagai R. Multifocal fibrosclerosis and IgG4-related disease involving the cardiovascular system. J Cardiol 2012; 59: 132-138.

2. Agaimy A, Weyand M and Strecker T. Inflammatory thoracic aortic aneurysm (lymphoplasmacytic thoracic aortitis): a 13-year-experience at a German Heart Center with emphasis on possible role of IgG4. Int J Clin Exp Pathol 2013; 6: 1713-1722.

3. Kasashima S, Zen Y, Kawashima A, et al. A clinicopathologic study of immunoglobulin G4-related sclerosing disease of the thoracic aorta. J Vasc Surg 2010; 52: 1587-1595.

4. Kasashima S, Zen Y, Kawashima A, Endo M, Matsumoto $\mathrm{Y}$ and Kasashima F. A new clinicopathological entity of IgG4-related inflammatory abdominal aortic aneurysm. J Vasc Surg 2009; 49: 1264-1271.

5. Vaglio A, Greco P, Corradi D, et al. Autoimmune aspects of chronic periaortitis. Autoimmun Rev 2006; 5: 458-464.

6. Karlsson L, Gnarpe J, Nääs J, et al. Detection of viable Chlamydia pneumoniae in abdominal aortic aneurysms. Eur J Vasc Endovasc Surg 2000; 19: 630-635.

7. Tanaka S, Komori K, Okadome K, Sugimachi K and Mori R. Detection of active cytomegalovirus infection in inflammatory aortic aneurysms with RNA polymerase chain reaction. J Vasc Surg 1994; 20: 235-243.

8. Lalueza A, Ruiz S, Villacampa F, et al. Recurrent aortitis associated with IgG4-related disease. Circ J 2016; 80: 1044-1046. 
VIII 


\title{
Transapical perfusion for peri-arrest salvage during transcutaneous aortic valve implantation
}

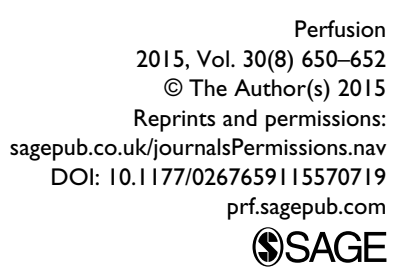

(S)AGE

\section{Göbölös,' GM Tsang,' N Curzen,, 2,3 AL Calver² and SK Ohri'}

\begin{abstract}
An 80-year-old man developed severe haemodynamic instability during a transapical aortic valve implantation. He was not suitable for a conventional surgical approach due to comorbidities and patent aortocoronary bypass grafts also limited further stabilizing actions. As a bail-out procedure, we demonstrate the feasibility of transapical arterial cannulation by crossing a newly implanted TAVI valve in order to establish an emergency bypass circuit
\end{abstract}

\section{Keywords}

TAVI; haemodynamic instability; transapical perfusion; ECMO; bridge-to-recovery

\section{Introduction}

Transcutaneous aortic valve implantation (TAVI) is increasingly the treatment of choice for high-risk patients with aortic stenosis who are not suitable for conventional aortic valve replacement. Implantation can be performed either through a vascular route, e.g., femoral artery, or transapically via a mini-thoracotomy if the transvascular route is contraindicated. However, if sustained haemodynamic instability occurs, this limited access poses a technical challenge to the institution of heart-lung bypass. As a bail-out procedure and to avoid the conventional median sternotomy, which could be extremely challenging in a significant proportion of this patient population, we report a case in which transapical arterial cannulation was used to establish a bypass circuit through the already implanted prosthetic valve.

\section{Case Report}

An 80-year-old man presented with severe aortic valve stenosis. He had undergone coronary bypass grafting in 1999. Recent angiography had shown patent grafts without new native disease. He was relatively immobile as a result of a previous laminectomy and had severely impaired lung function due to chronic obstructive pulmonary disease. For these reasons, the multidisciplinary TAVI meeting concluded that he was a candidate for this procedure. However, as the peripheral vascular access was inadequate on both sides due to significant flow-limiting lesions with extensive calcification, a transapical implantation route was planned through an anterolateral mini-thoracotomy.

During deployment of the transcatheter aortic valve (23 mm Edwards Sapien XT Transcatheter Heart Valve", Edwards Lifesciences, Irvine, CA, USA), the patient developed profound hypotension. This condition did not respond to inotropic support. A decision was, therefore, made to establish heart-lung bypass, although the arterial access was significantly limited by both the heavily calcified peripheral vascular bed and the mediastinal adhesions due to the previous bypass surgery with patent grafts. As an emergency salvation, a transapical Seldinger type arterial cannula (18 Fr Medtronic EOPA elongated one-piece arterial cannula,

\footnotetext{
'Department of Cardiothoracic Surgery, University Hospital Southampton, NHS Foundation Trust, Southampton, UK

2Department of Cardiology, University Hospital Southampton, NHS

Foundation Trust, Southampton, UK

${ }^{3}$ Faculty of Medicine, University of Southampton, Southampton, UK
}

\section{Corresponding author:}

Laszlo Göbölös

Department of Cardiothoracic Surgery

University Hospital Southampton

NHS Foundation Trust

Southampton SOI6 6YD

UK.

Email: isartor@hotmail.com 


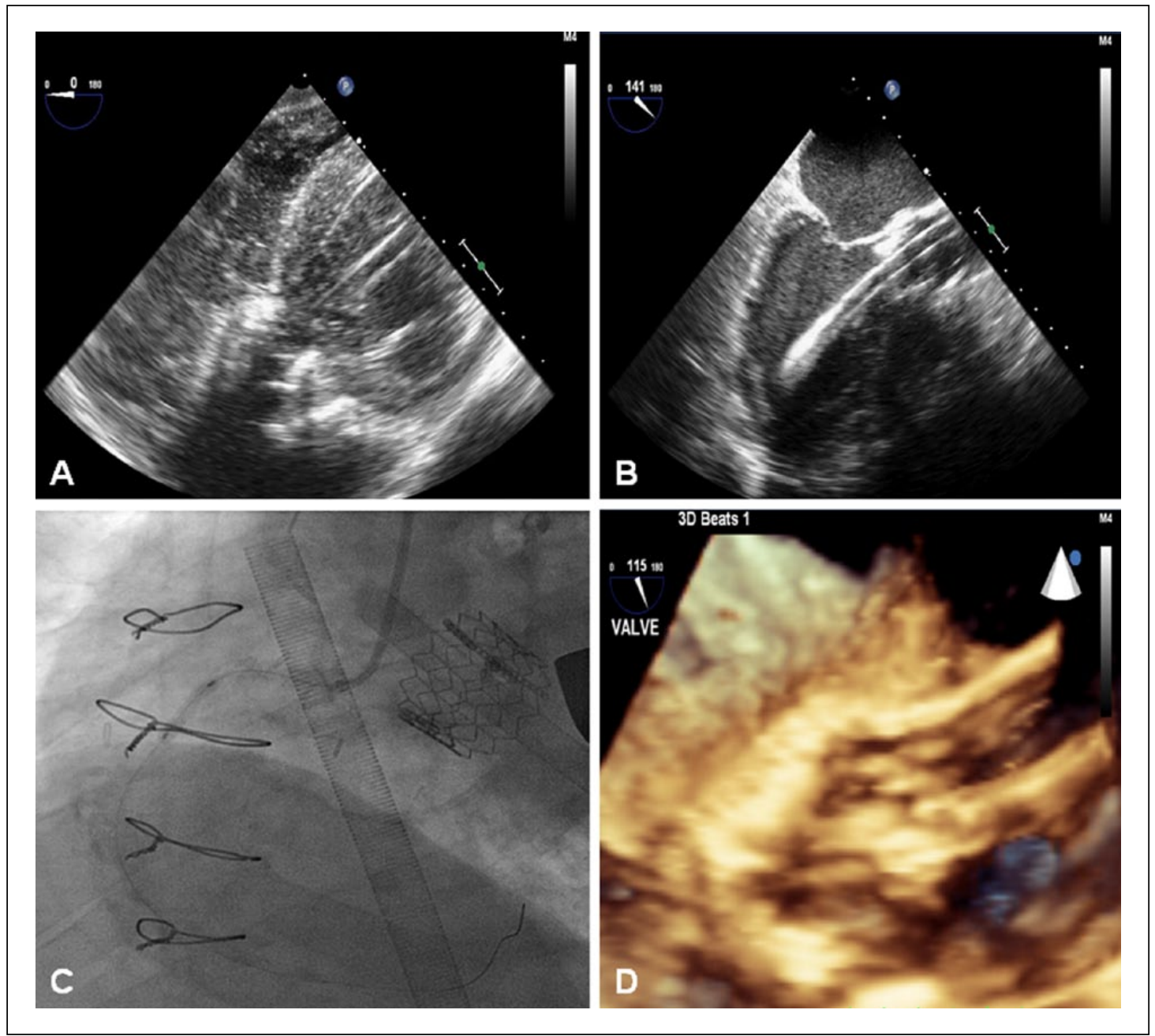

Figure I. Panel A - Apical view of left ventricle with the arterial cannula in situ on the transoesophageal echocardiogram. Panel B - Transvalvar position of the arterial cannula on the transoesophageal echocardiogram.

Panel C - Fluoroscopic image of both arterial and venous cannulae; arterial in the transvalvar position.

Panel D - 3D echocardiographic reconstruction of the transvalvar cannula.

Medtronic Inc., Minneapolis, MN, USA) was inserted, following the removal of the TAVI applicator sheath, with the aid of a guide-wire under simultaneous transoesophageal echocardiography and fluoroscopic guidance through the already implanted TAVI valve (Figure 1) and bypass was established between this site and the right femoral vein. During resuscitation, echocardiography demonstrated profound new right ventricular systolic dysfunction and inferoposterior left ventricular regional wall motion abnormality. Flow down the native right coronary was occluded and a balloon angioplasty was performed to re-establish flow. The left ventricular function improved with reperfusion, although the right ventricular dysfunction persisted. The patient was kept on an extracorporeal membrane oxygenation (ECMO) circuit (Maquet Rotaflow', Maquet Cardiopulmonary AG, Hirrlingen,
Germany) as a bridge-to-recovery for 24 hours, at which time, a haemodynamic stable stage was achieved and the patient could be weaned from the cardiorespiratory support. Although the immediate postoperative course was uneventful, the patient developed an irreversible severe lower respiratory tract infection several days later and died on the $10^{\text {th }}$ postoperative day.

\section{Discussion}

Aortic valve stenosis is the most widely prevalent valvular disease in the ageing population. Surgical valve replacement is the standard of care for both symptomatic and prognostic aspects; however, the conventional surgical approach is associated with an increased peroperative risk for those patients who present with pre-existing comorbidities. ${ }^{1-3}$ For the high peroperative 
risk population, an alternative was first provided by Cribier at al. in 2002; a transcatheter aortic valve was implanted following balloon valvuloplasty. ${ }^{4}$ Hence, this approach is using a minimal access, either through the femoral artery or the apex of the heart; in case of an emergency, further salvation steps are also limited. Furthermore, previous heart surgery results in significant mediastinal adhesions; therefore, an urgent sternotomy during profound haemodynamic instability is not feasible. A femoral artery cannulation is - even without pre-existing severe peripheral vascular disease - a time-consuming technical challenge during resuscitation in a frail patient; the already exposed heart apex offers an excellent arterial inflow target in this extreme situation. The safety of transapical aortic cannulation has already been proven by Wada et al. ${ }^{5}$ in a large number of type A aortic dissections although, in these patients, the set-up and the surgical control is not as much limited. We describe a case that illustrates the feasibility of transapical arterial cannulation by crossing a newly implanted TAVI valve in order to establish an emergency bypass circuit. This approach can provide nearly immediate circulatory support in a hybrid theatre and show an alternative for these high-risk patients as a bridge-to-recovery.

\section{Declaration of Conflicting Interest}

The authors declare that there is no conflict of interest.

\section{Funding}

This research received no specific grant from any funding agency in the public, commercial or not-for-profit sectors.

\section{References}

1. Iung B, Baron G, Butchart EG, et al. A prospective survey of patients with valvular heart disease in Europe: The Euro Heart Survey on Valvular Heart Disease. Eur Heart J 2003; 13: 1231-1243.

2. Vahanian A, Baumgartner H, Bax J, et al.; Task Force on the Management of Valvular Hearth Disease of the European Society of Cardiology; ESC Committee for Practice Guidelines. Guidelines on the management of valvular heart disease: The Task Force on the Management of Valvular Heart Disease of the European Society of Cardiology. Eur Heart J 2007; 28: 230-268.

3. Brown JM, O'Brien SM, Wu C, Sikora JA, Griffith BP, Gammie JS. Isolated aortic valve replacement in North America comprising 108,687 patients in 10 years: changes in risks, valve types, and outcomes in the Society of Thoracic Surgeons National Database. J Thorac Cardiovasc Surg 2009; 137: 82-90.

4. Cribier A, Eltchaninoff $\mathrm{H}$, Bash A, et al. Percutaneous transcatheter implantation of an aortic valve prosthesis for calcific aortic stenosis: first human case description. Circulation 2002; 106: 3006-3008.

5. Wada S, Yamamoto S, Honda J, Hiramoto A, Wada H, Hosoda Y. Transapical aortic cannulation for cardiopulmonary bypass in type A aortic dissection operations. $J$ Thorac Cardiovasc Surg 2006; 132: 369-372. 
Copyright of Perfusion is the property of Sage Publications, Ltd. and its content may not be copied or emailed to multiple sites or posted to a listserv without the copyright holder's express written permission. However, users may print, download, or email articles for individual use. 
IX 


New Emirates Medical Journal

\title{
CASE REPORT
}

\section{An Aortic "Supravalvular Shelf” is Not Always Innocuous}

\author{
Laszlo Göbölös ${ }^{1, *}$, Gurjyot Bajwa ${ }^{1}$, Jehad Ramahi ${ }^{1}$, Pier Carlo Bergonzi ${ }^{2}$ and Gopal Bhatnagar ${ }^{1}$ \\ ${ }^{1}$ Department of Cardiac Surgery, Heart and Vascular Institute, Cleveland Clinic Abu Dhabi, UAE \\ ${ }^{2}$ Department of Cardiovascular Intensive Care, Cleveland Clinic Abu Dhabi, UAE
}

\begin{abstract}
:
Supravalvular aortic stenosis is a rare cause of secondary aortic root distension and/or aortic valve regurgitation. Non-syndromic aortic aneurysms may also occur in young adults and can develop silently, representing an asymptomatic, life-threatening condition. Clinicians should, therefore, be alert to the possibility of this uncommon, but potentially serious disease, often first revealed by an imaging modality requested for other indications, even in case of an established, more benign diagnosis.
\end{abstract}

Keywords: Aortic valve, Supravalvular membrane, Chronic, Aortic dissection, Aortic root.

\begin{tabular}{l|l|l|l}
\hline Article History & Received: October 28, 2019 & Revised: December 26, 2019 & Accepted: December 30, 2019
\end{tabular}

\section{INTRODUCTION}

Supravalvular aortic stenosis is a rare congenital cardiac anomaly characterised by a variable degree of left ventricular outflow tract obstruction, originating from just above the aortic valve. Although the proximal aortic root is not primarily involved, it may show secondary pathological changes leading to the development of aortic valve regurgitation and/or coronary ischaemia. Thickening of the tunica media in the aortic wall secondary to excessive collagen deposition and hypertrophied smooth muscle cells leads to the build-up of the obstructive membrane in cases of supravalvular stenosis [1,2].

Non-syndromic aortic aneurysms are also deemed uncommon in comparison to other cardiovascular conditions in young adults, and may represent an asymptomatic, lifethreatening condition. Therefore, clinicians should be vigilant in the evaluation of patients, as aneurysms are often first detected incidentally on imaging requested for other indications. Any evidence of an enlarged aorta should trigger further investigations; awareness of aortic aneurysms facilitates the reduction of morbidity and mortality associated with this pathology [3 - 5].

\section{CASE DESCRIPTION}

We report the case of a 26-year-old woman who collapsed during her university exam. Her medical history was significant only for morbid obesity (body-mass index of 62

* Address correspondence to this author at the Department of Cardiac Surgery, Heart and Vascular Institute, Cleveland Clinic Abu Dhabi, POBox: 112412, United Arab Emirates; Tel: +971-554-313-513; +971-2-501-9000; Ext. 49700;

E-mail: isartor@hotmail.com $\mathrm{kg} / \mathrm{m}^{2}$ ). Echocardiography on admission diagnosed severe aortic valve regurgitation with a dilated aortic root and a supravalvular membrane above both the right- and left coronary cusps of the aortic valve (Fig. 1; Panels A, B). Surgical correction was recommended, however the patient refused to undergo surgery.

One month later, she was re-admitted with acute pulmonary oedema secondary to cardiac decompensation to our hospital. On physical examination, a faint, soft, decrescendo murmur was detected in the second intercostal space, on Erb's point, in addition to the bilateral crackles up to the mid-pulmonary zones. Routine blood sampling did not reveal any major pathological changes except mild hypokalaemia and mild iron deficiency anaemia. Chest X-ray showed a bovine heart without any further concomitant pathologies. In addition to the known severe aortic regurgitation, a DVT was diagnosed by ultrasound of the left calf, and a chest CT performed to assess for possible PE. Further to a segmental pulmonary embolus within the right upper lobe artery, CT measured a $55 \mathrm{~mm}$ aortic root diameter, and a structure consistent with either the supraaortic membrane considered previously from the echo, or the differential diagnostic possibility of a dissection flap was seen (Figure 1; Panel C). No further flaps or false lumen were visible, and the mid-ascending aorta demonstrated a diameter within the normal range. The peak gradient through the aortic valve measured $11 \mathrm{mmHg}$ with a peak velocity of $163 \mathrm{~cm} / \mathrm{s}$ on Doppler investigation. The aortic regurgitant radius was 1.1 $\mathrm{cm}$, EROA $0.48 \mathrm{~cm}^{2}$, regurgitant jet pressure half time measured $102 \mathrm{~ms}$. The right ventricle was mildly dilated with 
normal systolic function and a moderated pulmonary hypertension was registered.

Intravenous heparin was commenced as a treatment for the $\mathrm{PE}$, and the patient underwent a biological aortic root replacement as part of a Bentall-procedure with a preformed 29 mm xenograft (Medtronic Freesytle ${ }^{\circledR}$, Minneapolis, USA) one week later. The flap containing ascending aorta was resected, which appeared to be rather a localised chronic TAAD (Figure 1; Panel D) than a supravalvular shelf lesion on a visual inspection and was replaced by an interposition tube graft.

Histopathology revealed nodular myxoid degenerative changes in the aortic valve, focal myxoid degeneration and fibrosis of intima and media, with focal cystic medial degeneration in the resected aortic wall segment. There was no evidence of hemorrhage in the vessel wall.

After a short recovery period, the patient was discharged on anticoagulation for the PE and with advice to undergo genetic testing for consideration of hereditary connective tissue disease; the latter was refused by the patient.

\section{DISCUSSION}

Aortic aneurysms are exceptionally uncommon in young
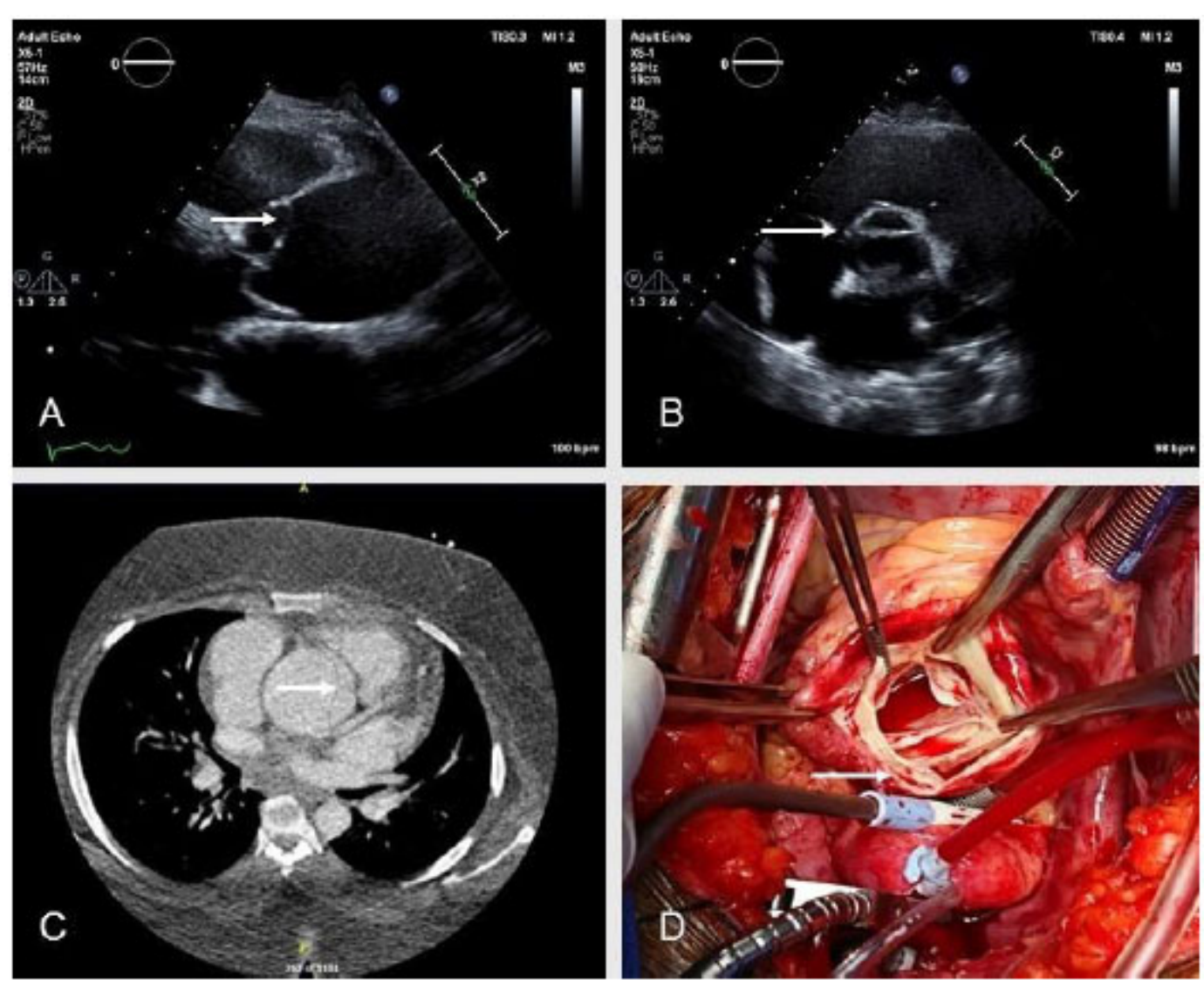

adults and are often asymptomatic, and first discovered incidentally. Surgical solution for younger patients should be more radical than for the elderly TAAD population, to achieve reliable long-term outcomes. More extensive involvement of proximal and distal aorta, myocardial ischaemia and syndromic connective disorders characterise younger patients. Intimal tears localised in the aortic root are also more common at the lower age of presentation. Besides the well known syndromic connective tissue disorders and bicuspid aortic valve, nonsyndromic familial thoracic aortic aneurysms are discovered in $20 \%$ of cases in diagnosed thoracic aneurysms and represent genetically heterogeneous disorders. Mutations in five genes (MYH11, TGFßR1, TGFßR2, MYLK, and ACTA2) have been identified so far with all autosomal dominant inheritance in these cases. From a molecular point of view, consequences of genetic alterations translate into a degenerative remodelling of the aortic medial extracellular matrix resulting in progressive loss of elastic properties. Clinical, anatomical, genetic and molecular evidence suggests that the prevalence of inherited aortic wall disorders in young people presenting with aortic complications is probably higher than expected and diagnosed [6]. Therefore, genetic testing for hereditary aortopathies is essential in young patients having aortic aneurysms.

Fig. (1). Chronic aortic dissection; pre- and intraoperative views.

Panel A - Parasternal long axis echocardiographic view; arrow points on supravalvular flap

Panel B - Parasternal short axis echocardiographic view; arrow marks supravalvular flap

Panel C - Chest computed tomography at level of left main stem; arrow highlights the flap

Panel D - Intraoperative view of chronic aortic dissection; arrow shows the flap 
Our patient had been treated with an intravenous heparin infusion for a DVT discovered incidentally on admission. In cases of a chronic TAAD, heparin does not pose any significant risks as strong connective tissue stabilises the aortic wall lesions. Nevertheless, in acute TAAD heparinisation may lead to fatal complications, including exsanguination from a covered aortic rupture or rapidly developing pericardial tamponade. Therefore, it is essential to distinguish between the symptoms and signs of the acute coronary syndrome and TAAD whenever possible.

\section{LIST OF ABBREVIATION}

$$
\begin{array}{lll}
\text { DVT } & = & \text { Deep venous thrombosis } \\
\text { CT } & = & \text { Computed tomography } \\
\text { PE } & = & \text { Pulmonary embolism } \\
\text { TAAD } & = & \text { Type A aortic dissection }
\end{array}
$$

\section{AUTHOR CONTRIBUTIONS}

- Laszlo Göbölös MD- manuscript writing, image extraction, image rendering, cardiosurgical patient care

- Gurjyot Bajwa MD - manuscript and image review, cardiosurgical patient care

- Jehad Ramahi MD - manuscript and image review, cardiosurgical patient care

- Pier Carlo Bergonzi MD - manuscript and image review, cardiac intensive patient care

- Gopal Bhatnagar MD - manuscript and image review, cardiosurgical patient care

\section{CONSENT FOR PUBLICATION}

Not applicable.

\section{FUNDING}

None.

\section{CONFLICT OF INTEREST}

The authors declare no conflict of interest, financial or otherwise.

\section{ACKNOWLEDGEMENTS}

Declared none.

\section{REFERENCES}

[1] Scott DJ, Campbell DN, Clarke DR, Goldberg SP, Karlin DR, Mitchell MB. Twenty-year surgical experience with congenital supravalvar aortic stenosis. Ann Thorac Surg 2009; 87(5): 1501-7. [http://dx.doi.org/10.1016/j.athoracsur.2009.01.070] [PMID: 19379894]

[2] Bakhtiary F, Amer M, Etz CD, et al. Mid-term outcome after surgical repair of congenital supravalvular aortic stenosis by extended aortoplasty. Interact Cardiovasc Thorac Surg 2013; 17(4): 688-90. [http://dx.doi.org/10.1093/icvts/ivt236] [PMID: 23793710]

[3] Isselbacher EM. Thoracic and abdominal aortic aneurysms. Circulation 2005; 111(6): 816-28. [http://dx.doi.org/10.1161/01.CIR.0000154569.08857.7A] [PMID: 15710776]

[4] Bonser RS, Ranasinghe AM, Loubani M, et al. Evidence, lack of evidence, controversy, and debate in the provision and performance of the surgery of acute type A aortic dissection. J Am Coll Cardiol 2011; 58(24): 2455-74.

[http://dx.doi.org/10.1016/j.jacc.2011.06.067] [PMID: 22133845]

[5] Peterss S, Hagl C, Pichlmaier M. Chronic aortic dissection type A: Simply an overlooked acute event? Eur J Cardiothorac Surg 2019.ezz218

[http://dx.doi.org/10.1093/ejcts/ezz218] [PMID: 31364697]

[6] Malvindi PG, Votano D, Ashoub A, et al. Age-related presentation of acute type A aortic dissection. Asian Cardiovasc Thorac Ann 2018; 26(9): 659-66.

[http://dx.doi.org/10.1177/0218492318810087] [PMID: 30379563]

This is an open access article distributed under the terms of the Creative Commons Attribution 4.0 International Public License (CC-BY 4.0), a copy of which is available at: (https://creativecommons.org/licenses/by/4.0/legalcode). This license permits unrestricted use, distribution, and reproduction in any medium, provided the original author and source are credited. 